\title{
Biology and Potential Biogeochemical Impacts of Novel Predatory Flavobacteria
}

By

\author{
Erin C. Banning
}

B.S., Syracuse University, 1999

B.S., University of South Florida, 2004

Submitted in partial fulfillment of the requirements for the degree of

Doctor of Philosophy

at the

MASSACHUSETTS INSTITUTE OF TECHNOLOGY

and the

WOODS HOLE OCEANOGRAPHIC INSTITUTION

June 2010

\section{(C) 2010 Erin C. Banning}

All rights reserved

The author hereby grants to MIT and WHOI permission to reproduce and to distribute publicly paper and electronic copies of this thesis document in whole or in part in any medium now known or hereafter created.

Signature of Author

Joint Program in Oceanography/Applied Ocean Science and Engineering Massachusetts Institute of Technology and Woods Hole Oceanographic Institution

Certified by

May 21, 2010

Karen Casciotti, Associate Scientist, WHOI Thesis Co-Supervisor

Elizabeth Kujawinski, Associate Scientist, WHOI Thesis Co-Supervisor

Accepted by

Simon Thorrold, Senior Scientist, WHOI

Chair, Joint Committee for Biological Oceanography 


\title{
Biology and Potential Biogeochemical Impacts of Novel Predatory Flavobacteria
}

\author{
By \\ Erin C. Banning \\ Submitted to the Department of Biology on May 21, 2010 in Partial Fulfillment of the \\ Requirements for the Degree of Doctor of Philosophy in Biological Oceanography
}

\begin{abstract}
Predatory bacteria are ubiquitous in aquatic environments and may be important players in the ecology and biogeochemistry of microbial communities. Three novel strains belonging to two genera of marine flavobacteria, Olleya and Tenacibaculum, were cultured from coastal sediments and found to be predatory on other bacteria on surfaces. Two published species of the genus Tenacibaculum were also observed to grow by lysis of prey bacteria, raising the possibility that predation may be a widespread lifestyle amongst marine flavobacteria, which are diverse and abundant in a variety of marine environments. The marine flavobacterial clade is known to include species capable of photoheterotrophy, scavenging of polymeric organic substances, pathogenesis on animals, the degradation and lysis of phytoplankton blooms and, now, predation on bacterial communities. Strains from the two genera were found to exhibit divergent prey specificities and growth yields when growing predatorily. Olleya sp. predatory cells accumulated to an order of magnitude greater cell densities than Tenacibaculum sp. cells on equivalent prey cell densities. Experiments were conducted to constrain the potential of the novel isolates to affect prey communities under more environmentally relevant conditions. An investigation of the minimum number of predatory cells needed to generate clearings of prey cells found that the inoculation of individual predatory flavobacteria cells can ultimately result in dense lytic swarms. In some cases, the susceptibility of particular prey species to lysis by a flavobacterial predator was found to vary based on the growth state of the prey cells or the presence of their spent growth media. A novel methodology for the experimental study of biofilms was used to assess the impact of exposure to predatory marine flavobacteria on the release of macronutrients from prey biofilms. The Olleya $\mathrm{sp}$. predator had a stimulative effect on macronutrient release while the Tenacibaculum sp. did not, further suggesting the two groups of predators are adapted to different ecological niches.
\end{abstract}

Thesis supervisor: Karen Casciotti

Title: Associate Scientist

Thesis supervisor: Elizabeth Kujawinski

Title: Associate Scientist 


\section{ACKNOWLEDGMENTS}

During my graduate career, I have been supported by the National Science Foundation (NSF) Division of Molecular and Cellular Biosciences Grant (MCB0348425), the MIT Student Assistance Fund, the Woods Hole Oceanographic Institution (WHOI) Academic Programs Office and the WHOI Coastal Ocean Institute (COI). The work described in this thesis has been supported by a WHOI Ocean Venture Fund grant, COI and the WHOI Ocean Life Institute.

I am grateful to my advisers, Liz Kujawinski and Karen Casciotti, for taking me on as a student when I needed to change labs and develop a new thesis project. I am indebted to them for their support through the many obstacles and difficulties that arose during the execution of this project. In addition, I would like to thank my committee members for their forbearance and advice during this process: Martin Polz of MIT, John Waterbury of WHOI, Ed Leadbetter of the University of Connecticut and Mark Martin of the University of Puget Sound. I am also grateful to the chairs of my thesis proposal and thesis defenses, Stefan Sievert and Sonya Dyhrman respectively, for their support and advice at the beginning and end of my thesis research.

I would also like to thank the students, technicians and postdocs who have worked alongside me here at WHOI for their field assistance, helpful discussions and laboratory support. They include Matt McIlvin, Dan Rogers, Carly Buchwald, James Saenz, Alyson Santoro, Misty Miller, Krista Longnecker, Maya Bhatia and Cornelia Wuchter, amongst others. I am indebted to Jeff Donnelly and Maya Gomes of WHOI for their loan of a vibracoring rig and core barrels which facilitated the collection of the samples upon which this project was based; to Louie Kerr of the Marine Biological Laboratory (MBL) for his technical assistance with confocal microscopy; to Kevin Kroeger, Sandy Baldwin and Laura Erban of the United States Geological Survey for field support and assistance; to Tracy Mincer for the use of his dissecting microscope and camera; and to Stefan Sievert of WHOI for the use of his lab for fluorescent in-situ hybridization. I am also very grateful to Vicke Starczak for her guidance and assistance with statistical analyses. 


\section{Table of Contents}

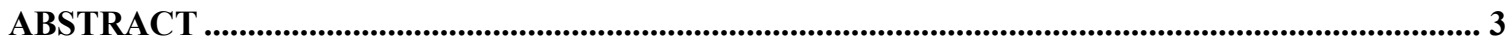

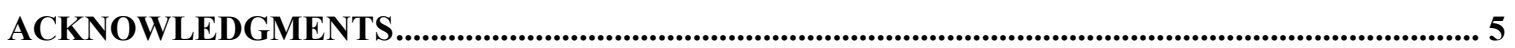

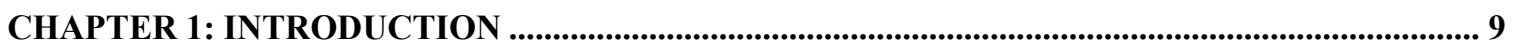

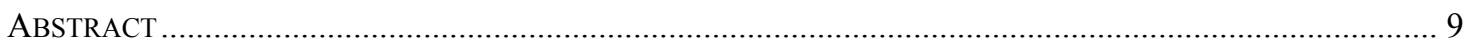

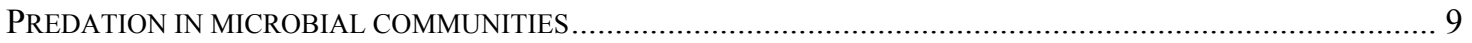

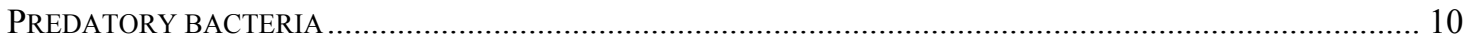

TOWARDS AN ASSESSMENT OF THE IMPORTANCE OF SURFACE-ASSOCIATED PREDATORY BACTERIA......... 12

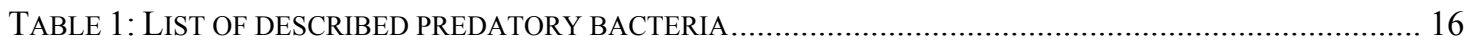

\section{CHAPTER 2: NOVEL STRAINS ISOLATED FROM A COASTAL AQUIFER SUGGEST A PREDATORY ROLE FOR FLAVOBACTERIA ……............................................................................. 17}

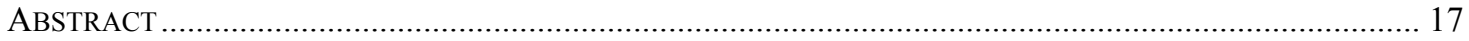

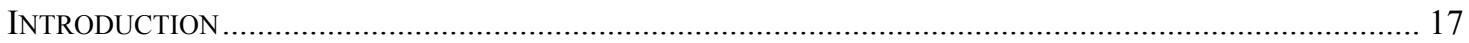

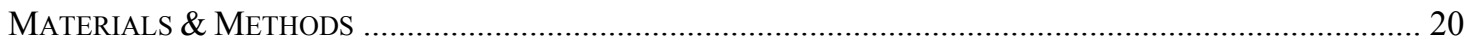

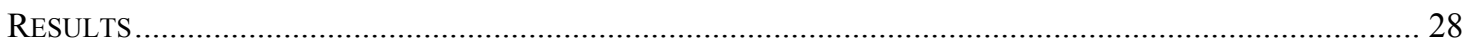

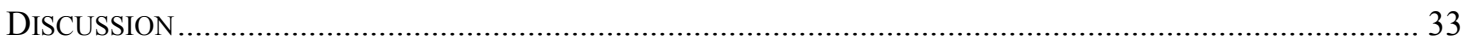

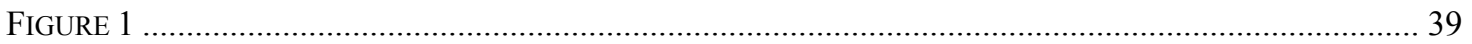

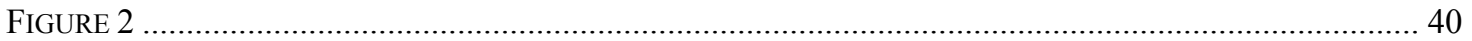

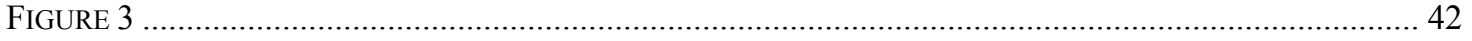

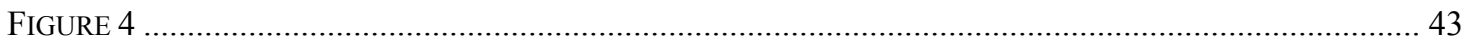

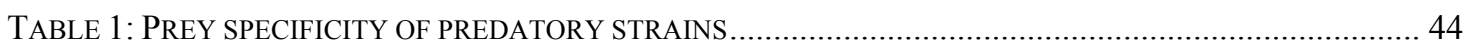

TABLE 2: PHYSIOLOGICAL CHARACTERISTICS OF PREDATORY STRAINS AND CLOSE RELATIVES ................ 45

CHAPTER 3: BIOLOGY OF PREDATORY MARINE FLAVOBACTERIA ...................................... 47

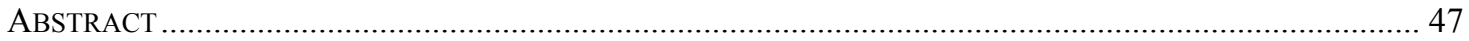

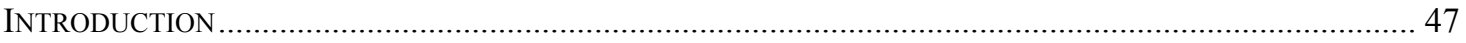

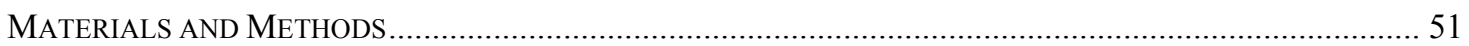

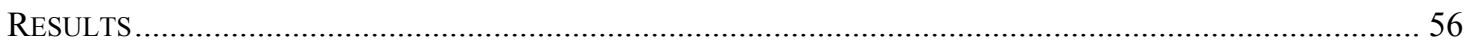

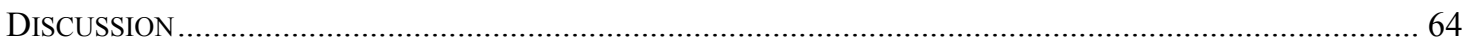

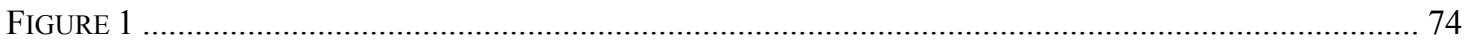

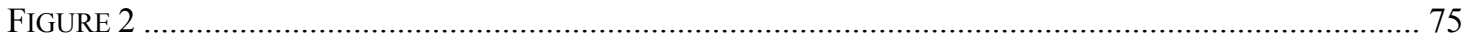

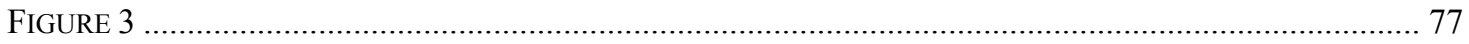

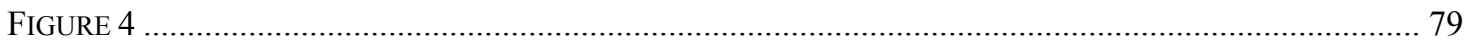

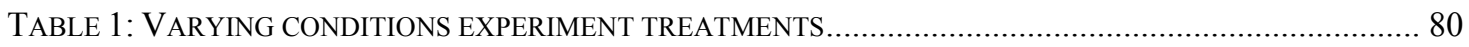

TABLE 2: CALCULATED GENERATION TIMES (HOURS) ACROSS TEMPERATURE AND SALINITY GRADIENTS 80

TABLE 3: PREDATION ACROSS TEMPERATURE AND SALINITY GRADIENTS ............................................. 81

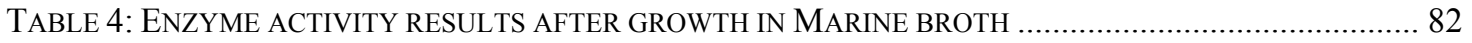

TABLE 5: ENZYME ACTIVITY RESULTS AFTER DIFFERENT GROWTH CONDITIONS …................................. 83

TABLE 6: ESTIMATED PREDATOR CELL DENSITIES ON FILTERS AFTER ADDITION OF $10^{1}$ PREDATOR CELLS

TABLE 7: GROWTH FEATURES WITH B. SUBTILIS PREY …………………………………………………… 85

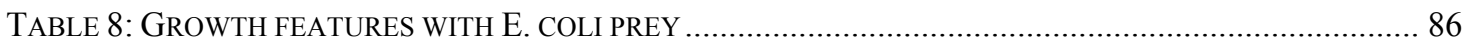

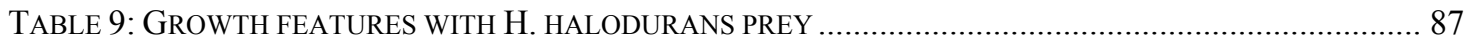

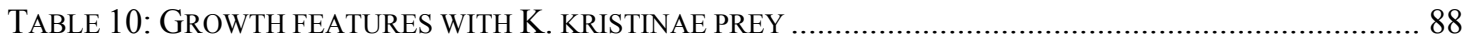

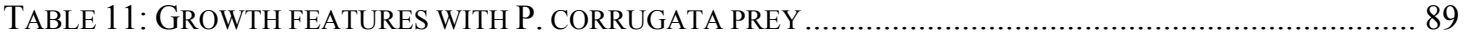

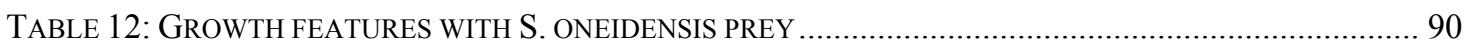

CHAPTER 4: BIOGEOCHEMICAL EFFECTS OF FLAVOBACTERIAL PREDATION................ 91

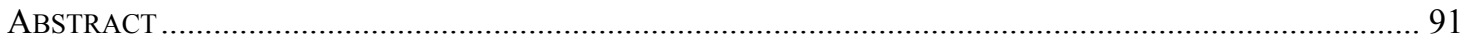




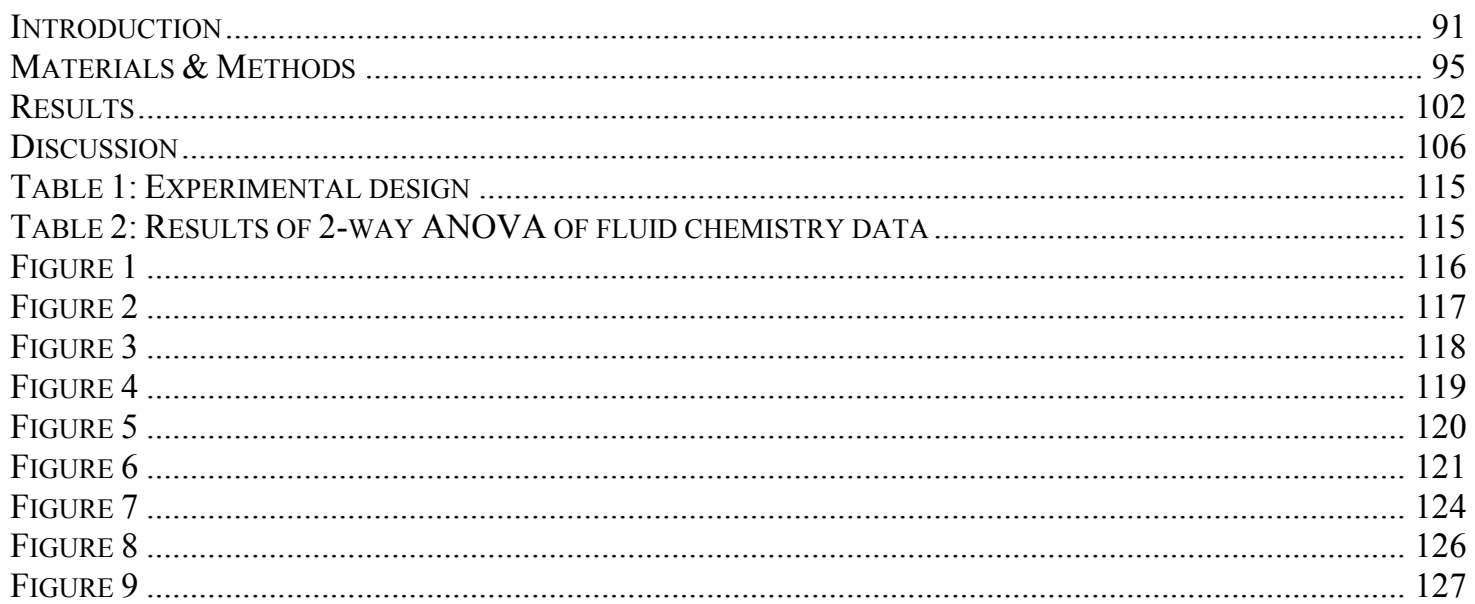

\section{CHAPTER 5: IMPLICATIONS OF BACTERIOLYTIC PREDATION AS A LIFESTYLE OF} MARINE FLAVOBACTERIA ................................................................................................................... 129

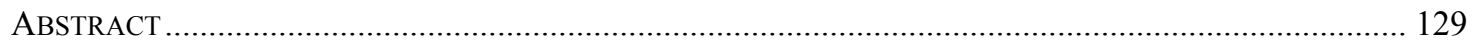

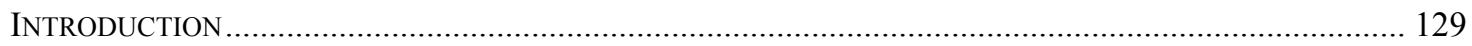

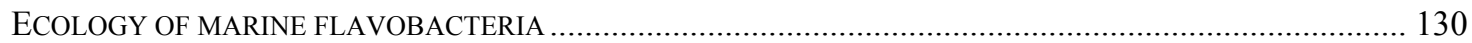

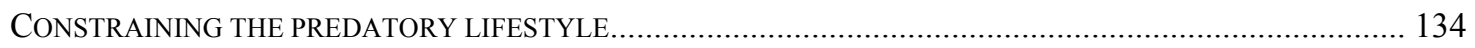

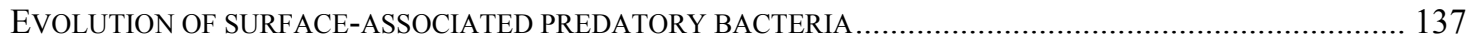

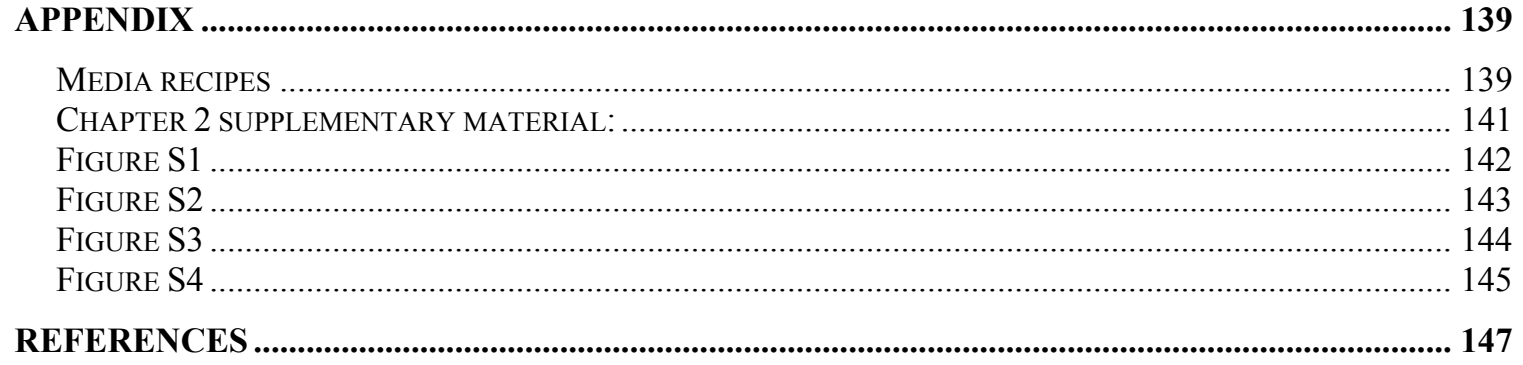




\title{
CHAPTER 1: INTRODUCTION
}

\author{
Abstract \\ Predation as a general ecological phenomenon has been frequently found to be \\ important in structuring and regulating microbial communities. Although \\ phylogenetically and physiologically diverse predatory bacteria have been described and \\ studied, our knowledge of their ecological roles in microbial communities remains small. \\ Their great variety of predatory strategies suggests that they may have novel effects on \\ microbial communities, relative to those already known for protozoan grazers and \\ viruses.
}

\section{Predation in microbial communities}

Predators have been found to have diverse impacts on communities on a variety of scales, from macroscopic to microscopic. These can include the maintenance of community diversity through selective predation on otherwise competitively dominant species $[1,2,3,4,5]$, the stimulation of primary production $[6,7]$ and direct selection for predation-resistant physiologies and behaviors [8]. Top-down, or mortality-driven, control of microbial communities can be exerted by organisms as diverse as metazoa $[9,10]$, protozoa $[11,12]$, bacteria $[13,14]$ and viruses $[15]$.

Predation has been associated with alteration in the rates of microbially mediated biogeochemical processes, including nitrogen fixation [16], nitrification [17], carbon fixation [6], the production of dissolved organic carbon (DOC) $[18,19]$ and jet fuel degradation [20]. In some cases in which predators are grazing directly on the microorganisms responsible for the process in question, evidence of lower prey populations and higher community productivity suggests increases in the prey per-cell metabolic activity $[16,17]$. However, it is unclear if this is a direct response to predation on the part of individual prey cells or an indirect result of lower prey population densities because of grazing pressure. Another major consequence of predation is the conversion and release of grazed prey biomass as inorganic nutrients and incompletely broken-down 
organic matter [7,21,22,23,24], which could sustain additional prey production and make nutrients available to other parts of the microbial community. These processes are integral to the operation of the microbial loop in aquatic ecosystems, which leads to more efficient cycling of organic matter and other nutrients [25].

The effect of a specific predator in a particular ecosystem is dependent on its predation mechanism and other adaptations to a predatory lifestyle. Since most protozoan grazers ingest their prey by phagocytosis into food vacuoles, they can only engulf prey cells within a particular size range, an example of limitations imposed by the predation mechanism [11]. As a result, prey communities often respond to protozoan grazing pressure with increases and/or decreases in cell size distribution or the formation of aggregates too large for protozoan grazers to engulf [26,27]. Other adaptations besides the predatory mechanism itself can also influence the components of a microbial community that are susceptible to a particular predator as well. For example, different heterotrophic microflagellates have divergent motility adaptations that appear to control whether they are specialized to grazing on attached or suspended prey populations [28]. Two microflagellate species with robust swimming ability were found to reduce suspended populations of prey bacteria without any decreases in attached bacterial populations. On the other hand, two microflagellates with weak swimming capability, but rapid movement over surfaces as a result of adaptations of their flagella, mainly fed on attached bacteria [28].

\section{Predatory bacteria}

Although prokaryotic microorganisms are often assumed to occupy basal roles in microbial food webs as consumers of dissolved organic carbon (DOC), diverse bacteria are known to grow by the lysis of a variety of prey microorganisms $[29,30,31,32,33]$. Their trophic role in microbial ecosystems could be more similar to that played by protozoan grazers and viruses than that of heterotrophic, non-predatory bacteria. Cultured predatory bacteria belong to a wide variety of phylogenetic groups (Table 1). The best- and longest-studied groups both belong to the $\delta$-Proteobacteria: the 
surface-associated myxobacteria and the genera Bdellovibrio, Bacteriovorax and Peredibacter. In addition, predatory bacteria have been isolated that belong to the $\alpha-, \beta$ and $\gamma$-Proteobacteria and the phyla Bacteroidetes, Chloroflexi and Actinobacteria. In some cases, such as the myxobacteria and the Bdellovibrio-like genera, all cultured members of these groups are predatory $[34,35]$ while most of the other known predatory bacteria are closely related to apparently non-predatory species. For example, Ensifer adhaerens, an $\alpha$-Proteobacterium isolated from soil that predates on the gram-positive Micrococcus luteus [30], is closely related to plant-associated rhizobia [36], none of which have been reported to possess predatory capabilities.

In addition to their broad phylogenetic diversity, predatory bacteria also utilize a variety of lytic mechanisms to attack prey cells. A distinctive periplasmic invasion mechanism is utilized by the $\delta$-Proteobacterial genera Bdellovibrio, Bacteriovorax and Peredibacter in which individual predatory cells attach to and penetrate the outer membranes of susceptible Gram-negative bacteria $[29,35]$. The predatory cell then degrades the cytoplasm and inner membrane of the prey, grows and divides before bursting the outer membrane and repeating the cycle. Some predatory bacteria belonging to the genera Micavibrio and Ensifer have been reported to attach to and degrade prey organisms' from a position on their outer surfaces, a strategy termed epibiotic predation $[30,37,38,39,40,41]$. In most other documented cases, some degree of cell-to-cell contact short of the tight association described as epibiotic has been observed $[42,43,44,45,46,47]$. Although these lytic mechanisms have not been well-characterized, they presumably involve either the release of lytic factors into the local cellular environment or the action of outer-membrane associated hydrolytic enzymes.

In addition to the diversity in the mechanisms of cell lysis, there is also diversity amongst predatory bacteria in their hunting strategies. The periplasmic predators and at least one of the described epibiotic predators, Micavibrio, possess flagella and swim at high speeds $[37,48]$. In addition to their solitary hunting habit, these swimming predators have all been found to be obligate predators, incapable of growth in the absence of live prey cells although host-independent mutants of Bdellovibrio sp. have been developed in 
culture. This obligate predatory metabolism stands in contrast to nearly all other described predatory bacteria, which can be grown non-predatorily as well as with live prey as a sole carbon source.

Amongst the non-obligate predatory bacteria, many groups lack flagella entirely and are motile by gliding on solid surfaces, including myxobacteria, Saprospira sp., Lysobacter sp. and Herpetosiphon sp. [33,34,44,45,49]. All of these gliding, non-obligate predatory bacteria, collectively referred to hereafter as surface-associated predatory bacteria, have been observed to lyse prey on solid surfaces and swarm cooperatively in a habit often termed wolfpack predation $[13,50]$. Despite their lack of motility in suspension, at least one species of myxobacteria has been observed to form their own particulate surfaces composed of floating microcolonies, which can trap and lyse cyanobacteria in suspension [46,51]. At least for the myxobacteria and Saprospira sp., the wolfpack growth habit does not appear to be required for predation to occur since both groups have been observed to singly lyse individual prey cells $[43,45]$. In fact, Saprospira grandis has been described as utilizing an additional strategy termed ixotrophy, or the feeding on prey caught on a sticky surface [45]. In suspension, $S$. grandis was observed to catch flagellated Vibrio cells by the ends of their flagella and 'reel' them in up and down the predator cell's length.

Most cultured predatory bacteria have been isolated from soil and aquatic sediments, as shown in Table 1, although some cultures have also been isolated from seawater and freshwater lakes and ponds. A cursory search of the Genbank sequence database will reveal that culture-independent surveys of microbial $16 \mathrm{~S}$ rRNA genes have detected sequences closely related to known predatory bacteria in nearly all aquatic environments [14]. Although predatory bacteria are clearly ubiquitous, the question of their ecological and biogeochemical importance has rarely been investigated.

\section{Towards an assessment of the importance of surface-associated predatory bacteria}

In light of present knowledge of predatory bacteria, they seem likely to affect microbial communities in ways distinct from those of protozoan grazers and viruses. As a 
result of their high intra-guild diversity, different groups of predatory bacteria may also diverge from each other with respect to their effects on prey communities. Similar to the coevolutionary interactions between prey and protozoa, many predatory bacteria seem likely to select for certain cell wall and membrane characteristics as suggested by already described prey specificities.

Although predatory bacteria have been relatively less studied than both larger and smaller predators, some have been shown to affect prey communities. Much of this work has focused on the Bdellovibrio-type predatory bacteria, which are capable of drastically lowering the viability and density of Gram-negative bacterial biofilms [52,53] and provoking increases in cell size [54]. Coevolutionary interactions between Bdellovibriotype predators and their prey have been inferred from the fact that predators isolated from the Great Salt Lake have prey specificities apparently better adapted to the indigenous heterotrophic bacteria relative to reference strains [55].

In a study of the removal of Escherichia coli cells from estuarine water, predation by Bdellovibrio-type predator was detected but judged to be less important than protozoan grazing, since the presence of protozoan grazers was associated with greater decreases in E. coli cells [56]. However, the study was carried out using estuarine surface water communities, which may not have contained a predatory bacterial community adapted to efficiently utilize $E$. coli. In addition, surface-associated predatory bacteria were unlikely to have been present in the samples used. Particularly with respect to surface-associated predatory bacteria, little is known regarding their impacts on the surrounding microbial communities.

The non-obligate predatory metabolism possessed by all known surfaceassociated predatory bacteria presents a significant challenge to interpreting the consequences of their presence in the environment. For instance, myxobacteria can be difficult to separate from solid substrates, rendering traditional approaches used for Bdellovibrio-type predators of little use [34]. Even though modern molecular techniques have made it possible to quantify the numbers of known non-obligate predators in an environment, it is currently impossible to tell with certainty whether non-obligate 
predators detected in the environment are growing predatorily or non-predatorily. In addition, since most non-obligate predators are closely related to non-predatory species $[36,49,57,58]$, a priori knowledge of which species are predatory and which are not is necessary to interpret the results of culture-independent diversity surveys.

For example, even when a molecular technique can be targeted to a particular ecological category, the molecular identification by itself is insufficient to identify novel predators. A stable-isotope probing study using ${ }^{13} \mathrm{C}$-labeled E. coli prey added to soil microcosms detected an interesting diversity of microorganisms within the labeled RNA fraction at various time points in the experiment [59]. Sequences closely related to those of known non-obligate predatory bacteria, including myxobacteria and Lysobacter sp., were detected in the labeled RNA fractions. It is important note, however, that labeled sequences were detected at the same time points from a variety of other phylogenetic groups, which may or may not represent predatory bacteria. Since non-obligate predatory bacteria lyse their prey extracellularly, it is possible that some of the labeled biomass would be consumed by predation-resistant scavenging heterotrophs in the same vicinity. The fact of assimilation of labeled biomass, by itself, is of limited usefulness in identifying novel predatory bacteria.

Therefore, the most viable approach currently available for determining the potential ecological and biogeochemical importance of surface-associated predatory bacteria is to conduct laboratory experiments with controlled cocultures of predator and prey. Such an approach has been widely used in exploring the effects of protozoan grazing on prey communities $[22,23,24,27,60,61,62]$.

The following thesis chapters describe the results of the enrichment and isolation of surface-associated predatory bacteria and experiments conducted to elucidate their predatory biology and potential biogeochemical effects on a simple prey community. I addressed the following questions:

- What surface-associated predatory bacteria can be cultured from coastal sediments? 
- How are the isolates' predatory activities influenced by factors such as the size and distribution of predatory inocula and the composition and activity of prey communities?

- How is macronutrient release from a simple prey community affected by exposure to the predatory isolates? 
Table 1: List of described predatory bacteria

\begin{tabular}{|c|c|c|c|c|}
\hline Group & $\begin{array}{l}\text { Predatory } \\
\text { strategy }\end{array}$ & Known habitats & Known prey & References \\
\hline \multicolumn{5}{|l|}{$\alpha$-Proteobacteria } \\
\hline $\begin{array}{l}\text { Alcaligenes } \\
\text { denitrificans }\end{array}$ & n.d. & $\begin{array}{l}\text { Eutrophic freshwater } \\
\text { pond }\end{array}$ & cyanobacteria & {$[57]$} \\
\hline Ensifer adhaerens & Epibiotic & Soil & Gram $(+)$ bacteria & {$[30]$} \\
\hline Micavibrio sp. & Epibiotic & Soil, sewage & Gram(-) bacteria & {$[37,63,64,65]$} \\
\hline $\begin{array}{l}\text { Candidatus Midichloria } \\
\text { mitochondrii }\end{array}$ & Periplasmic & Tick ovary & mitochondria & {$[66,67]$} \\
\hline \multicolumn{5}{|l|}{$\beta$-Proteobacteria } \\
\hline Cupriavidus necator & n.d. & Soil & $\operatorname{Gram}(-) /(+)$ bacteria & {$[68]$} \\
\hline Aristabacter necator & n.d. & Soil & $\begin{array}{l}\operatorname{Gram}(-) /(+) \text { bacteria, yeast } \\
\text { and other fungi }\end{array}$ & [69] \\
\hline \multicolumn{5}{|l|}{$\gamma$-Proteobacteria } \\
\hline Lysobacter sp. & $\begin{array}{l}\text { Wolfpack, } \\
\text { cell contact }\end{array}$ & Soil, freshwater & $\begin{array}{l}\text { Cyanobacteria, } \operatorname{Gram}(-) /(+) \\
\text { bacteria }\end{array}$ & {$[49,70,71,72]$} \\
\hline $\begin{array}{l}\begin{array}{l}\text { Stenotrophomonas } \\
\text { maltophila }\end{array} \\
\end{array}$ & n.d. & Stratified lake, soil & $\begin{array}{l}\text { Chlorobi, Gram }(-) /(+) \\
\text { bacteria }\end{array}$ & {$[58]$} \\
\hline \multicolumn{5}{|l|}{$\delta$-Proteobacteria } \\
\hline $\begin{array}{l}\text { Bdellovibrio sp., } \\
\text { Bacteriovorax sp., } \\
\text { Peredibacter sp. } \\
\end{array}$ & Periplasmic & $\begin{array}{l}\text { Soil, freshwater, } \\
\text { estuaries, sewage, } \\
\text { marine sediments }\end{array}$ & Gram(-) bacteria & {$[29,35,64]$} \\
\hline Myxobacteria & $\begin{array}{l}\text { Wolfpack, } \\
\text { cell contact }\end{array}$ & $\begin{array}{l}\text { Soil, dung, bark, } \\
\text { sediments }\end{array}$ & $\begin{array}{l}\text { Bacteria, fungi, protozoa, } \\
\text { nematodes }\end{array}$ & {$[31,34,43,73]$} \\
\hline \multicolumn{5}{|l|}{\begin{tabular}{|l|} 
Chloroflexi \\
\end{tabular}} \\
\hline Herpetosiphon sp. & $\begin{array}{l}\text { Wolfpack, } \\
\text { cell contact }\end{array}$ & Freshwater lakes & Un-encapsulated bacteria & {$[33,74]$} \\
\hline \multicolumn{5}{|l|}{ Bacteroidetes } \\
\hline Saprospira sp. & $\begin{array}{l}\text { Ixotrophy, } \\
\text { wolfpack, } \\
\text { cell contact }\end{array}$ & $\begin{array}{l}\text { Coastal sediment, sea } \\
\text { water }\end{array}$ & $\begin{array}{l}\text { Bacteria, cyanobacteria, } \\
\text { diatoms }\end{array}$ & {$[32,44,45,75]$} \\
\hline \multicolumn{5}{|l|}{ Actinobacteria } \\
\hline Agromyces ramosus & n.d. & Soil & Gram(-) bacteria, yeast & {$[42,76]$} \\
\hline Streptoverticillium sp. & n.d. & Soil & $\operatorname{Gram}(+)$ bacteria & {$[77]$} \\
\hline
\end{tabular}




\title{
CHAPTER 2: NOVEL STRAINS ISOLATED FROM A COASTAL AQUIFER SUGGEST A PREDATORY ROLE FOR FLAVOBACTERIA
}

Accepted for publication by and included with permission of FEMS Microbiology

Ecology

\begin{abstract}
Three newly isolated strains of flavobacteria from coastal aquifer sediments have been found to be predatory, lysing a range of live and pasteurized microbial prey. The three strains have been classified on the basis of 16S rRNA gene phylogeny as belonging to the recently described Olleya (strains VCSA23 and VCSM12) and Tenacibaculum (strain VCSA14A) genera. Two of the closest cultured relatives to the strain VCSA14A, T. discolor and T. gallaicum, were also found to be bacteriolytic. These five predatory strains exhibit gliding motility and have been observed to lyse prey cells after surrounding them with social swarms, similar to known predatory bacteria such as myxobacteria and members of the genus Lysobacter. Flavobacteria are often numerically significant in a wide variety of freshwater and marine environments, particularly in association with particles, and are thought to be involved in the degradation of biopolymeric substances. If predatory capability is widespread among flavobacteria, they may be a previously unrecognized source of 'top-down' bacterial mortality with influence on the composition and activity of surrounding microbial communities.
\end{abstract}

\section{Introduction}

Microbial communities can be structured by top-down mortality resulting from the activity of predators, which include protists, viruses and bacteria. The action of microbial predators also causes the release of dissolved organic matter (DOM), much of which is accessible to heterotrophic microorganisms and can support secondary production in the microbial loop [25]. Many experimental studies have shown that protistan grazing can strongly influence the morphological, physiological and phylogenetic composition (reviewed by Pernthaler [12] and Hahn and Höfle [11]) and 
metabolic activity $[16,78,79]$ of prey communities. Due to high host specificity and rapid production rates, viruses are hypothesized to affect the most abundant populations in a community, promoting high overall community diversity [15]. The impacts of protistanand viral-mediated mortality on microbial communities' composition and function have garnered significant study recently. On the other hand, the activities of predatory bacteria are virtually unconstrained. Indeed, many studies have assumed that bacteria can be approximated as a single trophic level with respect to predation pressure [15,25]. However, this assumption ignores the trophic diversity known to exist within the bacterial domain.

Predatory bacteria, capable of growing with live bacterial prey as a sole substrate, have been detected in and cultured from a wide variety of environments and phylogenetic groups $[13,14]$. The longest-studied predatory bacteria, the myxobacteria and the genus Bdellovibrio and its close relatives, belong to the $\delta$-Proteobacteria $[35,80]$, but predatory species have also been characterized from the $\alpha$-, $\beta$ - and $\gamma$-Proteobacteria [30,37,65,68,70,72] and the phyla Chloroflexi [33], Bacteroidetes [45] and Actinobacteria [42]. These well-characterized predatory species have been cultured from soils, estuaries, rivers, lakes, bogs and marine and freshwater sediments, and have been detected using PCR-based techniques in an even wider range of environments, including groundwater, human skin and hydrothermal vents. In addition to these relatively wellstudied predatory bacteria, a growing number of less well-characterized lytic bacteria have been reported in culture, microscopy and stable-isotope probing studies $[57,58,59,66,81,82,83]$. Many of these potentially predatory bacteria belong to genera such as Cytophaga, Pseudoalteromonas, and Alcaligenes which, while actively studied, had not been previously thought to include predatory species $[57,82,83]$.

Predatory bacteria employ a wide array of predatory mechanisms, ranging from the invasion of Gram-negative periplasms carried out by Bdellovibrio and its relatives [29] to the production of lytic exoenzymes by myxobacteria [84,85] and some members of the genus Lysobacter [70]. Other predatory mechanisms include attachment to prey cells coupled with production of a diffusible lytic factor $[30,77]$ and the capture of prey 
cells by their flagella [45]. Predatory bacteria can be considered obligate or non-obligate predators, depending on whether they can assimilate exogenous DOM as a growth substrate in addition utilizing live prey. Most described predatory bacteria are nonobligate predators, the exceptions being members of the genera Bdellovibrio, Bacteriovorax and Peridibacter in the $\delta$-Proteobacteria and Micavibrio in the $\alpha$ Proteobacteria, which require live prey as their growth substrate.

The great diversity in the phylogeny and physiology of known predatory bacteria makes them difficult to study them as a group using culture-independent techniques. For example, some predatory bacteria, such as Ensifer adhaerens, are very closely related to non-predatory bacteria [86], which renders 16S-rDNA-based phylogenetic probes incapable of distinguishing predatory from non-predatory organisms. In addition, the culture-independent study of non-obligate predatory bacteria is complicated by the current inability to assess whether an organism was actively lysing prey or merely assimilating exogenous DOM at the time of its detection. One recent study [59], designed to detect predatory bacteria using ${ }^{13} \mathrm{C}$-labeled prey bacteria, successfully detected known non-obligate predatory bacteria such as myxobacteria and a member of the genus Lysobacter, as well as many gene sequences belonging to groups of bacteria containing no well-characterized predatory species. However, this approach is complicated by the fact that predatory bacteria are unlikely to be the only assimilators of lysed prey biomass, resulting in the possibility of uptake of ${ }^{13} \mathrm{C}$-labeled biomolecules by non-predatory heterotrophs.

In order to assess the efficacy of culture-independent approaches for the detection of predatory bacteria and to examine the environmental and ecological significance of the functional guild as a whole, a wider range of predatory bacteria needs to be isolated and characterized. With this goal in mind, we conducted a study to identify the presence and diversity of culturable predatory bacteria from a coastal aquifer on Cape Cod, MA. This site contains a variety of chemical niches $[87,88,89]$ in a surface-rich environment which could provide substrate for microbial communities supporting a variety of predatory bacteria. Aquifers have been found to harbor significant protist communities, as reviewed 
by Novarino et al. [90], but other than the detection of Bdellovibrio in a groundwater-fed cave [91], other sources of top-down bacterial mortality have not been extensively studied in groundwater systems.

\section{Materials \& Methods}

Field collection: A vibrocorer was used to sample aquifer sediments beneath the intertidal zone at the Waquoit Bay National Estuarine Research Reserve, Cape Cod, MA, in November 2007. The Cape Cod aquifer is primarily composed of fine to coarse sand and gravel [92]. A mixing zone between fresh groundwater and sea water intruding into the aquifer from the head of the bay results in a steep, tidally and seasonally influenced salinity gradient $[87,89,93]$ providing a variety of chemical environments. Before coring, a piezometer profile was taken, sampling every six inches, to locate the salinity gradient. A vibrocoring rig and four-inch-diameter aluminum barrels, rinsed with sea water from the intertidal zone, were used for coring within the intertidal zone at the head of Waquoit Bay. The core barrel was split lengthwise with an electric saw and sediment collected at four-inch depth intervals from the center of the core using flame-sterilized spatulas. The sediment samples were transported to the laboratory in autoclaved glass jars on ice and kept refrigerated for less than 24 hours before being sampled for culturing.

Reference and prey bacterial cultures: Tenacibaculum discolor DSM 18842, T. gallaicum DSM 18841, Kocuria kristinae DSM 20032, Pseudomonas putida DSM 50906 and Planctomyces maris DSM 8797 were obtained from the German Collection of Microorganisms and Cell Cultures (DSMZ). Bacillus subtilis PY79 was kindly provided by Tonja Bosak, Saccharomyces cerevisiae by Lynn Miller, Flavobacterium johnsoniae by Mark McBride, Shewanella oneidensis MR-1 by Dianne Newman, P. corrugata by Edouard Jurkevitch and Escherichia coli JM109 by Daniel Rogers. Olleya marilimosa strain $\mathrm{CAM} 030^{\mathrm{T}}$ was kindly provided by Carol Mancuso Nichols. Nitrosomonas sp. C113a (Red Sea isolate) is maintained in the lab of Karen Casciotti. Halomonas halodurans is maintained in the lab of Elizabeth Kujawinski (originally isolated by $\mathrm{G}$ Jones, University of New Hampshire). Unless otherwise noted, all reagents were obtained 
from Thermo Fisher Scientific, Inc., Waltham, Massachusetts, USA. The details of the culture media used are described in the supplemental material.

Predatory culture isolation and purification: We prepared bacterial prey for initial enrichment and isolation from cultures of Serratia marcescens, S. oneidensis MR-1 and Nitrosomonas sp. C-113a, grown as described in the supplemental material. Cultures of $S$. oneidensis and $S$. marcescens were harvested by centrifugation and washed three times in HEPES buffer at a salinity of 20. The final cell suspension represented a twentyfold concentration of the original culture. As a result of relatively low cell densities, Nitrosomonas sp. C-113a was handled differently -300 to $500 \mathrm{~mL}$ of a stationary phase culture was filtered onto a $0.2 \mu \mathrm{m}$ filter and resuspended in its own sterile medium, with a final concentration factor of at least a hundred-fold. The bacterial prey smears were prepared by spreading $30 \mu \mathrm{L}$ of the concentrated prey suspension over an area about one centimeter wide and several centimeters in length on no-nutrient water agar containing cycloheximide (WCX agar) [34]. Cycloheximide was included in the initial enrichment agar to prevent fungal growth, but was excluded after the first two to three transfers. The smears were allowed to dry before inoculation with sediment aliquots.

Small (approximately thimble-sized) aliquots of sediment, taken from different depths in the sediment core, were placed directly at one end of bacterial prey smears. After inoculation, plates were observed every one to three days using a dissecting microscope at magnifications of $6 \mathrm{X}$ and $12 \mathrm{X}$. Swarms associated with unambiguous clearing of the prey smear were transferred to fresh prey smears by cutting out a small block of agar from the leading edge of the swarm with a sterile syringe needle. Purification was accomplished by transfer of the freshest, leading edges of expanding swarms to new prey smears at least ten times and then to dilute nutrient agar (DNa; see recipe in supplemental material), from which isolated colony morphologies were repeatedly transferred. Purity was assessed by phase-contrast microscopy using a 100X oil-immersion objective lens of wet-mounted slides from agar chunks of spreading swarms, direct sequencing of $16 \mathrm{~S}$ rRNA gene PCR products with the general primer 1492R (5'- GGT TAC CTT GTT ACG ACT T-3'), and colony morphology on DNa. 
Cultures were maintained non-predatorily on $\mathrm{DNa}$ of the appropriate salinity and predatorily on water agar without cycloheximide (WAT) once fungal contaminants had been eliminated. Two salinities were used for the initial enrichments to represent the salinity range of the sampling site: one using deionized water, and the other substituting artificial sea water (ASW, recipe in the supplemental materials) for $71.5 \%$ of the final volume to reach a final salinity of about 25 .

Culture experiments: The production of lytic exoenzymes by VCSA23 was tested by resuspending a live $S$. oneidensis cell concentrate in the cell-free supernatant from a heterotrophically grown VCSA23 stationary-phase culture, grown in Marine broth. The cell-free supernatant was obtained by pelleting the VCSA23 cells by centrifugation and then filtering the collected fluid through a $0.2-\mu \mathrm{m}$ syringe filter. The $S$. oneidensis culture was split into two equal volumes and harvested by centrifugation. One of the resulting pellets was resuspended in spent Marine broth from VCSA23 $(10 \mathrm{~mL})$ and the other was resuspended in the spent Marine broth from the S. oneidensis culture $(10 \mathrm{~mL})$. The absorbance of the two suspensions was monitored by spectrophotometry over the course of two weeks relative to sterile Marine broth.

Unless specified otherwise, DN broth with a salinity of 25 was used as a basal medium for non-predatory growth tests, and WAT with a salinity of 25 (WAT25) was used as a basal medium for predatory growth tests with S. oneidensis MR-1 as the live prey organism. Pasteurized prey smears were also used as a predatory growth substrate, prepared by exposing the $S$. oneidensis prey to $70^{\circ} \mathrm{C}$ for at least 15 minutes followed by normal washing procedures as described above.

Both predatory and non-predatory growth of VCSA23, VCSM12 and VCSA14A were tested at five different temperatures $\left(4^{\circ} \mathrm{C}, 15^{\circ} \mathrm{C}, 23^{\circ} \mathrm{C}, 30^{\circ} \mathrm{C}\right.$ and $\left.37^{\circ} \mathrm{C}\right)$ and salinities $(0,10,20,25$ and 30$)$. The response of the three strains to increasing concentrations of organic matter was also assessed by growing them on WAT25 amended with $0.01,0.1$ or 1 gram of yeast extract per liter with pasteurized S. oneidensis MR-1 prey washed and concentrated to about 10 times the stationary culture cell density (final concentration about $10^{10}$ cells $/ \mathrm{mL}$ ). Degradation of casein and starch by the three isolates 
and O. marilimosa, T. discolor and T. gallaicum were tested by inoculation onto FMM agar [94,95], prepared in the same seawater matrix as WAT25 and amended with $0.4 \%$ $\mathrm{w} / \mathrm{v}$ casein or starch. Requirement for sea salts was tested by growth on DN agar at $25 \mathrm{ppt}$ salinity with only sodium chloride as a salt.

Prey specificity was tested by inoculating each test strain onto live smears of each prey organism, prepared by repeated centrifugation and resuspension as described above, except for Nitrosomonas sp. C-113a and P. maris, which were concentrated by filtration. Two different prey densities were tested for many of the other prey organisms - about 10 times the prey's stationary phase cell density and about one tenth the prey's stationary phase cell density. Clearing presence and progress was monitored every two to three days via dissecting microscope. A strain was scored as predatory on a particular prey organism if macroscopically visible clearing expanded progressively in either of the replicate smears for the test prey.

To facilitate observation of the predatory behavior and spatial relationships between predators and prey, cultures were grown on autoclaved polycarbonate membrane filters (Millipore, Billerica, MA; $0.2 \mu \mathrm{m}$ pore size) placed onto WAT25 and analyzed by fluorescent in-situ hybridization (FISH) and confocal microscopy. $180 \mu \mathrm{L}$ of $S$. oneidensis live cell suspension was spread evenly onto the filters using a pipet tip. In parallel, prey was applied in the same manner directly onto the agar to facilitate the monitoring of clearing progress during the experiment. Excess fluid from the suspensions was allowed to absorb overnight. For each predatory strain tested (strains VCSA23, VCSM12, VCSA14 and T. gallaicum A37.1 ${ }^{\mathrm{T}}$ ), a small agar block covered with the strain in question was inoculated onto the center of the prey-covered membrane filters, as well as onto prey spots on the agar. Each experiment included three replicate plates per predatory strain, with each plate containing two prey-covered filters inoculated with predator, one filter inoculated with predator only and two filter-less prey spots, one inoculated with predator and one not. In addition, a separate plate contained prey-covered filters which were not inoculated with predator. The experiment was monitored daily by checking the filter-less predator + prey spots using a dissecting microscope. 
Once clearing zones of approximately 1-cm diameter had developed (approximately three days after predator inoculation), one predator + prey filter from each plate and three prey-only filters were fixed and frozen. When clearing zones in the filter-less predator + prey spots came close to the edges of the prey lawns, the remaining filters were fixed and frozen (after five days for strains VCSA23, VCSM12 and VCSA14A and after 12 days for T. gallaicum). Filters were fixed in Petri dishes using $4 \%$ paraformaldehyde in phosphate-buffered saline (PBS; for recipe see supplemental material) for one to two hours at $4^{\circ} \mathrm{C}$. Filters were washed by successive transfer through three Petri dishes containing PBS, with full immersion in each dish for at least five minutes at room temperature. After washing, each filter was dipped into a 1:1 mixture of PBS and ethanol and dried in a Petri dish before freezing at $-20^{\circ} \mathrm{C}$.

16S rRNA gene sequencing: Cells from strains VCSA23, VCSM12 and VCSA14A were suspended in HEPES buffer at a salinity of 20 and frozen at $-20^{\circ} \mathrm{C}$. Thawed suspensions ( $1 \mu \mathrm{L}$ per reaction) were used as the template for polymerase-chainreaction (PCR) amplification. General bacterial $16 \mathrm{~S}$ rRNA primers $(10 \mu \mathrm{M} ; 27 \mathrm{~F}$ : 5'AGA GTT TGA TCC TGG CTC AG -3', 1492R) and 2X GoTaq Green Master Mix (Promega, Madison, WI) were used in the reaction mixes. Thermal cycling was performed under the following conditions: denaturation at $94^{\circ} \mathrm{C}$ for two minutes followed by 30 cycles of denaturation at $94^{\circ} \mathrm{C}$ for 30 seconds, annealing at $47^{\circ} \mathrm{C}$ for 90 seconds and extension at $72^{\circ} \mathrm{C}$ for three minutes followed by a final extension of 10 minutes at $72^{\circ} \mathrm{C}$. PCR products were checked for single, coherent bands of the appropriate size (about 1500 base pairs) by agarose gel electrophoresis and ethidium bromide staining.

Full-length 16S rRNA gene sequences (about 1500 base pairs) were cloned from VCSA23, VCSM12 and VCSA14A using the pGEM®-T Easy cloning kit (Promega Corp., Madison, WI) according to the manufacturer's instructions. For each strain, 16 colonies were picked and grown up overnight in $\mathrm{LB}$ at $37^{\circ} \mathrm{C}$ with shaking at $180 \mathrm{rpm}$. No colonies were recoverable from the VCSM12 clone library, which was not further pursued due to the high similarity between the partial 16S rRNA gene sequences of VCSM12 and VCSA23. Cells were collected by centrifugation and plasmids were 
extracted and purified by a Beckman-Coulter BiomekFX alkaline-lysis plasmid preparation machine and used as template in two parallel sequencing reactions with the M13F (5'- GTA AAA CGA CGG CCA G -3') and M13R primers (5'- CAG GAA ACA GCT ATG AC -3'), respectively. Partial sequences (600-800 base pairs) were acquired for strain VCSM12 by using the full-length PCR product as the template for sequencing with the 1492R primer after purification with the Wizard SV PCR Cleanup Kit (Promega, Madison, WI). Sequencing reactions were carried out in 6- $\mu \mathrm{L}$ volumes using Applied Biosystems BigDye 3.1 chemistry. All sequencing was performed using an Applied Biosystems 3730XL capillary sequencer at the Josephine Bay Paul Center at the Marine Biological Laboratory in Woods Hole, MA.

Phylogenetic analysis: Bases were called and vector sequences were trimmed from the 16S rRNA gene clone sequences using the Ribosomal Database Project pipeline [96,97]. The trimmed sequences were imported into ARB [98, version December 2007] and aligned to closely related sequences in the Greengenes ARB database [99] using the ARB aligner. The ARB editor was used to construct consensus sequences from cloned $16 \mathrm{~S}$ rRNA gene sequences for each half of the full 16S rRNA gene, which were then exported to FASTA files and manually merged into a single consensus full-length contig and imported into the Silva Reference database [100, SSURef 97 release]. The full-length consensus sequences from VCSA14A and VCSA23 and a partial sequence from VCSM12 have been deposited in GenBank under the accession numbers $\underline{\mathbf{G Q 9 9 6 3 8 3}}$, GQ996384 and GQ996385, respectively. The percent similarity between the full-length consensus 16S rRNA gene sequences of VCSA23 and VCSA14A, the approximately 750-base-pair partial sequence of VCSM12 and their closest relatives was determined using the "Align two sequences" function of the Basic Local Alignment Search Tool (BLAST) [101].

The full-length consensus sequences for strains VCSA23 and VCSA14A were aligned with the ARB aligner and manually checked against the 16S rRNA sequences of 204 species of marine flavobacteria in the Living Tree Project database release 100 [102]. The 16S rRNA sequence of O. marilimosa CAM $030^{\mathrm{T}}$ was obtained from Genbank and 
aligned in the Living Tree Project database as well. A positional conservancy filter was calculated using the filter by base frequency method in ARB at 30\% minimal similarity, then manually checked against the 207 aligned sequences and ultimately included 1,266 positions present and aligned in all sequences. Trees were constructed and compared in ARB using the neighbor-joining (ARB), maximum likelihood (RAxML v7.04 [103]), and maximum parsimony (DNAPars v1.8 [104]) methods. A smaller set of 76 species was exported using the conservancy filter for tree-building in PHYLIP. Trees were built using the neighbor-joining, maximum likelihood and maximum parsimony methods in PHYLIP [104]. The maximum-likelihood tree was converted to an extended post script file using the PHY·FI online tree drawing tool and manually formatted in Adobe Illustrator. Bootstrap values were obtained for 100 replicates for the maximum likelihood tree in PHYLIP.

Probe design and optimization: Oligonucleotide probes were designed using the Probe Design tool in ARB [98] in the Greengenes database [99] and their specificity checked using BLAST [101]. The VCSA23 probe (5'- GTC ATC TCT CAC CGT AAC CT -3') is also an exact match for VCSM12, but not to any other sequences in GenBank. The VCSA14A (5'- ACC GAT CTC TCA GTC TGT CAC TCT AC -3') probe matches T. discolor and T. litoreum exactly, but no other sequences in GenBank. O. marilimosa $\mathrm{CAM} 030^{\mathrm{T}}$ and T. gallaicum $\mathrm{A} 37.1^{\mathrm{T}}$ have single mismatches to the VCSA23 and VCSA14A probes, respectively, and were used as negative controls during probe optimization experiments. Both probes were determined to be specific to the single mismatch level at a formamide concentration of 35\%, although the VCSA14A probe did exhibit weak hybridization to T. gallaicum cells at formamide concentrations up to $50 \%$ (data not shown). This was not a concern for the two-strain predator/prey tests described here, but could be significant if the VCSA14A probe is used on environmental samples. Finally, neither VCSA23 nor VCSA14A probes hybridized to fixed suspensions of $S$. oneidensis with $35 \%$ formamide in the hybridization buffer. The GAM42a probe [105], specific to the large subunit of the ribosomal RNA of $\beta$ - and $\gamma$-Proteobacteria, was used 
as a prey-specific probe since it hybridized reliably to $S$. oneidensis cells but not to VCSA23 or VCSA14A cells at 35\% formamide.

In all cases, FISH was carried out on whole membrane filters by placing them on a microscope slide and pipetting $300 \mu \mathrm{L}$ of hybridization buffer ( $35 \%$ formamide) and 9 $\mu \mathrm{L}$ of each probe's working stock (GAM42A conjugated with fluorescein and a predator probe conjugated with $\mathrm{Cy} 3$ on each filter as appropriate; $100 \mathrm{ng} / \mu \mathrm{L}$ ) onto each filter. Hybridization and wash buffers and probe stock solutions were prepared according to previously published protocols [106]. The slides were hybridized in 50-mL centrifuge tubes prewarmed to $46^{\circ} \mathrm{C}$ with hybridization-buffer-soaked Kim-wipes inside. Hybridization was conducted at $46^{\circ} \mathrm{C}$ for two to three hours before removing the filters from the humidification chambers and gently placing them in Petri dishes filled with wash buffer and treating them as described elsewhere [106]. To hybridize filters inoculated with T. gallaicum, which has a single mismatch with the VCSA14A probe, hybridization buffer containing 0\% formamide was used. After hybridization, each filter was mounted with a small drop of DAPI mountant mix [107] on a precleaned microscope slide with a large coverslip ( 24 by $50 \mathrm{~mm}$ ) and kept at $4^{\circ} \mathrm{C}$ in the dark until imaging.

Confocal microscopy: While control slides were examined using a Zeiss Axioplan 2 microscope, experimental filters were imaged on a Zeiss LSM 510 META NLO confocal microscope using 488-nm Argon gas and 543-nm Helium-Neon gas lasers and a Zeiss Plan-Apochromat 63X oil-immersion objective with a numerical aperture of 1.4. In most cases, the filter was initially explored in fluorescence mode using a mercury lamp to visualize DAPI, Cy3 and FITC labels and to mark locations of interest in the LSM software for later imaging. Detector gain and amplifier offset settings were manually optimized on each filter in response to varying signal-to-noise ratios between filters. Cy3 and FITC image z-stacks were collected in frame scanning mode using the averaging method over four scans at either 1024-by-1024 or 2048-by-2048 pixel resolution. For each stack, slices were captured at $0.5 \mu \mathrm{m}$ intervals and pinhole settings were optimized for one airy unit. Images were collected primarily in transects crossing the predatory-prey interaction zones. 
Image analysis: Z-stacks were exported as tiff files using the Zeiss LSM Image Browser version 4.2.0.121 and imported into the daime digital image analysis tool, version 1.2 [108]. The histogram stretch and noise reduction tools of daime were used to improve the contrast between cells and filter backgrounds. The same settings were used for all images collected in a given channel from a particular filter. Two-dimensional image projections were then calculated using the maximum intensity projection tool of daime and exported to the tiff file format for display. Scale bars were added manually using Adobe Photoshop.

For labeled cell volume measurements, sub-transects of 128-by-128 pixel stacks were cropped from selected full image stacks (1024-by-1024 pixels) in transects using Adobe Photoshop and individually processed in daime using the same settings for histogram stretch and noise reduction as for the larger image stacks. The cropped image stacks were segmented using the 3D segmentation tool in daime with the edge detection algorithm, ignoring any putative objects of 5 voxels or smaller. Volumes for each channel in each cropped image stack were measured using daime's measurement tool.

\section{Results}

Predatory activity: Live bacterial prey were used as a sole carbon source to isolate three strains of predatory bacteria, designated VCSA23, VCSM12 and VCSA14A, from a Cape Cod aquifer. These isolates generated macroscopic clearing zones in a variety of live and pasteurized bacterial prey smears and swarmed beyond the prey smears on water agar. In addition, two already-described species closely related to strain VCSA14A, T. discolor and T. gallaicum, also cleared prey smears. Figure 1 contains images of typical macroscopic clearings caused by T. gallaicum and strains VCSA23, VCSM12 and VCSA14A on live prey lawns of S. oneidensis. O. marilimosa strain CAM030 ${ }^{\mathrm{T}}$, which is closely related to strains VCSA23 and VCSM12, did not generate any clearings on the same prey bacteria. We cannot currently determine if $O$. marilimosa CAM $030^{\mathrm{T}}$ was never predatory or if it has lost its predatory capability in culture. 
The predatory specificity of the five strains was tested on 11 prey organisms selected on the basis of cell wall structure and taxonomic diversity (Table 1). Strains VCSA23 and VCSM12 had the broadest prey specificity of the strains tested, showing unambiguous and expanding clearing on smears of all but three of the prey organisms onto which they were inoculated. With the Gram-positive K. kristinae and the yeast $S$. cerevisiae, clearing zones developed around the inoculum site and expanded to varying degrees before ceasing growth well short of full prey consumption. Neither strain cleared H. halodurans. The three Tenacibaculum strains (VCSA14A, T. discolor LL04 11.1.1 ${ }^{\mathrm{T}}$ and T. gallaicum A37. $1^{\mathrm{T}}$ ) displayed narrower specificity than strains VCSA23 and VCSM12. Strain VCSA14A had the narrowest prey specificity tested, unambiguously clearing only S. oneidensis and F. johnsoniae. T. discolor and T. gallaicum each cleared both of those prey as well as B. subtilis, E. coli and, in the case of T. gallaicum, Nitrosomonas sp. C-113a. None of the three Tenacibaculum strains visibly cleared $K$. kristinae, P. maris, S. cerevisiae or any of the pseudomonads tested. Like the Olleya strains, none of the Tenacibaculum strains affected $H$. halodurans. All five strains were also found to be non-obligate predators, capable of growing heterotrophically on complex organic media.

Since predatory bacteria are known to employ a variety of lytic mechanisms $[13,14]$, the predatory flavobacteria were further investigated to constrain the mechanism of prey lysis. We investigated the possibility that lytic exoenzymes are released into culture fluid by the predator, as has been observed for a Lysobacter species [70]. In our study, live S. oneidensis cells were resuspended into cell-free culture supernatant collected from a stationary-phase broth culture of VCSA23. No decrease in cell density was observed relative to a control culture resuspended in spent media from S. oneidensis (data not shown), suggesting that the enzymes responsible for cell lysis either (1) are not released extracellularly by VCSA23 or (2) are not expressed during non-predatory growth of VCSA23.

We also explored the possibility that direct cell-to-cell contact was required for prey lysis. Live cell microscopy was used in an attempt to visualize lytic events caused 
by cell contact between individual cells of all three isolated strains and the S. oneidensis prey. The predators frequently exhibited gliding motility on slides in wet mount preparations, but no direct lysis of prey cells by single predator cells was observed. However, it is possible that the wet mount environment is not conducive to predatory activity (or its observation) due to a number of factors, such as low predator cell density or disturbance associated with preparation of a wet mount slide.

In order to facilitate imaging of predator-prey spatial relationships with a minimum of physical disturbance, membrane filters were used as a growth surface for three- to five-day incubations and visualized using FISH. The two sets of predatory flavobacteria (Olleya sp. VCSA23 and VCSM12 and Tenacibaculum sp. VCSA14A and T. gallaicum $\mathrm{A} 37.1^{\mathrm{T}}$ ) exhibited different patterns of prey clearing when visualized at high magnification. On prey-coated filters inoculated with strain VCSA23, a decrease in prey abundance was observed coincident with the position of a dense, expanding front of VCSA23 cells (Figure 2). Measurements of labeled prey and predator biovolume show that $S$. oneidensis cell volume decreased by approximately two orders of magnitude within about $150 \mu \mathrm{m}$ crossing into the predator swarm (Figure 2). At least one millimeter inward from the main interaction zone, both VCSA23 and VCSM12 formed very dense round aggregates with small central hollows. These aggregates appeared to expand over time to become a dense mass of predator cells (Figures S1 and S2). However, despite extremely high densities of predator cell in the aggregates, a small number of prey cells were still present. Strain VCSM12 showed a broadly similar pattern, with predator cells eventually clearing most, but not all of the prey cells.

On filters inoculated with strain VCSA14A, prey cell density dropped quickly to very low levels coincident with the predator cell front (Figure 3), with most of the drop in S. oneidensis volume complete within $50 \mu \mathrm{m}$. Strain VCSA14A's cell front had a visibly lower density than that of strain VCSA23 (approximately six times less labeled cell volume), and no dense aggregates of VCSA14A cells could be found in the cleared areas of the filter. Instead, low densities of small spherical cells labeled with the VCSA14Aspecific probe were observed (Figure S3). Such shortened, often spherical cells have been 
frequently reported from older, late exponential or stationary phase cultures in several Tenacibaculum species [94,109,110,111], and may represent a dormant life stage. $T$. gallaicum $\mathrm{A} 37.1^{\mathrm{T}}$ was observed to have a similar pattern of predation on S. oneidensis cells (Figure S4).

For all strains tested, at least a few cells hybridizing with the prey-specific probe could be found in cleared areas, suggesting that not all susceptible prey cells are lysed. In addition, small numbers of scattered predatory cells were observed well in advance of the main density fronts for all four strains. Despite this, the areas ahead of the predator density fronts appeared essentially identical to prey lawns on control filters that never received predatory bacteria. A general tendency of higher prey cell volumes in close proximity to predatory cell fronts was observed on most filters. We attribute this to the regrowth of prey cells on DOM released from neighboring prey cell lysis at and behind the predatory cell front.

Since VCSA23, VCSM12 and VCSA14A are non-obligate predators, we examined whether their lytic behavior was affected by availability of exogenous DOM using yeast extract as a complex DOM source. All three strains cleared the pasteurized prey smears at all of the DOM concentrations tested. However, the growth habits of strains VCSA23 and VCSM12 changed from a swarming growth habit with filamentous margins to a thick, slimy growth habit with smooth-edged, entire margins at the highest DOM concentration tested $(0.1 \% \mathrm{w} / \mathrm{v}$ yeast extract $)$. In contrast, strain VCSA14A retained a swarming growth habit with filamentous margins at $0.1 \%$ yeast extract. Strain VCSA14A did, however, switch to a thicker growth habit with initially entire edges when grown on marine agar, which has a concentration of complex DOM of about $0.6 \%$. These results showed that although all three of the tested strains continued to track and lyse pasteurized prey cells in the presence of high concentrations of exogenous DOM, they changed their social and motility behavior in response to increasing DOM concentrations.

Phylogenetic analysis: The $16 \mathrm{~S}$ ribosomal RNA (16S rRNA) gene sequences of VCSA23 (1483 base pairs) and VCSM12 (three partial sequences between 708 and 756 base pairs) are nearly identical, with $99 \%$ identity between the overlapping regions of the 
full-length consensus sequence for VCSA23 and the partial sequences for VCSM12, suggesting that they may be two strains belonging to a single species. Phylogenetic analysis based on 1,299 well-aligned base pairs of the 16S rRNA gene sequences indicates that VCSA23 belongs to the genus Olleya (Figure 4). The 16S rRNA gene sequence of VCSA23 is $97 \%$ identical to O. marilimosa CAM030 ${ }^{\mathrm{T}}$, which is the only described species in the genus [112]. These levels of 16S rRNA gene sequence identity suggest that VCSA23 and VCSM12 could represent a second species in the Olleya genus, given the often-used threshold of $97 \%$ identity in this marker gene for species-level differentiation. The next closest cultured relative on the basis of 16S rRNA gene sequence is Lacinutrix algicola, which is 95\% identical to VCSA23.

The 16S rRNA sequence (1486 base pairs) of the third isolate, VCSA14A, is 89 to 91\% identical to those of VCSA23 (full length) and VCSM12 (partial), respectively. It branches tightly within the genus Tenacibaculum, and is most closely related to the recently described species T. discolor, T. gallaicum [95], and T. litoreum [113], which are $99 \%, 97 \%$ and $99 \%$ identical to VCSA14A in their 16S rRNA gene sequences, respectively (Figure 4).

Physiology: Physiological tests used to compare the three newly isolated strains with other closely related cultured strains are shown in Table 2 . With respect to the physiological characteristics tested, strains VCSA23 and VCSM12 are both very similar to their closest cultured relative, O. marilimosa strain CAM030 ${ }^{\mathrm{T}}$. These three strains have gliding motility, are mesophiles incapable of growth at $37^{\circ} \mathrm{C}$ and require at least some salt for growth. In fact, the only major characteristics assessed in which the two predatory strains differ from strain $\mathrm{CAM} 030^{\mathrm{T}}$ is the ability to grow by lysing prey bacteria and a requirement for sea salts. Their next closest cultured relative, L. algicola strain AKS293 ${ }^{\mathrm{T}}$, cannot glide, is incapable of growing at $30^{\circ} \mathrm{C}$ and does not require salt [114]. Strain VCSA14A was found to be very similar to its closest relatives, T. discolor strain LL04 11.1.1 ${ }^{\mathrm{T}}$, T. litoreum strain CL-TF13 ${ }^{\mathrm{T}}$ and T. gallaicum strain $\mathrm{A} 37.1^{\mathrm{T}}$. All four strains possess gliding motility, are capable of growth at $37^{\circ} \mathrm{C}$ and are incapable of utilizing either (+)-D-glucose or citrate as sole carbon sources with ammonia and nitrate as 
nitrogen sources. All six of the strains tested in this study were unable to degrade starch with ammonia and nitrate as nitrogen sources but were able to degrade casein, exhibiting clearing halos indicative of diffusible proteases on casein FMM agar plates.

\section{Discussion}

Surface-associated predatory flavobacteria such as those described in this study could influence the biogeochemistry of a wide variety of environments. In a manner similar to that already known for predatory protozoa $[11,12]$, they could increase the mobility and cycling of organic matter and suppress or stimulate particular members of microbial communities. The strength and persistence of such an influence is dependent on a variety of factors, including the accessibility of susceptible prey and details of the predatory biology of particular predatory flavobacteria present, such as the breadth of their prey specificity and environmental cues that either stimulate or discourage predatory activity. The isolates described in this study are undergoing further characterization with respect to their predatory biology. In addition, the discovery that two type strains of the genus Tenacibaculum are predatory raises the possibility that existing culture collections may contain clues as to the phylogenetic distribution of additional predatory bacteria.

This study provides the first definitive evidence for predatory activity within the class Flavobacteria. Flavobacteria are found in a wide variety of habitats, including seawater [115], lakes [116,117], marine sediments [118,119], polar sea ice [120] and hydrothermal settings [121]. This group has been reported as being important in the degradation of polymeric substances in aquatic environments [122,123,124,125]. They are also frequently associated with particulate matter in the oceans [126,127], as well as with phytoplankton and bacterial blooms $[117,128]$. If some fraction of the flavobacteria

in these habitats is accessing living biomass as a growth substrate, our observations have broad implications for the role of flavobacteria in microbial ecology and biogeochemistry.

Our results suggest that the predatory flavobacteria described in this study might employ a lytic mechanism requiring at least close proximity, if not direct contact, to prey 
cells. Many myxobacteria and some members of the genus Lysobacter release constitutively produced lytic exoenzymes $[70,71,84,85,129]$. Although all of the strains produced diffusible proteases (Table 2), the culture supernatant of strain VCSA23 showed no lytic activity (data not shown). This suggests either that the production of lytic exoenzymes is contingent on the presence of prey cells or that they are not released extracellularly. If lytic enzymes are not released extracellularly, they may be membraneassociated similarly to those commonly found in genomic and biochemical studies of marine flavobacteria $[130,131,132,133]$. Further study is needed to fully constrain the lytic mechanism of the predatory flavobacteria.

The diversity in prey specificity displayed by the strains tested in this study suggests varying degrees of specialization within the predatory flavobacteria, as has been found for other predatory bacteria $[29,64,134,135,136]$. At least with respect to the prey species and growth conditions assayed here, the strains VCSA23 and VCSM12 appear to be more cosmopolitan in terms of susceptible prey than the Tenacibaculum strains. Their range of susceptible prey was very broad, with only $H$. halodurans proving completely impervious (Table 1) under the conditions tested. Even among the Tenacibaculum strains, all of which are very closely related to each other according to $16 \mathrm{~S}$ rRNA analysis, there was considerable diversity in prey specificity. In fact, no two Tenacibaculum strains had the same prey specificity profile. Prey specificity may be related to the predators' mechanism of lysis and to physiological or chemical characteristics of the prey under the tested conditions. It is clear from the prey specificity profiles that the cell wall structure of the prey is not a dominant factor in prey susceptibility to the predatory flavobacteria. Four out of the five predatory strains tested were found to lyse both Gram-negative and Gram-positive prey. Despite the susceptibility of S. oneidensis to all the predatory strains tested, at least one other member of the class $\gamma$-Proteobacteria proved to be resistant to predation by each predator. Since the lytic mechanism of these predatory flavobacteria appears to require direct contact (or at least close proximity) with prey, other prey characteristics may be important, including the production of extracellular polymeric 
substances, the presence or absence of specific proteins or compounds on the prey cell surface or the production and release of compounds antagonistic to predator cells.

Interestingly, the images collected from cleared zones of prey lawns on membrane filters indicate that $S$. oneidensis prey is not completely eliminated by any of the predators tested (Figures 2, 3, S1-S4). Although incomplete elimination of prey populations has been commonly observed for obligate planktonic predators, such as Bdellovibrio [54,136,137], it has often been assumed that gliding predators such as myxobacteria completely lyse their local prey populations [135]. However, attempts to assess prey survival after myxobacterial predation have shown that complete elimination of prey cells is rare $[31,138]$ and that a small number of viable prey cells can be recovered after the lysis of more than $99 \%$ of the original prey population. The basis for predatory resistance of these surviving cells is currently unknown, whether it be from genotypic or phenotypic differences from lysed prey cells. A minority of prey cells under Bdellovibrio predation have been shown to develop a temporarily increased resistance to predatory attack, termed plastic phenotypic resistance [54]. Prey populations under attack by gliding non-obligate predators, such as myxobacteria and the flavobacteria in this study, may undergo a similar physiological change in which a small subset become temporarily resistant to predation. Another, less studied, possibility is that the predatory flavobacteria may stop active predation in response to external factors, such as nutrient concentration or prey cell density. Either possibility could serve as a mechanism that allows prey populations to escape complete elimination by bacterial predation.

In addition to differences of prey specificity, the tested predatory strains displayed contrasting growth efficiencies. As represented in Figures 2 and 3, the same density of prey cells presented to and lysed by the different predator strains resulted in an order of magnitude more cells (as measured by total volume) of Olleya sp. VCSA23 (Figure 2) and VCSM12 (Figure S2) than those of Tenacibaculum sp. VCSA14A (Figure 3) and T. gallaicum A37.1 ${ }^{\mathrm{T}}$ (Figure S4). Although both sets of predators were responsible for approximately the same amount of prey lysis, the lower predation efficiency of the Tenacibaculum strains suggests that they may be unable to assimilate as much prey 
biomass as the Olleya strains. Both T. discolor and T. gallaicum, as well as other members of the genus Tenacibaculum, have been reported to be unable to assimilate a variety of sugars $[94,95,113,139]$ while the closest relative to strains VCSA23 and VCSM12, O. marilimosa CAM030 ${ }^{\mathrm{T}}$, has been described as utilizing several sugars [112]. This suggests that the predatory Olleya strains could owe their higher predation efficiency to a broader capacity for carbohydrate assimilation. However, carbohydrates generally compose a minority of bacterial cell dry weight - less than $10 \%$ in E. coli, as reviewed by Neidhardt et al. [140] - and so seem unlikely to be solely responsible for the large differences in predatory cell density between the strains. The Tenacibaculum and Olleya strains may also differ in their hydrolytic capabilities, with Tenacibaculum strains able to access fewer of the prey macromolecules.

Determining the prevalence of predation among flavobacterial species remains a significant challenge. As mentioned earlier, predatory capability is not a monophyletic trait and predatory bacteria can be very closely related to non-predatory species. Nonobligate predatory lifestyles may have evolved repeatedly and independently from saprophytic gliding bacteria [14], both within the class Flavobacteria and in other groups. In addition, the utilization of functional gene markers, which has been successful in assessing the presence and diversity of other functional guilds, is not possible for detecting predatory bacteria at this time. Many of the hydrolytic enzymes presumably used by predatory flavobacteria to break down prey macromolecules after cell lysis could also be used to break down non-living particulate and dissolved organic matter, and so would not be diagnostic of predatory capability. Until an unambiguous functional marker for predatory flavobacteria can be identified, culture-based approaches may be the most reliable way of establishing whether a particular species is capable of predation.

Nonetheless, in addition to this study, other reports have presented evidence that supports the possibility that predation may not be a rare lifestyle for flavobacteria. For example, Tenacibaculum maritimum was described to lyse dead cells of E. coli, Aeromonas hydrophila and Edwardsiella tarda [94,109], although it is unclear whether it was tested for growth on live prey cells. Kordia algicida has been described to have a 
strongly algicidal effect on some diatoms and other algae in liquid [141]. At least four other types of marine flavobacteria have also shown lytic activity towards eukaryotic phytoplankton, though they have not been taxonomically characterized [82,142]. In addition, a stable-isotope probing study using ${ }^{13} \mathrm{C}$-labeled prey cells added to soil microcosms detected a flavobacterial 16S rRNA sequence along with sequences belonging to known predatory bacteria such as myxobacteria and members of the genus Lysobacter within the ${ }^{13} \mathrm{C}$-labeled RNA fraction [59]. This result suggests that the labeled Flavobacterium sp., which took up stable-isotope-labeled carbon from the added prey cells, is a predatory bacterium. However, this type of labeling study is ambiguous by nature, since it is possible that non-predatory bacteria could have scavenged labeled carbon from the prey after it was lysed.

The results of this study and mounting circumstantial evidence in recent literature indicate that predation should be considered as a potential ecological role for flavobacteria and other members of the Bacteroidetes. If predatory flavobacteria are significant sources of microbial mortality, then flavobacteria as a group cannot be accurately treated as equivalent to other, more 'passive,' heterotrophic bacteria in biogeochemical models as some may represent a higher trophic level. In other words, these results argue that the bacterial size fraction in aquatic environments can possess significant trophic complexity, with potential consequences for the efficiency of biogeochemical cycling.

\section{Acknowledgments}

We would like to thank Ed Leadbetter, Dan Rogers, Mark Martin and James Saenz for helpful discussions during the course of this study and four anonymous reviewers whose useful comments improved this manuscript. We are grateful for field support and assistance from Dan Rogers, Paul Henderson, Matt McIlvin, James Saenz, Sandy Baldwin, Laura Erban, Matt Charette and Kevin Kroeger. We thank Jeff Donnelly and Maya Gomes for the loan of a vibrocorer and advice, and Cornelia Wuchter and Stefan Sievert for assistance with FISH. Louis Kerr is acknowledged for his technical assistance 
with confocal microscopy. This work was supported by NSF grant EAR-0525166 to E.B.K., a WHOI Ocean Ventures Fund award and a WHOI Coastal Ocean Institute fellowship, both awarded to E.C.B. 


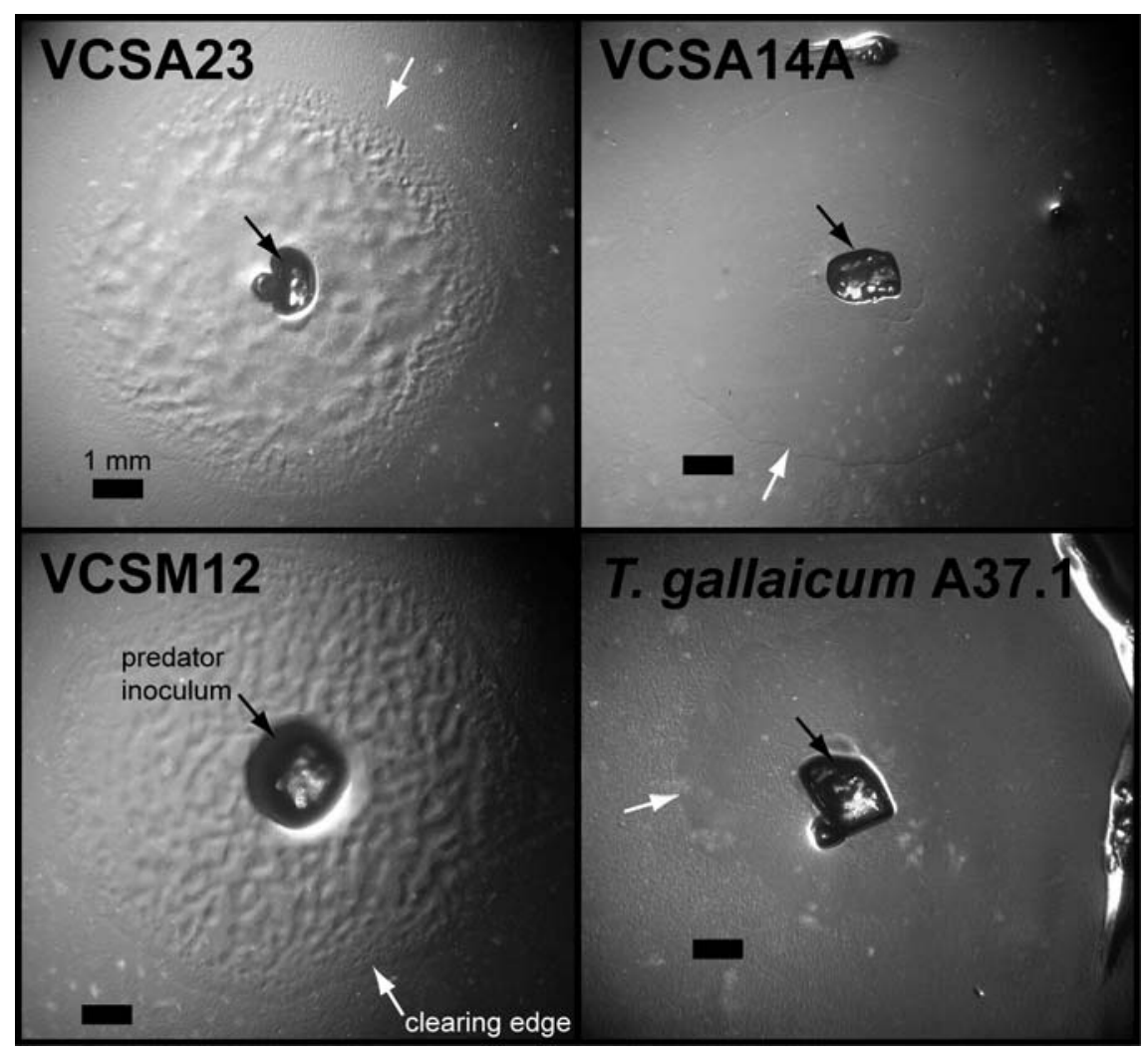

Figure 1: Photographs of typical predatory clearings of prey lawns. The predatory inoculum (a chunk of agar from a previous culture), is at the center of each panel (black arrow). Each inoculum is surrounded by a roughly circular cleared zone, the expanding edge of which is indicated by a white arrow. Beyond the edge of each clearing edge is a lawn of live $S$. oneidensis prey on WAT25. The photographs of strains VCSA23, VCSM12 and VCSA14A were taken of three-day-old cultures while the photograph of $T$. gallaicum strain $\mathrm{A} 37.1^{\mathrm{T}}$ is of a five-day-old culture. 

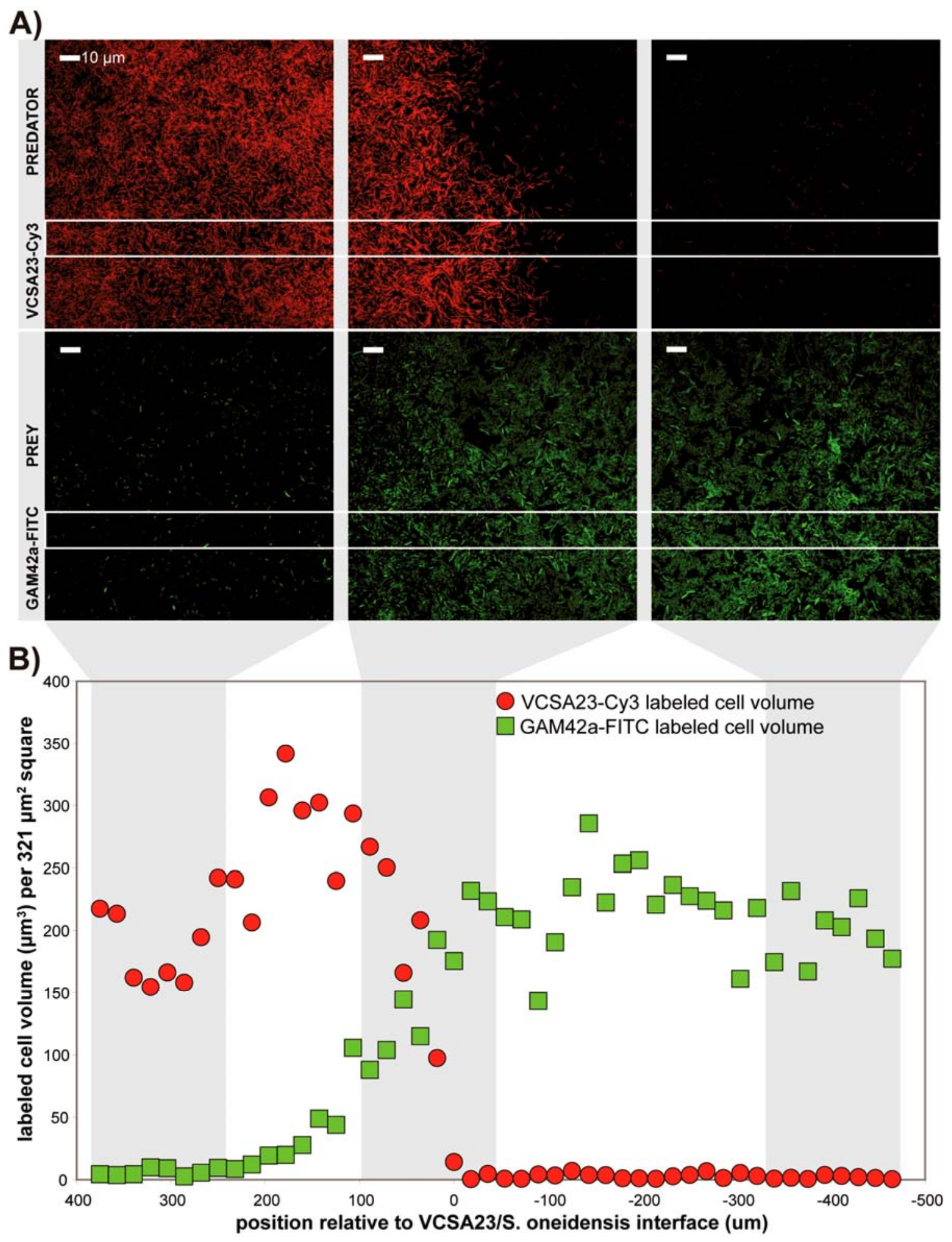

Figure 2: (A) Two-dimensional confocal projections of VCSA23 cells (labeled with the VCSA23-Cy3 probe, top, in red) and S. oneidensis prey (labeled with the GAM42a-FITC 
probe, bottom, in green). From left to right are shown the most recently cleared zone, the interface between the expanding VCSA23 cell front and the prey lawn, and the prey lawn relatively undisturbed by VCSA23 cells. All scale bars are $10 \mu \mathrm{m}$. In the lower graph (B), labeled cell volume data are plotted against the transect coordinate using a section of the collected images, delineated by white boxes on the 2-D projections in (A). Each point was calculated from a $321-\mu \mathrm{m}^{2}$ square. The volumes of GAM42a-FITC-labeled cells (S. oneidensis) are plotted with green squares while the VCSA23-Cy3-labeled cell volumes (strain VCSA23) are represented by red circles. Grey shading in the graph indicates the spatial orientation of the 2-D projections shown in (A). 

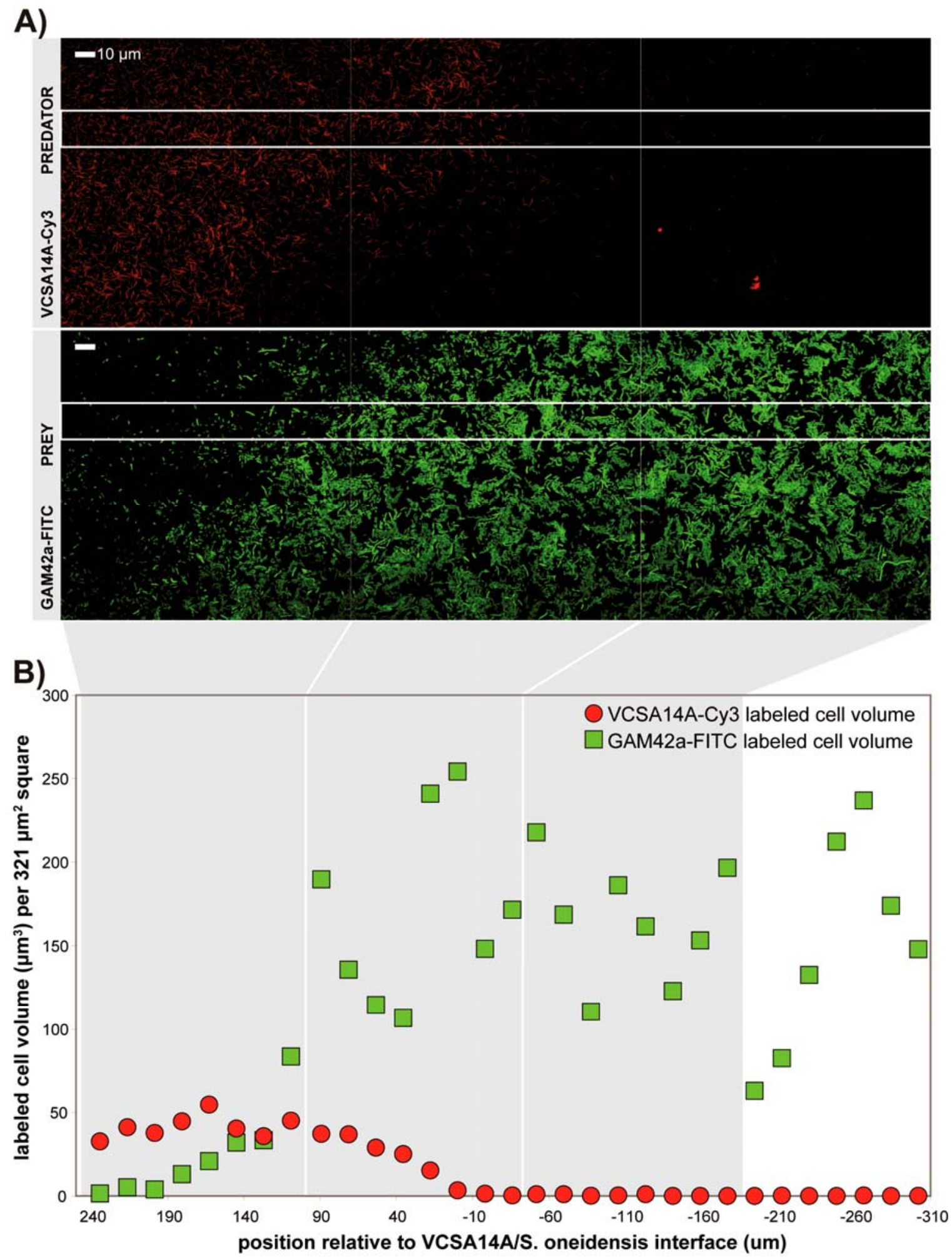

Figure 3: (A) Two-dimensional confocal projections of strain VCSA14A cells (labeled with the VCSA14A-Cy3 probe, top, in red) and S. oneidensis prey (labeled with the 
GAM42a-FITC probe, bottom, in green) show, from left to right, the most recently cleared zone, the interface between the expanding VCSA14A cell front and the prey lawn, and the prey lawn relatively undisturbed by VCSA14A cells. The three sets of 2-D projections were acquired adjacent to each other along a transect crossing the VCSA14A cell front. The graph at bottom (B) was constructed identically to that in Figure 2B.

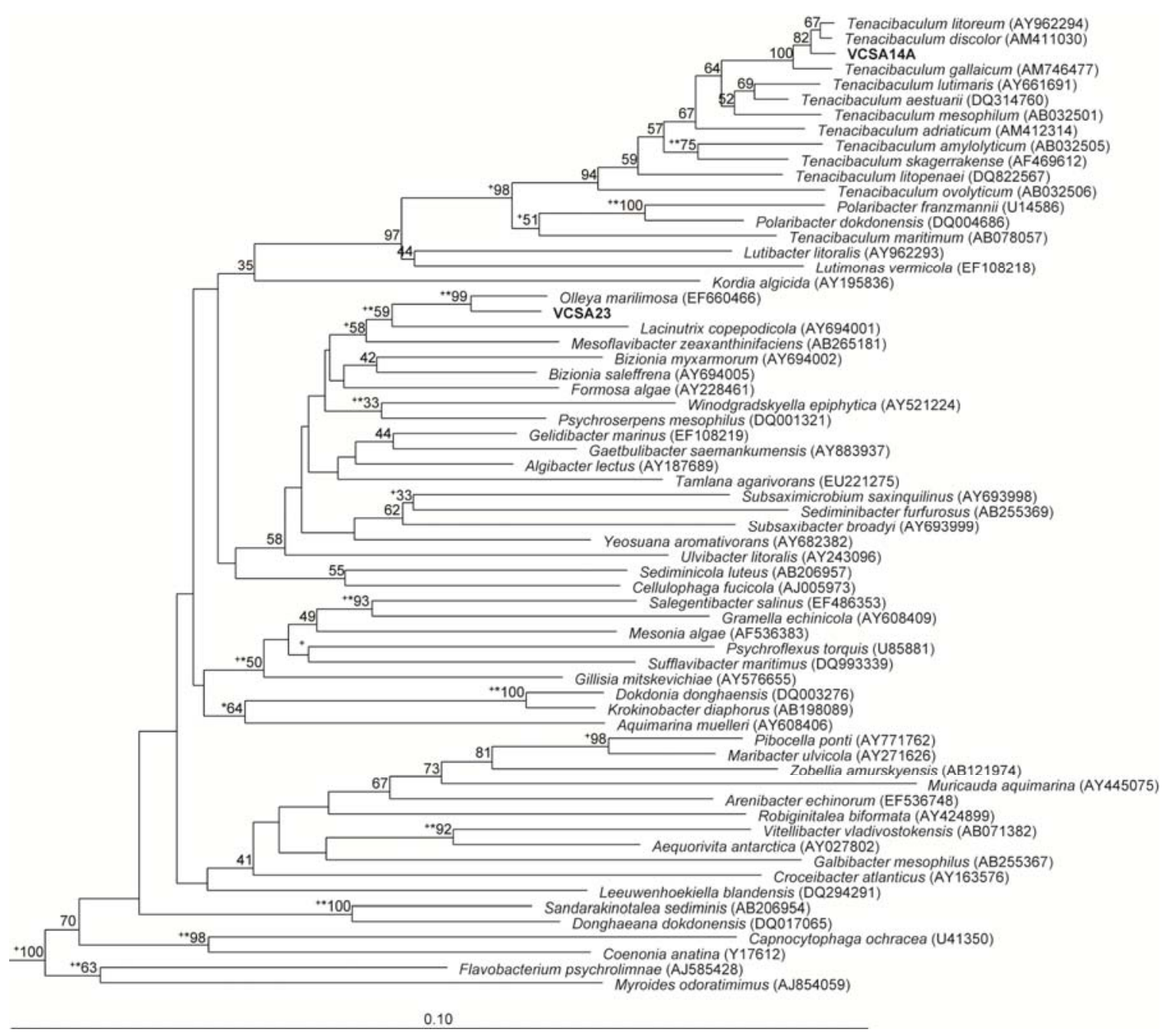

Figure 4: Maximum-likelihood tree showing the phylogenetic relationship between strains VCSA23, VCSA14A and other members of the family Flavobacteriaceae based on full-length 16S rRNA sequences. The tree was built from an alignment containing the 76 species shown here using 1,266 positions present and aligned in all 76 sequences. GenBank nucleotide accession numbers are provided for each sequence in parentheses. Numbers at nodes indicate the percent bootstrap support for that node in a 100-replicate bootstrap analysis of the maximum-likelihood tree. Open back circles and filled grey circles indicate nodes recovered in neighbor-joining and maximum parsimony trees, 
respectively, built from the same alignment. The scale bar indicates the branch length corresponding to 0.1 changes per mean nucleotide position.

Table 1: Prey specificity of predatory strains

\begin{tabular}{|c|c|c|c|c|c|}
\hline $\begin{array}{l}\text { Predator species: } \\
\text { Predator strain: }\end{array}$ & $\begin{array}{c}\text { Olleya } \\
\text { sp. } \\
\text { VCSA23 }\end{array}$ & $\begin{array}{c}\text { Olleya } \\
\text { sp. } \\
\text { VCSM12 }\end{array}$ & $\begin{array}{l}\text { Tenacibaculum } \\
\text { sp. } \\
\text { VCSA14A }\end{array}$ & $\begin{array}{c}\text { T. } \\
\text { discolor } \\
\text { LL04 } \\
11.1 .1^{\mathrm{T}} \\
\end{array}$ & $\begin{array}{c}\text { T. } \\
\text { gallaicum } \\
\text { A37.1 }\end{array}$ \\
\hline \multicolumn{6}{|l|}{ Prey species: } \\
\hline $\begin{array}{l}\text { Shewanella oneidensis } \\
\text { MR-1 }\end{array}$ & + & + & + & + & + \\
\hline Escherichia coli JM109 & + & + & - & + & + \\
\hline $\begin{array}{l}\text { Pseudomonas putida } \\
\text { DSM } 50906\end{array}$ & + & + & - & - & - \\
\hline P. corrugata & + & + & - & - & - \\
\hline Halomonas halodurans & - & - & - & - & - \\
\hline Nitrosomonas sp. C113a & + & + & - & - & + \\
\hline $\begin{array}{l}\text { Flavobacterium } \\
\text { johnsoniae }\end{array}$ & + & + & + & + & + \\
\hline $\begin{array}{l}\text { Planctomyces maris } \\
\text { DSM } 8797\end{array}$ & + & + & - & - & - \\
\hline $\begin{array}{l}\text { Kocuria kristinae } \\
\text { DSM } 20032\end{array}$ & $+/-$ & $+/-$ & - & - & - \\
\hline Bacillus subtilis PY79 & + & + & - & + & + \\
\hline Saccharomyces cerevisiae & $+/-$ & $+/-$ & - & - & - \\
\hline
\end{tabular}


Table 2: Physiological characteristics of predatory strains and close relatives

\begin{tabular}{|c|c|c|c|c|c|c|c|c|c|}
\hline $\begin{array}{l}\text { Species: } \\
\text { Strain: }\end{array}$ & VCSA23 & VCSM12 & $\begin{array}{c}\text { Olleya } \\
\text { marilimosa } \\
\text { CAM030 }^{\mathrm{T}}\end{array}$ & $\begin{array}{c}\text { Lacinutrix } \\
\text { algicola } \\
\text { AKS293 }^{\mathrm{T}}\end{array}$ & $\begin{array}{c}\text { VCSA14 } \\
\text { A }\end{array}$ & $\begin{array}{c}\text { T. discolor } \\
\\
\text { LL04 } \\
11.1 .1^{\mathrm{T}}\end{array}$ & $\begin{array}{c}. \\
\text { litoreum } \\
\text { CL-TF13 }^{\mathrm{T}}\end{array}$ & $\begin{array}{c}\text { T. gallaicum } \\
\text { A } 37.1^{\mathrm{T}}\end{array}$ & $\begin{array}{c}T . \\
\text { mesophilum } \\
\text { MBIC } 1140^{\mathrm{T}}\end{array}$ \\
\hline Reference: & This study & This study & [112] & [114] & This study & [95] & [113] & [95] & [94] \\
\hline \multicolumn{10}{|l|}{ Characteristic: } \\
\hline $\begin{array}{l}\text { Gliding } \\
\text { motility }\end{array}$ & + & + & + & - & + & + & + & + & + \\
\hline $\begin{array}{l}\text { Growth at } 0 \\
\text { salinity } \\
\text { Growth at } 25 \\
\text { salinity w/only } \\
\mathrm{NaCl}\end{array}$ & - & - & + & + & W & W & + & - & - \\
\hline $\begin{array}{l}\text { Growth at } \\
30^{\circ} \mathrm{C} \\
\text { Growth at } \\
37^{\circ} \mathrm{C}\end{array}$ & + & + & + & - & $\begin{array}{l}+ \\
+\end{array}$ & $\begin{array}{l}+ \\
+\end{array}$ & $\begin{array}{l}+ \\
+\end{array}$ & $\begin{array}{l}+ \\
+\end{array}$ & $\begin{array}{l}+ \\
+\end{array}$ \\
\hline Bacteriolytic & + & + & - & ND & + & + & ND & + & ND \\
\hline $\begin{array}{l}\text { Starch } \\
\text { degradation } \\
\text { Casein } \\
\text { degradation }\end{array}$ & + & $\begin{array}{l}- \\
+\end{array}$ & $\begin{array}{c}- \\
+*\end{array}$ & $\begin{array}{l}\text { ND } \\
+\end{array}$ & $\begin{array}{l}- \\
+\end{array}$ & $\begin{array}{l}- \\
+\end{array}$ & $\begin{array}{c}+ \\
\text { ND }\end{array}$ & $\begin{array}{l}- \\
+\end{array}$ & $\begin{array}{l}- \\
+\end{array}$ \\
\hline
\end{tabular}

ND: no data, *: Mancuso Nichols et al. [112] reports no casein hydrolysis, but O. marilimosa strain CAM030 ${ }^{\mathrm{T}}$ was observed to hydrolyze casein in this study, w: weak growth without characteristic swarming at colony edges observed. 


\title{
CHAPTER 3: BIOLOGY OF PREDATORY MARINE FLAVOBACTERIA
}

\begin{abstract}
Constraining the potential ecological impact of predatory marine flavobacteria requires an understanding of the biological factors influencing their grazing activity. After the observation of dense predatory swarms in previous experiments, the minimum number of predatory cells required to generate clearing of prey cells was investigated and found to be on the order of $10^{1}$ for both Olleya sp. VCSA23 and Tenacibaculum sp. VCSA14A. Microscopic observation of the distribution of predator cells within prey lawns suggests that incipient swarms form through the aggregation of previously independently growing flavobacterial cells, which may be predating as single cells. A greater capability for polysaccharide degradation amongst the Olleya strains supports the hypothesis that differences in predatory growth yields between the Olleya and Tenacibaculum genera are related to differing abilities to access prey biomass. To assess the effects of varying culture and prey conditions on flavobacterial predation, a multifactorial experiment was conducted with an array of prey treatments suspended in varying media and plated on either no-nutrient, starvation agar or a defined, low-nutrient agar capable of supporting most of the prey species. Its results suggest that the metabolic state of prey bacteria affects their susceptibility to lysis by predatory marine flavobacteria.
\end{abstract}

\section{Introduction}

The biology of predatory microorganisms, particularly with respect to their feeding behavior and locomotion, influences their impact on prey communities. For example, different protozoan grazers selectively consume prey based on factors including cell size [26,143,144,145], attachment to surfaces [28], prey motility [8] and cell-surface chemistry $[146,147,148]$. In addition, biofilm formation has been observed to provide protection against some protists but not others [149]. Many of these factors are the direct result of the protists' need to engulf, or phagocytize, prey cells into food vacuoles in 
order for lysis to occur. Examination of the biological capabilities and limits of protozoan grazers has been tremendously informative - revealing that some protozoan grazers, such as amoebae and some ciliates, are well-adapted to feeding on established biofilms while others, including some flagellates, are better adapted for feeding on suspended cells within characteristic size ranges $[28,61,62,149,150,151,152,153,154]$. These types of findings have shown that biofilms do not provide absolute protection against predation. In addition, other studies have shown that protozoan grazers can enhance prey communities' rate of metabolic activity and diversity [4,5,16,20,61,146].

Since predatory bacteria utilize lytic mechanisms other than those of protozoans, it is likely that surface-associated predatory bacteria may play ecological and biogeochemical roles quite distinct from protozoans. Previous observations of the novel marine flavobacteria strains described in Chapter 2 as well as the body of literature developed during the last century on predatory bacteria make it clear that known predatory bacteria do not utilize phagocytosis to lyse prey cells. In the case of surfaceassociated gliding predatory bacteria, such as myxobacteria [34], members of the genera Lysobacter [49,70], Herpetosiphon [33] and Saprospira [45] and the novel predatory marine flavobacteria described in Chapter 2, prey cells are lysed in the predator cells' extracellular neighborhood by currently undescribed mechanisms.

In part due to the inherent difficulties in directly observing the cell-to-cell interactions between predator and prey bacteria, the lytic mechanism of predatory marine flavobacteria is not immediately evident. In membrane-filter coculture experiments, described in Chapter 2, dense aggregations of gliding cells were observed to coincide with the disappearance of the majority of FISH-probe hybridizing prey cells. Such an apparently social growth habit is highly reminiscent of the swarms documented for myxobacteria, which have long been observed to form dense swarms and aggregations during the elimination of bacterial prey $[34,155,156]$, termed wolf-pack predation. In light of this observation, the question of whether predatory marine flavobacteria require a substantial quorum of cells sufficient to form a swarm becomes a potentially critical constraint on their environmental significance as grazers. 
If predatory marine flavobacteria are only able to lyse prey cells when they are socially cooperating in swarms, their ecological significance is likely to be more limited. They might only act as predators when either a critical mass of flavobacteria cells simultaneously colonize a susceptible prey community or sufficient nutrients are available to allow them to grow to swarm-type densities. The first case would be facilitated if predatory marine flavobacteria are able to form aggregates, similar to myxobacterial fruiting bodies, containing a large number of cells and capable of being dispersed intact. The results of Chapter 2 show that Olleya sp. VCSA23 and VCSM12 readily aggregate after prey clearance, which might lead to the development of such a dispersal structure. On the other hand, Tenacibaculum sp. VCSA14A scattered and decreased its cell size after the prey lawn was cleared. In the second case, flavobacterial predation might only occur in ecosystems in which the non-predatory competitiveness of predatory marine flavobacteria allowed them to reach high cell densities.

However, both myxobacteria [43] and Saprospira sp. [45] have been reported to possess the capability for individual cells to grow predatorily in the absence of social coordination. If single cells of predatory marine flavobacteria are able to lyse prey cells as well, flavobacterial predation would not be limited to habitats capable of sustaining dense blooms of predatory cells.

Many marine flavobacteria have been found to be important components of particle-associated communities in sediments, suspended marine snow and other types of particulate matter $[126,127,157]$. If one or a few cells are capable of predating in the absence of a swarm, flavobacterial predation could be ubiquitous within aquatic microbial communities. Substrate colonization experiments with natural bacterioplankton communities have indicated that at least a portion of marine flavobacteria readily attach to particle surfaces from suspension $[128,158]$.

Another observation from Chapter 2 was the major difference in cell yield between the Olleya strains and Tenacibaculum strains during predatory growth. All tested Olleya strains produced an order of magnitude more cells from the exploitation of the same prey density than the Tenacibaculum strains (Ch. 2). One hypothesis that might 
explain this disparity would be that the Olleya strains are capable of assimilating a broader range of organic compounds from prey biomass than the Tenacibaculum strains. This hypothesis is partially supported by previous findings that $T$. discolor and $T$. gallaicum, two of the closest cultured relatives of Tenacibaculum sp. VCSA14A and themselves predatory, do not appear to be capable of growth on carbohydrates [95], while O. marilimosa (the closest cultured relative to the predatory Olleya strains) has been reported to be capable of growth on a variety of sugars [112]. In order to further explore this hypothesis, all three novel predatory marine flavobacteria strains and the three already described reference species were assayed for the activity of 19 enzymes involved in the utilization of a variety of substrates, including lipids, carbohydrates and proteins.

An additional biological dimension that could influence the grazing activity of predatory marine flavobacteria in the environment is their response to cues in the prey community, including prey density, metabolic state and any chemical signals present. In at least two reports, bacteria that lyse eukaryotic phytoplankton have been found to limit their lytic activity to particular conditions. For three algal-lytic strains isolated from cultures of the toxic dinoflagellate Alexandrium catanella, including one identified as a Cytophaga sp., lytic compounds were found to be released under high-nutrient conditions but not under the low-nutrient conditions in coculture with the dinoflagellate [82]. In another case, a strain identified as a Cytophaga sp. was observed to coexist with diatoms up to a Cytophaga cell density of about $10^{5}$ cell $/ \mathrm{mL}$, at which point it began to lyse the diatoms as its cell density increased to about $10^{7}$ cells $/ \mathrm{mL}$ [83].

In this chapter, a series of experiments were carried out to assess whether high inoculum densities are needed for predation by marine flavobacteria to occur. In addition, the effect of varying prey condition and culture media on flavobacterial predation was tested. Constitutive expression of a range of enzyme functions was assayed to shed light on possible explanations for the gap in predatory growth efficiency between the Olleya and Tenacibaculum genera. 


\section{Materials and Methods}

Temperature and salinity optima: The growth and predation for all three novel predatory marine flavobacteria - Olleya sp. VCSA23 and VCSM12 and Tenacibaculum sp. VCSA14A - was tested at varying temperatures and salinities.

Non-predatory growth experiments were conducted in 10-mL volumes in capped borosilicate glass test tubes $(16 \times 100 \mathrm{~mm})$ using modified $\mathrm{DNb}$ media mixed from sterile stock solutions (see appendix). For each of the three strains, a single suspension made from colonies grown non-predatorily on agar was used as inoculum for all broths to standardize inoculum size. Four temperatures, 15, 21 (room temperature), 30 and $38{ }^{\circ} \mathrm{C}$, and three salinities, 20, 25 and $30 \mathrm{ppt}$, were tested with shaking at $150 \mathrm{rpm}$. The different salinities were tested at $21^{\circ} \mathrm{C}$. Absorbance at $540 \mathrm{~nm}$ was monitored by spectrophotometer every four to eight hours for two days and cell densities were estimated using standard curve equations that had been calibrated with direct cell counts. An individual standard curve was generated each for VCSM12 (also used for VCSA23) and VCSA14A. Spot checks for purity were conducted by streaking 20 to $40 \mu \mathrm{L}$ of culture onto DN agar plates. Generation times for each test condition were calculated using the growth rate constant, calculated from the log-phase of growth in each growth curve.

Predation experiments were conducted on WAT plates with live Shewanella oneidensis MR-1 cells (grown up overnight in LB at $30^{\circ} \mathrm{C}$ shaken at $150 \mathrm{rpm}$ ) that had been washed and 10X-concentrated as prey. Plates were made up at five different salinities by altering the amount of ASW added to the media: 0, 10, 20, 25 and 30 ppt. Prey smears were prepared and inoculated with predator using standard procedures, as described in Chapter 2. Plates were incubated at six different temperatures: $4{ }^{\circ} \mathrm{C}, 15^{\circ} \mathrm{C}$, $21^{\circ} \mathrm{C}, 23{ }^{\circ} \mathrm{C}, 30^{\circ} \mathrm{C}$ and $38^{\circ} \mathrm{C}$. Plates of differing salinity were all incubated at $23{ }^{\circ} \mathrm{C}$. Extent of clearing and swarm development on all plates was checked and marked every two to four days using a dissecting microscope. Plates that did not develop rapid growth were monitored for slower development for 24 days before ending the experiment. 
Enzyme activity: For each strain undergoing enzyme activity testing, three cultures were grown up with shaking at $150 \mathrm{rpm}$ at $30^{\circ} \mathrm{C}$ over about 36 hours: one in Difco marine broth, one in DNb25 (see appendix) and one in DNb25 with pasteurized $S$. oneidensis MR-1 cells added, all at a final volume of $10 \mathrm{~mL}$. Broth cultures were inoculated with a loopful of colony from a fresh marine-agar plate culture of the appropriate strain. Pasteurized prey cells were prepared by growing up six $10-\mathrm{mL}$ broth cultures of $S$. oneidensis in 1/10 strength LB25 (see appendix) to stationary phase and pasteurizing at $70{ }^{\circ} \mathrm{C}$ for 30 minutes. The pasteurized suspensions were pelleted by centrifugation, resuspended in sterile $\mathrm{DNb} 25$ and pooled to a final volume of $7 \mathrm{~mL}$ before aliquoting into tubes with $9 \mathrm{~mL}$ of sterile DNb25.

The API ZYM system (Biomerieux, Durham, NC) was used to assess activity levels of a variety of enzymes of live marine flavobacteria cells according to the manufacturer's instructions. For each broth culture to be tested, the culture was pelleted by centrifugation and resuspended to a total volume of $2 \mathrm{~mL}$ in $\mathrm{ASW}+\mathrm{Ca}$ (see appendix) instead of the manufacturer's prescribed medium before addition of $65 \mu \mathrm{L}$ to each of the test strip cupules. Test strips were incubated at $30{ }^{\circ} \mathrm{C}$ in the dark for 4.5 hours before reading. Sterile negative control cultures for each media condition were incubated in parallel with the test cultures and also tested.

Minimum predatory unit experiments: Two experiments were conducted using controlled concentrations of predatory cells to constrain the minimum number of predatory cells required to generate lytic clearing of prey cells. In both experiments, suspensions of stationary phase $S$. oneidensis MR-1 cells, grown overnight at $30^{\circ} \mathrm{C}$ shaken at $150 \mathrm{rpm}$, washed by centrifugation and resuspension three times in $20 \mathrm{ppt}$ ASW-HEPES buffer (see appendix) and concentrated 10 times were used as prey. For each experiment, a single batch culture of S. oneidensis was used - resulting in uniform prey concentration within each experiment. $100 \mu \mathrm{L}$ of the washed prey suspension was added for each prey spot in all cases. For both experiments, predator suspensions were obtained by harvesting VCSA23 and VCSA14A cells from 1-day DNb25 cultures (grown at $30{ }^{\circ} \mathrm{C}$ with $150 \mathrm{rpm}$ shaking) and washing them three times by centrifugation and 
resuspension in 20 ppt ASW-HEPES buffer. A standard curve was built for each strain by correlating direct counting of washed cell suspensions in a cell counting chamber with absorbance measurements at $540 \mathrm{~nm}$ in a spectrophotometer and used to estimate cell densities in washed suspensions. Washed predator suspensions were diluted as necessary to facilitate the delivery of controlled numbers of predator cells by pipetting of 2 to $20 \mu \mathrm{L}$ volumes.

In the first experiment, prey and predator suspensions were mixed together and pipetted directly onto WA25 plates to create spots of about 1.5 to $2 \mathrm{~cm}$ in diameter. For each of the two predatory strains being tested, seven inoculum concentrations were used: $10^{5}, 10^{4}, 5^{*} 10^{3}, 10^{3}, 5^{*} 10^{2}, 10^{2}, 10^{1}$ total cells per prey spot. An appropriate volume (between 2 and $20 \mu \mathrm{L}$ ) of the required dilution of washed predator suspension was mixed with the washed prey suspension prior to spotting. Prey only and predator only spots were also made as controls. For each plate, all filters received the same treatment. The plates were kept right-side up at room temperature until no liquid was visible on the agar surface, then they were incubated upside-down at $23{ }^{\circ} \mathrm{C}$ in the dark. Spots were monitored daily using a dissecting microscope for three days.

In the second experiment, only a single predator inoculum concentration was used $-10^{1}$ cells per prey spot. In order to visualize the predator-prey dynamics during the formation of incipient clearing swarms using confocal microscopy, the second experiment was conducted on $0.2-\mu \mathrm{m}$ black polycarbonate membrane filters (Millipore, Billerica, MA). Washed prey and predator suspensions were mixed as needed to ensure that each filter would receive on the order of $10^{1}$ cells of the appropriate predator and the number of live prey cells contained in $100 \mu \mathrm{L}$ of washed prey suspension, and then diluted with sterile PBS to a total volume of $1.2 \mathrm{~mL}$ for each filter. The diluted suspensions were gently filtered onto autoclaved membrane filters using a vacuum pump and white polycarbonate membrane filters $(0.2 \mu \mathrm{m}$ pore size $)$ as backing, and then placed directly on WA25 plates using flame-sterilized forceps. In between filtrations, the filter apparatus was flame-sterilized briefly using ethanol. Four to five filters of a single predator treatment were placed on each plate, and $200-\mu \mathrm{L}$ control suspensions of each 
treatment were also spotted to allow monitoring of clearing progress by dissecting microscope. The filters were sampled at a variety of time points between 0 and 53 hours by fixing and freezing filters as described in Chapter 2 .

Fluorescent in-situ hybridization (FISH), confocal microscopy and image analysis to measure labeled bio-volumes were carried out using the methods described in Chapter 2. DAPI images were not collected for this data set as a result of a misalignment of the DAPI excitation laser's optics. To estimate predator cell densities in the images analyzed, labeled predator cells were manually counted in as many of the collected images as was feasible - a total of 25 images from the VCSA23 treatment containing between 0 and 873 cells and 11 images from the VCSA14A treatment containing between 0 and 250 cells. The resulting cell counts for each of the two predators were correlated using a linear regression with the labeled bio-volumes to calculate standard-curve equations, which were used to estimate the cell numbers in images in which the cell densities were too high to allow direct counting. The edges of swarms, when located, were mapped manually in the LSM 510 software and later plotted to estimate the diameter of large clearing zones.

Predation on different prey conditions: A multifactorial experiment was designed and executed to assess the effects of species, metabolic activity, density and washing of prey cells on flavobacterial predatory lysis. The generic design for treatments involving a single prey species in this experiment is shown in Table 1. Six prey species were employed in this experiment: Bacillus subtilis, Escherichia coli, Halomonas halodurans, Kocuria kristinae, Pseudomonas corrugata and Shewanella oneidensis. All prey strains were handled and grown as described in Chapter 2, with the exception that all of the six prey bacteria except for $K$. kristinae and $S$. oneidensis were also grown in parallel in the defined growth medium BD1 (at $2 \mathrm{~g} / \mathrm{L}$ sugar substrate; see appendix). $K$. kristinae and S. oneidensis were not grown in BD1 because of a failure to achieve sufficient densities and the inability to grow in the defined medium, respectively. As shown in Table 1, plating medium was varied as a way to control prey growth. Prey were presumed to be starving on the no-nutrient medium WAT, in contrast to BD1 medium (at $0.01 \mathrm{~g} / \mathrm{L}$ sugar substrate; see appendix) which was able to support colony formation by 
most of the prey organisms used in this experiment (data not shown). The BD1 medium was incapable of supporting growth of any of the strains of predatory marine flavobacteria in this study. When feasible, based on the prey cell density in the source culture, both 10- or 20-times concentrated and unconcentrated prey treatments were included to assess the importance of prey density to flavobacterial predation. In addition, the suspension medium of the prey was varied - with all prey being presented to the predators either washed (three times in 20 ppt ASW HEPES buffer) or unwashed (and still in the spent media from their growth phase). For all prey organisms except $H$. halodurans, a treatment of pasteurized (at $70{ }^{\circ} \mathrm{C}$ for at least 15 minutes) and then washed prey was also offered. Two unwashed treatments were used for the prey bacteria capable of rapid growth on the BD1 media: one suspended in spent complex media (as appropriate to the particular organism: LB for E. coli, S. oneidensis, B. subtilis and $P$. corrugata; M53 for K. kristinae; Marine broth for H. halodurans) and the other suspended in the spent BD1 media. All treatments were duplicated.

For each duplicate, three prey smears of the same suspension and density treatment were made using standard procedures on the appropriate plating medium. The two outer smears were inoculated with Olleya sp. VCSA23 and Tenacibaculum sp. VCSA14A, respectively, taken from two-day-old Marine agar plate cultures and the middle smear was left as a prey-only control for comparison. For each combination of treatments, two plates with the same prey and media treatments were inoculated. All plates were incubated in Zip-loc bags at $23{ }^{\circ} \mathrm{C}$ in the dark for three weeks and checked using a dissecting microscope on a rolling basis, due to the large number of plates in the experiment. The extent of spreading and swarm development was marked on the plate lids in permanent marker, and photographs of representative features were taken using a Canon Powershot A70 camera on a Zeiss SteREO Discovery.V8 stereomicroscope. For each set of photographs, a ruler was photographed at the same magnification in order to provide scale. At the end of the experiment, all plate lids were photographed and the marked progress of clearing and swarm features was traced manually in Adobe Illustrator before measurement of front advance rates in Photoshop. 
For each treatment/predator pair, the plate lid images were scored for the presence of definite and diffuse clearing fronts and radial and fringe swarm fronts. Clearing fronts showing clearly defined relief across the boundary and substantial textural differences between cleared and uncleared areas were scored as definite. If clearings could be observed due to higher transparency of the cleared zones but the front was hard to pinpoint because it was indistinct, the front was scored as diffuse. Swarms were scored as radial when they expanded away from the prey smears onto open agar, and as fringing when they were visible but were tightly confined to the immediate vicinity of the prey smear.

Photographs of clearing and swarm features were processed in Adobe Photoshop by converting them to grayscale and using the Auto Tone and Auto Contrast functions to adjust the contrast and brightness. In addition, the Smart Sharpen filter (100\% amount, 10-pixel radius, Gaussian blur setting) was used on images for display to improve feature clarity.

\section{Results}

Temperature and salinity optima: All three of the tested predatory marine flavobacteria strains were found to be mesophilic with regard to their temperature optima and capable of growing non-predatorily at a range of salinities, as shown in Table 2. None of the strains were capable of growth with sodium chloride alone in the absence of sea salts (data not shown). Tenacibaculum sp. VCSA14A was capable of growth at $38^{\circ} \mathrm{C}$ while the Olleya strains were not. The measured generation times during non-predatory growth for the Olleya strains ranged between about 1.5 and 3 generations per hour over a range of salinities and temperatures (Table 2). The fastest measured growth rate for an Olleya strain was a doubling every 1.47 hours for Olleya sp. VCSM12, at 25 ppt salinity and $21{ }^{\circ} \mathrm{C}$. Under the conditions tested for non-predatory growth, the fastest growth rate measured for Olleya sp. VCSA23 was a doubling every 2.04 hours at 20 ppt salinity and $21^{\circ} \mathrm{C}$. In contrast, Tenacibaculum sp. VCSA14A was measured doubling every 1.05 hours at $38^{\circ} \mathrm{C}$ and $25 \mathrm{ppt}$ salinity. 
Tests of predation across temperature and salinity gradients (Table 3 ) showed a similar pattern, with VCSA14A capable of predation at $38{ }^{\circ} \mathrm{C}$ while the highest temperature at which Olleya sp. predation was observed was $30^{\circ} \mathrm{C}$. Another difference between the Olleya strains and VCSA14A was observed at the low end of the temperature and salinity gradients. Although none of the strains showed any predatory activity at $0 \mathrm{ppt}$ salinity, both Olleya strains cleared prey cells at $10 \mathrm{ppt}$ salinity while VCSA14A showed no activity. Similarly, both Olleya strains were observed to clear prey at $4{ }^{\circ} \mathrm{C}$ while the lowest temperature at which VCSA14A was observed to clear prey was $15{ }^{\circ} \mathrm{C}$ after 24 days of observation.

Enzyme activity: All marine flavobacteria strains tested for enzyme activity profiles showed strong activity under all growth conditions for alkaline phosphatase, acid phosphatase and naphthol-AS-BI-phosphohydrolase, enzymes involved in the cleavage of phosphate from organic compounds. In general the six tested strains also had activity of most of the enzymes tested involved in lipid, amino acid and protein utilization but rarely showed activity of polysaccharide metabolism enzymes (Tables 4 and 5).

When grown in marine broth prior to testing for enzyme activity, results for $T$. discolor and T. gallaicum were consistent with those previously published (Pineiro-Vidal et al. 2008) with the exception of a weak positive $\mathrm{N}$-acetyl- $\beta$-glucosaminidase signal for T. gallaicum. Although ZYM results for O. marilimosa have not been previously reported, results from other API tests have been published (Mancuso Nichols et al. 2005) and those that overlap with the ZYM test are shown in Table 4. O. marilimosa failed to generate a positive $\mathrm{N}$-acetyl- $\beta$-glucosaminidase result using the ZYM test and did generate a weak positive $\alpha$-glucosidase signal, both contrary to previously reported results. The discrepancies may be an artifact of the different substrates used in each test.

There was no major difference in enzyme activity profile between the predatory (VCSA23 and VCSM12) and non-predatory (O. marilimosa CAM030) Olleya strains (Table 4) grown in marine broth prior to testing. All three of the Olleya strains showed activity in all of the tested lipid-, amino acid- and protein-associated enzymes except $\alpha$ chymotrypsin, for which no activity was observed, and had no activity for most of the 
polysaccharide degradation enzymes tested. The only exceptions were $\alpha$-glucosidase, which had weak to strong activity for all three, and $\alpha$-fucosidase, which showed weak activity for VCSA23.

All of the Tenacibaculum species tested in this study showed strong activity for the enzymes involved in lipid, amino acid and protein metabolism and weak or no activity for the polysaccharide-involved enzymes (Table 4), similar to previously reported results for other members of the Tenacibaculum genus (Pineiro-Vidal et al 2008, Jung et al 2006, Choi et al 2006).

For the most part, all six tested strains showed similar enzyme activity profiles when they were grown with and without the addition of pasteurized S. oneidensis MR-1 cells on a dilute nutrient broth before testing (Table 5). However, there were some noteworthy differences. Olleya sp. VCSA23 had higher activity for lipase when grown in the presence of pasteurized prey cells than under either of the other two conditions. This might be explained by differences in cell load going into the ZYM test resulting from additional substrate coming from the pasteurized cells during growth. Interestingly, the lipase activity was higher than that observed for cells grown on marine broth, suggesting that VCSA23 lipase activity might be induced by the presence of prey cells. Although both marine broth and dilute nutrient broth are unlikely to contain significant lipid concentrations, a difference in the lipid levels of the two media cannot be completely ruled out. However, it seems unlikely given the fact that higher lipase activity on dilute nutrient broth than marine broth was only observed for two out of the six strains, Olleya sp. VCSA23 and Tenacibaculum sp. VCSA14A.

Esterase, an enzyme likely involved in the hydrolyis of lipid ester bonds, showed higher activity from Olleya sp. VCSM12 under both dilute-nutrient conditions than under the richer marine-broth condition. Although their esterase activity in marine broth was high, Olleya sp. VCSA23, T. gallaicum and Tenacibaculum sp. VCSA14A showed more esterase activity in the presence of pasteurized prey than without it when grown in dilute nutrient broth. Similarly, VCSM12 showed activity of several enzymes after growth in the presence of pasteurized prey cells roughly equivalent to that observed after growth on 
marine broth (Table 5). Although this could be a result of additional substrate contained in prey cells, it is notable that most of the enzymes tested did not show marked differences in activity level between dilute-nutrient and marine broth growth conditions, suggesting that the ZYM test was not sensitive to the lower cell yield obtained from the dilute-nutrient conditions.

Interestingly, non-predatory O. marilimosa CAM030 had indistinguishable enzyme activity levels under the dilute-nutrient broth treatment regardless of the presence of pasteurized S. oneidensis cells, with the exception of the weak $\alpha$-glucosidase activity detected only when pasteurized cells had been added.

Minimum predatory unit: In the preliminary experiment, in which the initial predator cell inoculum was varied between $10^{1}$ and $10^{5}$ cells, all of the predatorinoculated spots with $10^{2}$ cells or more were promptly cleared within two days, as monitored by dissecting microscope. On all $10^{1}$-cell-loaded spots, between five and 10 and five and 35 discrete circular clearing plaques appeared within three days for Olleya sp. VCSA23 and Tenacibaculum sp. VCSA14A, respectively.

Since a very low predator inoculum showed the ability to ultimately clear a prey spot, the second experiment to examine the dynamics of initial swarm formation from a minimal number of predator cells was conducted using $10^{1}$ cells as the predatory inoculum. Control prey and predator spots, spotted directly onto the agar plate to allow easy visualization during the experiment, developed circular clearing plaques visible under the dissecting microscope in about three days, similar to the results of the preliminary experiment.

Analysis of the three treatments of prey-covered membrane filters (S. oneidensis only, Olleya sp. VCSA23 and S. oneidensis and Tenacibaculum sp. VCSA14A and S. oneidensis) from early, intermediate and late stages of the experimental incubation showed that overall bio-volume of $S$. oneidensis cells hybridized with the GAM42A FISH probe dropped quickly after the initial time point independent of the presence of predatory flavobacteria (Figure 1). The largest drop measured was of nearly $90 \%$ in the $S$. oneidensis-only treatment between filters sacrificed at 0.6 and 11.3 hours in the 
experiment, respectively. Therefore it is important to note that the large initial drop in labeled prey density visible in Figure 2 is apparently not a result of predation.

Predator cells were not observed at the initial sampling points, within an hour of experiment initiation, for either of the two predator and prey treatments (Figure 2), despite extensive exploration of the filters. This is consistent with the initial predator inoculation, since the calculated detection threshold for individual cells by random sampling of the filter surface with the imaging parameters used is on the order of $10^{3}$ cells on the entire filter.

By 14 hours into the experiment, individual cells and small clusters of cells hybridizing to the appropriate predator-specific FISH probes could be readily located on the membrane filters (Figure 2). The small clusters consisted of, at maximum, on the order of a dozen cells and did not appear to coincide with a visible local decrease in the surrounding prey cell density. Predator cell numbers were manually counted in all available intermediate-time-point images, and the resulting estimates of cell density on the filters are tabulated in Table 6 . For both predators, the cell density per square millimeter of filter was estimated to be on the order of $10^{2}$. In the case of Olleya sp. VCSA23 (but not Tenacibaculum sp. VCSA14A), the variability amongst the images was high and zero is included within a single standard deviation of the mean.

On filters fixed later in the experiment, incipient swarms were documented. At 34 hours, an incipient VCSA23 swarm with a diameter of about $40 \mu \mathrm{m}$ was imaged (data not shown). By 53 hours, expanding swarms were located on filters from both predator treatments (as mapped in Figure 3). The dimensions and cell densities (estimated using standard curves when cell density too high for manual counting) are listed in Table 6 for both clearing zones. In short, the approximately $650-\mu \mathrm{m}$-diameter VCSA23 swarm was smaller than the VCSA14A swarm, which had an estimated diameter of $1600 \mu \mathrm{m}$. Both swarms could be easily divided into outer and inner cell-density zones. However, consistent with the findings of Chapter 2, the distribution of cells between the outer and inner zones was diametrically opposite between the two strains. While the two swarms' outer zones had roughly equivalent cell densities, Olleya sp. VCSA23's inner zone had 
about three times more cells per square millimeter than its outer zone while Tenacibaculum sp. VCSA14A's inner zone contained about ten times fewer cells per square millimeter than its outer zone (Table 6).

Another observed difference between the two strains of predatory flavobacteria after 53 hours of incubation was the predator cell density outside of the swarms, in the uncleared prey lawn (Table 6). On the VCSA23-inoculated filter, the estimated cell density in the prey lawn after 53 hours was lower than that after 14 hours, although the low numbers and patchiness of predator cell density was too high for either estimate's standard deviation to exclude zero. In contrast, the VCSA14A cell density in the prey lawn increased nearly an order of magnitude between 14 and 53 hours.

Predation under differing conditions: Considerable variability was found amongst the results of the multifactorial predation experiment on the basis of nearly all of the factors tested as well as between duplicate plates of the same treatment. For the six prey species tested in the experiment, both Olleya sp. VCSA23 and Tenacibaculum sp. VCSA14A showed some ability to clear portions of the smears under at least some of the conditions tested for each prey species.

Intra-treatment variability was surprisingly high, as 32 out of the 66 treatments were identified as having substantial discrepancies between the duplicate plates. The discrepancies range from differences in the expansion rates of swarms and clearings for both predators to one plate showing growth for one or both predators and the other showing no or substantially diminished activity for both predators. The treatments with discrepancies are widely distributed with no apparent pattern throughout the experiment across all prey except $B$. subtilis and across all other factors, including density, plating media and suspension media. However, the discrepancies appear to predominantly affect both predators on a plate relative to its duplicate. Great care was taken to avoid the switching of plates or plate lids, and in fact the discrepancies were observed directly during the experiment. The plating media for the experiment was drawn without tracking from multiple batches of plates, which is one possible source of unaccounted-for variation. 
Despite the unanticipated high variability between duplicate plates, some patterns were observable in the occurrence of clearing and swarm features on the basis of the controlled factors for both strains of predatory flavobacteria. Swarms were scored as radial when they expanded away from the prey smears onto open agar, and as fringing when they were visible but were tightly confined to the immediate vicinity of the prey smear. Overall, fringing swarms remaining close to the edge of the prey smear were developed much more frequently by Tenacibaculum sp. VCSA14A than by Olleya sp. VCSA23 (Tables 7-12). When such fringing swarms did occur on smears inoculated with VCSA23, radial swarms were also observed under the same conditions and sometimes on another part of the same smear. VCSA23 fringing swarms were mostly limited to smears of $H$. halodurans and $P$. corrugata prey that were washed or suspended in spent defined growth media and plated onto no-nutrient agar. In contrast, VCSA14A formed fringing swarms on smears of all six prey species, often without any radial swarms at all observed on either the same smear or the duplicate smear.

B. subtilis was tested as a prey organism under two plating media and four suspension media conditions (Table 7). Both Olleya sp. VCSA23 and Tenacibaculum sp. VCSA14A developed at least some clearing on B. subtilis under nearly all of the conditions tested. However, VCSA14A only developed diffuse clearings when the prey was suspended in spent minimal growth medium BD1 (regardless of plate medium) and when it was suspended in spent LB on no-nutrient agar.

For E. coli as prey, both VCSA23 and VCSA14A produced definite clearings under many different test conditions (Table 8). In the case of Olleya sp. VCSA23, definite clearings were observed under nearly all treatments except the lowest density one - E. coli suspended in spent defined growth medium without concentration and plated on no-nutrient agar, where the prey would have no substrate for growth. VCSA14A also showed no activity under that condition on either duplicate plate, although it did generate definite and/or diffuse clearings on E. coli under a variety of other test conditions. In particular, VCSA14A was shown to be capable of clearing E. coli when it was suspended in spent LB or washed and pasteurized, regardless of density and plating medium. In 
addition to forming radial swarms under many of the E. coli test conditions, VCSA14A often developed fringing swarms even when no clearing of the E. coli prey was observed - specifically when the prey was washed or washed and pasteurized.

When $H$. halodurans was tested as prey bacterium, both predators failed to develop definite clearings under the standard condition previously used (Table 9) of washed live prey on no-nutrient agar. However, Olleya sp. VCSA23 was observed to develop subtle, diffuse clearings under that condition suggesting some prey clearing was being accomplished. Under most other conditions, Olleya sp. VCSA23 did form definite, well-defined clearings on $H$. halodurans. Tenacibaculum sp. VCSA14A was not observed to develop definite clearings under any test condition, except when diffuse clearings were observed with $H$. halodurans suspended in spent Marine broth. Despite the lack of observable clearing features, VCSA14A formed swarms under nearly every test condition on $H$. halodurans. Only fringing swarms were developed on no-nutrient agar, but robust radial swarms were observed on BD1 agar, which supports $H$. halodurans growth.

On K. kristinae as prey, Olleya sp. VCSA23 was observed to develop clearings under all tested conditions (Table 10). This included in particular the washed prey, nonutrient agar condition previously used (Ch. 2) to test for prey specificity, under which VCSA23 had been scored as generating ambiguous results. In contrast, no definite clearings were observed for Tenacibaculum sp. VCSA14A under any condition although diffuse clearings were sporadically observed under a couple of disparate conditions. Both predators swarmed under all conditions, though in different forms: all of the VCSA23 swarms were radial, while most of the VCSA14A swarms were fringing in habit.

In the case of $P$. corrugata as prey, plating media appeared to have a profound effect on both predators' activity (Table 11). On no-nutrient agar, Olleya sp. VCSA23 cleared P. corrugata and swarmed under all conditions. However, on BD1 agar VCSA23 failed to develop any observable clearing or swarm on either washed or washed and pasteurized prey, and was limited to diffuse clearings on $P$. corrugata suspended in spent LB. A similar pattern was observed for Tenacibaculum sp. VCSA14A - which cleared $P$. 
corrugata diffusely under most conditions on no-nutrient agar, though not on washed prey, consistent with the results of Chapter 2. On BD1 agar, no VCSA14A activity was observed on any kind of washed or washed-and-pasteurized prey. The two predators' swarming activity differed somewhat as well. VCSA23 swarms only occurred in the presence of clearing features, while VCSA14A swarmed on no-nutrient agar even when no clearing features were observed.

On S. oneidensis prey, both predators developed definite clearings and radial swarms under most conditions tested, including the previously used washed prey on nonutrient agar condition.

\section{Discussion}

Temperature \& salinity: The temperature and salinity tolerances found for Tenacibaculum sp. VCSA14A were similar to other described members of the genus, none of which have been found to grow at $4{ }^{\circ} \mathrm{C}$. In addition, most described Tenacibaculum species are capable of growth at $37{ }^{\circ} \mathrm{C}[94,95,111,113,139,159]$. The temperature tolerances for the Olleya strains, VCSA23 and VCSM12, were identical to those reported for O. marilimosa CAM030 [112]. In contrast to O. marilimosa, VCSA23 and VCSM12 required sea salts to grow.

In general, the conditions of the sediments at the time of sampling fall within the measured temperature and salinity ranges. The temperature and salinity throughout the sediment column was measured by piezometer immediately before coring. The temperature of all sampled depths was relatively uniform at $15^{\circ} \mathrm{C}$, within the observed temperature tolerance for all three strains. Salinity varied between greater than $20 \mathrm{ppt}$ salinity and $5 \mathrm{ppt}$ from the surface to the bottom of the cored column. Tenacibaculum sp. VCSA14A was isolated from sediment taken from the top of the core which was submerged at high tide and likely heavily influenced by the bay water. In contrast, the Olleya strains were isolated from sediments collected from around three and seven feet deep in the core, at which the salinity at the time of coring was $11 \mathrm{ppt}$ and $5 \mathrm{ppt}$, respectively. These salinities were at the lower range tolerated by the Olleya strains and 
below the minimum salinity required by Tenacibaculum sp. VCSA14A. The salinity within the sediments is likely to be variable since the site is a subterranean estuary with a deep saltwater/freshwater mixing zone whose position is influenced by seasonal groundwater flux.

Enzyme activity differences: Conclusions from the enzyme activity profiles are limited by the specific enzyme activities tested and the coarse resolution of the API ZYM system. For example, all of the tested strains probably express additional proteases beyond the two specific proteolytic activities assessed, trypsin and $\alpha$-chymotrypsin, and more robust conclusions could be drawn from quantitative per-cell measurements of specific enzyme activities.

With respect to large-scale enzyme differences between the closely related predator and non-predatory Olleya species, there was no enzyme activity detected solely from either the two predatory strains, Olleya sp. VCSA23 and VCSM12, or the nonpredatory O. marilimosa CAM030 that might be associated with predatory capability. The API ZYM results for O. marilimosa CAM030 generally agreed with those previously published, with the sole major exception of the failure of the API ZYM test to detect any $\mathrm{N}$-acetyl- $\beta$-glucosaminidase activity. This discrepancy may be a result of the use of a different method to test for the activity [112]. Interestingly, the enzyme activities of the two predatory Olleya strains were more variable in response to the presence of pasteurized susceptible prey cells in the growth medium than the non-predatory strain. However, there was no uniform pattern to this response amongst the two predatory strains. The results for strain VCSA23 suggest that esterase and lipase may be more highly expressed in the presence of susceptible prey cells. On the other hand, the results for VCSM12 suggest that cystine arylamidase, trypsin and $\alpha$-glucosidase are most likely to be more highly expressed in response to prey cells - and esterase and lipase had identical activity levels whether prey cells were present or not. Of course, it is possible that the changes in activity level were too subtle to be detected by the API ZYM system, which is mainly designed as a presence/absence test. 
All three of the Tenacibaculum strains tested for enzyme activity profiles were previously found to be predatory, as described in Chapter 2 . The differences in activity profiles as a function of growth treatment were even less marked than amongst the Olleya strains. Despite this, Tenacibaculum sp. VCSA14A and T. gallaicum did show higher esterase activity in association with prey cells than the same media treatment without them, similarly to Olleya sp. VCSA23, and T. discolor had a similar lipase activity pattern in relation to prey cell presence to that shown by Olleya sp. VCSM12.

Weak to positive activity of $\alpha$-glucosidase, which hydrolyzes glucose monomers from polysaccharides, was detected for all three Olleya strains and none of the Tenacibaculum strains. This suggests that the Olleya strains are at least able to break down glucose-containing polysaccharides to a greater extent than Tenacibaculum strains, possibly both increasing their access to prey biomass and improving their ability to degrade any extracellular biofilm matrix. However, the question of whether the glucose released as a result of $\alpha$-glucosidase activity can be assimilated by Olleya sp. requires confirmation by either appropriate growth experiments or an assay testing assimilation.

The results also indicate that there are genus-level differences between the Olleya and Tenacibaculum genera, specifically in the presence of $\alpha$-chymotrypsin activity in Tenacibaculum species and weak $\alpha$-glucosidase activity in Olleya species. Comparing these results to previously published API ZYM data for the genus Lacinutrix, which is very closely related to Olleya based on 16S rRNA phylogeny (as described in Chapter 2), show that Lacinutrix species possess $\alpha$-chymotrypsin activity, lack $\alpha$-glucosidase activity and possesss $\beta$-galactosidase activity. This suggests that the API ZYM test may be useful for genus-level identification of marine flavobacteria.

Minimum predatory unit: A decrease in hybridized cell density of as much as $90 \%$ was observed as a function of time regardless of the presence or absence of either predator (Figure 1), suggesting that at least substantial changes in the number of ribosomes per cell took place as a result of some combination of washing, filtration and incubation under starvation conditions. Since FISH probes hybridize one-to-one to $16 \mathrm{~S}$ ribosomal RNA, a single copy of which is present in each ribosome, FISH signal strength 
is proportional to ribosome complement [as reviewed by 160]. The failure of cells to hybridize could have been caused by decreases in cell and/or ribosome numbers. $S$. oneidensis cells may have autolysed in response to starvation conditions, in which case there could be substantial cellular debris and soluble organic matter available for the initial growth stages of the predatory inocula. Another possibility is that a large proportion of the $S$. oneidensis cells might have lowered their ribosome complement below the FISH detection threshold in response to starvation conditions. In biofilms formed in drinking water, a recent study found that the percent of cells with detectable FISH signals could be increased from 50 percent to 80 percent by the addition of fresh media [161]. This would also provide an alternative explanation for the increases in hybridizing $S$. oneidensis density observed in close proximity to predatory swarm fronts (Ch. 2). Instead of the increase in density being accounted for by cell division, dormant cells with low ribosome complements (and therefore effectively invisible to FISH probes) may have up-regulated their protein synthesis machinery in response to the availability of DOC released by predatory lysis at the swarm front. In addition, a decrease in ribosomes/cell in many starving prey cells would be consistent with observations during pilot membrane filter experiments. During a pilot experiment using live/dead staining, more than $99 \%$ of cells in uncleared prey lawns were stained in a manner consistent with intact cell membranes (data not shown).

If the drop in prey cell hybridization within two hours of experiment initiation had been the result of autolysis, then ample dead biomass should have been available to sustain non-predatory growth. The flavobacteria might have scavenged the cellular debris until it was exhausted, and then switched to cooperative swarms in order to predate on live, hybridizing S. oneidensis cells. On the other hand, it seems likely that nonhybridizing $S$. oneidensis cells were merely dormant and the amount of non-cellular organic substrate available for non-predatory growth would have been very small. In that case, the flavobacteria may have been predating as individual cells, but needed social coordination in order to attack more active prey cells with higher ribosome contents. 
The coincident imaging of DNA stains with prey-specific FISH probes over a similar time-course of prey smears would be necessary to conclusively distinguish between the two possible causes of the decrease in prey hybridization. Without the data from general DNA stains (unavailable because of maintenance issues on the confocal microscope), it is impossible to distinguish between predatory and non-predatory growth for the flavobacterial cells during the initial and intermediate stages of the membranefilter experiment. In either case, hybridizing S. oneidensis cell density has been observed to drop precipitously as swarms of predatory marine flavobacteria pass. If this drop were caused by a drop into dormancy by $S$. oneidensis cells and not their lysis by flavobacteria, the massive predatory cell yields would have to be explained by some alternate carbon source. To the contrary, no evidence has been observed either in this study or in Chapter 2 that implies that the marine flavobacterial strains are capable of visible, much less substantial, growth on no-nutrient agar in the absence of any prey cell additions.

The substantial numbers of independent predator cells of both strains observed widely distributed in prey lawns at the intermediate stage of the experiment are inconsistent with the hypothesis of a dense predatory swarm directly originating from the division of a single predator cell at a single location. Under both predator treatments, the number of predator cells observed in the imaged area were on the order of hundreds of cells per square millimeter. Extrapolated to a total cell-covered area on each membrane filter of at least $200 \mathrm{~mm}^{2}$, tens of thousands of predator cells were present on each membrane filter within 15 hours of the experiment's initiation with an initial predator cell inoculum of about 10 cells. If each individual cell at this stage had later generated an expanding predatory swarm, the discrete circular clearing zones observed on the control spots by dissecting microscopes would have been too numerous to visualize before they overlapped. Instead, the evidence suggests that at some point between 15 and 50 hours of incubation, predatory cells of both strains aggregated into a small number of swarms and began predating cooperatively. In this case, the number and spacing of predatory swarms forming on the prey lawn is probably controlled by the cells' response to some condition in the prey lawn, and its rough correspondence to the initial number of predatory cells 
would be coincidental. Factors influencing aggregation into cooperative swarms might include predator cell density, prey cell density and the availability of nutrients for nonpredatory growth.

Olleya sp. VCSA23 and Tenacibaculum sp. VCSA14A were observed to produce profoundly different distributions of cell density within their predatory swarms (Table 6, Figure 3), consistent with previous observations (Ch. 2). The Olleya strain's highest cell density of about $3 \times 10^{5}$ cells $/ \mathrm{mm}^{2}$ was found at the center of a large predatory swarm, surrounded by a zone of lower density between the core and edge of the swarm. Altogether, the VCSA23 cell density within expanding swarms was three orders of magnitude greater than that observed in the uncleared prey lawn areas (Table 6). In contrast, Tenacibaculum sp. VCSA14A's highest cell density of about $2 \times 10^{5}$ cells $/ \mathrm{mm}^{2}$ was observed in the outer zone between the swarm core and edge, while the swarm core's cell density was an order of magnitude less (Table 6). These results further confirm the disparity in cell yield from predatory growth between the two strains described in Chapter 2.

In the event that the overall drop in hybridizing $S$. oneidensis cells on the membrane filters is substantially a result of cells entering a dormant, low-ribosome state, it is possible that those 'invisible' cells were the growth substrate for the independently roving predator cells in the intermediate stages of the experiment. If so, the dense coordinated swarms may be required to utilize prey cells with higher ribosome contents and other potential differences in physiology. The hypothetical predatory lifestyle consisting of two such habits, one a low-density scavenging of inactive or dead cells and the other a high-density elimination of more active prey cells, suggests the possibility that flavobacterial predation may impact the active, growing component of the prey community only when the amount of nonliving or inactive substrate can support sufficient numbers of predator cells. Experiments utilizing growing prey communities with controlled amounts of dead or inactive material for scavenging consumption might facilitate testing of this hypothesis. 
Determining the fate of $S$. oneidensis cells that stopped hybridizing with the preyspecific FISH probe is critical to constraining the growth mode of the independent predator cells in the early and intermediate stages of the experiment. As mentioned above, a general DNA stain would allow detection of cells with an insufficient number of ribosomes for hybridization, but still containing DNA. However, this measure on its own would provide no additional information on the availability of non-cellular material. If possible, the coupling of a DNA stain with FISH probes and fluorescent stains for protein and/or extracellular polymeric substances (EPS) in an approach similar to that of the membrane-filter experiment would yield an assessment of both the integrity of nonhybridizing prey cells and the prevalence of extracellular material. An alternative approach would be to conduct experiments in flow cells on the microscope stage with prey organisms modified to produce fluorescent proteins. An example of this type of approach is described by Teal et al. [162], who produced S. oneidensis MR-1 mutant strains that each produced two different fluorescent protein labels - one label constitutively and the other coupled to a reporter gene for either protein synthesis or anaerobic metabolism. Although FISH was not used in the study, the results indicated that $S$. oneidensis MR-1, the same species used in this study, is capable of entering a metabolic state in which ribosome and protein synthesis is minimized, but the cells are still metabolically active [162].

Overall, the results of the membrane-filter experiment suggest that cooperative swarming is an emergent behavior under particular environmental conditions, and that predatory marine flavobacteria are capable of growing in the presence of prey without swarming. Consequently, the minimum predatory unit in fact may be a single cell, but the path from a single cell to an expanding predatory swarm appears to pass through a separate, potentially non-predatory growth habit.

Predation under differing conditions: The extreme variability between replicate plates in the multifactorial experiment in which Olleya sp. VCSA23 and Tenacibaculum sp. VCSA14A were incubated on prey under different conditions is of serious concern. The observation of plate-level differences between replicates, for which both predators 
cleared robustly on one replicate plate but either cleared or swarmed less extensively on the other, suggests that differences in the plate media was the source of the problem. This is a real possibility, since plates from multiple media batches were used in the experiment without tracking of their source batches and although great care was taken in labeling and sorting the plates, simple mistakes in handling and labeling cannot be completely ruled out. It is possible that some of the batches were made with a different brand of agar than the others, and this may have seriously compromised the data set. In the case that some of the plates were unfavorable for flavobacterial growth, it is also possible that some treatments may have received both replicate plates from such a batch and be completely compromised. This possibility cannot be excluded, and so all of the results should be evaluated critically in the absence of a more rigorous repeat of the experiment with more thorough control of media source.

Another measure that could have improved the power of the results would have been quantifying and normalizing the number of prey cells to facilitate comparison between prey species treatments. Although the density treatments within a prey species treatment are comparable to each other as long as they originated from the same source culture, their numerical relationships to the density treatments for other prey species are unknown.

The results of inoculating predatory marine flavobacteria strains onto prey incubated under differing growth and suspension conditions showed that the prey specificity of both Olleya sp. VCSA23 and Tenacibaculum sp. VCSA14A is wider than previously observed. In one case, this was not limited to previously untested incubation conditions; specifically, VCSA14A was observed developing clearing features on washed B. subtilis prey on no-nutrient agar. This would suggest that, to some degree, the prey specificity of VCSA14A may have broadened after its initial isolation. In light of this result, the need to minimize serial transfers of predatory microorganisms after isolation should be emphasized. A similar broadening of prey specificity has been documented for the predatory bacterium Micavibrio admirandus after three years of maintenance by serial transfers no less often than every three months [63], resulting in a possible total 
number of serial transfers likely on the same order as in this study. In addition, prey specificity tests in general should be conducted under a variety of conditions with replication.

A general phenomenon that had been incidentally observed but not systematically tracked during the work described in Chapter 2 was the frequent development of swarms in the absence of any observation of clearing features, particularly for Tenacibaculum sp. VCSA14A. Often these swarms were observed to have a fringing habit, in which the swarm front only extended beyond the prey smear by a millimeter or two (Figure 4). It is possible that this reduced swarming habit is the product of lower substrate availability, compared with smears in which either the flavobacterial strain is able to lyse prey cells or some exogenous organic substrate is available (such as in the case of unwashed prey cells). As a result, the fringing swarm habit may be a sign of either non-predatory growth by the marine flavobacteria on organic matter exuded by unsusceptible prey cells or a limited ability to lyse potential prey. This further emphasizes the non-obligate nature of the novel marine flavobacteria strains' predatory capability. Of course, it should be noted that fringing and radial swarm habits were not mutually exclusive - sometimes occurring in different locations on the same smear.

A broad finding from the multifactorial experiment is that some prey bacteria are more susceptible to predation when under starvation conditions than when they are actively growing. On the other hand, other prey bacteria are more susceptible to predation under growing conditions than under starvation. For example, clearing features were almost universally observed from both predatory strains on all preparations of $P$. corrugata prey when smeared on no-nutrient agar (Table 11). In contrast, clearing features were only observed on P. corrugata prey smeared on BD1 agar, which supports $P$. corrugata growth, when the prey cells were unwashed. On the other hand, K. kristinae prey on BD1 agar, which also supports their growth, only supported definite clearing fronts of Olleya sp. VCSA23 when they were pasteurized (Table 10). The same K. kristinae cells supported definite VCSA23 clearing fronts under all test conditions when plated on no-nutrient agar. 
It is currently unclear what the basis for these differences in susceptibility might be. The possibilities fall into at least two broad categories. They might be based on changes in prey cell susceptibility to predation or on changes in the predator cells' regulation of predatory behavior. Bacteria have been found to employ anti-predator behaviors against protozoan grazers including the release of toxins and changes in the cell's structure affecting its digestibility $[163,164]$. In addition, a plastic phenotypic resistance to Bdellovibrio bacteriovorus predation has been observed in several $\gamma$ Proteobacteria species after exposure to the predator [54]. The basis for resistance has not been elucidated, but resistant cells were observed to be significantly larger than naïve cells. The resistance was quickly lost when the cells were grown up in the absence of the predator. There is some evidence for a similar phenomenon occurring in myxobacterial plate cultures, from which viable prey cells were nearly always recoverable in one study [138]. Any of these strategies might be effective against predatory marine flavobacteria as well. It is also possible that the predatory strains tested in this study are adapted to respond to variables such as prey density, metabolic state or cell-to-cell signals by up- or down-regulating their predatory behavior. Such predator-prey interactions likely underlie the dynamics of grazing by predatory marine flavobacteria in natural microbial communities, and may vary considerably amongst predator-prey pairs. In order to ultimately understand the dynamics governing the impacts of predatory marine flavobacteria, it may be necessary to map such predator-prey interactions.

\section{Acknowledgements:}

The work in this chapter was supported by the Coastal Ocean and Ocean Life Institutes and the WHOI Academic Programs Office. I would like to thank Tracy Mincer for the use of his stereomicroscope and digital camera for documentation of the multifactorial differing conditions experiment and incubator for growth curves. I am grateful to Matthew McIlvin, Daniel Rogers, James Saenz, Carolyn Buchwald and Ed Leadbetter for helpful discussions and to Cornelia Wuchter and Stefan Sievert for the use of their FISH laboratory facilities, filtering apparatus and stock solutions. 


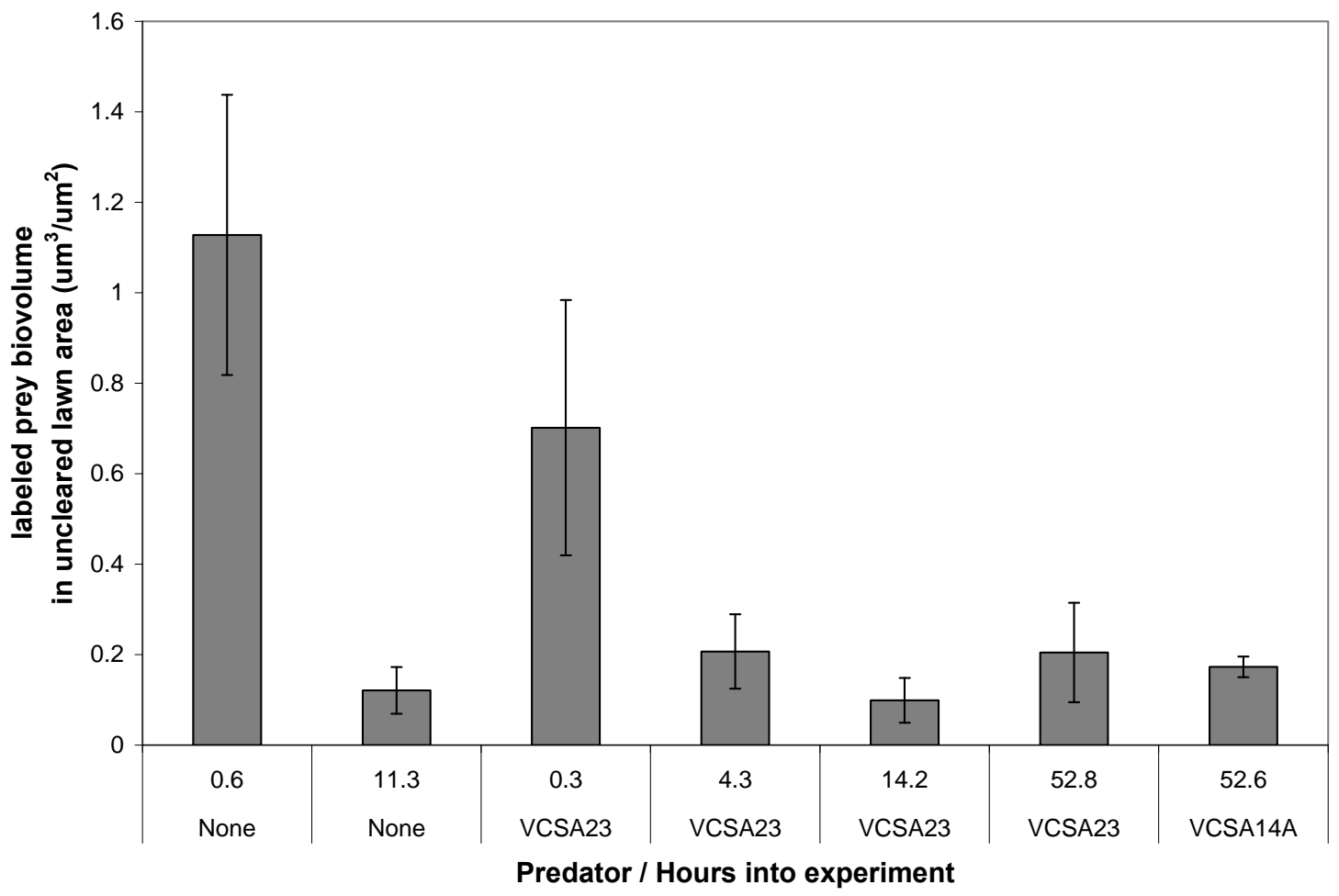

Figure 1: Bar graph showing the average labeled S. oneidensis biovolume per square micrometer in uncleared, prey lawn areas across different treatments and time points in the minimum predatory unit membrane filter experiment. The error bars show a single standard deviation for each average. Between six and 13 randomly located images were used to calculate each average. 


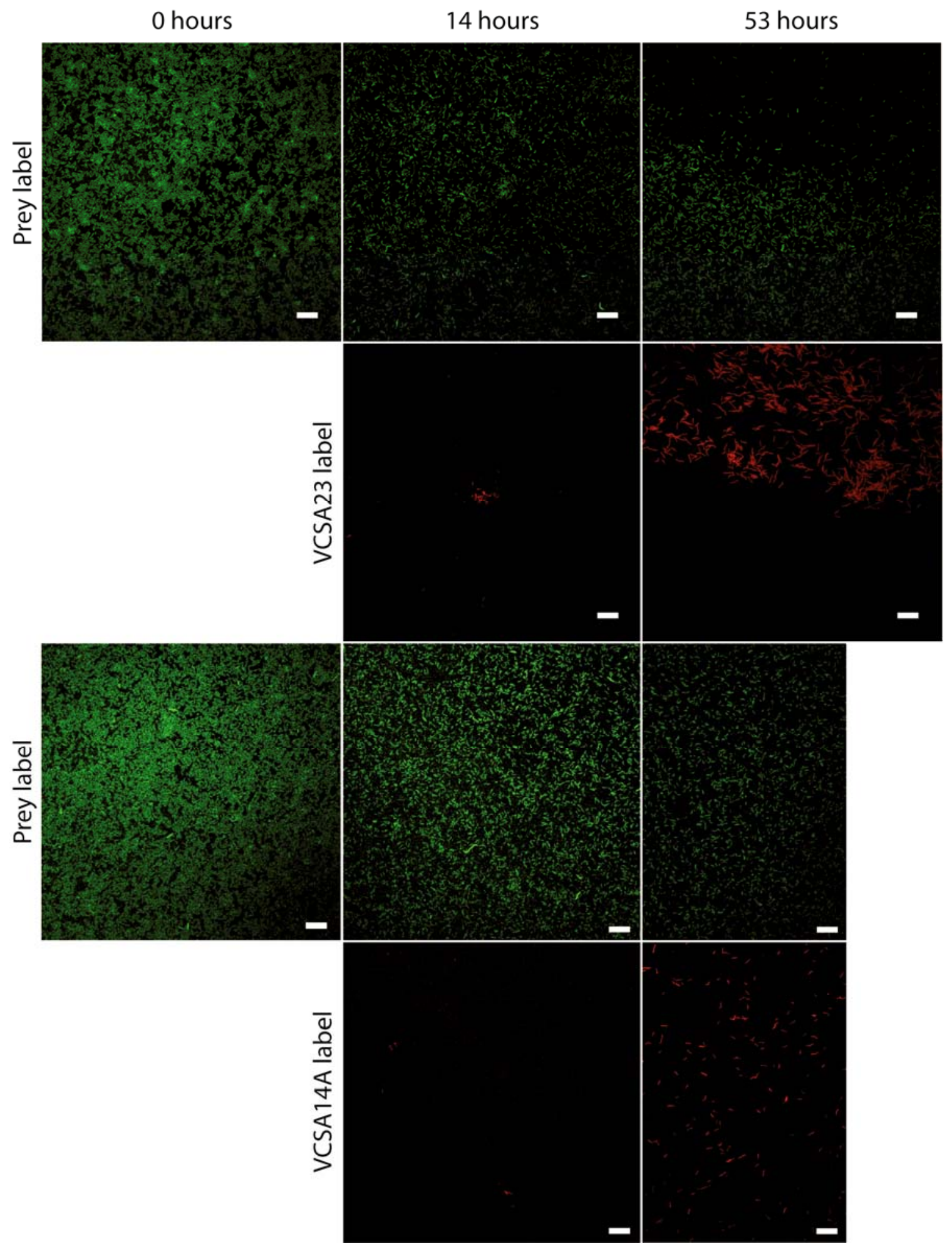

Figure 2: Representative fields from three time points sampled from the VCSA23 and VCSA14A treatments during the minimum predatory unit experiment. From left to right, the image sets are from filters sacrificed after 0,14 and 53 hours, respectively. The 
locations of the images for the first two time-points were randomly chosen, while the third time-point's images are from the edge (at top) or just outside (at bottom) of growing clearing zones. The top rows of images show the GAM42A-hybridized S. oneidensis prey cells and the bottom rows of images show the corresponding VCSA23-hybridized Olleya sp. VCSA23 cells (top set of images) and VCSA14A-hybridized Tenacibaculum sp. VCSA14A cells (bottom set of images). The white scale bars at the lower right corner of each image represent $10 \mu \mathrm{m}$. The 53-hour images shown for the VCSA14A treatment were cropped to exclude the right side of the image, which had a very low signal-to-noise ratio. 

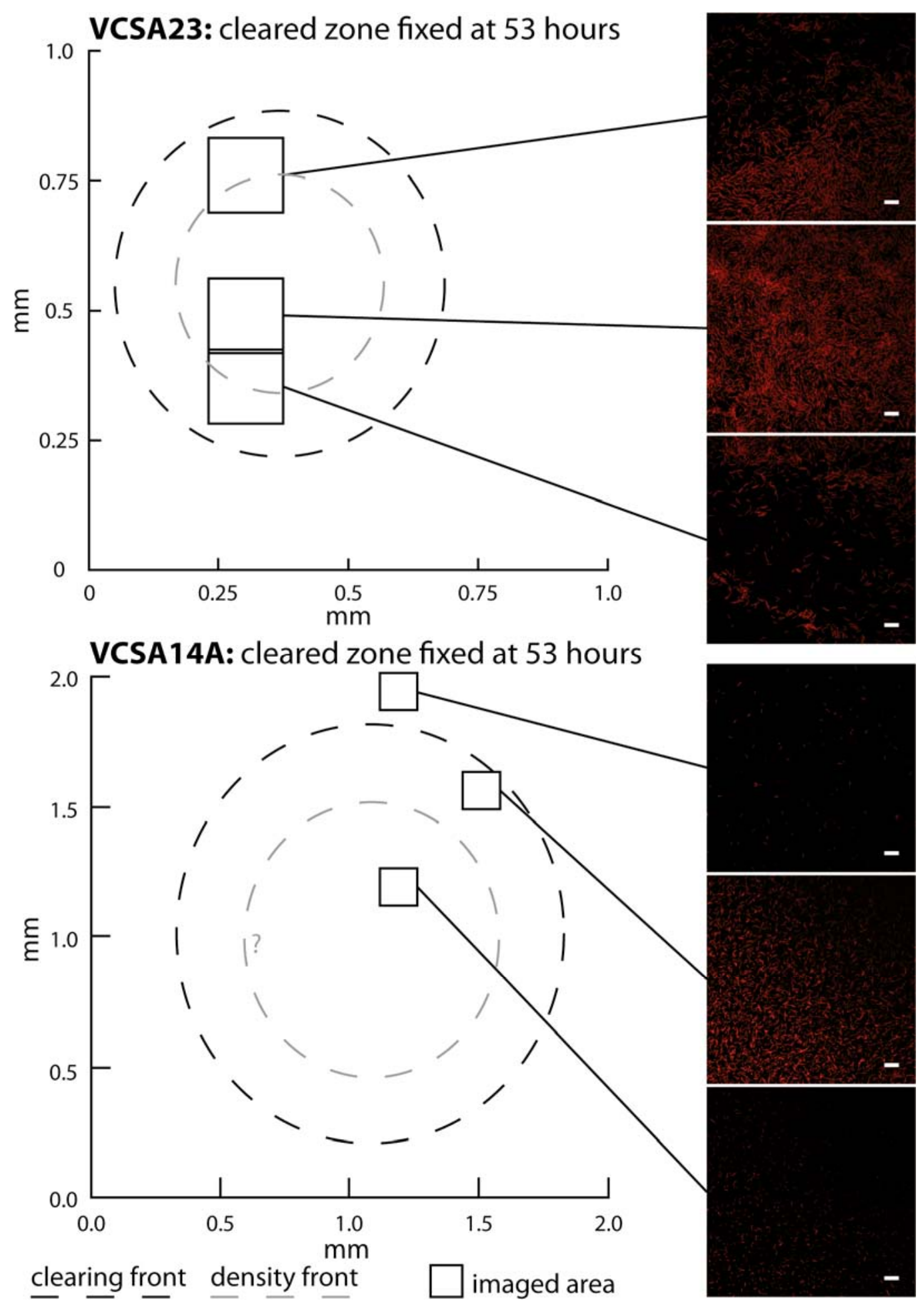

Figure 3: Figure showing the distribution of predator cell density within incipient marine flavobacteria swarms for VCSA23, at top, and VCSA14A, at bottom. To the left are xyplots showing the spatial relationships between the images shown at right and major 
features of the incipient swarms. The clearing front, at which prey density drops coincident with increasing predator cell numbers is shown by a dashed black line. The predator cell density front within the cleared zone, at which there is a transition between the predator cell densities observed in the central core of the swarm and those closer to the borders, is designated by a dashed grey line. In the case of the incipient VCSA14A swarm, insufficient imaging was done to precisely place the density front's location, as indicated by the grey question mark. The images on the right-hand side of the figure show the labeled predator cells within the corresponding imaged area in the graphs at left, as connected by a black line between the images and imaged areas. The white bar in each image shows a scale of $10 \mu \mathrm{m}$. 


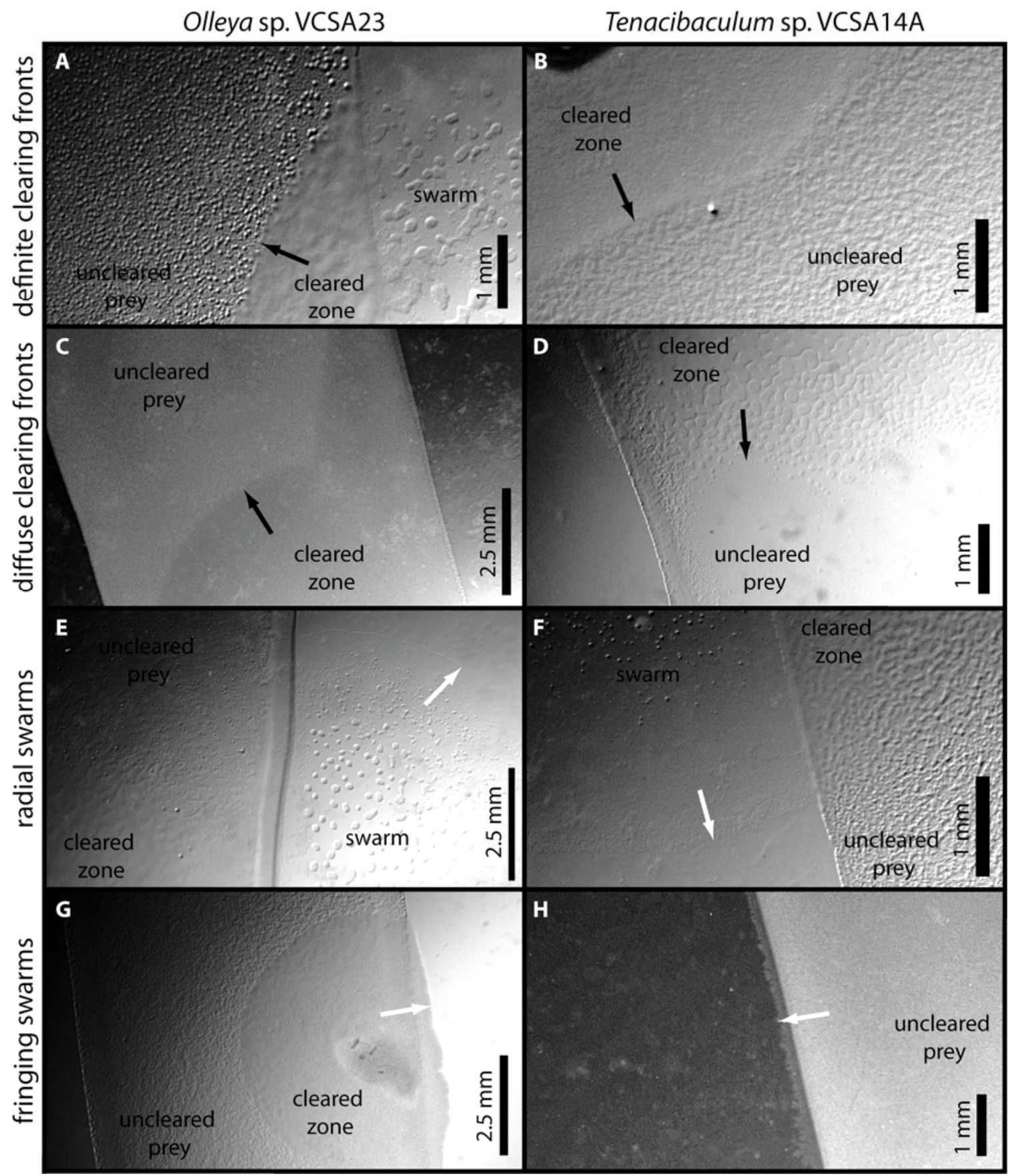

Figure 4: Photographs of typical clearing and swarm morphologies observed for Olleya sp. VCSA23 and Tenacibaculum sp. VCSA14A. Clearing fronts are labeled by black arrows pointing from within the cleared area toward the clearing front and swarm fronts are labeled by white arrows pointing from within the swarm toward the swarm front. At top, images A and B show the typical appearance of definite (clearly defined) clearing fronts within prey smears for VCSA23 and VCSA14A, respectively. Images C and D show examples of diffuse clearing fronts in which there is either no clearly defined 
boundary or no obvious textural difference between cleared and uncleared areas. Images $\mathrm{E}$ and $\mathrm{F}$ show examples of robust, radially expanding swarms that extend far from the prey smear onto open agar. At bottom, images $\mathrm{G}$ and $\mathrm{H}$ show examples of fringing swarms which do not extend away from the prey smear more than a minimal distance. Images were captured from: low density LB-suspended $S$. oneidensis on no-nutrient agar (A), high density LB-suspended S. oneidensis on no-nutrient agar (B), M53-suspended K. kristinae on no-nutrient agar (C), low density Marine-broth-suspended $H$. halodurans on BD1 agar (D), high density BD1-suspended $H$. halodurans on no-nutrient agar (E), low density LB-suspended E. coli on no-nutrient agar (F), high density washed S. oneidensis on no-nutrient agar $(\mathrm{G})$ and pasteurized K. kristinae on no-nutrient agar $(\mathrm{H})$.

\section{Table 1: Varying conditions experiment treatments}

\begin{tabular}{|c|c|c|}
\hline Plating media & Suspension treatment & Density treatment \\
\hline \multirow{8}{*}{$\begin{array}{c}\text { No-nutrient } \\
\text { ASW } \\
\text { agar }\end{array}$} & \multirow{2}{*}{ Spent complex media } & Unconcentrated \\
\hline & & Concentrated \\
\hline & \multirow{2}{*}{ Spent defined media } & Unconcentrated \\
\hline & & Concentrated \\
\hline & \multirow{2}{*}{ Washed } & Unconcentrated \\
\hline & & Concentrated \\
\hline & \multirow{2}{*}{ Washed + pasteurized } & Unconcentrated \\
\hline & & Concentrated \\
\hline \multirow{8}{*}{$\begin{array}{c}\text { BD1 } \\
\text { defined growth agar } \\
(25 \text { ppt ASW }) \\
\text { Supports growth of all but } \\
\text { one prey (S. oneidensis) }\end{array}$} & \multirow{2}{*}{ Spent complex media } & Unconcentrated \\
\hline & & Concentrated \\
\hline & \multirow{2}{*}{ Spent defined media } & Unconcentrated \\
\hline & & Concentrated \\
\hline & \multirow{2}{*}{ Washed } & Unconcentrated \\
\hline & & Concentrated \\
\hline & \multirow{2}{*}{ Washed + pasteurized } & Unconcentrated \\
\hline & & Concentrated \\
\hline
\end{tabular}

Table 2: Calculated generation times (hours) across temperature and salinity gradients

\begin{tabular}{|c|c|c|c|c|c|c|}
\hline & $15^{\circ} \mathrm{C}$ & \multicolumn{3}{|c|}{$21^{\circ} \mathrm{C}$} & $30^{\circ} \mathrm{C}$ & $38^{\circ} \mathrm{C}$ \\
\hline Salinity: & 25 & 20 & 25 & 30 & 25 & 25 \\
\hline Strain: & & & & & & \\
\hline Olleya sp. VCSA23 & 3.15 & 2.04 & 2.24 & 2.40 & 2.68 & - \\
\hline Olleya sp. VCSM12 & 1.71 & 3.08 & 1.47 & 2.49 & 2.66 & - \\
\hline Tenacibaculum sp. VCSA14A & 2.63 & 1.79 & 1.70 & 1.60 & 1.15 & 1.05 \\
\hline
\end{tabular}


Table 3: Predation across temperature and salinity gradients

\begin{tabular}{|c|c|c|c|c|}
\hline & & $\begin{array}{l}\text { Olleya sp. } \\
\text { VCSA23 }\end{array}$ & $\begin{array}{l}\text { Olleya sp. } \\
\text { VCSM12 }\end{array}$ & $\begin{array}{l}\text { Tenacibaculum } \\
\text { sp. VCSA14A }\end{array}$ \\
\hline & Temperature $\left({ }^{\circ} \mathrm{C}\right)$ & & & \\
\hline \multirow{6}{*}{ 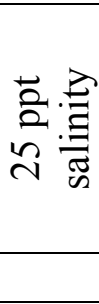 } & $4^{\circ} \mathrm{C}$ & + & + & - \\
\hline & $15^{\circ} \mathrm{C}$ & + & + & + \\
\hline & $23^{\circ} \mathrm{C}$ & + & + & + \\
\hline & $30^{\circ} \mathrm{C}$ & + & + & + \\
\hline & $38^{\circ} \mathrm{C}$ & - & - & + \\
\hline & Salinity (ppt) & & & \\
\hline \multirow{5}{*}{$\begin{array}{l}0 \\
0 \\
\end{array}$} & 0 & - & - & - \\
\hline & 10 & + & + & - \\
\hline & 20 & + & + & + \\
\hline & 25 & + & + & + \\
\hline & 30 & + & + & + \\
\hline
\end{tabular}


Table 4: Enzyme activity results after growth in Marine broth

\begin{tabular}{|c|c|c|c|c|c|c|c|c|c|c|c|c|c|c|c|c|c|c|c|c|}
\hline \multirow[b]{2}{*}{ Species } & \multirow[t]{2}{*}{$\begin{array}{r}\text { Enzymes } \\
\text { degrading: }\end{array}$} & \multicolumn{3}{|c|}{ Lipid } & \multicolumn{5}{|c|}{$\begin{array}{l}\text { Amino acids and } \\
\text { protein }\end{array}$} & \multicolumn{8}{|c|}{ Polysaccharide } & \multicolumn{3}{|c|}{$\begin{array}{c}\text { Organic } \\
\text { phosphorus }\end{array}$} \\
\hline & & 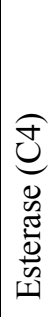 & 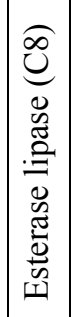 & 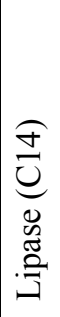 & 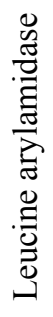 & 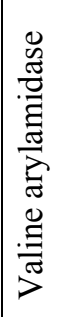 & 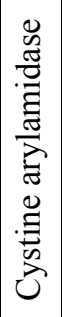 & $\sum_{\mathfrak{E}}^{\stackrel{\Xi}{n}}$ & 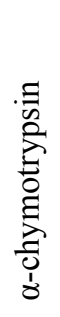 & 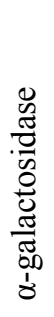 & 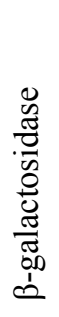 & $\begin{array}{l}0 \\
0 \\
0 \\
.0 \\
0 \\
0 \\
0 \\
0 \\
0 \\
0.0 \\
0 \\
0\end{array}$ & 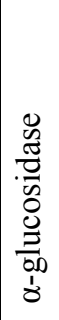 & 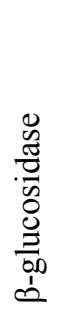 & 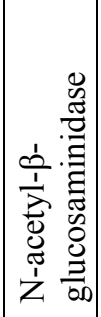 & 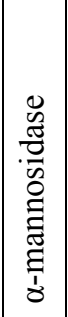 & $\begin{array}{l}0 \\
0 \\
\frac{\pi}{0} \\
\cdot \frac{0}{0} \\
0 \\
0 \\
0 \\
\frac{1}{1} \\
0\end{array}$ & 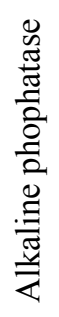 & 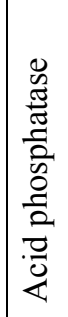 & 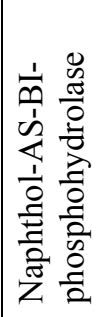 \\
\hline $\begin{array}{l}\text { Olleya sp. VCSA23 } \\
\text { Olleya sp. VCSM12 } \\
\text { O. marilimosa CAM030 } \\
\text { O. marilimosa CAM030 }\end{array}$ & $\begin{array}{l}\text { This study } \\
\text { This study } \\
\text { This study }\end{array}$ & $\begin{array}{l}+ \\
\mathrm{w} \\
+ \\
\text { nd }\end{array}$ & $\begin{array}{l}+ \\
+ \\
+ \\
\text { nd }\end{array}$ & $\begin{array}{l}\text { W } \\
+ \\
+ \\
\text { nd }\end{array}$ & $\begin{array}{l}+ \\
+ \\
+ \\
+\end{array}$ & $\begin{array}{l}+ \\
+ \\
+ \\
\text { nd }\end{array}$ & $\begin{array}{c}+ \\
+ \\
+ \\
\text { nd }\end{array}$ & $\begin{array}{l}\mathrm{w} \\
+ \\
\mathrm{w} \\
\mathrm{nd}\end{array}$ & $\begin{array}{c}- \\
- \\
- \\
\text { nd }\end{array}$ & $\begin{array}{l}- \\
- \\
- \\
-\end{array}$ & $\begin{array}{l}- \\
- \\
- \\
-\end{array}$ & $\begin{array}{l}- \\
- \\
- \\
-\end{array}$ & $\begin{array}{c}\mathrm{W} \\
+ \\
\mathrm{W} \\
-\end{array}$ & - & $\begin{array}{l}- \\
- \\
- \\
+\end{array}$ & $\begin{array}{c} \\
- \\
- \\
\text { nd }\end{array}$ & $\begin{array}{l}\text { W } \\
- \\
- \\
-\end{array}$ & $\begin{array}{l}+ \\
+ \\
+ \\
+\end{array}$ & $\begin{array}{c}+ \\
+ \\
+ \\
\text { nd }\end{array}$ & $\begin{array}{c}+ \\
+ \\
+ \\
\text { nd }\end{array}$ \\
\hline $\begin{array}{l}\text { Lacinutrix algicola } \\
\text { L. mariniflava }\end{array}$ & & $\begin{array}{l}+ \\
+\end{array}$ & $\begin{array}{l}+ \\
+\end{array}$ & $\begin{array}{l}- \\
-\end{array}$ & $\begin{array}{l}+ \\
+ \\
\end{array}$ & $\begin{array}{l}+ \\
+\end{array}$ & $\begin{array}{l}+ \\
+\end{array}$ & $\begin{array}{l}+ \\
+\end{array}$ & $\begin{array}{l}+ \\
+\end{array}$ & $\begin{array}{l}- \\
-\end{array}$ & $\begin{array}{l}+ \\
+\end{array}$ & $\begin{array}{l}- \\
-\end{array}$ & $\begin{array}{l}- \\
-\end{array}$ & - & - & - & $\begin{array}{l}- \\
-\end{array}$ & $\begin{array}{l}+ \\
+\end{array}$ & $\begin{array}{l}+ \\
+ \\
\end{array}$ & $\begin{array}{l}+ \\
+\end{array}$ \\
\hline $\begin{array}{l}\text { Tenacibaculum sp. VCSA14A } \\
\text { T. discolor LL04 } 11.1 .1 \\
\text { T. discolor LL04 } 11.1 .1 \\
\text { T. gallaicum A37.1 } \\
\text { T. gallaicum A37.1 } \\
\text { T. litoreum } \\
\text { T. aestuarii }\end{array}$ & $\begin{array}{l}\text { This study } \\
\text { This study }\end{array}$ & $\begin{array}{l}+ \\
+ \\
+ \\
+ \\
+ \\
+ \\
+\end{array}$ & $\begin{array}{l}+ \\
+ \\
+ \\
+ \\
+ \\
+ \\
\text { nd }\end{array}$ & $\begin{array}{l}\text { W } \\
+ \\
+ \\
+ \\
+ \\
- \\
\text { nd }\end{array}$ & $\begin{array}{l}+ \\
+ \\
+ \\
+ \\
+ \\
+ \\
+\end{array}$ & $\begin{array}{l}+ \\
+ \\
+ \\
+ \\
+ \\
+ \\
+\end{array}$ & $\begin{array}{l}+ \\
+ \\
+ \\
+ \\
+ \\
+ \\
-\end{array}$ & $\begin{array}{c}+ \\
+ \\
+ \\
+ \\
+ \\
+ \\
\text { nd }\end{array}$ & $\begin{array}{l}+ \\
+ \\
+ \\
+ \\
+ \\
+ \\
+\end{array}$ & $\begin{array}{l}- \\
- \\
- \\
- \\
- \\
- \\
-\end{array}$ & $\begin{array}{l}- \\
- \\
- \\
- \\
- \\
- \\
-\end{array}$ & $\begin{array}{l}- \\
- \\
- \\
- \\
- \\
-\end{array}$ & $\begin{array}{l}- \\
- \\
- \\
- \\
- \\
- \\
-\end{array}$ & $\begin{array}{l}- \\
- \\
- \\
- \\
- \\
- \\
+\end{array}$ & $\begin{array}{l}- \\
- \\
- \\
\mathrm{W} \\
- \\
- \\
-\end{array}$ & $\begin{array}{l}- \\
- \\
- \\
- \\
- \\
- \\
-\end{array}$ & $\begin{array}{l}- \\
- \\
- \\
- \\
- \\
- \\
-\end{array}$ & $\begin{array}{l}+ \\
+ \\
+ \\
+ \\
+ \\
+ \\
+\end{array}$ & $\begin{array}{l}+ \\
+ \\
+ \\
+ \\
+ \\
+ \\
+\end{array}$ & $\begin{array}{l}+ \\
+ \\
+ \\
+ \\
+ \\
+ \\
+\end{array}$ \\
\hline
\end{tabular}

+: unambiguous positive reaction; w: weak positive reaction; -: negative for enzyme activity; nd: not determined in the available reference 
Table 5: Enzyme activity results after different growth conditions

\begin{tabular}{|c|c|c|c|c|c|c|c|c|c|c|c|c|c|c|c|c|c|c|c|c|c|}
\hline \multirow[b]{2}{*}{ Strain } & \multirow[b]{2}{*}{ Growth media } & $\begin{array}{r}\text { Enzymes } \\
\text { degrading: }\end{array}$ & \multicolumn{3}{|c|}{ Lipid } & \multicolumn{5}{|c|}{$\begin{array}{c}\text { Amino acids and } \\
\text { protein }\end{array}$} & \multicolumn{8}{|c|}{ Polysaccharide } & \multicolumn{3}{|c|}{$\begin{array}{c}\text { Organic } \\
\text { phosphorus }\end{array}$} \\
\hline & & 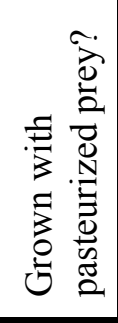 & 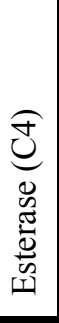 & 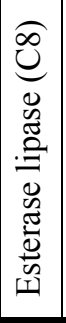 & 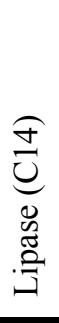 & 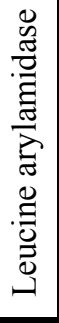 & 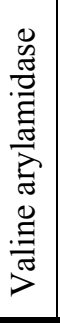 & 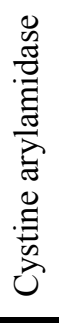 & $\sum_{=}^{\Xi}$ & 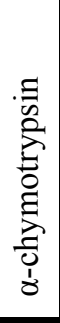 & 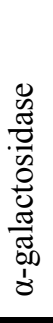 & 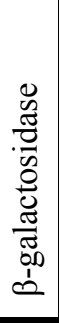 & 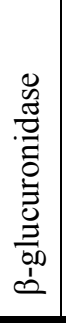 & $\begin{array}{l}0 \\
0 \\
0 \\
0 \\
0 \\
0 \\
0 \\
0 \\
0 \\
0 \\
0 \\
0.0 \\
0 \\
0\end{array}$ & 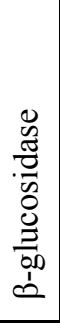 & 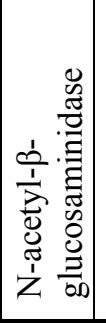 & 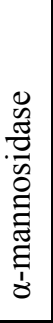 & 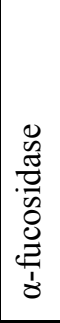 & 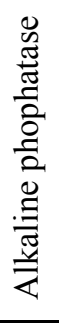 & 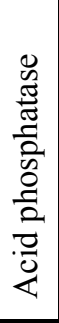 & 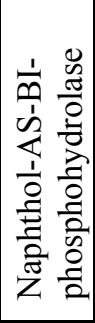 \\
\hline \multicolumn{3}{|c|}{ Pasteurized S. oneidensis MR-1 } & $\mathrm{W}$ & $\mathrm{W}$ & - & $\mathrm{W}$ & - & - & - & - & - & - & - & $\mathrm{W}$ & - & - & - & - & + & $\mathrm{W}$ & $\mathrm{W}$ \\
\hline $\begin{array}{l}\text { Olleya sp. } \\
\text { VCSA23 }\end{array}$ & $\begin{array}{l}\text { Dilute nutrient broth } \\
\text { Dilute nutrient broth } \\
\text { Marine broth }\end{array}$ & $\begin{array}{l}\text { No } \\
\text { Yes } \\
\text { No }\end{array}$ & $\begin{array}{l}\mathrm{W} \\
+ \\
+\end{array}$ & $\begin{array}{l}+ \\
+ \\
+\end{array}$ & $\begin{array}{l}\mathrm{W} \\
+ \\
\mathrm{W}\end{array}$ & $\begin{array}{l}+ \\
+ \\
+\end{array}$ & $\begin{array}{l}+ \\
+ \\
+\end{array}$ & $\begin{array}{l}+ \\
+ \\
+\end{array}$ & $\begin{array}{l}\mathrm{W} \\
\mathrm{W} \\
\mathrm{W}\end{array}$ & $\begin{array}{l}- \\
- \\
-\end{array}$ & $\begin{array}{l}- \\
- \\
-\end{array}$ & $\begin{array}{l}- \\
- \\
-\end{array}$ & $\begin{array}{l}- \\
- \\
-\end{array}$ & $\begin{array}{l}\mathrm{W} \\
\mathrm{W} \\
\mathrm{W}\end{array}$ & $\begin{array}{l}- \\
- \\
-\end{array}$ & $\begin{array}{l}- \\
- \\
-\end{array}$ & $\begin{array}{l}- \\
- \\
-\end{array}$ & $\begin{array}{l}- \\
- \\
\mathrm{W}\end{array}$ & $\begin{array}{l}+ \\
+ \\
+\end{array}$ & $\begin{array}{l}+ \\
+ \\
+\end{array}$ & $\begin{array}{l}+ \\
+ \\
+\end{array}$ \\
\hline $\begin{array}{l}\text { Olleya sp. } \\
\text { VCSM12 }\end{array}$ & $\begin{array}{l}\text { Dilute nutrient broth } \\
\text { Dilute nutrient broth } \\
\text { Marine broth }\end{array}$ & $\begin{array}{l}\text { No } \\
\text { Yes } \\
\text { No }\end{array}$ & $\begin{array}{l}+ \\
+ \\
\mathrm{W}\end{array}$ & $\begin{array}{l}+ \\
+ \\
+\end{array}$ & $\begin{array}{l}\mathrm{W} \\
\mathrm{W} \\
+\end{array}$ & $\begin{array}{l}+ \\
+ \\
+\end{array}$ & $\begin{array}{l}+ \\
+ \\
+\end{array}$ & $\begin{array}{l}\mathrm{W} \\
+ \\
+\end{array}$ & $\begin{array}{l}\mathrm{W} \\
+ \\
+\end{array}$ & $\begin{array}{l}- \\
- \\
- \\
\end{array}$ & $\begin{array}{l}\mathrm{W} \\
- \\
-\end{array}$ & $\begin{array}{l}\mathrm{W} \\
- \\
-\end{array}$ & $\begin{array}{l}- \\
- \\
-\end{array}$ & $\begin{array}{l}\mathrm{W} \\
+ \\
+\end{array}$ & $\begin{array}{l}- \\
- \\
-\end{array}$ & $\begin{array}{l}- \\
- \\
-\end{array}$ & $\begin{array}{l}- \\
- \\
-\end{array}$ & $\begin{array}{l}- \\
- \\
-\end{array}$ & $\begin{array}{l}+ \\
+ \\
+\end{array}$ & $\begin{array}{l}+ \\
+ \\
+\end{array}$ & $\begin{array}{l}+ \\
+ \\
+\end{array}$ \\
\hline $\begin{array}{l}\text { O. marilimosa } \\
\text { CAM030 }\end{array}$ & $\begin{array}{l}\text { Dilute nutrient broth } \\
\text { Dilute nutrient broth } \\
\text { Marine broth }\end{array}$ & $\begin{array}{l}\text { No } \\
\text { Yes } \\
\text { No }\end{array}$ & $\begin{array}{l}\mathrm{W} \\
\mathrm{W} \\
+\end{array}$ & $\begin{array}{l}+ \\
+ \\
+\end{array}$ & $\begin{array}{l}\mathrm{W} \\
\mathrm{W} \\
+\end{array}$ & $\begin{array}{l}+ \\
+ \\
+\end{array}$ & $\begin{array}{l}+ \\
+ \\
+\end{array}$ & $\begin{array}{l}\mathrm{W} \\
\mathrm{W} \\
+\end{array}$ & $\begin{array}{l}- \\
-\end{array}$ & $\begin{array}{l}- \\
- \\
-\end{array}$ & $\begin{array}{l}- \\
- \\
-\end{array}$ & $\begin{array}{l}- \\
- \\
-\end{array}$ & $\begin{array}{l}- \\
- \\
-\end{array}$ & $\begin{array}{c}- \\
\mathrm{W} \\
\mathrm{W}\end{array}$ & $\begin{array}{l}- \\
- \\
-\end{array}$ & $\begin{array}{l}- \\
- \\
-\end{array}$ & $\begin{array}{l}- \\
- \\
-\end{array}$ & $\begin{array}{l}- \\
- \\
-\end{array}$ & $\begin{array}{l}+ \\
+ \\
+\end{array}$ & $\begin{array}{l}+ \\
+ \\
+\end{array}$ & $\begin{array}{l}+ \\
+ \\
+\end{array}$ \\
\hline $\begin{array}{l}\text { Tenacibaculum sp. } \\
\text { VCSA14A }\end{array}$ & $\begin{array}{l}\text { Dilute nutrient broth } \\
\text { Dilute nutrient broth } \\
\text { Marine broth }\end{array}$ & $\begin{array}{l}\text { No } \\
\text { Yes } \\
\text { No }\end{array}$ & $\begin{array}{l}\mathrm{W} \\
+ \\
+\end{array}$ & $\begin{array}{l}+ \\
+ \\
+\end{array}$ & $\begin{array}{l}+ \\
+ \\
\mathrm{W}\end{array}$ & $\begin{array}{l}+ \\
+ \\
+\end{array}$ & $\begin{array}{l}+ \\
+ \\
+\end{array}$ & $\begin{array}{l}+ \\
+ \\
+\end{array}$ & $\begin{array}{l}+ \\
+ \\
+\end{array}$ & $\begin{array}{l}+ \\
+ \\
+\end{array}$ & $\begin{array}{l}- \\
- \\
-\end{array}$ & $\begin{array}{l}- \\
- \\
-\end{array}$ & $\begin{array}{l}- \\
- \\
-\end{array}$ & $\begin{array}{l}- \\
- \\
-\end{array}$ & $\begin{array}{l}- \\
- \\
-\end{array}$ & $\begin{array}{l}- \\
- \\
-\end{array}$ & $\begin{array}{l}- \\
- \\
-\end{array}$ & $\begin{array}{l}- \\
- \\
-\end{array}$ & $\begin{array}{l}+ \\
+ \\
+\end{array}$ & $\begin{array}{l}+ \\
+ \\
+\end{array}$ & $\begin{array}{l}+ \\
+ \\
+\end{array}$ \\
\hline $\begin{array}{l}\text { T. discolor LL04 } \\
11.1 .1\end{array}$ & $\begin{array}{l}\text { Dilute nutrient broth } \\
\text { Dilute nutrient broth } \\
\text { Marine broth }\end{array}$ & $\begin{array}{l}\text { No } \\
\text { Yes } \\
\text { No }\end{array}$ & $\begin{array}{l}+ \\
+ \\
+\end{array}$ & $\begin{array}{l}+ \\
+ \\
+\end{array}$ & $\begin{array}{l}\mathrm{W} \\
+ \\
+\end{array}$ & $\begin{array}{l}+ \\
+ \\
+\end{array}$ & $\begin{array}{l}+ \\
+ \\
+\end{array}$ & $\begin{array}{l}+ \\
+ \\
+\end{array}$ & $\begin{array}{l}+ \\
+ \\
+\end{array}$ & $\begin{array}{c}\mathrm{W} \\
\mathrm{W} \\
+\end{array}$ & $\begin{array}{l}- \\
- \\
-\end{array}$ & $\begin{array}{l}- \\
- \\
-\end{array}$ & $\begin{array}{l}- \\
- \\
-\end{array}$ & $\begin{array}{l}- \\
- \\
-\end{array}$ & $\begin{array}{l}- \\
- \\
-\end{array}$ & $\begin{array}{l}- \\
- \\
-\end{array}$ & $\begin{array}{l}- \\
- \\
-\end{array}$ & $\begin{array}{l}- \\
- \\
-\end{array}$ & $\begin{array}{l}+ \\
+ \\
+\end{array}$ & $\begin{array}{l}+ \\
+ \\
+\end{array}$ & $\begin{array}{l}+ \\
+ \\
+\end{array}$ \\
\hline $\begin{array}{l}\text { T. gallaicum } \\
\text { A37.1 }\end{array}$ & $\begin{array}{l}\text { Dilute nutrient broth } \\
\text { Dilute nutrient broth } \\
\text { Marine broth }\end{array}$ & $\begin{array}{l}\text { No } \\
\text { Yes } \\
\text { No }\end{array}$ & $\begin{array}{l}\mathrm{W} \\
+ \\
+\end{array}$ & $\begin{array}{l}+ \\
+ \\
+\end{array}$ & $\begin{array}{c}+ \\
\mathrm{W} \\
+\end{array}$ & $\begin{array}{l}+ \\
+ \\
+\end{array}$ & $\begin{array}{l}+ \\
+ \\
+\end{array}$ & $\begin{array}{l}+ \\
+ \\
+\end{array}$ & $\begin{array}{l}+ \\
+ \\
+\end{array}$ & $\begin{array}{c}\mathrm{W} \\
\mathrm{W} \\
+\end{array}$ & $\begin{array}{l}- \\
- \\
-\end{array}$ & $\begin{array}{l}- \\
- \\
-\end{array}$ & $\begin{array}{l}- \\
- \\
-\end{array}$ & $\begin{array}{l}- \\
- \\
-\end{array}$ & $\begin{array}{l}- \\
- \\
-\end{array}$ & $\begin{array}{l}\mathrm{W} \\
\mathrm{W} \\
\mathrm{W}\end{array}$ & $\begin{array}{l}- \\
- \\
-\end{array}$ & $\begin{array}{l}- \\
- \\
-\end{array}$ & $\begin{array}{l}+ \\
+ \\
+\end{array}$ & $\begin{array}{l}+ \\
+ \\
+\end{array}$ & $\begin{array}{l}+ \\
+ \\
+\end{array}$ \\
\hline
\end{tabular}


+: unambiguous positive reaction; w: weak positive reaction; -: negative for enzyme activity; nd: not determined in the available reference 
Table 6: Estimated predator cell densities on filters after addition of $\sim 10^{1}$ predator cells

\begin{tabular}{|l|c|c|c|c|}
\hline Predator: & \multicolumn{2}{|c|}{ Olleya sp. VCSA23 } & \multicolumn{2}{c|}{ Tenacibaculum sp. VCSA14A } \\
\hline Time $(\mathrm{h}):$ & 14 & 53 & 14 & 53 \\
\hline $\begin{array}{l}\text { Cells } / \mathrm{mm}^{2} \text { in } \\
\text { uncleared areas }\end{array}$ & $\begin{array}{c}(4.99 \pm 5.92) \\
\times 10^{2}\end{array}$ & $\begin{array}{c}(1.13 \pm 1.78) \\
\times 10^{2}\end{array}$ & $\begin{array}{c}(2.33 \pm 1.67) \\
\times 10^{2}\end{array}$ & $\begin{array}{c}(1.21 \pm 0.57) \\
\times 10^{3}\end{array}$ \\
\hline $\begin{array}{l}\text { Cells } / \mathrm{mm}^{2} \text { in } \\
\text { outer cleared area }\end{array}$ & & $\begin{array}{c}(1.07 \pm 0.64) \\
\times 10^{5}\end{array}$ & & $1.82 \times 10^{5}$ \\
\hline $\begin{array}{l}\text { Cells } / \mathrm{mm}^{2} \text { in } \\
\text { inner cleared area }\end{array}$ & \begin{tabular}{c}
$\left(\begin{array}{c}45 \pm 0.23) \\
\times 10^{5}\end{array}\right.$ \\
\hline $\begin{array}{l}\text { Cleared area } \\
\text { diameter }(\mu \mathrm{m})\end{array}$
\end{tabular} & 650 & & $2.36 \times 10^{4}$ \\
\hline $\begin{array}{l}\text { Inner cleared area } \\
\text { diamater }(\mu \mathrm{m})\end{array}$ & & $\sim 400$ & & $500-1200$ \\
\hline
\end{tabular}

Error estimates are a single standard deviation based on the variability in cell numbers among images used to calculate the estimate. Error estimates are not available for Tenacibaculum sp. VCSA14A's cleared area cell densities because only one image was available to calculate each estimate.

Table 7: Growth features with B. subtilis prey

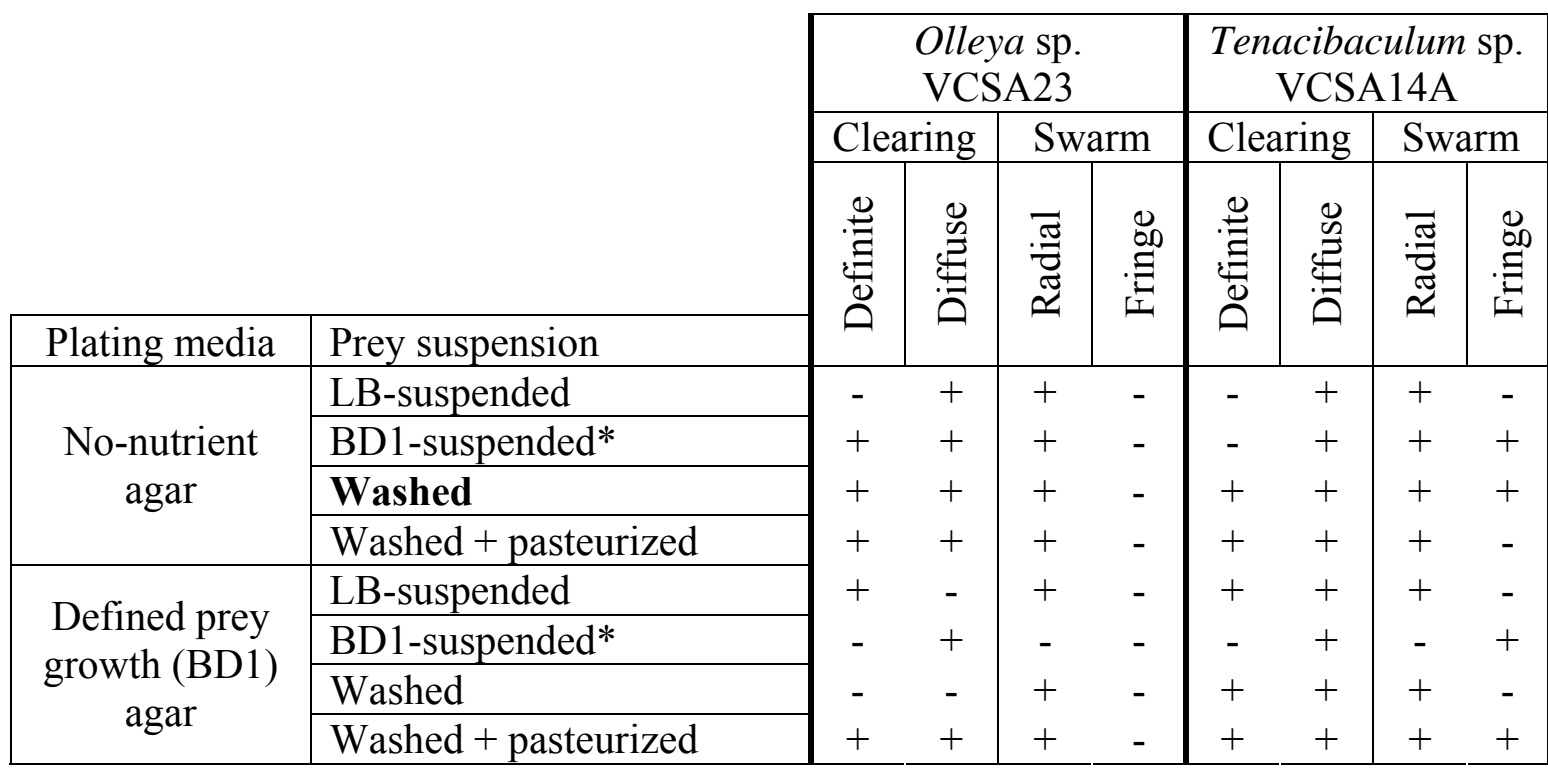

* -- The BD1-suspended culture was not at the same density as the other prey treatments. Definite clearings had sharp, defined edges while diffuse clearings were only distinguishable by a textural change. Radial swarms expanded onto open agar away from prey smears, while fringe swarms did not. Swarm fronts sometimes switched habits during the experiment on a single smear. In some cases, both radial and fringing swarms were observed from the same replicate smear; in other cases the two replicates diverged from each other with respect to swarm habit. The treatment that had been used to test 
prey specificity as described in Chapter 2, in which Olleya sp. VCSA23 was observed to clear B. subtilis and Tenacibaculum sp. VCSA14A was not, is bolded for reference.

Table 8: Growth features with $\mathrm{E}$. coli prey

\begin{tabular}{|c|c|c|c|c|c|c|c|c|c|c|}
\hline \multirow[b]{3}{*}{$\begin{array}{l}\text { Plating } \\
\text { media }\end{array}$} & \multirow[b]{3}{*}{$\begin{array}{l}\text { Prey } \\
\text { density }\end{array}$} & \multirow[b]{3}{*}{ Prey suspension } & \multicolumn{4}{|c|}{$\begin{array}{l}\text { Olleya sp. } \\
\text { VCSA23 }\end{array}$} & \multicolumn{4}{|c|}{$\begin{array}{c}\text { Tenacibaculum sp. } \\
\text { VCSA14A }\end{array}$} \\
\hline & & & \multicolumn{2}{|c|}{ Clearing } & \multicolumn{2}{|c|}{ Swarm } & \multicolumn{2}{|c|}{ Clearing } & \multicolumn{2}{|c|}{ Swarm } \\
\hline & & & 莺 & 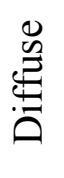 & 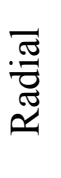 & 兽 & 连 & 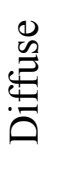 & 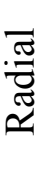 & 离 \\
\hline \multirow{8}{*}{$\begin{array}{c}\text { No- } \\
\text { nutrient } \\
\text { agar }\end{array}$} & \multirow{3}{*}{1} & LB-suspended & + & - & + & - & + & + & + & - \\
\hline & & Washed & + & + & + & - & - & - & - & + \\
\hline & & Washed + pasteurized & + & - & + & - & + & - & + & - \\
\hline & \multirow{3}{*}{10} & LB-suspended & + & - & + & - & + & + & + & - \\
\hline & & Washed & + & - & + & - & - & - & - & + \\
\hline & & Washed + pasteurized & + & - & + & - & + & - & + & + \\
\hline & 1 & BD1-suspended* & - & - & - & - & - & - & - & - \\
\hline & 20 & BD1-suspended* & + & + & + & - & - & + & + & - \\
\hline \multirow{8}{*}{$\begin{array}{l}\text { Defined } \\
\text { prey } \\
\text { growth } \\
\text { (BD1) } \\
\text { agar }\end{array}$} & \multirow{3}{*}{1} & LB-suspended & + & + & + & - & + & + & + & - \\
\hline & & Washed & + & + & + & - & - & + & + & + \\
\hline & & Washed + pasteurized & + & - & + & - & + & + & + & + \\
\hline & \multirow{3}{*}{10} & LB-suspended & + & - & + & - & + & - & + & - \\
\hline & & Washed & + & - & + & - & - & - & - & + \\
\hline & & Washed + pasteurized & + & - & + & - & + & - & + & + \\
\hline & 1 & BD1-suspended* & + & - & + & + & + & - & + & - \\
\hline & 20 & BD1-suspended* & + & - & + & - & - & + & + & - \\
\hline
\end{tabular}

* -- The BD1-suspended culture was not at the same density as the other prey treatments. Definite clearings had sharp, defined edges while diffuse clearings were only distinguishable by a textural change. Radial swarms expanded onto open agar away from prey smears, while fringe swarms did not. Swarm fronts sometimes switched habits during the experiment on a single smear. In some cases, both radial and fringing swarms were observed from the same replicate smear; in other cases the two replicates diverged from each other with respect to swarm habit. The treatments that had been used to test prey specificity as described in Chapter 2, under which Olleya sp. VCSA23 was observed to clear E. coli and Tenacibaculum sp. VCSA14A was not, are bolded for reference. 
Table 9: Growth features with H. halodurans prey

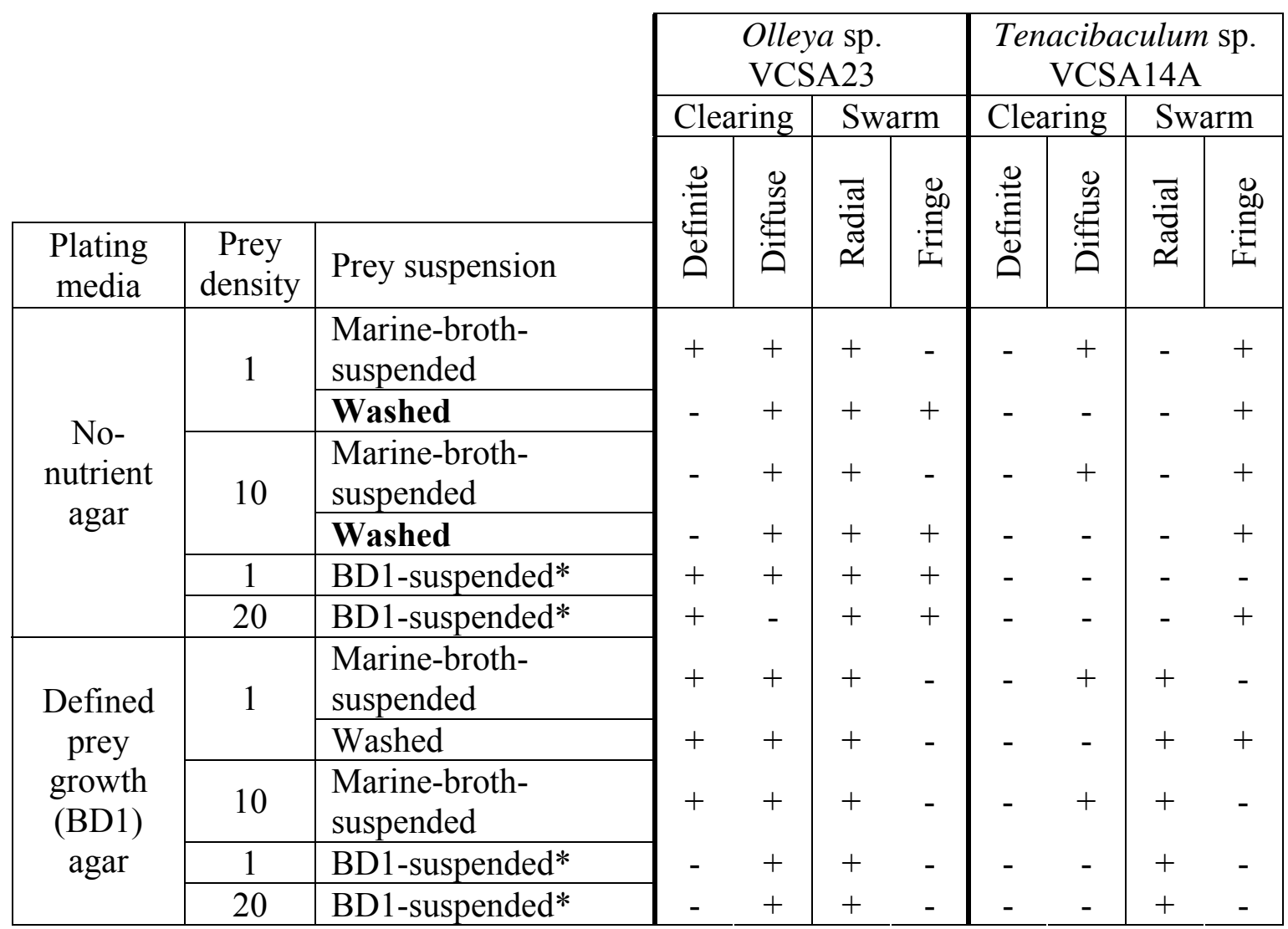

* -- The BD1-suspended culture was not at the same density as the other prey treatments. Definite clearings had sharp, defined edges while diffuse clearings were only distinguishable by a textural change. Radial swarms expanded onto open agar away from prey smears, while fringe swarms did not. Swarm fronts sometimes switched habits during the experiment on a single smear. In some cases, both radial and fringing swarms were observed from the same replicate smear; in other cases the two replicates diverged from each other with respect to swarm habit. The treatments that had been used to test prey specificity as described in Chapter 2, under which neither strain was observed to clear $H$. halodurans, are bolded for reference. 
Table 10: Growth features with K. kristinae prey

\begin{tabular}{|c|c|c|c|c|c|c|c|c|c|}
\hline & & \multicolumn{4}{|c|}{$\begin{array}{l}\text { Olleya sp. } \\
\text { VCSA23 }\end{array}$} & \multicolumn{4}{|c|}{$\begin{array}{c}\text { Tenacibaculum sp. } \\
\text { VCSA14A }\end{array}$} \\
\hline & & \multicolumn{2}{|c|}{ Clearing } & \multicolumn{2}{|c|}{ Swarm } & \multicolumn{2}{|c|}{ Clearing } & \multicolumn{2}{|c|}{ Swarm } \\
\hline & & : & $\underbrace{\mathscr{E}}_{\mathscr{E}}$ & : & 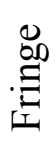 & 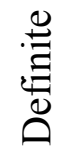 & 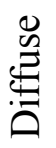 & : & $\underset{\Xi}{\stackrel{\infty}{\Xi}}$ \\
\hline Plating media & Prey suspension & & & & & & & & \\
\hline \multirow{3}{*}{$\begin{array}{c}\text { No-nutrient } \\
\text { agar }\end{array}$} & M53-suspended & + & - & + & - & - & + & + & + \\
\hline & Washed & + & + & + & - & - & - & - & + \\
\hline & Washed + pasteurized & + & - & + & - & - & - & - & + \\
\hline \multirow{3}{*}{$\begin{array}{c}\text { Defined prey } \\
\text { growth (BD1) } \\
\text { agar }\end{array}$} & M53-suspended & - & + & + & - & - & - & - & + \\
\hline & Washed & - & + & + & - & - & - & + & + \\
\hline & Washed + pasteurized & + & + & + & - & - & + & + & + \\
\hline
\end{tabular}

Definite clearings had sharp, defined edges while diffuse clearings were only distinguishable by a textural change. Radial swarms expanded onto open agar away from prey smears, while fringe swarms did not. Swarm fronts sometimes switched habits during the experiment on a single smear. In some cases, both radial and fringing swarms were observed from the same replicate smear; in other cases the two replicates diverged from each other with respect to swarm habit. The treatment that had been used to test prey specificity as described in Chapter 2, under which Olleya sp. VCSA23 was observed to develop diffuse clearing features and Tenacibaculum sp. VCSA14A did not grow, are bolded for reference. 
Table 11: Growth features with P. corrugata prey

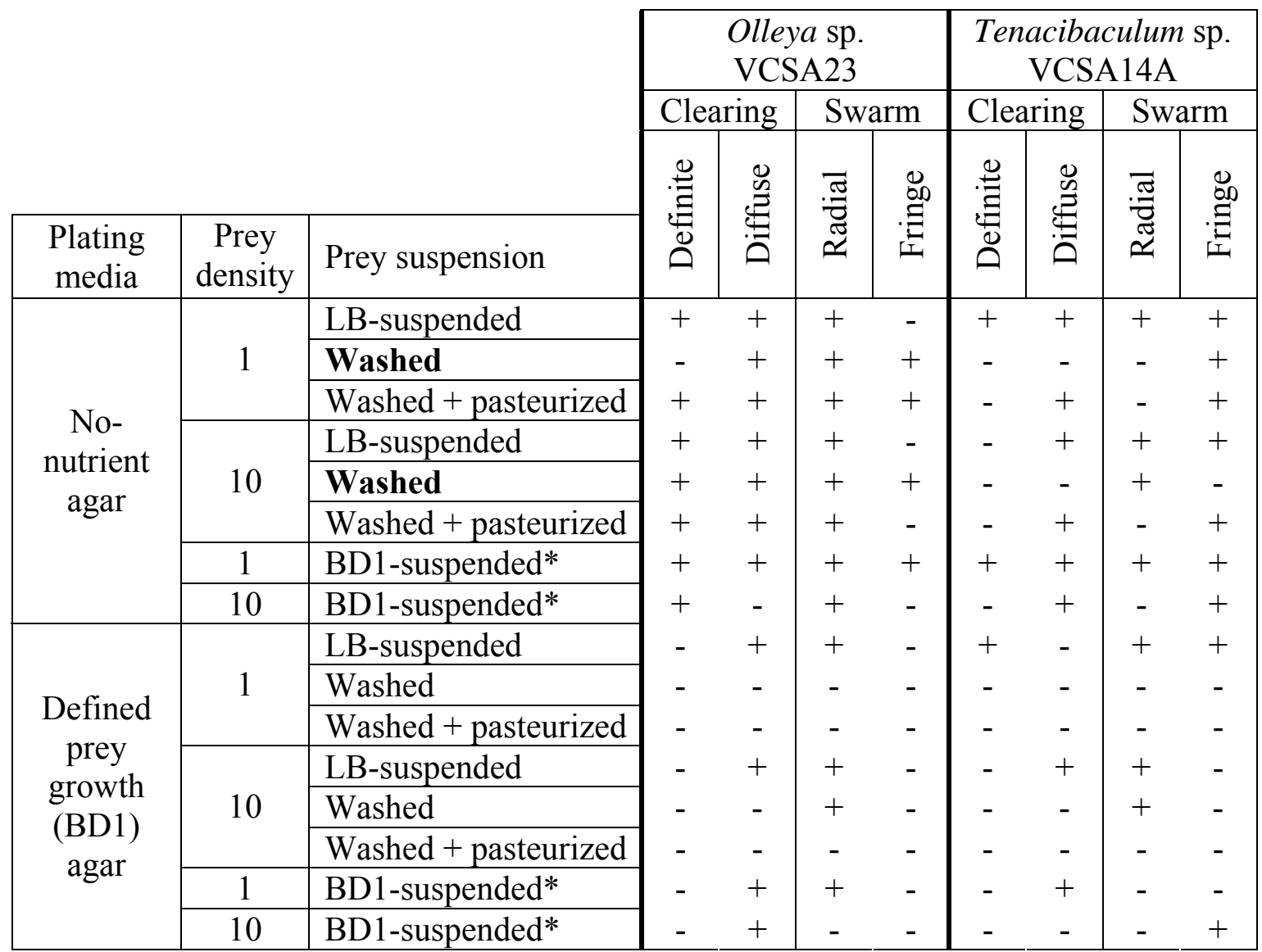

* -- The BD1-suspended culture was not at the same density as the other prey treatments. Definite clearings had sharp, defined edges while diffuse clearings were only distinguishable by a textural change. Radial swarms expanded onto open agar away from prey smears, while fringe swarms did not. Swarm fronts sometimes switched habits during the experiment on a single smear. In some cases, both radial and fringing swarms were observed from the same replicate smear; in other cases the two replicates diverged from each other with respect to swarm habit. The treatments that had been used to test prey specificity as described in Chapter 2, under which Olleya sp. VCSA23 was observed to clear P. corrugata and Tenacibaculum sp. VCSA14A was not, are bolded for reference. 
Table 12: Growth features with S. oneidensis prey

\begin{tabular}{|c|c|c|c|c|c|c|c|c|c|c|}
\hline & \multicolumn{4}{|c|}{$\begin{array}{l}\text { Olleya sp. } \\
\text { VCSA23 }\end{array}$} & \multicolumn{4}{|c|}{$\begin{array}{c}\text { Tenacibaculum sp. } \\
\text { VCSA14A }\end{array}$} \\
\hline & & & \multicolumn{2}{|c|}{ Clearing } & \multicolumn{2}{|c|}{ Swarm } & \multicolumn{2}{|c|}{ Clearing } & \multicolumn{2}{|c|}{ Swarm } \\
\hline & & & $\stackrel{\mathscr{V}}{g}$ & $\ddot{0}$ &. $\bar{\pi}$ & 8 & $\stackrel{\mathscr{V}}{\leftrightarrows}$ & $\mathscr{D}_{己}^{\infty}$ &. $\bar{\Xi}$ & 8 \\
\hline $\begin{array}{c}\text { Plating } \\
\text { media }\end{array}$ & $\begin{array}{l}\text { Prey } \\
\text { density }\end{array}$ & Prey suspension & อั & & & & صี & $\stackrel{\oplus}{\vec{\theta}}$ & & \\
\hline \multirow{6}{*}{$\begin{array}{l}\text { No- } \\
\text { nutrient } \\
\text { agar }\end{array}$} & \multirow{3}{*}{1} & LB-suspended & + & - & + & - & + & + & + & - \\
\hline & & Washed & + & - & - & + & + & + & - & - \\
\hline & & Washed + pasteurized & + & - & + & - & - & + & - & + \\
\hline & \multirow{3}{*}{10} & LB-suspended & + & - & + & - & + & - & + & - \\
\hline & & Washed & + & - & + & - & + & - & - & - \\
\hline & & Washed + pasteurized & + & + & + & - & + & + & - & + \\
\hline \multirow{5}{*}{$\begin{array}{c}\text { Defined } \\
\text { prey } \\
\text { growth } \\
\text { (BD1) } \\
\text { agar }\end{array}$} & \multirow{3}{*}{1} & LB-suspended & + & - & + & + & - & + & + & - \\
\hline & & Washed & + & - & - & - & - & - & + & - \\
\hline & & Washed + pasteurized & + & + & + & - & + & + & + & + \\
\hline & \multirow{2}{*}{10} & LB-suspended & + & - & + & - & + & - & + & - \\
\hline & & Washed & + & - & + & - & + & + & + & - \\
\hline
\end{tabular}

Definite clearings had sharp, defined edges while diffuse clearings were only distinguishable by a textural change. Radial swarms expanded onto open agar away from prey smears, while fringe swarms did not. Swarm fronts sometimes switched habits during the experiment on a single smear. In some cases, both radial and fringing swarms were observed from the same replicate smear; in other cases the two replicates diverged from each other with respect to swarm habit. The treatments that had been used to test prey specificity as described in Chapter 2, under which both predatory strains cleared $S$. oneidensis, are bolded for reference. 


\title{
CHAPTER 4: BIOGEOCHEMICAL EFFECTS OF FLAVOBACTERIAL PREDATION
}

\author{
Abstract \\ Two experiments were conducted to test the effects of predatory marine \\ flavobacteria strains on nutrient release by susceptible prey biofilms. A novel \\ methodology using Shewanella oneidensis biofilms grown on microscope slides was \\ developed to facilitate the recovery of both fluids for geochemical analysis and biofilms \\ for elemental composition and microscopic analysis. The predator strains tested \\ represented two phylogenetically distant genera within the marine flavobacteria, Olleya \\ and Tenacibaculum, which have previously been observed to differ in prey specificity \\ and predatory growth yield. Both predatory strains were found to have statistically \\ significant but divergent effects on the release of ammonium from prey biofilms, with \\ Olleya sp. VCSA23 stimulating ammonium release and Tenacibaculum sp. VCSA14A \\ appearing to suppress it. Analysis of the carbon and nitrogen content of the biofilms \\ suggested that $\mathrm{C}: \mathrm{N}$ ratios may increase in biofilms under flavobacterial predation \\ pressure, although sample sizes available from the experimental setup presented detection \\ limit problems for the analysis. Microscopy and image analysis on selected biofilms \\ suggest the two predatory strains may be adapted to different predatory niches, indicating \\ ecological diversity amongst predatory marine flavobacteria.
}

\section{Introduction}

Knowledge of the factors that structure microbial communities and influence their biogeochemical function is of critical importance to understanding a wide variety of processes, including the elemental cycles of macronutrients such as nitrogen and carbon, ecosystems' reaction to climate change and the bioremediation of contaminated environments. The activity of bacterivorous predators forms an integral part of the microbial loop, a cycle in which the regeneration of macronutrients and oxidation of organic carbon is accelerated by rapid predation-driven turnover of the heterotrophic 
microbial community $[18,25]$. Most work on the microbial loop has focused on the role of protists and viruses as the main drivers of microbial turnover $[4,18,165,166]$. However, the potential for predatory bacteria to play a role in increasing the efficiency of microbe-mediated nutrient cycles has been relatively little explored.

As the results of the previous two chapters have shown, at least some marine flavobacteria possess the ability to grow predatorily at the expense of surface-associated living bacterial prey. Marine flavobacteria have often been reported to be important components of temperate and polar marine ecosystems $[115,120,167,168]$. In addition, they have been found on particles and detritus in the marine water column [126,127] as well as on surfaces in coastal environments, including sediments [118,119], macrophytes [94,169] and in close association with animals and sponges [95,109,110,170,171,172]. In fact, the closest cultured relatives of the novel strains described in the earlier chapters were isolated from some of these aquatic surfaces, specifically Southern Ocean particulate matter and diseased fish for Olleya marilimosa CAM030 [112] and Tenacibaculum discolor [95], respectively. If even a small proportion of marine flavobacteria are predatory, they might heavily influence microbial communities on particles and other surfaces, which are thought to be hot spots of microbial activity [173].

Few studies have focused on the impact of predatory bacteria on prey communities, and most were directed at Bdellovibrio-type rapidly swimming predators $[52,54,137]$. Surface-associated gliding predatory bacteria have been less investigated with respect to ecological and biogeochemical questions. One reason for the rarity of such studies is the artificial nature of the most commonly used culturing environment for such bacteria, involving high densities of inactive prey on an agar surface, as described in Chapter 2. This culture approach, first used for the isolation of myxobacteria early in the $20^{\text {th }}$ century [31], allows the easy visualization of predation by expanding predatory swarms but poorly mimics natural habitats.

Many gliding predatory bacteria form dense swarms of cells that move across the plate and lyse prey bacteria. These bacteria include myxobacteria [31], members of the genera Herpetosiphon [33] and Saprospira [32] and the novel strains described in this 
thesis (Ch. 2). In myxobacteria, dense swarming during predation and reports of lytic ectoenzymes $[70,71,84,85,174]$ and a dependence of casein hydrolysis on high cell densities [175] support the 'wolfpack' hypothesis: that swarms of predatory cells lyse prey by the release of extracellular lytic enzymes $[13,50]$.

However, the prey smear culture environment does not resemble some likely natural habitats of predatory bacteria in many respects. First, the prey are very dense, monocultural, and either dead or starving when emplaced on the agar. These characteristics result in a prey smear that lacks the architecture and extracellular components of a natural biofilm. Second, the predator inoculum is usually a block of agar with predatory swarm on its surface or a myxobacterial fruiting body, both of which contain a high density of predatory cells. This high dose of predatory inoculum is introduced at a single point of the prey smear. The results, highly visible lytic swarms, have been the focus of most efforts to elucidate the dyamics of myxobacterial predation and behavior $[138,176,177,178,179]$. However, the dramatic wolfpack growth habit could be a result of a tendency for high densities of conspecific predatory bacteria to cooperate. A different predatory growth habit may occur in more natural habitats containing mixed bacterial communities in biofilms less capable of sustaining such high predator densities.

In fact, other evidence from the study of myxobacteria indicates that alternate culture methods can yield insight into other, lower-density predation. In a study using microcolonies of prey cells, lysis by Myхососcus xanthus was observed to occur between single predator and single prey cells [43]. The observation that myxobacteria do not require high cell densities for prey lysis calls into question the necessity of a wolfpackstyle swarm for predation by myxobacteria and similar organisms. This underlines the importance of developing more environmentally relevant culture methods for surfaceassociated predatory bacteria.

In addition to the disparity between the normal culture environment for gliding predatory bacteria and natural habitats, the smear plate is a highly intractable platform for addressing questions pertaining to the biogeochemical effects of bacterial predation. 
Chemical analyses routinely used to quantitatively track production and consumption of metabolic intermediates are conducted on fluid samples, which cannot be easily obtained from bacteria on the surface of an agar plate. It is also difficult to quantify cells on an agar plate without substantially disturbing their spatial arrangement.

To overcome these difficulties, an alternative predatory-growth culture environment was developed. Pilot experiments (data not shown) established that the strains of predatory marine flavobacteria described in Chapter 2 are capable of colonizing Shewanella oneidensis biofilms on glass microscope slides from suspension. This culture setup has several benefits with regard to addressing questions related to the ecological and biogeochemical impact of predatory flavobacteria in natural habitats. The prey are present as a mixed community of living and dead cells embedded within a robust biofilm architecture, and are only minimally disturbed by handling during culture setup. Predatory bacteria are inoculated onto the biofilm via their own capacity for colonization of the surface after their addition to the suspension. In addition, both fluid and slide can be analyzed quantitatively. In the following experiments, this culture approach was used to assess two of the novel predatory marine flavobacteria for their impact on macronutrient release and biofilm cell density. The major macronutrients ammonium and dissolved organic carbon (DOC) were used to track the regeneration of prey biomass as dissolved nutrients in the experimental fluids.

Nitrogen, of which ammonium is the most accessible form for microbial growth, is often a limiting macronutrient in aquatic ecosystems [180,181]. Ammonium is particularly useful in this experiment because of the apparent inability to utilize it of the marine flavobacteria characterized in this study (Ch. 2). A pilot experiment showed that released ammonium is not oxidized to nitrite or nitrate (data not shown). Consequently, ammonium in solution should only be reassimilated during regrowth of the $S$. oneidensis prey in response to the release of organic carbon during either autolysis of starving prey cells or their lysis by predatory flavobacteria. In addition, ammonium is more amenable for measurement than other regenerated inorganic nutrients such as sulfate and phosphate due to the relative ease of its analysis and its absence from the experimental buffer (while 
sulfate is present at substantial concentrations in the ASW used). As a result, ammonium is likely to be a macronutrient readily associated with the breakdown of prey biomass.

Many protozoan grazers have been found to release DOC after predation, which helps to drive the microbial loop [18,24,60]. Therefore, the bulk concentration of DOC was also monitored to assess whether predatory marine flavobacteria have a similar effect.

Two experiments were carried out, each one testing a predatory flavobacterium from one of the two predatory genera - Olleya and Tenacibaculum. Ammonium and DOC were analyzed during each experiment's time course to determine whether exposure to the test predatory strain resulted in increased release of either macronutrient from the prey biofilms under starvation conditions.

\section{Materials \& Methods}

Experimental setup and sampling: S. oneidensis MR-1 was used as the sole prey organism in both sets of experiments. It was freshly grown from a $20 \%$ glycerol freezer stock in advance of each experiment on a Lysogeny Broth (LB) agar plate. Olleya sp. VCSA23 and Tenacibaculum sp. VCSA14A, selected as representatives of their respective genera, were used as test predators. They were grown from $20 \%$ glycerol freezer stocks on Marine Broth agar plates in preparation for each experiment.

The experimental design is summarized in Table 1. Due to the large number of tubes needed to facilitate replication in the experiments, each of the two predatory strains was tested in a separate experiment. Microscope slides with a width of $25 \mathrm{~mm}$ were combusted at $460{ }^{\circ} \mathrm{C}$ for four hours in preparation for their use as a solid substrate for prey biofilm development. Slides with frosted glass surfaces on both sides of one end were used for the first experiment with Olleya sp. VCSA23. Slides with a frosted glass surface on only one side were used for the second experiment with Tenacibaculum sp. VCSA14A.

For each experiment, 84 combusted slides were placed in $50-\mathrm{mL}$ tubes (disposable polypropylene centrifuge tubes, Fisher Brand) filled with $30 \mathrm{~mL}$ of sterile 
LB25 (see appendix). A suspension of S. oneidensis was made by suspending loopfuls of fresh culture in $1.5 \mathrm{~mL}$ of sterile $\mathrm{LB} 25$ and mixing by repeated pipetting. A $30-\mu \mathrm{L}$ aliquot of the $S$. oneidensis suspension was added to half of the Falcon tubes containing combusted slides and sterile media, and the inoculated tubes were incubated at $30^{\circ} \mathrm{C}$ and $150 \mathrm{rpm}$ shaking. The biofilm growth tubes were rotated so that all of the slides had the same orientation before being placed in the incubator, to minimize hydrodynamic difference between tubes as much as possible. The remaining tubes were incubated at room temperature without shaking for four days and checked daily for any contaminating growth. Each day at about the same time as the initial inoculation, the majority of the medium from the inoculated tubes was gently poured out and replaced with $30 \mathrm{~mL}$ of sterile LB25. The fresh medium was added carefully along the walls of each tube in an effort to minimize disturbance to the developing biofilms.

After four days of incubation and three medium changes, the slides were removed from the biofilm growth tubes and placed in Falcon tubes containing $30 \mathrm{~mL}$ of sterile ASW25 (made in combusted Pyrex bottles, see appendix). At the same time, the control slides that received no $S$. oneidensis inoculum were also removed from their LB25 tubes and placed into $30 \mathrm{~mL}$ of sterile ASW25. All slides were incubated in the first wash for two hours at $30{ }^{\circ} \mathrm{C}$ with $150 \mathrm{rpm}$ of shaking. All 84 slides were then removed from the first wash tubes and placed in a fresh set of 50-mL Falcon tubes containing $30 \mathrm{~mL}$ of sterile ASW25, and incubated at $30^{\circ} \mathrm{C}$ with $150 \mathrm{rpm}$ of shaking again, this time for one hour. The slides were then moved to a third set of wash tubes, also containing $30 \mathrm{~mL}$ of sterile ASW25, and incubated at $30^{\circ} \mathrm{C}$ and $150 \mathrm{rpm}$ for a further hour for a total of three washes over four hours. At the end of the third wash period, every slide was removed from its tube and placed in an acid-washed $(24$ hours in $10 \% \mathrm{HCl}$, rinsed $3 \mathrm{X}$ with deionized water), autoclaved 50-mL tube (brand) filled with $35 \mathrm{~mL}$ of sterile ASW25.

A washed suspension of the test predator was made by suspending a few loopfuls of fresh culture in ASW25 and washing at least once by pelleting the cells by centrifugation and resuspending in fresh sterile ASW25. The absorbance of the resulting suspension was measured at $543 \mathrm{~nm}$ in a spectrophotometer relative to sterile ASW25. 
Standard curves previously calculated using direct cell count figures were used to calculate the cell concentration in the washed suspension $\left(\sim 10^{9}\right.$ cells $\left./ \mathrm{mL}\right)$, and the volume of a hundred-fold dilution needed to deliver $10^{5}$ cells was estimated ( 5 and $6 \mu \mathrm{L}$ for the VCSA23 and VCSA14A experiments, respectively). Half of the tubes containing biofilm slides and half of the tubes containing control slides were inoculated with the appropriate predatory flavobacterium. All of the tubes containing slides, whether supporting biofilms or not, were then covered with foil to block out all light and incubated at room temperature $\left(\sim 21^{\circ} \mathrm{C}\right)$ with shaking at $150 \mathrm{rpm}$.

Each experiment was sampled within 12 hours of predator inoculation, and afterward at two to four day intervals for about two weeks. For sampling, three tubes were randomly selected from each of the four treatments and removed from the shaker. The slides were removed from the tubes using flame-sterilized forceps. Two slides from each treatment were placed in sterile $50-\mathrm{mL}$ tubes and frozen at $-20{ }^{\circ} \mathrm{C}$ immediately for later direct sampling of biofilms. One slide from each treatment was fixed with $4 \%$ paraformaldehyde for at least two hours at $4{ }^{\circ} \mathrm{C}$ by gently submerging it in the fixative in a covered dish. The slides were then washed serially three times by gently submerging in phosphate buffer saline (PBS; see appendix) in covered dishes for at least five minutes at each wash before being dipped briefly in a 1:1 mixture of PBS and ethanol (PBS:EtOH) and frozen at $-20^{\circ} \mathrm{C}$ in a sterile $50-\mathrm{mL}$ tube. Throughout the fixation and washing, the slides were kept with the same side facing up to minimize disturbance to one face of the slide, and the direction that face was facing was marked on the $50-\mathrm{mL}$ tube before freezing.

For fluid sampling, a series of subsamples were collected. For direct counts, a 2$\mathrm{mL}$ subsample was taken from each tube, the cells pelleted by centrifugation, resuspended in $4 \%$ paraformaldehyde and fixed for at least two hours at $4{ }^{\circ} \mathrm{C}$. After fixation, cells were washed in sterile PBS by centrifugation and resuspension and stored at $-20^{\circ} \mathrm{C}$ in PBS:EtOH. A sterile $10-\mathrm{mL}$ syringe was used to withdraw about $6 \mathrm{~mL}$ of sample from each tube for ammonium and $\mathrm{pH}$ analysis, which was then passed through a syringe filter with a pore size of $0.2 \mu \mathrm{m}$ and frozen at $-20{ }^{\circ} \mathrm{C}$. The same syringe filter was 
used for the three replicates of each treatment, and washed with the first 0.5 to $1 \mathrm{~mL}$ of each sample before collecting the remainder of the sample. Each remaining sample was filtered through a $0.2-\mu \mathrm{m}$ pore size Anodisc filter and further split: $10 \mathrm{~mL}$ of the filtrate was frozen in a combusted EPA vial and the remainder was frozen in a sterile $50-\mathrm{mL}$ Falcon tube. All glassware used in filtration was pre-combusted at $460{ }^{\circ} \mathrm{C}$ and rinsed with deionized water between samples. The Anodisc filters were laid face down on combusted $\mathrm{GF} / \mathrm{F}$ filters, wrapped in combusted foil and frozen at $-20^{\circ} \mathrm{C}$. For all time points after the first in the VCSA14A experiment, combusted Anodisc filters were used for filtration rather than the uncombusted filters used for the preceding samples.

Fluid chemistry analysis: For ammonium analysis, the 5-6 mL subsamples were thawed to room temperature. Ammonium concentrations were measured using the phenol/hypochlorite method [182] scaled to a total sample volume of $2 \mathrm{~mL}$. All ammonium concentration measurements were made in duplicate. Early time points in each experiment were measured without dilution. For each experiment, within three or four time points the biofilm-positive treatments ammonium concentrations began to exceed the linear range of the ammonium standard curve $(5 \mu \mathrm{M}$ to $50 \mu \mathrm{M})$, and thereafter all biofilm samples for that experiment were diluted at least 4-8X as necessary.

For DOC analysis, EPA vials containing $10 \mathrm{~mL}$ of frozen sample filtrate were thawed and diluted with $20 \mathrm{~mL}$ of MilliQ water and then acidified by the addition of $1 \mu \mathrm{L}$ of $12 \mathrm{~N} \mathrm{HCl}$ per milliliter of total volume. The vials were recapped and placed in the autosampler of a TOC-V CSH Total Organic Carbon Analyzer (Shimadzu, Kyoto, Japan), which was used to measure the non-purgeable organic carbon with gas flow from a Parker Balston TOC Gas Generator. A stock solution of $105 \mathrm{mM}$ potassium hydrogen phthalate was used to make daily standard solutions of about 1.5-2.5 mM organic carbon. On every day samples were run on the instrument, a fresh standard solution was mixed up and run at four dilutions (between 50 and $300 \mu \mathrm{M}$ organic carbon) to obtain calibration points for a standard curve. DOC concentrations were calculated using the standard curve run with the samples and corrected by subtracting the average blank (MilliQ water) from all sample measurements prior to multiplication to account for sample dilutions. 
Biofilm analysis: Frozen biofilms were scraped off their slides into sterile $1.5-\mathrm{mL}$ microcentrifuge tubes using a clean, flame-sterilized spatula. The spatula was rinsed with deionized water, wiped with a Kimwipe and flame-sterilized between each slide. Biofilm scrapings were resuspended in sterile ASW25 (500 $\mu \mathrm{L}$ for VCSA23 experiment biofilms, $400 \mu \mathrm{L}$ for VCSA14A experiment biofilms), vigorously vortexed and kept frozen at -80 ${ }^{\circ} \mathrm{C}$. For $\mathrm{CHN}$ analysis, biofilm suspensions were thawed and 100 to $150 \mu \mathrm{L}$ were pipetted at a time into combusted, preweighed tin boats. The aliquots were dried at $60{ }^{\circ} \mathrm{C}$. For VCSA14A experiment biofilm suspensions, an additional aliquot of suspension was added to the dried samples and again dried at $60{ }^{\circ} \mathrm{C}$. All dried samples were formed into pellets and weighed after drying. Dry weights for VCSA23 experiment samples ranged between 4.2 and $8.3 \mathrm{mg}$, the dry weights for VCSA14A experiment samples were between 11.6 and $26.1 \mathrm{mg}$. The samples' carbon and nitrogen contents were measured by dynamic flash combustion on a ThermoQuest EA1112 Carbon/Nitrogen Analyzer. The resulting signal was integrated and quantified using a five-point standard curve of anelimide (contains both $\mathrm{C}$ and $\mathrm{N}$ ). After the computation of $\mu$ moles of carbon and nitrogen using the standard curve, carbon-to-nitrogen $(\mathrm{C}: \mathrm{N})$ ratios were computed. Although the detection limit of the instrument was $0.05 \mu$ mole, only $\mathrm{C}: \mathrm{N}$ ratios for samples in which at least $0.25 \mu$ mole of nitrogen was detected were retained. Below that threshold nitrogen concentrations were highly variable between replicate measurements even when the carbon results were very similar (data not shown).

Fixed biofilms were prepared for hybridization by thawing and drying them at 46 ${ }^{\circ} \mathrm{C}$ in 50-mL tubes. For each set of hybridizations, fresh $35 \%$ formamide hybridization buffer was mixed. A hybridization-buffer-saturated Kimwipe was placed in the bottom of the hybridization chamber (an empty pipet tip box, allowing the hybridization of a maximum of four slides simultaneously) and the chamber equilibrated to $46{ }^{\circ} \mathrm{C}$ before hybridization. After drying, all four edges of each slide were carefully rubbed against a block of paraffin wax to minimize the possibility of buffer spilling off the slide and placed on rubber gaskets (made by coring the center out of gray butyl stoppers) in the hybridization chamber with the undisturbed side facing up. After replacement of the open 
hybridization chamber into the oven, $450-500 \mu \mathrm{L}$ of hybridization buffer was added to the top of each slide drop-wise to cover the entire unfrosted area of the upward-facing side. Each slide then received $11 \mu \mathrm{L}$ each of the fluorescein-conjugated GAM42A [105] and Cy3-conjugated predator-specific probe stocks (100 ng/ $\mu \mathrm{L})$, and the chamber closed and incubated at $46^{\circ} \mathrm{C}$ for at least two hours. After two hours, the oven temperature was increased to $48{ }^{\circ} \mathrm{C}$ and each slide removed to a $50-\mathrm{mL}$ tube containing appropriately prepared, prewarmed wash buffer (as described in Ch. 2) and incubated for at least 20 minutes. The orientation of the hybridized face of the slide was marked on each wash tube. Each slide was briefly submerged in water and then dried overnight in the dark before the addition of three small drops of DAPI mountant mix [107] and mounted with a large coverslip ( 24 by $60 \mathrm{~mm}$ ). The slides were kept at $4{ }^{\circ} \mathrm{C}$ until imaging. Hybridization and wash buffers and probe stock solutions were prepared according to previously published protocols [106].

Slides were visualized using an Axioplan 2 epifluorescence microscope and a Plan-NEOFLUAR 20X objective lens. Images of three fluorescence channels (DAPI, fluorescein and $\mathrm{Cy} 3$ with exposure times of $0.5,2$ and 1.5 seconds respectively) were captured by an Axiocam at the highest possible image resolution of 3900 by 3090 pixels using the Axiovision software package (version 4.6). The number of pixels per micrometer was determined by imaging a scale slide with 10 - and $100-\mu \mathrm{m}$ markings with the same magnification and resolution settings. Each slide was imaged at about 20 random positions along two length-wise transects - one running near the center of the slide and the other within a centimeter of one slide edge or the other. The location on the slide was recorded from the position of the stage for most images. Captured images were exported from Axiovision as TIF files and analyzed using the daime (v1.2) image analysis program [108].

In daime, the histogram stretch and blur and subtract tools were used to eliminate background and increase contrast as much as possible for all images. In each image's case, the effects of the settings were carefully monitored to ensure no significant loss of cell signals from the image during preprocessing. The $\mu \mathrm{m}$-scale was set as appropriate for 
each image, based on the measured scale. The RATS-L algorithm was used to automatically segment each image. In some cases (particularly images with a high cell density in one or more channels and those in which parts of the image frame were out of focus), the automatic segmentation did not perform well and the image was subsequently cropped in Adobe Photoshop into quarters or ninths as necessary for individual processing. At lower image sizes, the automatic segmentation was manually inspected and adjusted as necessary. The total labeled area of the segmented images was measured, tabulated and used to calculate the ratio between predator area and prey area and the total cell coverage per square micrometer for each channel at each imaged location.

Statistical analysis: The ammonium and DOC concentration data sets were evaluated for statistical analysis. The DOC data for the VCSA14A experiment was excluded as a result of inconsistencies in the DOC concentrations measured in the Nocell and Predator-only tubes which suggest contamination after sampling. The average measurements for each replicate tube in the three remaining data sets were found to be approximately normal in their probability distributions, but highly variable in the ranges within each treatment. Although analysis of variance (ANOVA) is robust to small deviations from a normal probability distribution, it is vulnerable to large differences in variance between groups. As a result, the data sets were transformed by taking the square root of each measurement to decrease the magnitude of variation in the variances between treatments.

All statistical analyses were completed using the Statistics Toolbox of Matlab version 7.5.0.342. The transformed data sets were analyzed using a 2-way ANOVA model using treatment (no cells, predator cells only, prey biofilm only, predator cells + prey biofilm) and time point (hours between inoculation and sampling) as fixed factors and testing for significant effects of combinations of the two factors. The results were evaluated at a significance level of 0.05 . Multiple comparison tests were conducted using Tukey's Honestly Significant Difference test with alpha equal to 0.05 . 


\section{Results}

Fluid chemistry: The ammonium concentrations of the predator-and-prey treatments diverged from those of the corresponding prey-only treatments in the two experiments (Figures 1 and 2). In both cases, the ammonium concentrations in the fluid of the two biofilm treatments closely mirrored each other for the first 100 and 150 hours in the VCSA23 and VCSA14A experiments, respectively. After 100 hours, the 'VCSA23 + prey biofilm' treatment began to develop ammonium concentrations that grew to almost $100 \mu \mathrm{M}$ greater than those in the 'Prey biofilm only,' and by 200 hours into the experiment this was reflected in all three replicates sampled (Figure 1). The higher ammonium concentrations associated with the combination of VCSA23 cells and $S$. oneidensis biofilm remained stable through the end of the experiment. In contrast, the combination of VCSA14A cells and S. oneidensis biofilm appeared to be associated with a lower ammonium concentration (Figure 2). After 150 hours into the VCSA14A experiment, the ammonium concentration in the 'VCSA14A + prey biofilm' treatment averaged more than $30 \mu \mathrm{M}$ lower than that in the 'Prey biofilm only' treatment. By the end of the experiment, the gap had closed to little more than $10 \mu \mathrm{M}$ - also in contrast to the pattern in the VCSA23 experiment, in which both treatments' ammonium concentrations had leveled off at the end. At all time points in both experiments, the ammonium concentrations in the no-biofilm treatments ('No cells added' and 'Predator only') were close to the minimal detection limit.

Similar to the ammonium concentrations, DOC concentrations were elevated in the presence of $S$. oneidensis biofilms with or without the presence of a predatory flavobacteria strain. In the VCSA23 experiment, the DOC levels of the two biofilm treatments roughly mirrored each other for the first 200 hours of the experiment before the 'Prey biofilm only' DOC concentration started to drop relative to the leveled-off 'VCSA23 + prey biofilm' treatment (Figure 3). The DOC concentration in the no-biofilm treatments remained low at around $100 \mu \mathrm{M}$, showing the background organic carbon associated with the experimental apparatus and reagents. DOC concentrations in the VCSA14A experiment were more variable between sample time points (Figure 4), 
possibly as a result of switching to combusted Anodisc filters, which were fragile and may have cracked during filtration in some cases. Cracked filters alone, however, does not explain high DOC concentrations detected in no-cell control tubes during the VCSA14A experiment - suggesting the potential for sample carryover in the filtering apparatus between filtrations despite washing. Similarly to the VCSA23 experiment, the predator + prey treatment in the VCSA14A experiment developed higher DOC concentrations by 250 hours (Figure 4). However, the prey-only treatment had higher DOC levels by 300 hours. In general, the baseline control DOC levels for the 'no biofilm' and 'VCSA14A only' treatments were highly variable across time points (Figure 4), suggesting problems with carbon contamination at some point during sample handling.

Biofilm analysis: Biofilms were visibly different between the two experiments. In the VCSA23 experiment, slides with prey biofilms had dense accumulations of cells just below the air-water interface on both sides of the slides. The color of this thick accumulation of biofilm was easily visible to the naked eye, with prey-only slides having a pinkish hue characteristic of $S$. oneidensis and the predator-and-prey slides developing a yellow color by the end of the experiment (similar to the yellow-orange color observed in Olleya sp. VCSA23 colonies). In contrast, the biofilms at all points in the VCSA14A experiment lacked a dense, easily visible accumulation of cells near the air-water interface, though thin biofilm was visible over both sides of the slides.

In many cases, insufficient nitrogen was detected during the $\mathrm{CHN}$ analysis to support the calculation of a $\mathrm{C}: \mathrm{N}$ ratio, mostly for VCSA23 experiment samples for which a lower amount of the total biofilm suspension was analyzed. A larger sample size was used for the VCSA14A samples, with a consequently higher proportion of measurements falling above the detection limit of the analysis. C:N ratios during the VCSA14A experiment did not vary consistently over time or between treatments (Figure 5). For the VCSA23 experiment, later-stage predator + prey slides produced higher C:N ratios than earlier stage slides, although the number of measurements from the experiment as a whole is low relative to the VCSA14A experiment. 
Microscopic examination of fixed, dual-hybridized biofilms in the two experiments confirmed that both species of predatory flavobacteria were able to colonize the prey biofilms during the course of the experiments (Figure 6). Abrupt swarm fronts of the type observed previously (Chapter 2) were never observed on either of the two predator-and-prey treatments. Instead, prey and predator cells were intermixed. VCSA23 cells were often tightly associated with each other and with prey cells, while VCSA14A cells were nearly always observed scattered singly amongst prey cells.

Another difference between the two experiments readily visible in Figure 5 is the greater average areal extent of predator coverage in the VCSA23 experiment relative to the VCSA14A experiment. The predator coverage in both predator-and-prey treatments was greater than the relatively constant background level of fluorescence artifacts in the Cy3 channel (detected in the no-predator treatments) and the areal extent of predator label in the predator-only treatment.

Examination of the spatial distribution of cell area coverage on each slide analyzed in depth (Figures 7-8) shows that cell density is highly heterogeneous across all of the experimental biofilms. In addition, it appears that there were major differences between the two experiments' biofilms as a whole, as suggested by the higher prey cell coverage on the 'Prey biofilm only' slide in the VCSA14A experiment at 251 hours relative to its counterpart in the VCSA23 experiment (Figures 7-8). In the VCSA23 experiment, cell density was highest close to the air-water interface and the center of the slide under both predator and no-predator treatments (Figure 7). In contrast, cell coverage area was generally higher and more even on the VCSA14A experiment slides (Figure 8) than in the VCSA23 experiment, with the higher cell coverage occurring lower on the slide relative to the water-air interface.

Plotting the coverage of predator and prey labels relative to each other shows robust linear relationships between them for both predatory flavobacteria (Figure 9). As expected, measurements from the 'Prey biofilm only' treatments fall exclusively along the x-axis, corresponding to a single-member community, and the 'VCSA23 only' treatment's measurements plot nearly on the origin. For both test predators in interaction 
with prey biofilms, the highest density of predator cells was found in locations where the highest density of prey cells was observed. However, the predators differed from each other with regard to their total density. On the 'VCSA23 and prey biofilm' slide from 257 hours into the VCSA23 experiment, Olleya sp. VCSA23 was at higher density than S. oneidensis at a ratio of predator area/ $\mu \mathrm{m}^{2}$ to prey area $/ \mu \mathrm{m}^{2}$ of about 1.7 . However, the ratio obtained from the 251-hour 'VCSA14A and prey biofilm' slide was two orders of magnitude smaller at about 0.02 . These widely divergent ratios of predator to prey suggest very different predator/prey dynamics between the two flavobacteria species under the test conditions.

Statistical analysis: For the three fluid chemistry data sets analyzed statistically, both fixed factors, time and treatment, and the combination of the two were found to be highly statistically significant (Table 2). In all cases, the null hypothesis that all groups share the same mean was rejected at an $\alpha$ of 0.05 . Post hoc multiple comparison tests were conducted using Tukey's Honestly Significant Difference test with an $\alpha$ of 0.05 to determine which pairwise combinations of time and treatment were significantly different from each other. Within each of the three data sets, there were no statistically significant differences between the no-cells and predator-only treatments or within any of the control treatments as a function of time. For all three data sets, the ammonium and DOC concentrations were significantly different as a function of time within each treatment that included prey biofilms, and diverged significantly from the no-biofilm control treatments. In both ammonium data sets, time points were identified at which statistically significant differences existed between the ammonium concentrations of prey-only tubes and those of predator-and-prey tubes. In the VCSA23 experiment, the predator-and-prey ammonium concentrations were significantly higher than the corresponding prey-only concentrations starting at 187 hours and running through the end of the experiment (Figure 1). In contrast, the VCSA14A predator-and-prey ammonium concentrations only differed significantly from the prey-only tubes at the 251-hour time point, when the ammonium concentration was lower in predator-and-prey tubes than in prey-only tubes (Figure 2). While the predator-and-prey and prey-only treatments diverged significantly 
from each other in both ammonium data sets, no statistically significant difference between the two biofilm treatments was found at any time point in the VCSA23 DOC data set.

\section{Discussion}

The experiments in this study confirmed the ability of both Olleya sp. VCSA23 and Tenacibaculum sp. VCSA14A to readily colonize prey biofilms from suspension in a matter of days. This suggests they can disperse between susceptible surface-associated communities in aquatic environments as suspended cells. Marine flavobacteria have been shown to colonize suspended particles derived from phytoplankton $[128,158,183]$. Members of the genera Tenacibaculum, Algibacter and Formosa (the latter two more closely related to the genus Olleya, see Chapter 2) from Southern Ocean bacterioplankton were specifically detected colonizing diatom detritus [128]. In addition, marine flavobacteria have frequently been detected on marine snow and other particles collected in ocean waters $[126,127]$.

Since sampling of the experiments involved extensive and immediate sample processing, it was not feasible to test both predators in parallel with replication and frequent sampling. Consequently each experiment drew from a separately grown batch of biofilms, allowing the possibility of systematic differences between the experiments with respect to prey density and biofilm architecture. As a result of a supply shortage, a change was made between the experiments from slides with frosted surfaces on both sides of the label-end to slides with a frosted surface on only one side. This textural change had a profound effect on the structure and density of prey cells on the slides, probably as a result of changes in the flow regime during biofilm growth. In addition to the observations of slide biofilm structures made during sampling, image analysis of the prey-only slides sampled at about 250 hours from each experiment revealed a major difference in the cell densities of the underlying prey biofilms between the two experiments (Figures 7-8). The easily visible biofilm accumulations near the air-water interface in the VCSA23 experiment were too dense to be effectively imaged by the 
techniques used in this study, and so are not included in the image analysis data set. Despite this difference, both sets of prey-only biofilms had broadly similar biogeochemical characteristics. In the absence of predatory flavobacteria, both released $100-150 \mu \mathrm{M}$ ammonium (Figures 1-2) and 150-250 $\mu \mathrm{M}$ organic carbon (above the negative control baseline, Figures 3-4) during the course of the experiments.

Preferential degradation of proteins and other nitrogenous compounds over carbohydrates might cause the $\mathrm{C}: \mathrm{N}$ ratios of biofilm biomass to increase during predation by marine flavobacteria. As described in Chapters 2 and 3, available evidence suggests the Olleya and Tenacibaculum predatory strains may be unable to degrade a variety of polysaccharides. In addition, enzyme activities (Ch. 3) suggest the Olleya strains may be able to assimilate at least some sugars that the Tenacibaculum strains cannot utilize. If either or both of these hypotheses are correct, then the $\mathrm{C}: \mathrm{N}$ of biofilm biomass during predation could rise at a faster rate than in prey-only biofilms and prove a useful measurement to distinguish between predated and unpredated biofilms. Partial biofilm suspensions from biofilms of the VCSA23 experiment were often either below the detection limit of the $\mathrm{CHN}$ analysis or close enough that nitrogen measurements were unreliable. Although the data set is patchy and largely without replication, there is a general upward trend in $\mathrm{C}: \mathrm{N}$ for the predator-and-prey biofilms (Figure 5). For samples in the VCSA14A experiment, from which a relatively robust set of $\mathrm{C}: \mathrm{N}$ ratios was obtained from both analyzed replicates and treatments from most time points, $\mathrm{C}: \mathrm{N}$ ratios were steady throughout the experiment. The visible trend in $\mathrm{C}: \mathrm{N}$ data from the VCSA23 experiment implies that at least some predatory marine flavobacteria may selectively partition surplus nutrients between the dissolved and particulate fractions of their environment by releasing inorganic nitrogen into solution but leaving partially degraded carbohydrates within the biofilm matrix. Taken together, the data suggest that $\mathrm{C}: \mathrm{N}$ analysis can be an informative measurement for biofilm grazing experiments. The detection limit difficulties observed during this study could be overcome in future experiments by modifying the experimental setup to increase either the density or surface area of the biofilms used. 
With respect to the cycling of ammonium, the no-biofilm controls (no-cells and predator-only) in both experiments indicate that the only significant ammonium source was prey biomass. Ammonium was not detected in the absence of prey biofilms in either experiment (Figures 1-2), ruling out ammonium contamination from the tube itself, the glass slides, the ASW medium and the washed predator inocula. Pilot experiments in which ammonium and nitrite + nitrate were monitored verified that neither of the predatory strains nor the $S$. oneidensis prey were capable of nitrification, eliminating ammonium oxidation as a potential sink for ammonium in the experiments (data not shown). Since the predatory marine flavobacteria appear unable to assimilate inorganic nitrogen (Ch. 2), the only microorganism in the experiments capable of removing ammonium from solution is $S$. oneidensis. Such reassimilation would require an additional carbon substrate, since the ASW does not include any organic carbon above an apparently refractory background level. Additional carbon substrate could, however, be supplied by prey cell lysis via either autolysis or predatory action.

Olleya sp. VCSA23 and Tenacibaculum sp. VCSA14A had diametrically opposed effects on the ammonium release of the prey biofilms during the two experiments. Biofilms inoculated with Olleya sp. VCSA23 released nearly twice as much ammonium as prey-only biofilms over the course of the experiment (Figure 1). On the other hand, biofilms colonized by Tenacibaculum sp. VCSA14A had not released more ammonium than the corresponding prey-only biofilms at any sampled time point. In fact, at one time point (about 250 hours, Figure 2) the predator-and-prey biofilms had released on average $40 \mu \mathrm{M}$ less ammonium than the prey-only biofilms. For both experiments, ANOVA analysis indicated that these disparities between the two treatments' ammonium concentrations were significantly different (Table 2, Figures 1-2).

In contrast to measured ammonium concentrations, a substantial DOC background was detectable in the no-biofilm treatments (no-cells and predator-only) throughout the experiments (Figures 3-4). The VCSA23 experiment's no-biofilm treatments were not significantly different from each other at any point in the experiment, ruling out the washed predator inoculum as a source of background DOC. Another 
potential source of background was the leaching of organic compounds from the walls of the polypropylene tube. However, such leaching should have been progressive over time and there was no change in the DOC concentration of the VCSA23 experiment nobiofilm controls during the incubation, indicating that any leaching from the tube walls was negligible. The two remaining non-biological sources of contaminating DOC are the slides and the ASW medium, for which uncombusted salts were used. One or both of these sources likely accounts for the background $100 \mu \mathrm{M}$ organic carbon measured during the VCSA23 experiment. There is only one other possible source for the additional DOC detected in solution during the experimental incubations: prey biofilms. In contrast, the DOC concentrations of the VCSA14A experiment's negative control treatments were highly variable between time points, sometimes reaching concentrations of nearly $300 \mu \mathrm{M}$ organic carbon, calling the integrity of the positive cell treatments' DOC concentrations into question. The main difference in sample handling between the two experiments was the switch to precombusted Anodisc $0.2-\mu \mathrm{m}$ filters as a result of a supply shortage. When combusted, Anodisc filters are very fragile and prone to cracking, which may have resulted in cells passing through the filter and being retained in the filtrate and/or the filtering apparatus (where they may have contaminated later filtrates).

On the basis of DOC measurements, there did not appear to be differences between predator-and-prey and prey-only treatments as pervasive as those observed in ammonium concentrations. For most of the VCSA23 experiment, DOC concentrations were nearly identical between the two treatments (Figure 3). Near the end of the incubation, prey-only DOC concentrations were found to have decreased relative to those of the predator-and-prey treatment, which had leveled off. This was presumably a result of prey reassimilation of some fraction of organic carbon released from previous autolysis. The DOC concentrations of the negative control treatments (no-cells and predator-only) in the VCSA23 experiment held steady across all the time points sampled. ANOVA analysis indicated that the interaction between predator cells and prey biofilms was statistically significant, but the higher p-values suggest it is not as strong an influence on DOC release as it is on ammonium release (Table 2). 
Since DOC concentration is a bulk measurement, it integrates across all organic carbon compounds. Both predator and prey are undoubtedly capable of assimilating some subset of the released DOC. Therefore the total DOC measurements made during the experiment are likely to integrate both accumulation of recalcitrant compounds unavailable to either predator or prey and the assimilation from solution of more labile compounds that one or both species can utilize. Attempts to identify compositional differences in DOC between experiments and treatments require analyses of narrower compound classes. Unfortunately, the fluid volumes $(\sim 30 \mathrm{~mL})$ and organic carbon concentrations ( $\sim 400 \mu \mathrm{M}$ carbon) produced by this experiment were too low to support such analyses. In order to generate samples amenable to finer-resolution analysis, the experimental setup would need to be modified to produce higher organic carbon concentrations, by increasing the biofilm cell density and/or surface area and allowing longer incubation times to enhance release of DOC from prey biomass via predation.

The two strains had highly divergent population dynamics in relation to $S$. oneidensis prey cells. After 250 hours of incubation, Olleya sp. VCSA23 numerically dominated the biofilm on the predator-and-prey slide at nearly every point imaged and VCSA23 cells were often in close association with each other and with prey cells (Figures 6-7). After a similar incubation time, Tenacibaculum sp. VCSA14A's areal coverage was less than a tenth that of $S$. oneidensis in every frame imaged, and VCSA14A cells were rarely in close proximity to each other (Figures 6,8 ). Interestingly, at 250 hours into each experiment the cell densities of both predators had linear relationships with prey density which held relatively constant across each slides images (Figure 9). Despite the high degree of patchiness in cell density within all biofilms analyzed and the lack of replication in the FISH biofilm data set, the highly linear relationships between predator and prey populations regardless of total cell density are striking at the 250-hour time point (Figure 9).

Differences in the numerical yield of the two strains and the divergent, highly linear relationship each predatory strain possessed with its prey population mirror the results of the membrane filter coculture experiments in Chapter 2 showing an order of 
magnitude difference in predator cell yield between Olleya and Tenacibaculum strains. In addition, when tested on prey smears of different species under different conditions $(\mathrm{Ch}$. 3), Tenacibaculum sp. VCSA14A developed diffuse clearings and swarms in the absence of clearing features more commonly than Olleya sp. VCSA23. Of course, this could be an artifact of the particular prey species, density and fluid chemistry conditions tested. Taken together with the results of this study, it seems possible that strains of the two different genera, Olleya and Tenacibaculum, are adapted to different predatory niches. At least under the conditions tested, predation by Olleya sp. has similar biogeochemical and ecological consequences to those observed for many protozoan grazers, including stimulation of macronutrient regeneration [7,21,22,23]. Tenacibaculum sp., however, appear to be adapted to a different niche in which recycling of regenerated macronutrients within the biofilm is stimulated at the expense of bulk release into solution and lower predator populations coexist with high prey populations.

A conservative predation strategy could be to avoid boom-bust population cycles by maintaining a low rate of predation allowing continual regrowth of the prey. This strategy would be especially effective if the predator is not well-adapted to survive periods of starvation. For example, the spherical cells often found in old Tenacibaculum cultures $[95,109,110,111]$, though little studied, have been reported to be incapable of generating growth when transferred to fresh medium [109]. Such spherical cells were observed in areas of prey lawn cleared by Tenacibaculum predators during membrane filter coculture experiments (Ch. 2), and may no longer be viable cells. In contrast, Olleya sp. formed dense accumulations of cells that did not appear smaller than those found elsewhere in the cocultures (Ch. 2), suggesting that they may have been entering a dormant, rather than non-viable, phase.

It was previously hypothesized (Ch. 2) that the disparity in predator cell yield between Olleya and Tenacibaculum strains might be the result of the Olleya strains being capable of assimilating a larger fraction of the prey biomass than the Tenacibaculum strains. If so, it would help explain the results of these experiments, in which the Tenacibaculum strain appeared to suppress inorganic nitrogen release while the Olleya 
strain stimulated it. Assuming that the prey community is carbon-limited during the experiments, the result of lower biomass utilization by Tenacibaculum sp. VCSA14A relative to Olleya sp. VCSA23 could be a greater availability of forms of DOC to $S$. oneidensis. Regrowth of $S$. oneidensis would be coupled to ammonium uptake, possibly explaining the lower ammonium concentrations in some predator treatments inoculated with Tenacibaculum sp. VCSA14A.

Another explanation for the disparity between the effects of the two predators is differences between the biofilms used in each experiment. It is possible that the more evenly distributed biofilms used in the VCSA14A experiment possessed a more extensive extracellular matrix that was more difficult for predatory flavobacteria to penetrate. On the other hand, it is also possible that Tenacibaculum sp. VCSA14A is inherently less capable of penetration into biofilm matrices than Olleya sp. VCSA23. Previous pilot experiments conducted with both predators on biofilms grown in parallel suggest this may be the case, since Olleya sp. VCSA23 apparently completely obliterated the biofilm structure while Tenacibaculum sp. VCSA14A eroded it to a lesser degree (data not shown). S. oneidensis was selected as prey for this experiment partially because both of the test strains of predatory marine flavobacteria routinely generated robust clearings on S. oneidensis smears (Ch. 2). However, those smears lack any native biofilm structure that might serve as a defense against predation. Further experimentation with thorough characterization and control of biofilm structure would be necessary to distinguish amongst these hypotheses. In addition, it would be beneficial to extend experimental incubations over a longer period and assess whether either strain would eventually completely eliminate the prey biofilm.

In contrast to the membrane filter coculture experiments (Ch. 2-3), dense coordinated swarms were not observed in either experiment's predator-and-prey slide biofilm. In the cleared zones of membrane filter cocultures, the ratios between predator and prey volume were also extremely high, ranging from 3 to more than 400, in contrast to the relatively low ratios evident in Figure 9. Here, predator cells were distributed more evenly within the prey biofilms. This probably results from the more environmentally 
relevant inoculation mechanism in the slide experiments - in which predatory cells colonize the biofilm individually at many points, rather than expanding en masse from a single location as in plate experiments with prey smears. The observed predator cell distribution within the biofilms would also be consistent with a lytic mechanism involving individual cell-to-cell contact, such as that observed for $M$. xanthus [43] and Lysobacter sp. [184], as opposed to a wolfpack mechanism involving the exudation of extracellular enzymes. If individual gliding predatory cells are capable of prey lysis, then lysis of bacteria by predatory bacteria is probably much more widespread and environmentally relevant than if it were limited to areas of high prey density, which would seem necessary to sustain the more extensively studied dense predatory swarms. Based on the results of this study, at least some predatory marine flavobacteria appear to readily colonize surfaces hosting susceptible prey communities and accelerate the regeneration of DOC, ammonium and presumably other macronutrients as well.

There are still substantial differences between the experimental conditions used in this study and the natural environments that flavobacteria inhabit. Prey communities in aquatic ecosystems can be both phylogenetically and metabolically diverse. Further study building on the approach used here could shed considerable light on the potential feedbacks between predation and a variety of factors including prey diversity and activity, biofilm architecture and predator inoculum size, on prey communities and their biogeochemical functions.

The disparate results for the two strains of predatory marine flavobacteria suggest that major differences in predatory biology and biogeochemical impact can exist between predators of relatively high phylogenetic similarity. Although the genera Olleya and Tenacibaculum cluster well apart in phylogenetic trees of the marine flavobacteria [112], most environmental studies of flavobacteria would fail to distinguish between them. Many studies have identified the phylum Bacteroidetes in general, and flavobacteria more specifically, as numerically important both in suspension and on particles in a variety of aquatic ecosystems $[122,126,157,168,185]$. However, much of that work has relied heavily on phylum- or class-specific quantitative-PCR primers and FISH probes 
$[118,167,186,187]$, which are unable to distinguish between marine and freshwater flavobacteria, much less smaller phylogenetic clades. Constraining the potential importance of flavobacterial predation in aquatic ecosystems would be greatly facilitated not only by further culture studies assessing the predatory capabilities of cultured and novel strains but also by the development and routine deployment of culture-independent molecular tools possessing at least genus-level phylogenetic resolution.

\section{Acknowledgments:}

The work in this chapter was supported by the Coastal Ocean and Ocean Life Institutes and the WHOI Academic Programs Office. I would like to thank Maya Bhatia, Mar Nieto-Cid and Krista Longnecker for assistance and advice in the use and maintenance of the Total Organic Carbon Analyzer. I am grateful to Matthew McIlvin, Daniel Rogers, James Saenz, Carolyn Buchwald and Ed Leadbetter for helpful discussions and to Cornelia Wuchter and Stefan Sievert for the use of FISH laboratory facilities and stock solutions. Matt McIlvin also provided guidance on the measurement

of ammonium measurements. I also would like to thank Paul Henderson for running the CHN analyses on the biofilm samples. 
Table 1: Experimental design.

\begin{tabular}{|c|c|c|c|c|c|c|c|c|}
\hline \multicolumn{3}{|c|}{ Time points: } & 1 & 2 & 3 & 4 & 5 & 6 \\
\hline Treatments: & $\begin{array}{c}\text { Prey } \\
\text { biofilm? }\end{array}$ & $\begin{array}{c}\text { Predator } \\
\text { cells? }\end{array}$ & \multicolumn{6}{|c|}{$\begin{array}{c}\text { \# of replicate tubes } \\
\text { sampled: }\end{array}$} \\
\hline Control & - & - & 3 & 3 & 3 & 3 & 3 & 3 \\
\hline Prey only & + & - & 3 & 3 & 3 & 3 & 3 & 3 \\
\hline Predator only & - & + & 5 & 3 & 3 & 3 & 3 & 3 \\
\hline Predator & + & + & 3 & 3 & 3 & 3 & 3 & 3 \\
\hline
\end{tabular}

Table 2: Results of 2-way ANOVA of fluid chemistry data

\begin{tabular}{|c|c|c|c|c|c|}
\hline $\begin{array}{l}\text { Predator, } \\
\text { Nutrient }\end{array}$ & Factor & Degrees of freedom & Mean Squares & F-statistic & $p$ \\
\hline & Time & 6 & 26.247 & 35.23 & 0 \\
\hline 2 & Treatment & 3 & 366.817 & 492.43 & 0 \\
\hline$\tilde{U}$ & Time * Treatment & 18 & 15.898 & 21.34 & 0 \\
\hline 寻 & Error & 52 & 0.745 & & \\
\hline 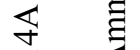 & Time & 5 & 17.776 & 66.93 & 0 \\
\hline Z & Treatment & 3 & 186.69 & 702.96 & 0 \\
\hline U & Time * Treatment & 15 & 8.372 & 31.52 & 0 \\
\hline$>$ & Error & 47 & 0.266 & & \\
\hline$\ddot{2}$ & Time & 6 & 21.516 & 10.72 & 0 \\
\hline 空 & Treatment & 3 & 255.722 & 127.45 & 0 \\
\hline$U^{2}$ & Time * Treatment & 18 & 9.848 & 4.91 & 0 \\
\hline & Error & 55 & 2.006 & & \\
\hline
\end{tabular}




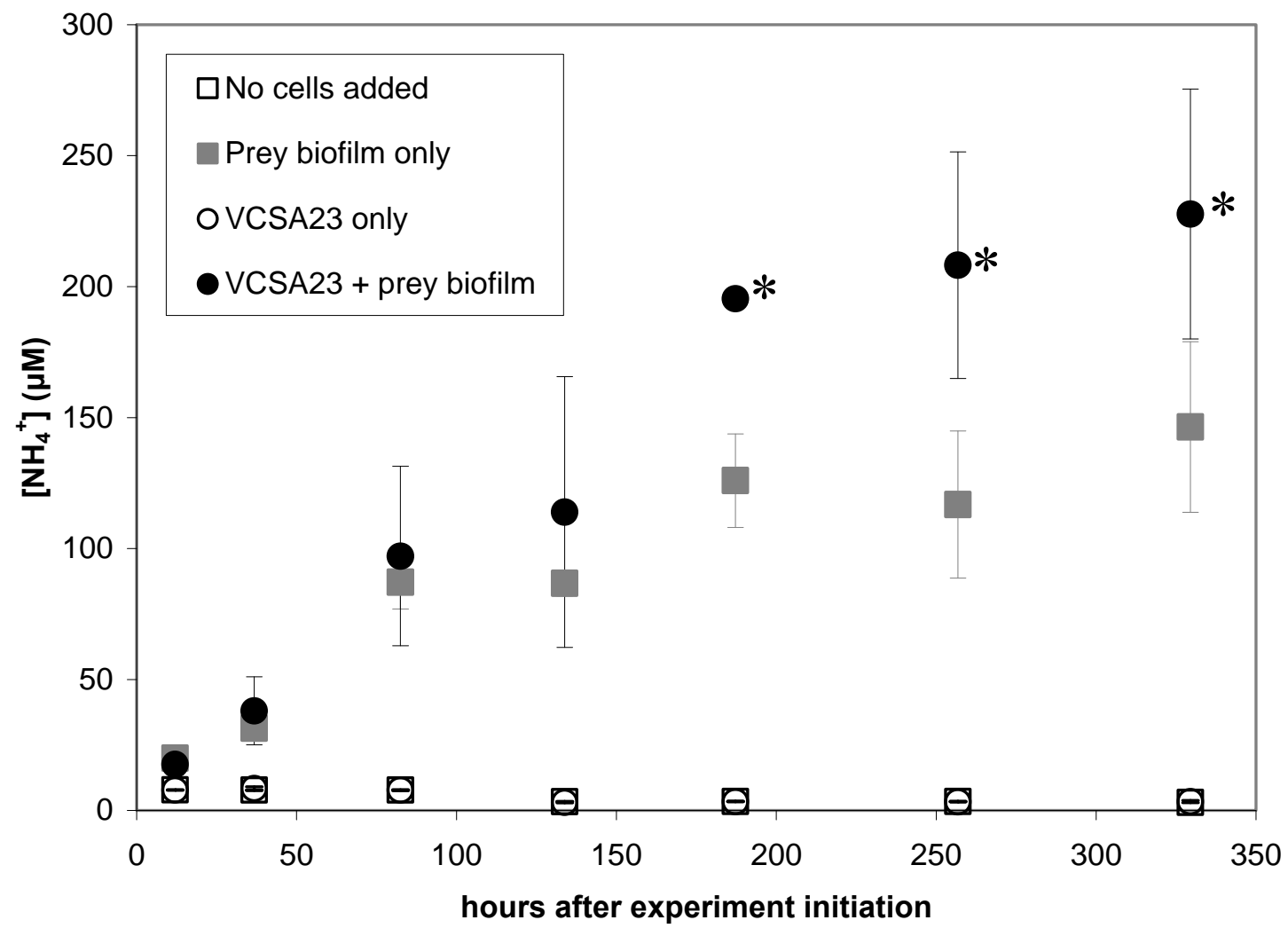

Figure 1: Graph plotting the average ammonium concentration for each experimental treatment during the VCSA23 experiment. Most points represent the average $\left[\mathrm{NH}_{4}{ }^{+}\right]$of three replicate tubes sacrificed at each time point from that treatment. At the last two time points (257 and 333 hours) two replicate VCSA23-only tubes are averaged and the final 333-hour time point only one replicate of the No cells added treatment was measured for $\left[\mathrm{NH}_{4}^{+}\right]$. The error bars show the standard deviation for the average. Points marked with asterisks were significantly different from their corresponding prey-only time points based on statistical analysis. 


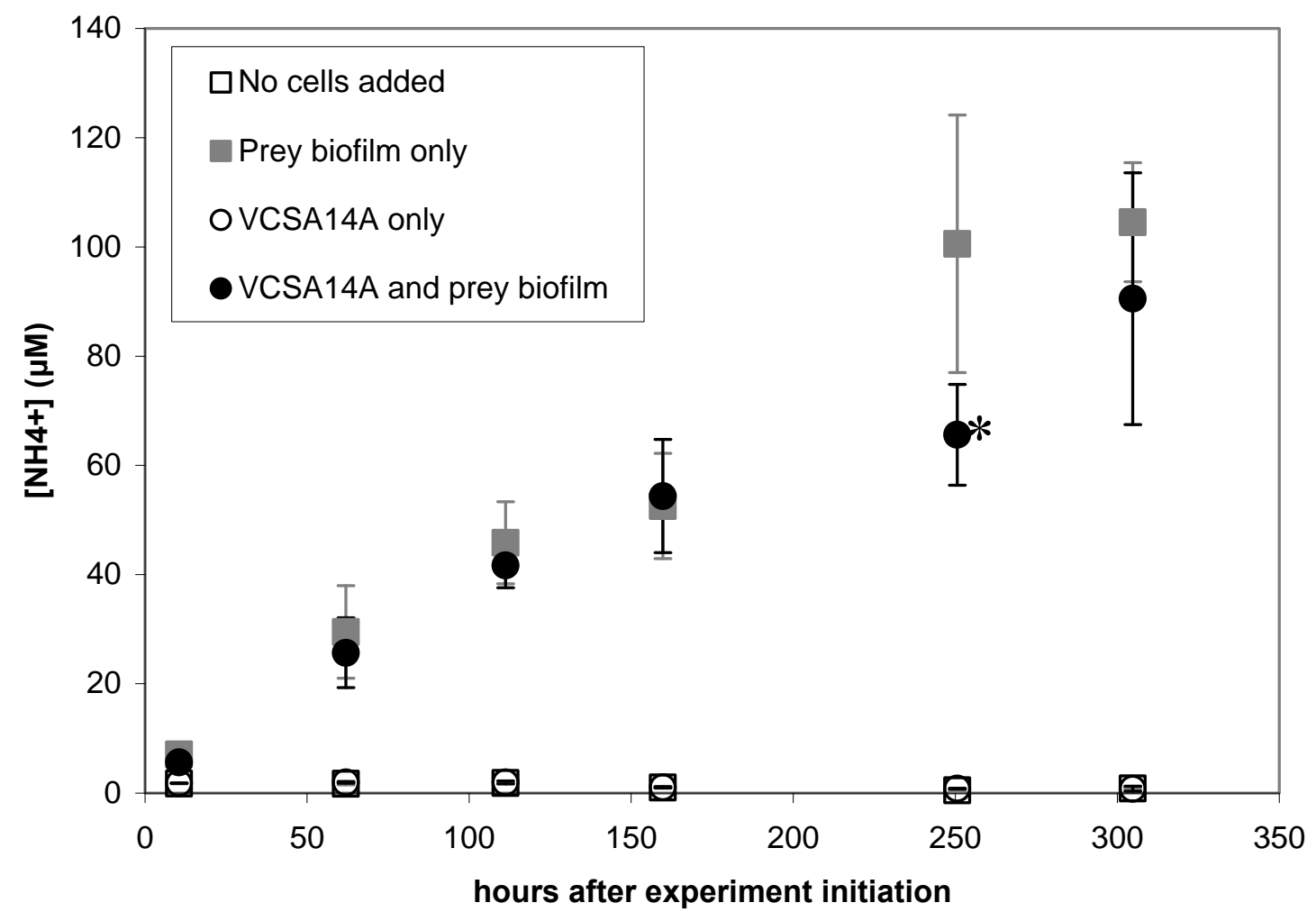

Figure 2: Graph plotting the average ammonium concentration for each experimental treatment during the VCSA14A experiment. Each point represents the average $\left[\mathrm{NH}_{4}{ }^{+}\right]$of three replicate tubes sacrificed at each time point from that treatment, except for the No cells added treatment at the 251-hour time point, at which only two replicates were measured for $\left[\mathrm{NH}_{4}^{+}\right]$. The error bars show the standard deviation for the average. The point marked with an asterisk was found to be significantly different from the corresponding prey-only time point based on statistical analysis. 


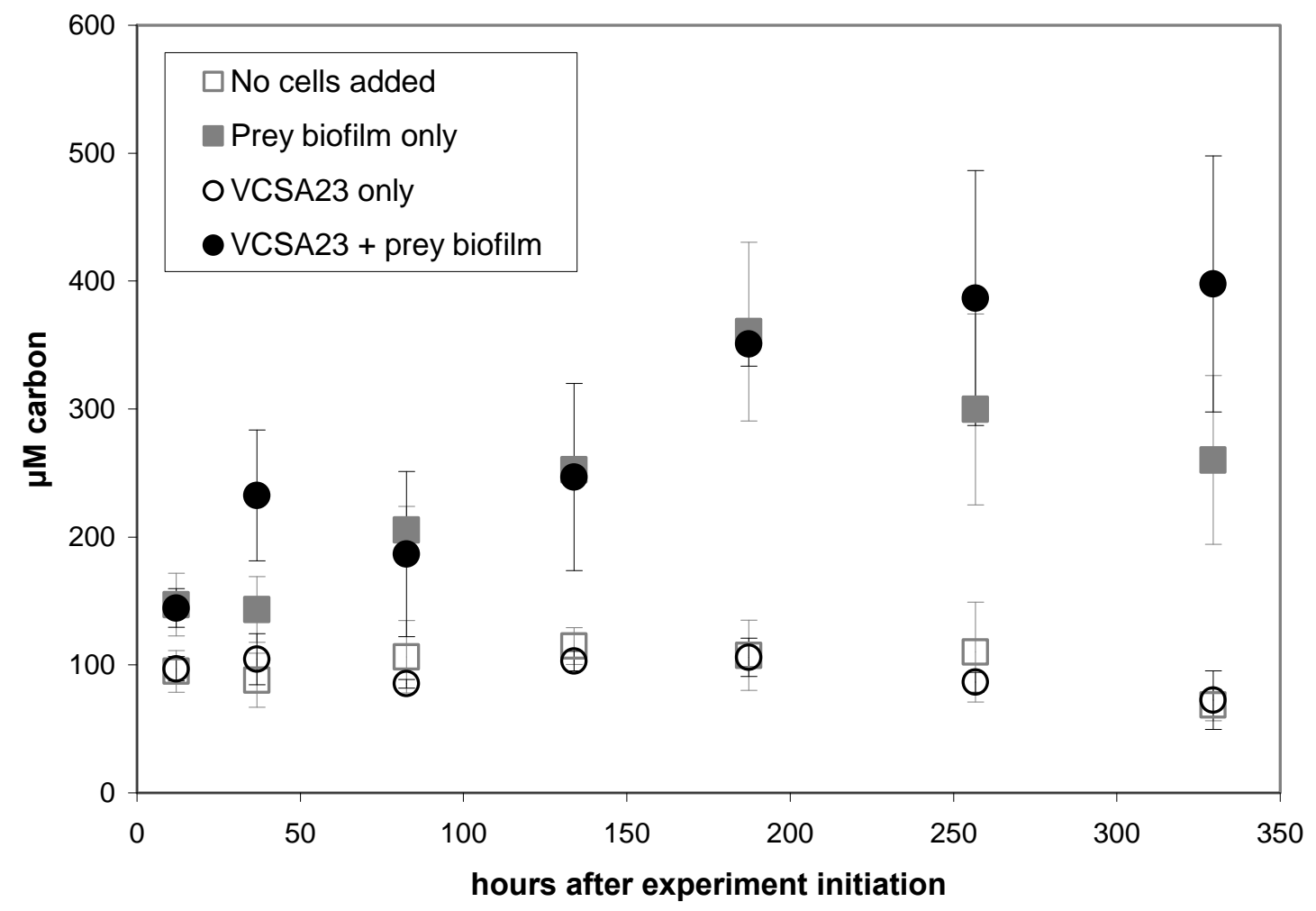

Figure 3: Graph showing dissolved organic carbon (DOC) in $\mu \mathrm{M}$ carbon during the course of the VCSA23 experiment. Each point represents the average of three replicates of that treatment sampled at each time point except for the 333-hour time point, at which two replicates were measured from the No cells added treatment. The error bars show the standard deviation of the three replicates. 


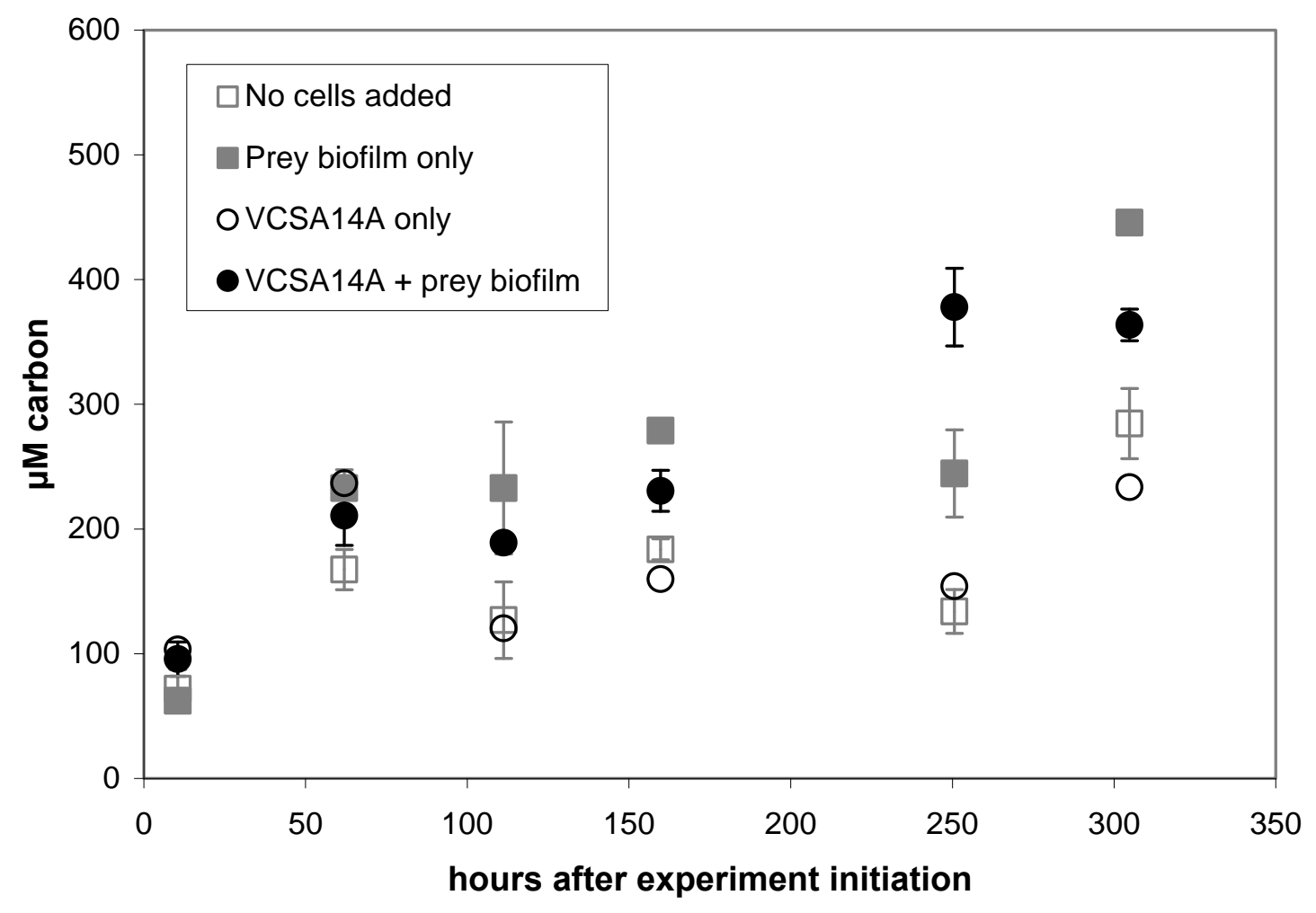

Figure 4: Graph showing DOC (in $\mu \mathrm{M}$ carbon) during the course of the VCSA14A experiment. Each point represents the average of the replicates of that treatment sampled at each time point. The error bars show the standard deviation of the replicates: three each for both 'Prey biofilm only' and 'VCSA14A + prey biofilm,' two for 'No cells added' and one for 'VCSA14A only.' 


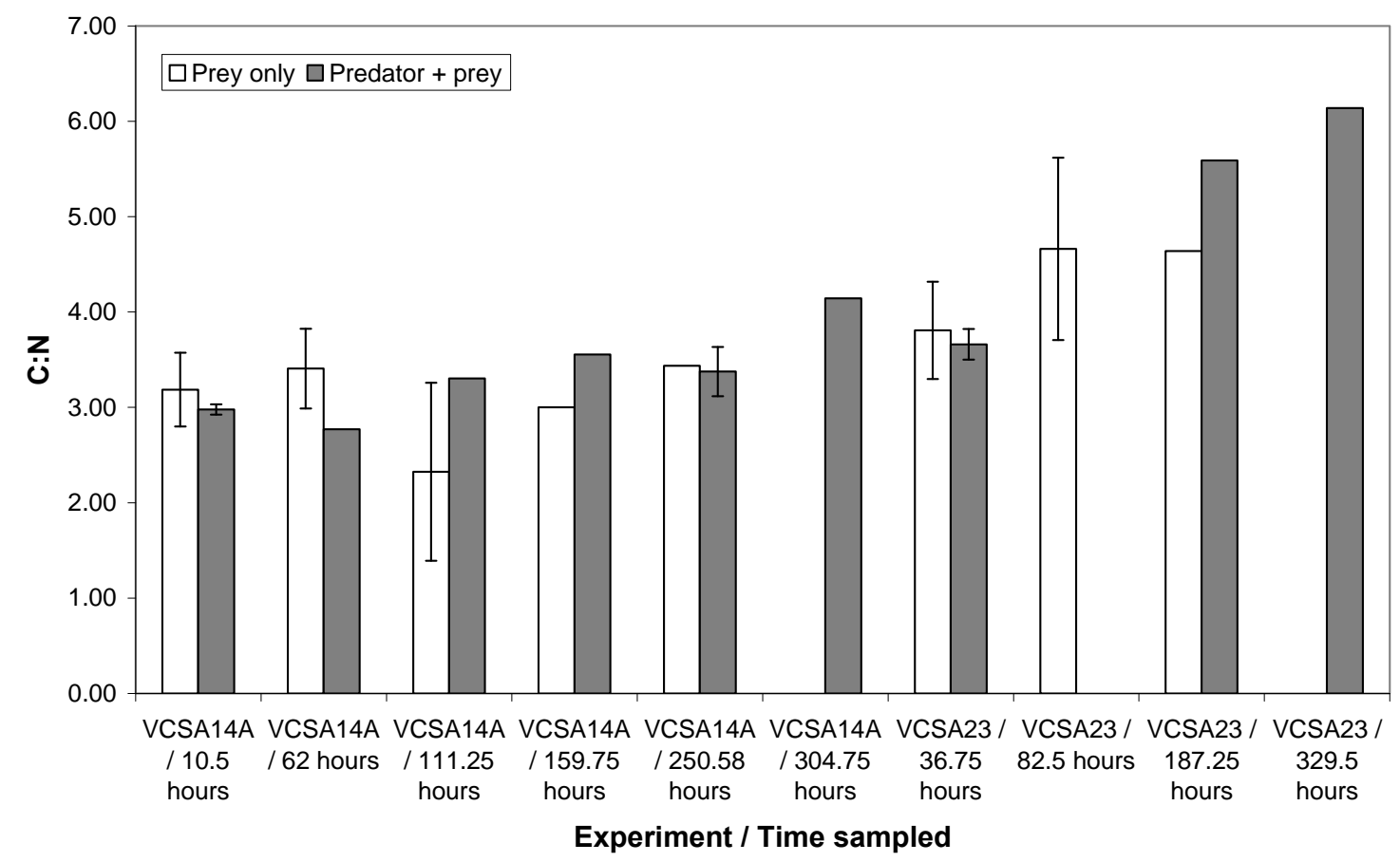

Figure 5: Graph of C:N for scraped biofilms from both experiments. White bars are for prey only slides - averaged by treatment when $\mathrm{C}: \mathrm{N}$ ratios from both replicates scraped were available. The sole exception is the 82.5-hour bar from the VCSA23 experiment, in which case the bar represents an average between two replicate measurements from the same slide's scrapings. Grey bars are for predator + prey slides and, when possible also represent averages of two replicate slides sampled at the same time point from the same experiment. The error bars show a single standard deviation around the mean. Bars without error bars are from a single replicate slide. 


\begin{tabular}{|c|c|c|}
\hline PREDATOR & PREY & TOTAL CELLS \\
\hline
\end{tabular}

Prey biofilm only; VCSA23 experiment; 257 hours

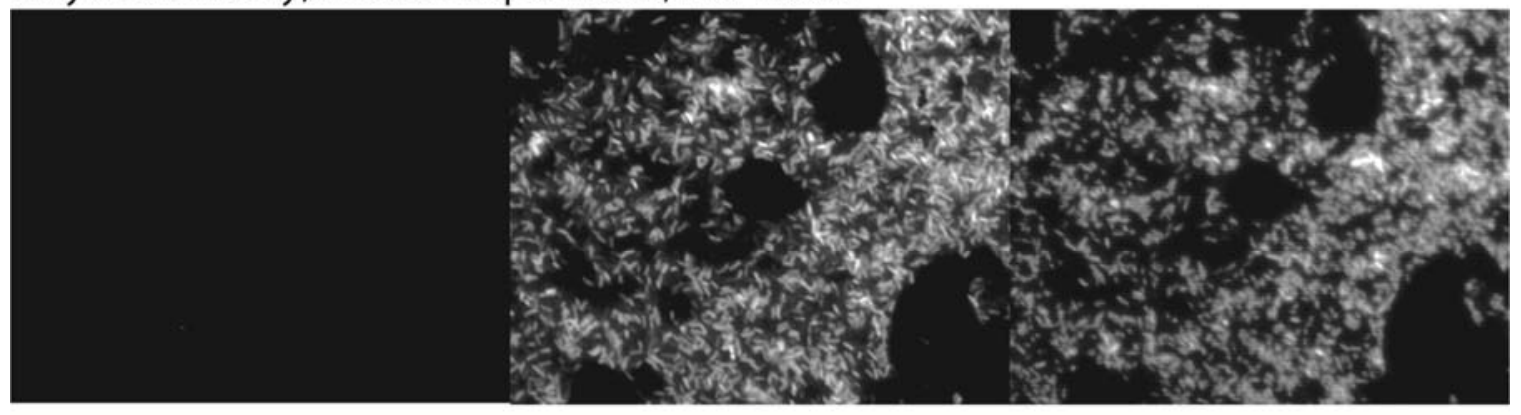

VCSA23 and prey biofilm; VCSA23 experiment; 257 hours

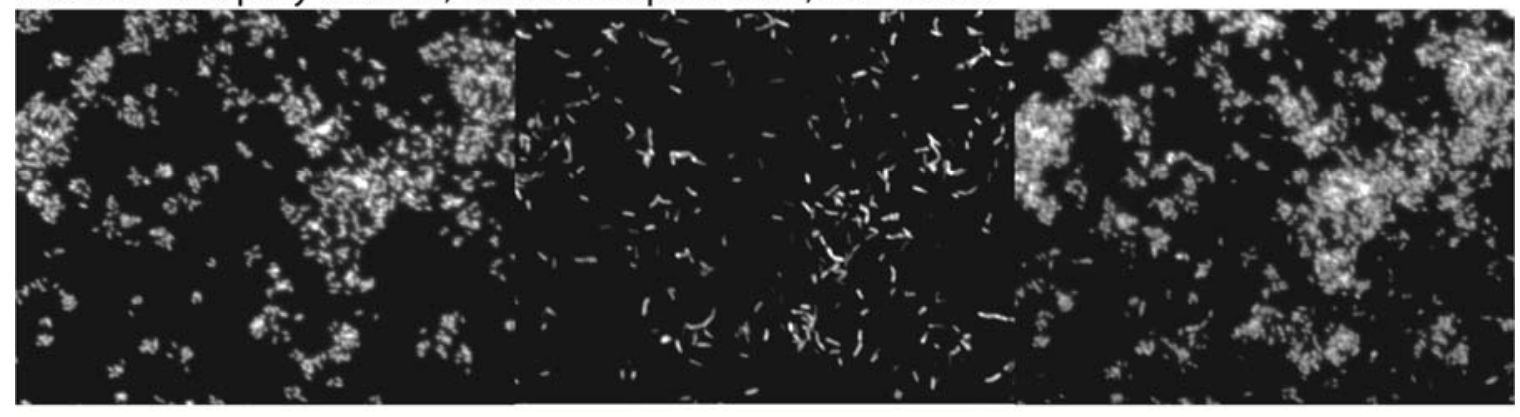

Prey biofilm only; VCSA14A experiment; 251 hours

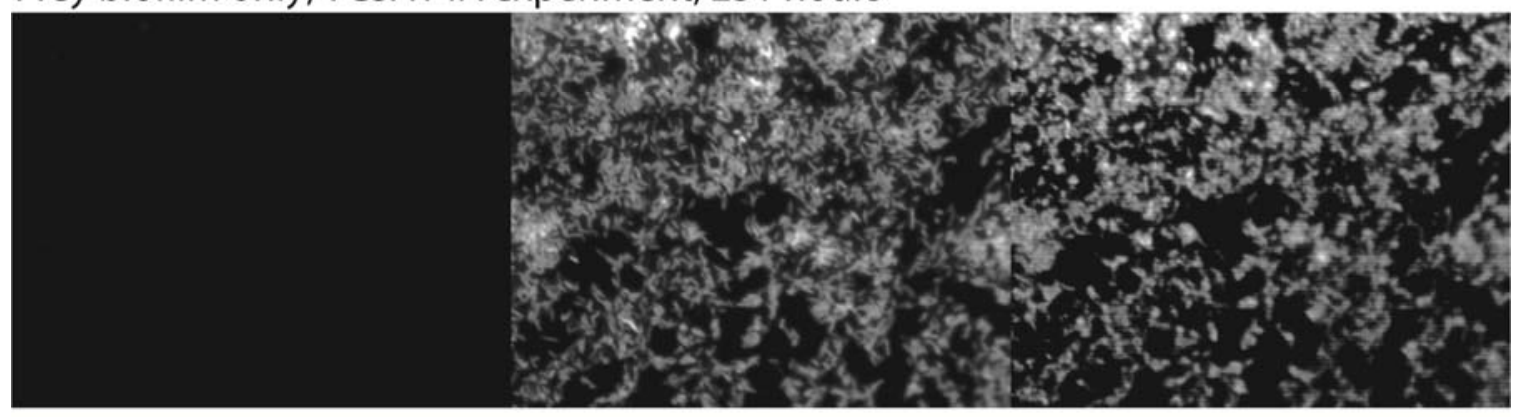

VCSA14A and prey biofilm; VCSA14A experiment; 251 hours

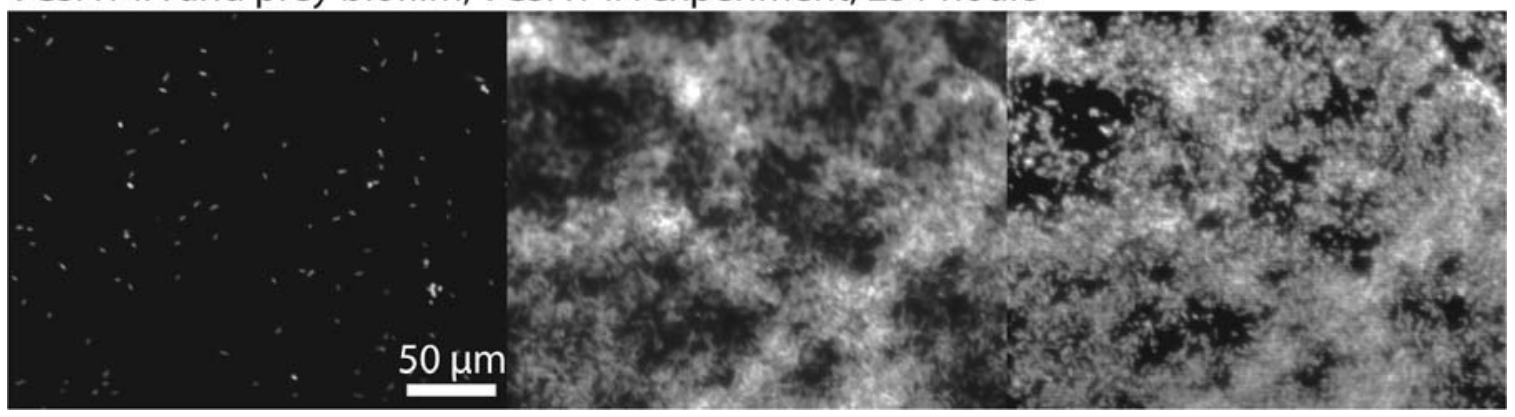

Figure 6: Set of representative fluorescence micrographs of fixed, dual-hybridized slides sampled from both experiments at about 250 hours. Each row of images contains the 
different fluorescence channels for a particular image location on the labeled treatment's slide, randomly selected from image data set. For each row of images, the left-most is the $\mathrm{Cy} 3$ channel showing the predator-specific FISH probe label. The middle image is the fluorescein channel showing the prey-specific GAM42A FISH probe label, and the rightmost image is the DAPI channel showing the total cells. All images have been processed in daime to increase contrast for display, and are at the same scale. The scale bar at the lower left of the figure is $50 \mu \mathrm{m}$. 
VCSA23 + prey biofilm; predator area/ $/ \mathrm{mm}^{2}$

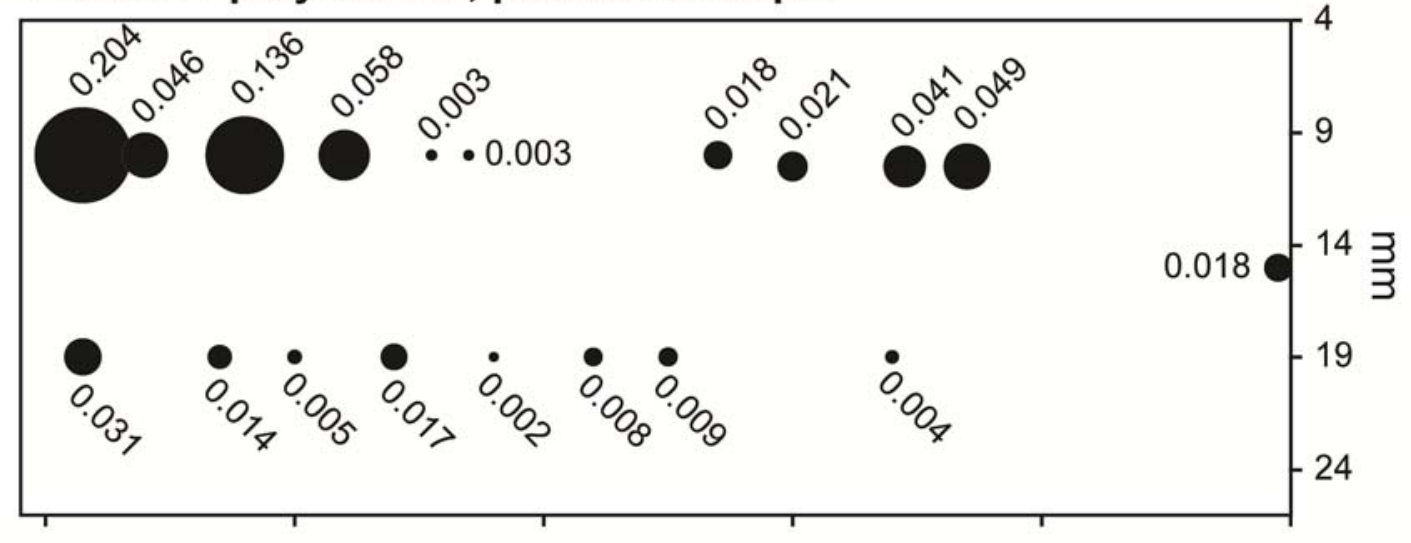

VCSA23 + prey biofilm; prey area/ $\mu \mathrm{m}^{2}$

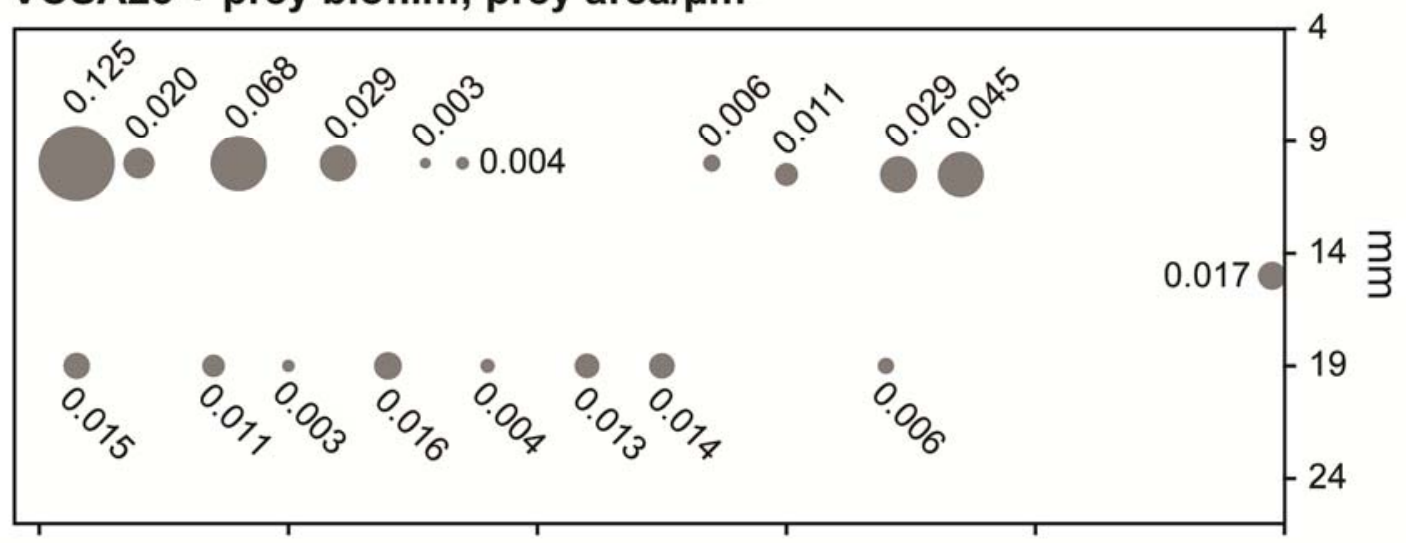

Prey biofilm only; prey area/ $\mu \mathrm{m}^{2}$

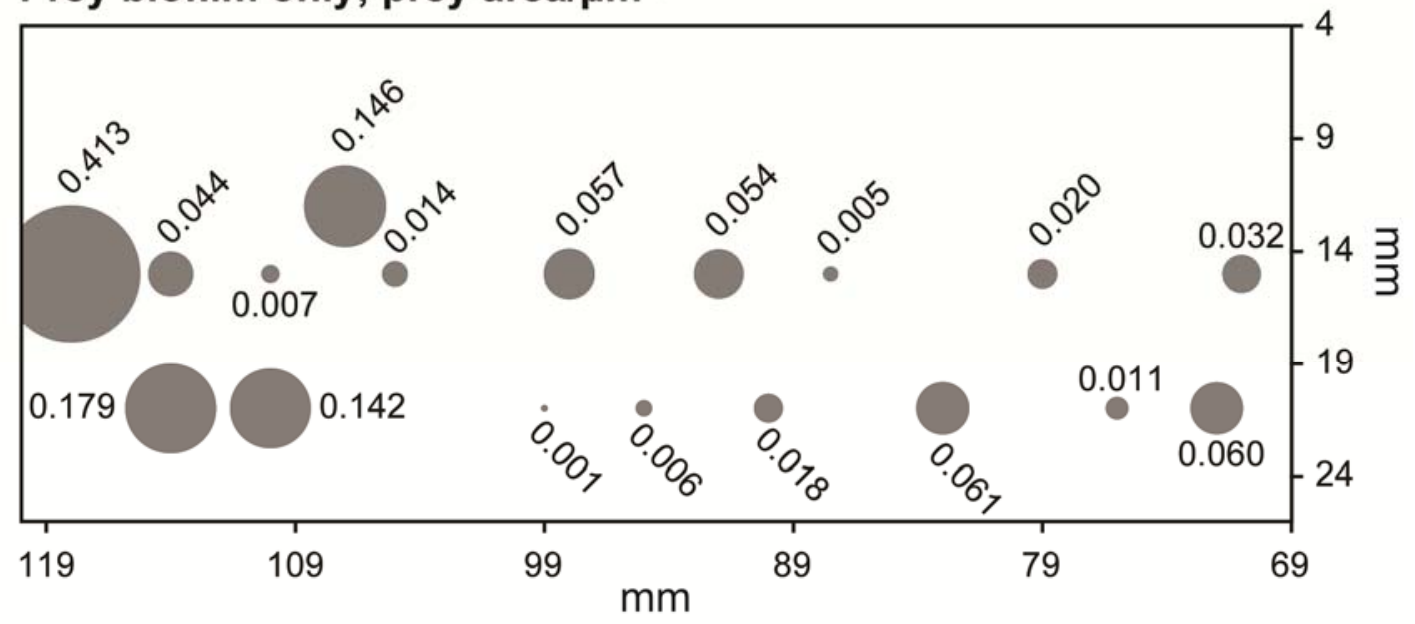

original slide orientation

AIR/WATER INTERFACE $\quad$ TUBE BOTTOM $\longrightarrow$


Figure 7 (preceding page): Maps of the VCSA23 + prey and corresponding Prey only biofilm slides sampled at 257 hours in the VCSA23 experiment, showing the spatial variability in predator and prey cell coverage area. For all three maps, the $\mathrm{x}$ - and $\mathrm{y}$ coordinates show the location of each image analyzed relative to the air/water interface (at left) and slides edges (top and bottom of each slide map). The cell area per square micrometer is represented by the diameter of the plotted circles and shown in the corresponding data labels. The top and middle maps show the predator and prey area coverage per square micrometer, respectively, for the VCSA23 + prey biofilm slide and the bottom map shows the prey area coverage per square micrometer for the Prey only biofilm slide. 
VCSA14A + prey biofilm; predator area/ $/ \mathrm{m}^{2}$

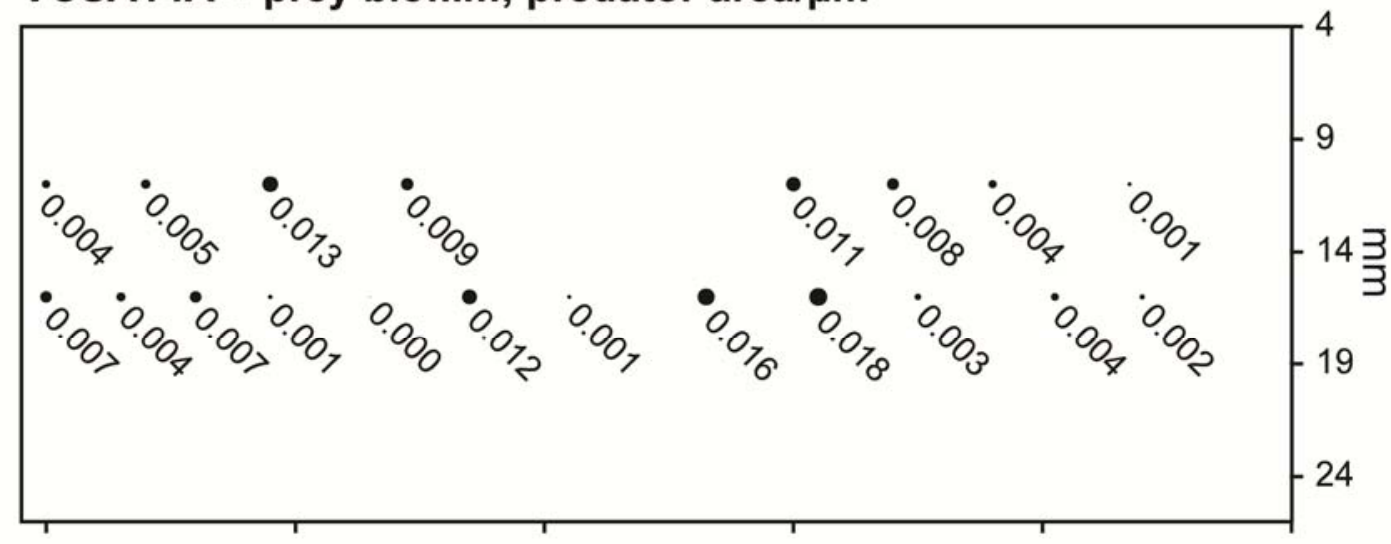

VCSA14A + prey biofilm; prey area $/ \mu m^{2}$

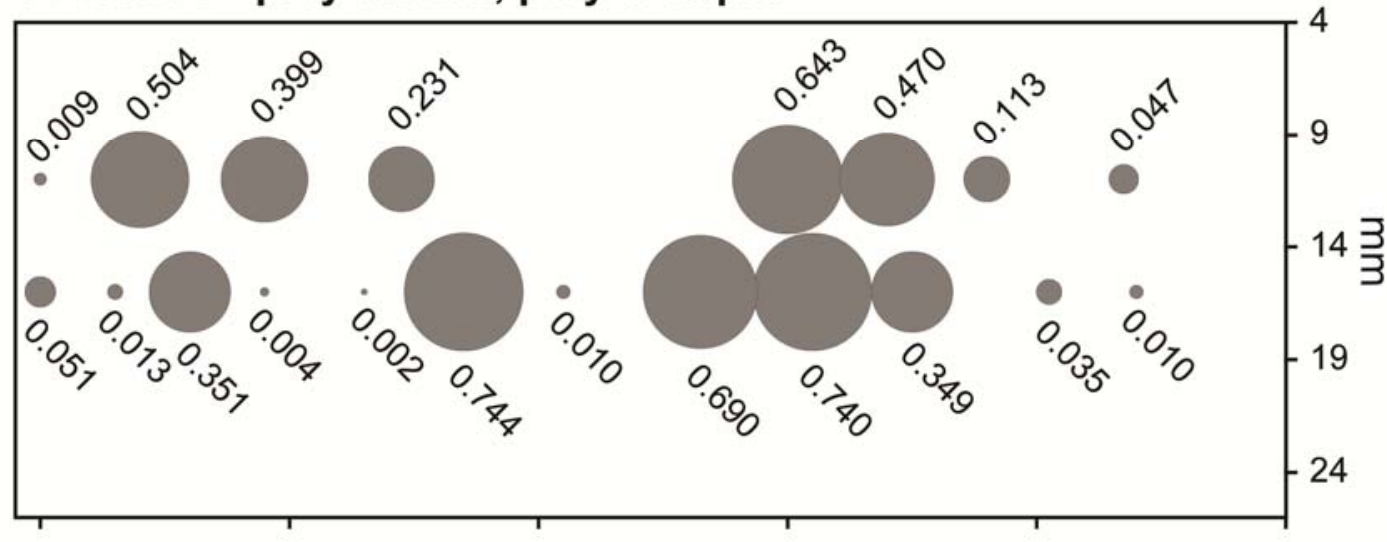

Prey biofilm only; prey area/ $/ \mathrm{m}^{2}$

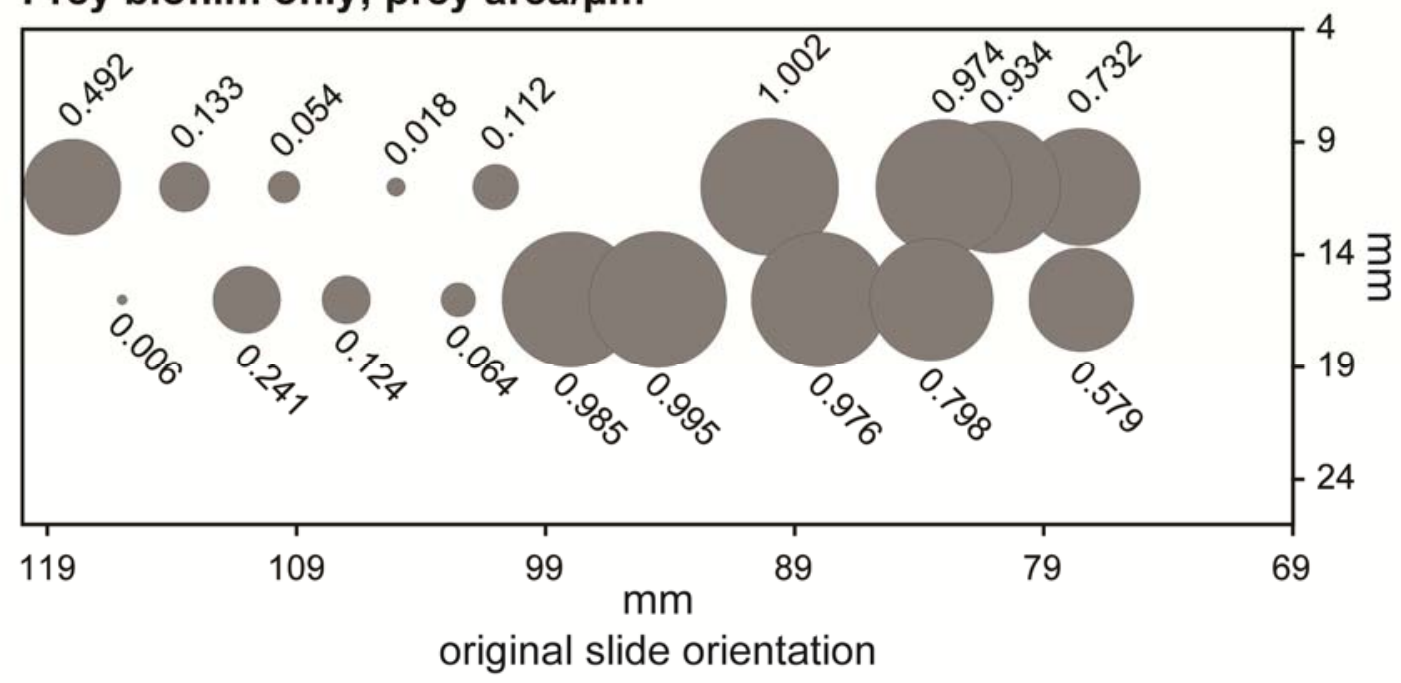


Figure 8 (preceding page): Map of the VCSA14A + prey and corresponding Prey only biofilm slides sampled at 251 hours in the VCSA14A experiment, showing the spatial variability in predator and prey cell coverage area. For all three maps, the $\mathrm{x}$ - and $\mathrm{y}-$ coordinates show the location of each image analyzed relative to the air/water interface (at left) and slides edges (top and bottom of each slide map). The cell area per square micrometer is represented by the diameter of the plotted circles and shown in the corresponding data labels. The top and middle maps show the predator and prey area coverage per square micrometer, respectively, for the VCSA14A + prey biofilm slide and the bottom map shows the prey area coverage per square micrometer for the Prey only biofilm slide. 


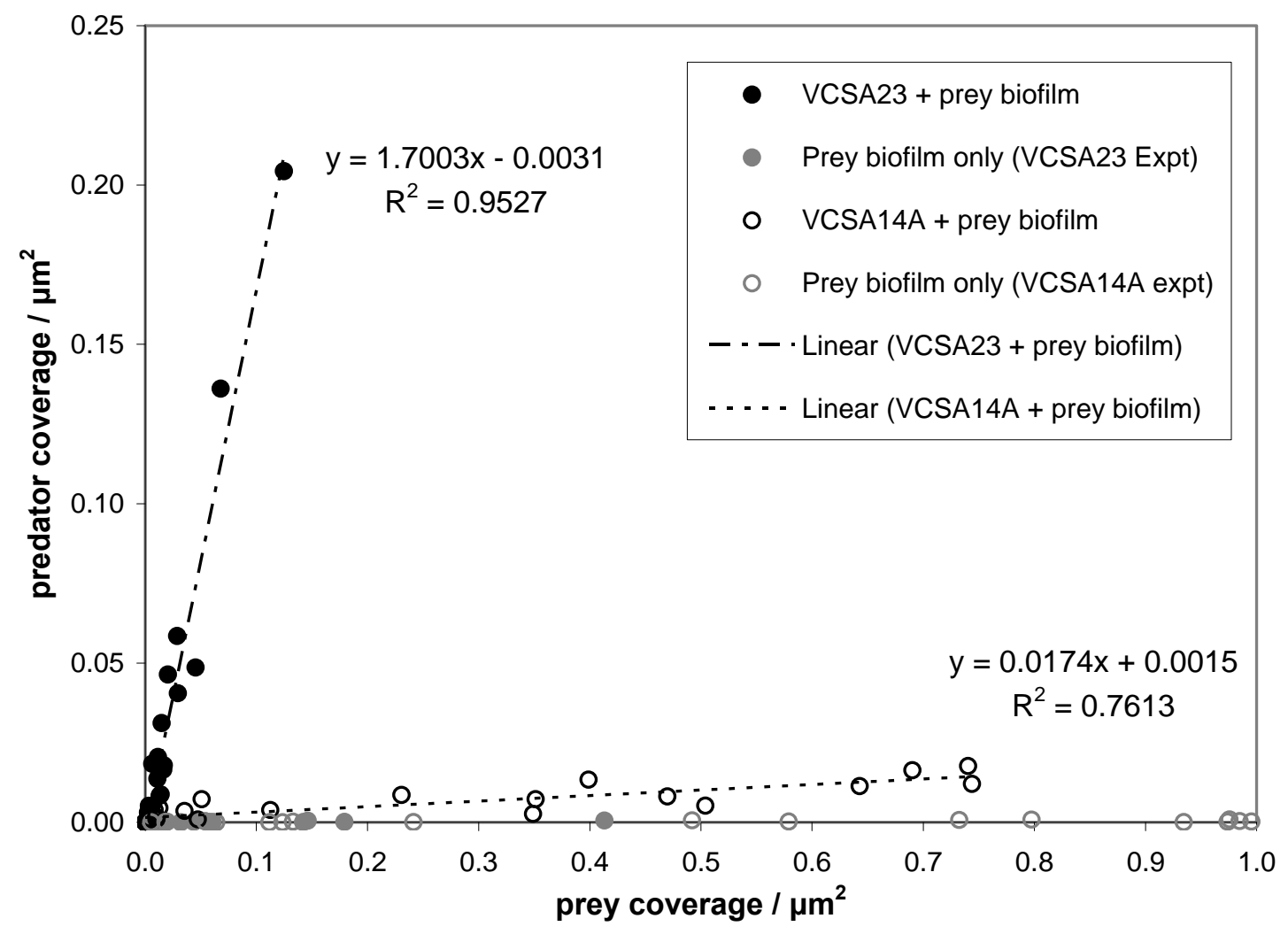

Figure 9: FISH-labeled predator cell area per square micrometer against FISH-labeled prey cell area per square micrometer. All points for a given treatment were calculated from a single replicate slide from that treatment fixed for microscopy and later dualhybridized. Each point was calculated from a single analyzed image. A value of 1.0 corresponds to complete cell coverage of the image - i.e., no gaps between cells at all and a value of 0.0 corresponds to no labeled cells detected. All slides from which the images plotted in this diagram were drawn were sampled at about 250 hours in each experiment. 


\title{
CHAPTER 5: IMPLICATIONS OF BACTERIOLYTIC PREDATION AS A LIFESTYLE OF MARINE FLAVOBACTERIA
}

\author{
Abstract \\ Marine flavobacteria are ecologically and metabolically diverse and ubiquitous in \\ marine environments. By necessity, many environmental studies of predatory \\ flavobacteria enumerate the total flavobacterial population. However, the ecological \\ niches known to be occupied by members of the marine flavobacteria include the \\ degradation of complex organic matter both on surfaces and in suspension, \\ photoheterotrophy, carbon-monoxide oxidation, animal pathogenesis, the lysis and \\ degradation of phytoplankton and, now, the predatory lysis of bacteria on surfaces. The \\ evidence for each of these ecological niches is distributed heterogeneously across the \\ marine flavobacterial phylogeny. This heterogeneous distribution of specialized \\ adaptations suggests that bacterial predation, at least, may have independently evolved \\ multiple times within the marine flavobacteria lineage.
}

\section{Introduction}

The marine flavobacteria, as they are referred to in this study, are composed of a collection of genera in the family Flavobacteriaceae of the phylum Bacteroidetes known to occur in marine environments, as opposed to the freshwater flavobacteria, which do not cluster amongst the marine genera in phylogenetic analyses [188]. As a group, the marine flavobacteria are ubiquitous in marine environments. Pure cultures have been isolated from habitats including sea water [111,189], suspended particles [112], pack ice [190,191,192], sediments [113], fish and other animals [94,95,110,193,194], and plant surfaces $[94,195,196]$. Culture-independent methods, including metagenomic and $16 \mathrm{~S}$ rRNA gene surveys and fluorescent in-situ hybridization (FISH), have detected substantial diversities of marine flavobacteria and confirmed their numerical significance in many of these environments $[118,119,120,122,126,167,169,172,197,198,199]$. 
Although a large number of the culture-independently detected marine flavobacteria are closely related to cultured representatives, phylogenetic analysis of environmental sequences often reveals whole branches without cultured representatives [197,200]. In addition, despite the fact that marine flavobacteria have been cultured from and detected in a wide variety of aquatic environments, their numerical importance in most cases remains incompletely constrained as a result of incomplete or overly broad specificity of the most commonly used molecular tools for their detection. For example, the FISH probe most commonly used to enumerate flavobacterial cells in the environment, CF319, was designed to target a broader set of taxa than just the marine flavobacteria [201], and does not hybridize to some marine flavobacterial groups [202]. On the other hand, an apparent bias against marine flavobacteria in clone libraries constructed using general bacterial primers has also been observed [122,203]. Taken together, these two methodological shortcomings suggest that current data on the abundance and diversity of marine flavobacteria may be underestimates.

\section{Ecology of marine flavobacteria}

Degradation of polymeric substances: Both cultured isolates and incubation experiments suggest that at least some marine flavobacteria are important in the assimilation and degradation of complex organic matter. Most cultured marine flavobacteria have been reported to possess the ability to hydrolyze at least some forms of polymeric organic compounds [188], including proteins such as gelatin or casein and polysaccharide such as starch, chitin or cellulose. In addition, both published genome sequences of marine flavobacteria harbor genes for substantial numbers of hydrolytic enzymes, suggesting the ability to utilize polymeric substrates $[130,131]$.

Incubation experiments with various substrate amendments have shown that the Cytophaga-Flavobacteria cluster as a group responds rapidly to organic carbon enrichment. For example, large increases in the abundance of several phylotypes of marine flavobacteria were observed after the amendment of natural bacterioplankton with protein, though no effect was observed after starch amendment [125]. The use of 
radioactively labeled organic substrates makes it possible to visualize individual cells that have assimilated the label via microautoradiography [204]. The application of this technique to coastal bacterioplankton showed that the Cytophaga-Flavobacteria cluster (as identified by FISH) was responsible for a disproportionately large amount of polymeric substrate assimilation relative to its abundance [205]. Chitin, $N$ acetylglucosamine (a chemical component of bacterial cell walls) and protein were all assimilated disproportionately by the Cytophaga-Flavobacteria cluster, while free amino acids were assimilated to a lesser degree than by other bacterial groups.

In addition, a frequently observed association of marine flavobacteria with phytoplankton blooms suggests they are involved in the degradation of phytoplanktonderived organic matter. Both mesocosm and field studies have shown that marine flavobacteria increase in relative abundance during phytoplankton blooms [157,183,206]. A quantitative survey of attached flavobacteria in the Southern Ocean also revealed a positive correlation between attached flavobacteria abundance and chlorophyll $a$ concentrations [185].

Particle- and surface-assocations: In addition to their numerical importance in the bacterioplankton, investigations of particle-associated communities have shown that marine flavobacteria can be enriched on particles relative to the suspended cell fraction [126,207,208]. Many cultured marine flavobacteria isolates have also been isolated from particles [112], the surfaces of plants and animals [109,194,195,196] and sediments $[113,209,210]$, including the strains described in this thesis.

A colonization study using diatom detritus exposed to natural bacterioplankton communities, filtered to remove particles, showed that a wide diversity of marine flavobacteria can rapidly colonize particles [128]. Interestingly, most of the phylotypes observed to colonize the particles were detectable in the original bacterioplankton communities, suggesting that a substantial proportion of the suspended flavobacterial community in the Southern Ocean can grow both in and out of association with particles.

Photoheterophy and lithotrophy: Metagenomic and PCR surveys of sea water and full genome sequencing of Polaribacter dokdonensis MED152 have detected genes 
from marine flavobacteria coding for the production of proteorhodopsin [131,211,212], thought to be a light-driven transmembrane pump [213]. A sea water incubation experiment and culture experiments using Dokdonia sp. MED134 and other strains have shown that at least some proteorhodopsin-containing marine flavobacteria grow to higher densities when exposed to light than when kept in the dark [214,215]. This strongly suggests that at least some marine flavobacteria have the ability to harvest light energy to increase their growth efficiency, a metabolic capability that could be extremely advantageous in oligotrophic marine settings.

In addition, some marine flavobacteria may have the ability to oxidize carbon monoxide. The sequencing of the whole genome of Gramella forsetii revealed the presence of two operons encoding aerobic carbon monoxide hydrogenases [130], which raises the possibility that marine flavobacteria may play a role in the cycling of carbon monoxide as well. No carbon monoxide hydrogenases were reported from the genome of Polaribacter sp. MED152 [131].

Pathogenesis: Five species belonging to the genus Tenacibaculum were isolated from diseased fish and have been confirmed as pathogens: T. maritimum, originally isolated from diseased bream [109] and now known to infect a wide variety of marine fishes [216]; T. ovolyticum, shown to infect halibut eggs and larvae [110]; T. soleae, a pathogen of sole [193]; and T. discolor and T. gallaicum, pathogens of sole and turbot, respectively [95]. T. maritimum and the other pathogens of adult fish infect the outer skin of susceptible fish, causing lesions and erosion of mouth, fins and tail by breaking down the host tissue [216]. Another species, T. aiptasiae was isolated from a diseased sea anemone, although its pathogenicity was not confirmed [217]. In addition to these pathogenic Tenacibaculum species, several of the other described members of the genus were cultured from close association with animals or macrophytes. T. adriaticum, T. crassostreae, T. litopenaei, T. mesophilum and T. amylolyticum were isolated from a bryozoan, an oyster, a shrimp mariculture pond, a sponge and a macroalga, respectively [94]. 
Algal-lysis: Diverse marine flavobacteria strains have been reported to lyse eukaryotic phytoplankton, principally in studies focused on the control of species responsible for red tides $[82,83,141,142]$. Such a lifestyle could easily be termed predatory, assuming that growth of the algal-lytic flavobacteria is coupled to algal lysis. Unfortunately the potential for growth of algal-lytic bacteria at the expense of susceptible phytoplankton is often left unexplored in such studies. In at least one exception to this trend, an algal-lytic marine flavobacterium Cytophaga sp. A5Y, isolated from a bloom of the red-tide-causing diatom Skeletonema costatum, was reported to increase in numbers as it lysed susceptible phytoplankton [83]. Interestingly, algal lysis did not occur until the flavobacteria had reached a density of $10^{6}$ cells $/ \mathrm{mL}$, suggesting that up to that point the lytic cells were growing non-predatorily on algal exudates. In addition, direct cell-to-cell contact was observed to be associated with algal lysis for this strain [83].

In another case, an algal-lytic marine flavobacterium only released algal-lytic compounds when grown under high-nutrient conditions in the absence of the toxic dinoflagellate Alexandrium catenella it was originally isolated from [82]. When returned to oligotrophic conditions in coculture with the dinoflagellate, the strain did not produce algal-lytic compounds and instead grew symbiotically.

Only one algal-lytic marine flavobacterium has been formally described to date, the non-motile Kordia algicida, which was isolated from a bloom of the red-tide-causing diatom Skeletonema costatum and showed lytic activity towards another diatom, a dinoflagellate and a chromalveolate [141]. However, little has been reported to date with regard to K. algicida's lytic mechanism or growth in the presence of susceptible algae. Other algal-lytic strains reported but not extensively described belong to the genera Aquimarina, Flavobacterium and Tenacibaculum [142].

Bacteriolytic predation: In this thesis, two separate lineages within the marine flavobacteria have been shown to include members capable of growing predatorily on other bacteria isolated from coastal sediments (Ch. 2). One of the two lineages, the genus Tenacibaculum, also includes fish pathogens and incompletely described algal-lytic strains. In fact, two pathogenic Tenacibaculum species, T. discolor and T. gallaicum, 
were found to possess bacteriolytic predatory capability as well. In addition, the widespread fish pathogen T. maritimum was reported to lyse dead bacterial cells in its original description [109]. Taken together, these observations suggest that more species in the genus Tenacibaculum likely possess bacteriolytic capabilities. Bacteriolysis may represent a refuge for pathogenic Tenacibaculum in between the colonization of susceptible animal hosts, which could explain sudden infections of fish populations by Tenacibaculum without a known pathogen source [216].

In contrast to the generally sediment- and animal-associated nature of cultured Tenacibaculum species, the other lineage including novel predatory members is the genus Olleya, the type species of which was isolated from suspended particles in the Southern Ocean [112]. O. marilimosa, the type species for the genus, showed no predatory capabilities while the closely related novel strains, Olleya sp. VCSA23 and VCSM12, were capable of predation on a broad array of prey microorganisms. The potential predatory capability of a newly described species in the genus, O. aquimarina [218], which was isolated from sea water, is currently unknown.

Taken together with existing knowledge of the ecological potential of marine flavobacteria as a group, the predatory lifestyle has clear connections to algal lysis and pathogenesis. Arguably, the main difference between these ecological phenomena lies in the target of lytic action. In all three cases, a marine flavobacterium has become adapted to destroy cells of other organisms, presumably to gain access to the wealth of polymeric organic substances and other substrates contained within living biomass. Regardless of the target, cell lysis requires the recognition and colonization of a surface populated by susceptible cells, some chemical mechanism for compromising the integrity of prey (or host) cells and the hydrolytic and assimilatory capability to utilize some portion of the resulting organic matter.

\section{Constraining the predatory lifestyle}

The predatory marine flavobacteria described in this thesis share a number of characteristics, which may be helpful in considering how widespread a bacteriolytic 
predatory lifestyle might be amongst marine flavobacteria. Of course, it should be noted that these characteristics are certainly not diagnostic of predatory flavobacteria, since the one non-predatory species studied in this thesis, O. marilimosa, shares them as well. They include gliding motility and an organic nitrogen requirement (Ch. 2).

Gliding motility would seem to be a prerequisite for the type of surfaceassociated, coordinated predatory growth habit observed for all five predatory strains in this thesis. In fact, a survey of the descriptive literature of marine flavobacteria reveals that gliding motility is highly heterogeneously distributed across the genera. For many genera, all or most of their described species have been reported to possess gliding motility, including Olleya, Formosa, Mesoflavibacter, Algibacter, Winogradskyella, Tenacibaculum, Gelidibacter, Cellulophaga, and Aquimarina. However, they do not form a monophyletic group to the exclusion of the genera for which all or most of the described species have not been observed to exhibit gliding motility, including Lacinutrix, Bizionia, Polaribacter, Kordia, Psychroserpens, Lutibacter and Gillisia. This lack of phylogenetic separation between genera possessing gliding motility and those lacking it suggests that the characteristic has either been frequently lost, frequently gained or both. Given that a physiological capability as sophisticated as gliding motility is the result of 15 interacting genes [131] and assuming that its lack is due to a loss of at least some of the genetic machinery in question, it seems unlikely to have either been laterally transferred or independently evolved many times. Instead, the distribution of gliding motility suggests that when marine flavobacteria enter an ecological niche in which motility is unnecessary, they lose the capability.

Interestingly, the algicidal species $K$. algicida is amongst the marine flavobacteria previously reported to lack gliding motility. This suggests that if K. algicida is predatory, it must carry out a predatory lifestyle that does not require surface motility. Possibilities might include either releasing lytic factors into solution or adhering to prey organisms upon chance contacts. The opposing alternative, of course, is that K. algicida and other marine flavobacteria possess algicidal capabilities for non-nutritional reasons. Potentially, 
algicidal factors could be expressed in a way analogous to more commonly known antibiotics.

In addition to the fact that alternative predatory mechanisms may exist in the absence of gliding motility, another complicating factor to attempting to use gliding motility as a potential constraint on predatory capability has emerged from full genome analyses. $P$. dokdonensis is amongst the species described as lacking gliding motility, as is the case for all described species in the genus Polaribacter, which clusters consistently and monophyletically with the genus Tenacibaculum [219]. Somewhat surprisingly, the sequencing of the full genome of $P$. dokdonensis MED152, a different strain than the fully described type strain for that species, revealed a full set of gliding motility genes [131]. Another marine flavobacterium whose full genome has been sequenced, $G$. forsetii, possesses all but one of the genes associated with gliding motility, suggesting that it may have lost gliding motility in recent evolutionary history [130]. However, genes for sensory systems were observed in association with some of the gliding motility genes, indicating that the expression of gliding motility could be dependent on environmental stimuli. If this is the case more broadly, any number of marine flavobacteria thought to lack gliding motility might only be non-motile under culture conditions.

A requirement for organic nitrogen may be a more feasible criterion for predicting potentially predator flavobacteria. Hypothetically, a bacterium that is adapted to graze on cellular biomass is unlikely to find itself in a nitrogen-limiting environment while growing. As with other predators [22], respiration of prey biomass should leave a surplus of nitrogen. Therefore, fully adapted predators would have the luxury of abandoning or at least down-regulating inorganic nitrogen transporters, relative to close relatives more adapted to a non-predatory, more conventionally heterotrophic lifestyle. Although the ability to assimilate inorganic nitrogen has not been explicitly assessed for most described marine flavobacteria species, four Tenacibaculum species as well as those studied in this thesis have been reported as requiring organic nitrogen sources. In addition, K. algicida was reported to require organic nitrogen as well. 
In any case, there is a definite limit to what can be hypothesized based on existing literature. Fundamentally, in order to better constrain the potential distribution of predatory lifestyles amongst marine flavobacteria, more existing cultures need to be assessed for bacteriolytic growth and more novel cultures need to be obtained. The nonobligate nature of flavobacterial predation suggests it is quite possible for a substantial number of predatory marine strains to be present in culture collections already. Since non-obligate predators lyse prey cells extracellularly, they actually assimilate complex organic matter and are able to grow on it in the absence of living prey.

Although testing of existing culture collections will be informative, it will be difficult to connect the test results to the original environment, given the possibility that the strains' predatory biology might have evolved significantly away from the wild-type while in laboratory culture. For example, Micavibrio admirandus has been reported to have lost its initially narrow prey specificity over time in the laboratory [63]. The mechanism by which this broadening of prey specificity occurred is unknown. Part of the disparity between the prey specificity tests in this thesis (Ch. 2-3) could be explained by a similar broadening in prey specificity in culture. In another study, Myхососcus xanthus cultures were successfully subjected to experimental evolution in the laboratory to increase their foraging proficiencies [176]. There may be other unintended selective pressures inherent in the culture protocols used to enrich and isolate surface-associated predatory bacteria as well. Therefore, when the goal is to assess the environmental role of predatory marine flavobacteria, an emphasis should be placed on culturing novel strains, exploring more environmentally relevant culture conditions and minimizing as much as possible the exposure of isolates to laboratory selection pressures.

\section{Evolution of surface-associated predatory bacteria}

The study of the distribution of predatory activity amongst such a metabolically and ecologically diverse group as the marine flavobacteria offers a thus far unique opportunity to explore the evolution of surface-associated predation. As noted previously (Ch. 1), the general life habit of gliding motility, social coordination and prey lysis by 
potentially cell-contact-mediated mechanisms is known to occur in six distinct bacterial groups: the myxobacteria ( $\delta$-Proteobacteria), the genera Herpetosiphon (Chloroflexi), Lysobacter ( $\gamma$-Proteobacteria), Saprospira, Olleya and Tenacibaculum (Bacteroidetes). The large phylogenetic distance between these groups strongly suggests that they have developed similar growth habits via convergent evolution.

In fact, it has been hypothesized that gliding predators may be easily able to move back and forth evolutionarily between scavenging, saprophytic lifestyles and more aggressive predatory or parasitic ones [14]. Such a case seems plausible, since essentially similar hydrolytic capabilities to degrade proteins and other polymeric macromolecules would be advantageous for both scavenging saprophytes and predators.

In contrast to a group like the myxobacteria, which are uniformly predatory and do not appear to include any non-predatory species [34], the predatory marine flavobacteria appear to be heterogeneously mixed with non-predatory relatives. In addition, the marine flavobacteria include at least some lytic species that do not appear to lyse in a strictly predatory manner, such as the algal-lytic strain AMA-01 [82]. This suggests that different lineages within the flavobacteria are in the process of developing and losing predatory capability, which could greatly facilitate both evolutionary studies of predatory bacteria and the development of culture-independent markers for predatory activity. 


\section{APPENDIX}

\section{Media recipes:}

DNb25 (for 1 liter)

715 mL Artificial Sea Water,

autoclaved separately

$185 \mathrm{~mL}$ deionized water

$0.8 \mathrm{~g}$ nutrient broth

0.5 g casamino acids

0.1 g yeast extract

$\mathrm{pH}$ adjusted to about 7.2, combined

after cooling with $100 \mathrm{~mL}$ of $\mathrm{Ca} / \mathrm{Mg}$

stock solution

1/10 LB25 (for 1 liter)

715 mL Artificial Sea Water,

autoclaved separately

$285 \mathrm{~mL}$ deionized water

1.55 g Difco Luria Broth base

$\mathrm{pH}$ adjusted to about 7.2, combine

after cooling

ASW25 (for 1 liter)

$715 \mathrm{~mL}$ Artificial Sea Water

$285 \mathrm{~mL}$ deionized water

$1 \mathrm{~g} \mathrm{CaCl}_{2} * 2 \mathrm{H}_{2} \mathrm{O}$

$\mathrm{pH}$ adjusted to about 7.2 and

autoclaved 20ppt ASW-HEPES buffer (for 1 liter)

$570 \mathrm{~mL}$ Artificial Sea Water

$410 \mathrm{~mL}$ deionized water

$20 \mathrm{~mL}$ 0.5 M HEPES $\mathrm{pH}=7.2$

$1 \mathrm{~g} \mathrm{CaCl}_{2} * 2 \mathrm{H}_{2} \mathrm{O}$

$\mathrm{pH}$ adjusted to about 7.2 and

autoclaved

BD1 broth (2 g/L sugar; for 1 liter)

$715 \mathrm{~mL}$ Artificial Sea water, autoclaved separately with 20 $\mathrm{mL}$ 0.5 M HEPES $\mathrm{pH}=7.2,1$ $\mathrm{mL}$ trace metals solution and $2 \mathrm{~g}\left(\mathrm{NH}_{4}\right)_{2} \mathrm{SO}_{4}$

$228 \mathrm{~mL}$ deionized water

$1 \mathrm{~g} \mathrm{NaH}_{2} \mathrm{PO}_{4}$

$\mathrm{pH}$ adjusted to about 7.2 and autoclaved, combine after cooling and add $22.2 \mathrm{~mL}$ filters-sterilized $20 \%$ (D)glucose $/ 2.5 \%$ sodium citrate stock solution $(\mathrm{w} / \mathrm{v})$ 
BD1 agar (0.01 g/L sugar; for 1 liter)

$715 \mathrm{~mL}$ Artificial Sea water, autoclaved separately with 20 $\mathrm{mL}$ 0.5 M HEPES $\mathrm{pH}=7.2,1$ $\mathrm{mL}$ trace metals solution and $2 \mathrm{~g}\left(\mathrm{NH}_{4}\right)_{2} \mathrm{SO}_{4}$

$228 \mathrm{~mL}$ deionized water

$15 \mathrm{~g}$ agar

$1 \mathrm{~g} \mathrm{NaH}_{2} \mathrm{PO}_{4}$

$\mathrm{pH}$ adjusted to about 7.2 and autoclaved, combine after cooling and add $111 \mu \mathrm{L}$ filters-sterilized 20\% (D)glucose $/ 2.5 \%$ sodium citrate stock solution $(\mathrm{w} / \mathrm{v})$

LB25 (for 1 liter)

$715 \mathrm{~mL}$ Artificial Sea Water $285 \mathrm{~mL}$ deionized water 15.5 g Difco Luria Broth base $\mathrm{pH}$ adjusted to about 7.2 and autoclave WAT agar (for 1 liter) $715 \mathrm{~mL}$ Artificial Sea Water $265 \mathrm{~mL}$ deionized water $20 \mathrm{~mL} 0.5 \mathrm{M}$ HEPES $\mathrm{pH}=7.2$ $15 \mathrm{~g}$ agar $1 \mathrm{~g} \mathrm{CaCl}_{2} * 2 \mathrm{H}_{2} \mathrm{O}$ $\mathrm{pH}$ adjusted to about 7.2 and autoclaved
Phosphate Buffer Saline (in 1 liter deionized water)

$8 \mathrm{~g} \mathrm{NaCl}$

$0.2 \mathrm{~g} \mathrm{KCl}$

$1.15 \mathrm{~g} \mathrm{Na}_{2} \mathrm{HPO}_{4} * 7 \mathrm{H}_{2} \mathrm{O}$

$0.2 \mathrm{~g} \mathrm{KH}_{2} \mathrm{PO}_{4}$

$\mathrm{pH}$ adjusted to about 7.3 and autoclaved

DN(30) concentrate stock (40 mL) $40 \mathrm{~mL}$ deionized water

$0.8 \mathrm{~g}$ nutrient broth

$0.5 \mathrm{~g}$ casamino acids

0.1 g yeast extract $\mathrm{pH}$ adjusted to 7.2 and autoclaved $D N$ at varying salinities (10 $\mathrm{mL}$ each) $400 \mu \mathrm{L} \mathrm{DN}(30)$ concentrate $1 \mathrm{~mL} \mathrm{Ca} / \mathrm{Mg}$ stock solution $8.6 \mathrm{~mL}$ sterile Artificial Sea Water for $30 \mathrm{ppt}, 8.6 \mathrm{~mL}$ sterile deionized water for $0 \mathrm{ppt}$ and proportions scaled as appropriate for all salinity points in between 


\section{Chapter 2 supplementary material:}

Detailed culture media:

T. discolor, T. gallaicum and O. marilimosa were maintained on marine agar (per liter of deionized water: $37.4 \mathrm{~g}$ Difco Marine Broth 2216, $15 \mathrm{~g}$ agar powder, autoclaved). Nitrosomonas sp. C113a was maintained in Watson broth (per liter of artificial sea water (ASW; per liter of deionized water: $24.72 \mathrm{~g} \mathrm{NaCl}, 0.671 \mathrm{~g} \mathrm{KCl}, 1.3625 \mathrm{~g} \mathrm{CaCl}_{2} * 2 \mathrm{H}_{2} \mathrm{O}$, $4.664 \mathrm{~g} \mathrm{MgCl}_{2} * 6 \mathrm{H}_{2} \mathrm{O}, 6.286 \mathrm{~g} \mathrm{MgSO}_{4} * 7 \mathrm{H}_{2} \mathrm{O}$ and $\left.0.18 \mathrm{~g} \mathrm{NaHCO}_{3}\right): 5 \mathrm{~mL}^{2} \mathrm{M} \mathrm{NH}_{4} \mathrm{Cl}, 0.5$ $\mathrm{mL} 0.27 \mathrm{M} \mathrm{CaCl}_{2}, 1 \mathrm{~mL} 1.45 \mathrm{M} \mathrm{MgCl}_{2}, 1 \mathrm{~mL}$ trace metal mix [220], $400 \mu \mathrm{L} 5 \mathrm{~g} / \mathrm{L}$ phenol red, autoclaved and amended with $\left.1 \mathrm{~mL} 0.05 \mathrm{M} \mathrm{K}_{2} \mathrm{HPO}_{4}\right)$. All other prey organisms were grown from $15 \%$ glycerol freezer stocks. E. coli, S. oneidensis, P. putida, $P$. corrugata and B. subtilis were routinely grown in Lysogeny broth (25 g Miller LB broth per liter of deionized water, autoclaved). K. kristinae was grown in Corynebacterium broth (per liter of deionized water: $10 \mathrm{~g}$ Bacto Proteose Peptone No.6, 5 $\mathrm{g}$ yeast extract, $5 \mathrm{~g}$ anhydrous reagent-grade $\mathrm{D}(+)$-glucose, $5 \mathrm{~g} \mathrm{NaCl}) . F$. johnsoniae was grown in deionized water amended with $0.03 \% \mathrm{w} / \mathrm{v}$ tryptone and $0.03 \% \mathrm{w} / \mathrm{v}$ yeast extract, with the $\mathrm{pH}$ adjusted to 7.2 and autoclaved. S. cerevisiae was grown in deionized water amended with $1 \% \mathrm{w} / \mathrm{v} \mathrm{D}(+)$-glucose and $1 \% \mathrm{w} / \mathrm{v}$ yeast extract, $\mathrm{pH}$ adjusted to 7.2 and autoclaved. P. maris was grown in peptone-ASW [221]. H. radiodurans was routinely grown on Marine agar.

Dilute nutrient agar (DNa; $0.8 \mathrm{~g}$ nutrient broth, $0.5 \mathrm{~g}$ cas-amino acids, $0.1 \mathrm{~g}$ yeast extract and $15 \mathrm{~g}$ agar powder in $900 \mathrm{~mL}$ water, adjusted to $\mathrm{pH} 7.2$, autoclaved and amended with $100 \mathrm{~mL}$ of a sterile solution of $3 \mathrm{~g} / \mathrm{L} \mathrm{CaCl}_{2} * 2 \mathrm{H}_{2} \mathrm{O}$ and $6 \mathrm{~g} / \mathrm{L} \mathrm{MgCl}_{2} * 6 \mathrm{H}_{2} \mathrm{O}$ ) was routinely used to grow the predatory strains non-predatorily, with $715 \mathrm{~mL}$ ASW substituted for deionized water when appropriate to achieve a salinity of 25 . PBS (for 1 $\mathrm{L}: 8 \mathrm{~g} \mathrm{NaCl}, 0.2 \mathrm{~g} \mathrm{KCl}, 1.15 \mathrm{~g} \mathrm{Na}_{2} \mathrm{HPO}_{4} * 7 \mathrm{H}_{2} \mathrm{O}, 0.2 \mathrm{~g} \mathrm{KH}_{2} \mathrm{PO}_{4}$ in 1 liter deionized water, $\mathrm{pH}$ adjusted to about 7.3 and autoclaved) was routinely used as a buffer for cell fixation and FISH. 


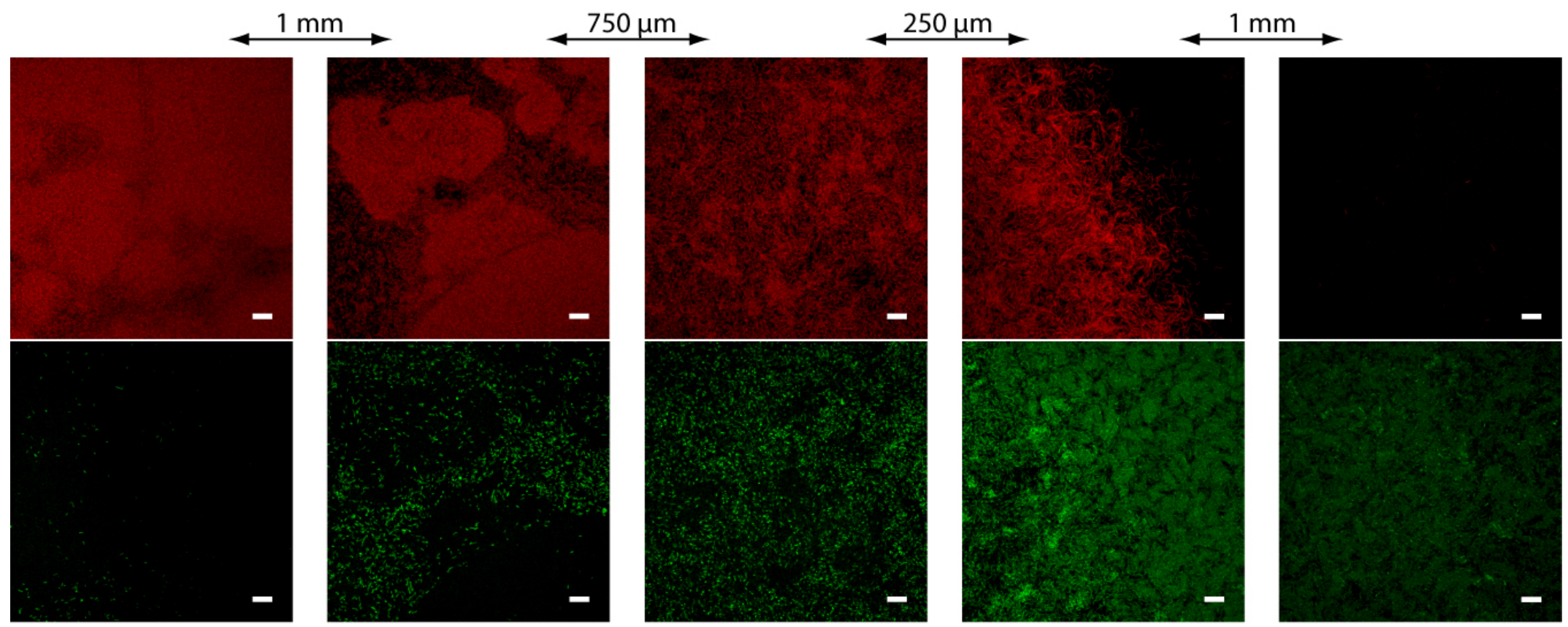

Figure S1: Two-dimensional projections of z-stacks of VCSA23 and S. oneidensis prey in a membrane filter culture captured by confocal microscopy. Scale bars are $10 \mu \mathrm{m}$. The top row of images shows the Cy3-labeled (red) probe specific to strains VCSA23 and VCSM12, while the bottom row shows the FITC-labeled (green) GAM42a probe. From left to right: About 2 $\mathrm{mm}$ from the predator-prey interface, extremely dense masses of VCSA23 cells are observed with very few prey cells. About 1 millimeter from the interface, the dense masses of VCSA23 cells are not as large and prey cells are present in higher density. About 250 micrometers from the interface a moderate density of prey cells is surrounded by swarming VCSA23 cells. At the VCSA23 cell front, a high density of VCSA23 cells is swarming into the $S$. oneidensis lawn, with a visible decrease in $S$. oneidensis density observed just behind the VCSA23 cell front. About 1 millimeter beyond the predator-prey interface, an undisturbed S. oneidensis lawn is observed, with a few scattered VCSA23 cells having penetrated ahead of the predator-prey interface. Approximate distances between each image along the transect across the predator-prey interface are shown at the top. 


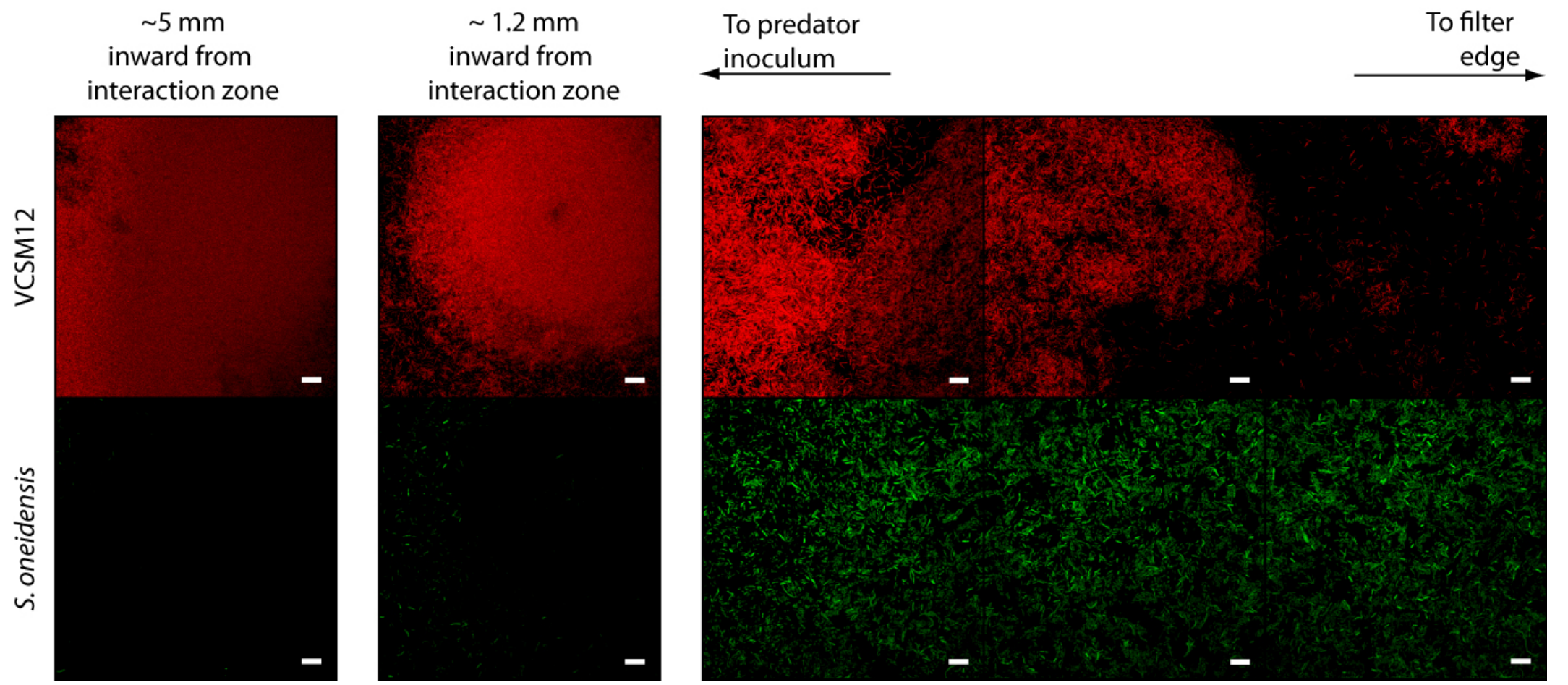

Figure S2: Two-dimensional projections of z-stacks of strain VCSM12 and S. oneidensis in a membrane filter culture, acquired by confocal microscopy. The top row of images show the Cy3 fluorescence channel, labeled with the VCSA23 probe. The bottom row of images shows the FITC fluorescence channel, labeled with the GAM42a probe. The set of three frames shown on the right side were taken along a transect across the front of interaction between VCSM12 and S. oneidensis. The frame on the far left was acquired at a location well within the cleared region, where VCSM12 cell density is extremely high. The second frame from the left was acquired at an intermediate location about $1200 \mu \mathrm{m}$ from the nearest interaction zone, showing an example of a round aggregate of VCSM12 cells generally formed about $1 \mathrm{~mm}$ behind the interaction zone. 


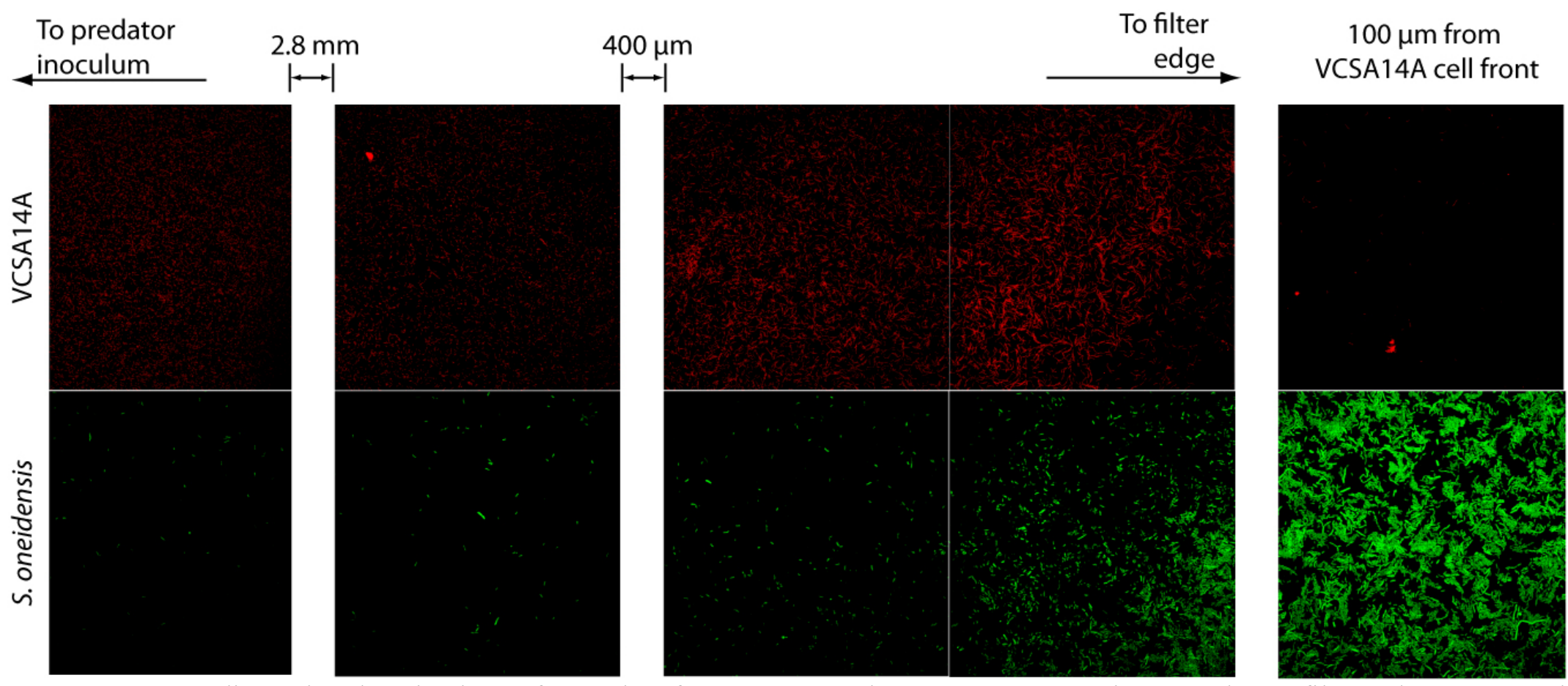

Figure S3: Two-dimensional projections of z-stacks of VCSA14A and S. oneidensis prey in a membrane filter culture captured by confocal microscopy. The top row of images show the Cy3-labeled probe (red) specific to strain VCSA14A and the bottom row of images show the FITC-labeled GAM42a probe (green). Approximate distances between each image along a transect across the predator-prey interface are shown at the top. The images on the left side of the figure show the low density and small size of VCSA14A cells after prey cells have been eliminated. 

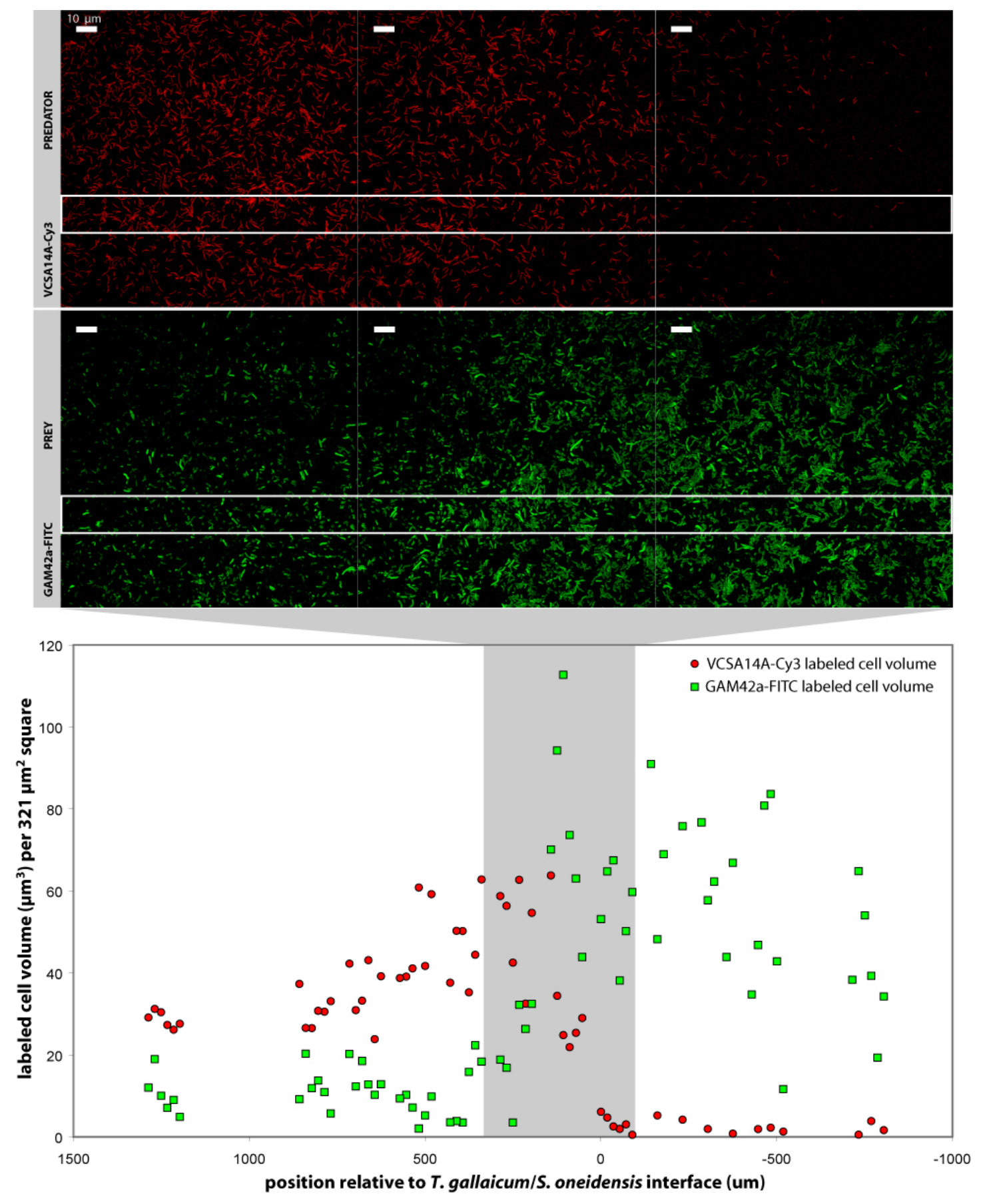

Figure S4: Two-dimensional projections of T. gallaicum A $37.1^{\mathrm{T}}$ cells (labeled with the VCSA14A-Cy3 probe hybridized at $0 \%$ formamide, top, in red) and $S$. oneidensis prey (labeled with the GAM42a-FITC probe, top, in green). From left to right: the most recently cleared zone, the interface between the expanding T. gallaicum cell front and the prey lawn, and the prey lawn relatively undisturbed by $T$. gallaicum cells. The three sets 
of 2-D projections were acquired adjacent to each other along a transect crossing the $T$. gallaicum cell front. The graph at bottom was constructed identically to that in Figures 2 and 3, using the full transect the set of images described above were drawn from. 


\section{REFERENCES}

1. Paine RT (1980) Food Webs: Linkage, Interaction Strength and Community Infrastructure. J Anim Ecol 49: 666-685.

2. Lewis SM (1986) The Role of Herbivorous Fishes in the Organization of a Caribbean Reef Community. Ecological Monographs 56: 183-200.

3. Creed R (1994) Direct and Indirect Effects of Crayfish Grazing in a Stream Community. Ecology 75: 2091-2103.

4. Zhang R, Weinbauer MG, Qian P-Y (2007) Viruses and flagellates sustain apparent richness and reduce biomass accumulation of bacterioplankton in coastal marine waters. Environ Microbiol 9: 3008-3018.

5. Murase J, Noll M, Frenzel P (2006) Impact of Protists on the Activity and Structure of the Bacterial Community in a Rice Field Soil. Appl Environ Microbiol 72: 54365444.

6. Ferrier C, Rassoulzadegan F (1991) Density-Dependent Effects of Protozoans on Specific Growth Rates in Pico- and Nanoplanktonic Assemblages. Limnol Oceanogr 36: 657-669.

7. Rothhaupt KO (1992) Stimulation of Phosphorus-Limited Phytoplankton by Bacterivorous Flagellates in Laboratory Experiments. Limnol Oceanogr 37: 750759.

8. Matz C, Jürgens K (2005) High motility reduces grazing mortality of planktonic bacteria. Appl Environ Microbiol 71: 921-929.

9. Langenheder S, Jurgens K (2001) Regulation of bacterial biomass and community structure by metazoan and protozoan predation. Limnol Oceanogr 46: 121-134.

10. Lawrence J, Scharf B, Packroff G, Neu T (2002) Microscale evaluation of the effects of grazing by invertebrates with contrasting feeding modes on river biofilm architecture and composition. Microb Ecol 44: 199-207.

11. Hahn MW, Höfle MG (2001) Grazing of protozoa and its effect on populations of aquatic bacteria. FEMS Microbiol Ecol 35: 113-121.

12. Pernthaler J (2005) Predation on prokaryotes in the water column and its ecological implications. Nat Rev Microbiol 3: 537-546.

13. Martin M (2002) Predatory prokaryotes: An emerging research opportunity. J Mol Microb Biotech 4: 467-477.

14. Jurkevitch E (2007) Predatory Behaviors in Bacteria -- Diversity and Transitions. Microbe 2: 67-73.

15. Fuhrman JA (1999) Marine viruses and their biogeochemical and ecological effects. Nature 399: 541-548.

16. Cutler D, Bal D (1926) Influence of Protozoa on the Process of Nitrogen Fixation by Azotobacter chroococcum. Ann Appl Biol 13: 516-534.

17. Verhagen FJM, Laanbroek HJ (1992) Effects Of Grazing By Flagellates On Competition For Ammonium Between Nitrifying And Heterotrophic Bacteria In Chemostats. Appl Environ Microbiol 58: 1962-1969.

18. Nagata T, Kirchman D (1991) Release of Dissolved Free and Combined AminoAcids by Bacterivorous Marine Flagellates. Limnol Oceanogr 36: 433-443. 
19. Nagata T, Kirchman D (1992) Release of Macromolecular Organic-Complexes by Heterotrophic Marine Flagellates. Mar Ecol-Prog Ser 83: 233-240.

20. Sinclair JL, Kampbell DH, Cook ML, Wilson JT (1993) Protozoa in Subsurface Sediments from Sites Contaminated with Aviation Gasoline or Jet Fuel. Appl Environ Microbiol 59: 467-472.

21. Rose JM, Vora NM, Caron DA (2008) Effect of Temperature and Prey Type on Nutrient Regeneration by an Antarctic Bacterivorous Protist. Microb Ecol 56: 101-111.

22. Sherr BF, Sherr EB, Berman T (1983) Grazing, Growth, and Ammonium Excretion Rates of a Heterotrophic Microflagellate Fed with Four Species of Bacteria. Appl Environ Microbiol 45: 1196-1201.

23. Caron DA, Goldman JC, Dennett MR (1988) Experimental Demonstration Of The Roles Of Bacteria And Bacterivorous Protozoa In Plankton Nutrient Cycles. Hydrobiologia 159: 27-40.

24. Gruber DF, Simjouw J-P, Seitzinger SP, Taghon GL (2006) Dynamics and Characterization of Refractory Dissolved Organic Matter Produced by a Pure Bacterial Culture in an Experimental Predator-Prey System. Appl Environ Microbiol 72: 4184-4191.

25. Azam F, Fenchel T, Field J, Gray J, Meyer-Reil L, et al. (1983) The Ecological Role of Water-Column Microbes in the Sea. Mar Ecol-Prog Ser 10: 257-263.

26. Hahn MW, Höfle MG (1999) Flagellate predation on a bacterial model community: Interplay of size-selective grazing, specific bacterial cell size, and bacterial community composition. Appl Environ Microbiol 65: 4863-4872.

27. Jezberova J, Komarkova J (2007) Morphological transformation in a freshwater Cyanobium sp. induced by grazers. Environ Microbiol 9: 1858-1862.

28. Caron DA (1987) Grazing of Attached Bacteria by Heterotrophic Microflagellates. Microb Ecol 13: 203-218.

29. Stolp H, Starr M (1963) Bdellovibrio bacteriovorus gen. et sp. n., a predatory, ectoparasitic, and bacteriolytic microorganism. Anton van Lee J M S 29: 217-248.

30. Casida LE (1982) Ensifer adhaerens gen. nov., sp. nov.: a Bacterial Predator of Bacteria in Soil. Int J Syst Evol Micr 32: 339-345.

31. Singh B (1947) Myxobacteria in Soils and Composts: Their Distribution, Number and Lytic Action on Bacteria. J Gen Microbiol 1: 1-10.

32. Sangkhobol V, Skerman V (1981) Saprospira species - natural predators. Curr Microbiol 5: 169-174.

33. Quinn GR, Skerman VBD (1980) Herpetosiphon - Natures Scavenger. Curr Microbiol 4: 57-62.

34. Shimkets LJ, Dworkin M, Reichenbach H (2006) The Myxobacteria. In: Dworkin M, Falkow S, Rosenberg E, Schleifer K-H, Stackebrandt E, editors. The Prokaryotes. New York: Springer New York. pp. 31-115.

35. Davidov Y, Jurkevitch E (2004) Diversity and evolution of Bdellovibrio-and-like organisms (BALOs), reclassification of Bacteriovorax starrii as Peredibacter starrii gen. nov., comb. nov., and description of the Bacteriovorax-Peredibacter clade as Bacteriovoracaceae fam. nov. Int J Syst Evol Micr 54: 1439-1452. 
36. Martens M, Delaere M, Coopman R, De Vos P, Gillis M, et al. (2007) Multilocus sequence analysis of Ensifer and related taxa. Int J Syst Evol Microbiol 57: 489503.

37. Lambina V, Afinogenova A, Penabad SR, Konovalova S, Andreev L (1983) A New Species of Exoparasitic Bacteria from the Genus Micavibrio Destroying GramNegative Bacteria. Microbiology 52: 607-611.

38. Casida LE (1992) Competitive Ability And Survival In Soil Of Pseudomonas Strain 679-2, A Dominant, Nonobligate Bacterial Predator Of Bacteria. Appl Environ Microbiol 58: 32-37.

39. Sillman CE, Casida LJ (1986) Isolation of nonobligate bacterial predators of bacteria from soil. Can J Microbiol 32: 760-762.

40. Zeph LR, Casida LJ (1986) Gram-Negative Versus Gram-Positive (Actinomycete) Nonobligate Bacterial Predators of Bacteria in Soil. Appl Environ Microbiol 52: 819-823.

41. Byrd JJ, Zeph LR, Casida LE (1985) Bacterial Control Of Agromyces ramosus In Soil. Can J Microbiol 31: 1157-1163.

42. Casida LE (1983) Interaction of Agromyces ramosus with Other Bacteria in Soil. Appl Environ Microbiol 46: 881-888.

43. McBride MJ, Zusman DR (1996) Behavioral analysis of single cells of Myxococcus xanthus in response to prey cells of Escherichia coli. FEMS Microbiol Lett 137: 227-231.

44. Furusawa G, Yoshikawa T, Yasuda A, Sakata T (2003) Algicidal activity and gliding motility of Saprospira sp SS98-5. Can J Microbiol 49: 92-100.

45. Lewin R (1997) Saprospira grandis: A flexibacterium that can catch bacterial prey by "ixotrophy". Microb Ecol 34: 232-236.

46. Burnham JC, Collart SA, Highison BW (1981) Entrapment and lysis of the Cyanobacterium Phormidium luridum by Aqueous Colonies of Myxococcus xanthus PCO2. Arch Microbiol 129: 285-294.

47. Daft MJ, Stewart WDP (1973) Light and Electron Microscope Observations on Algal Lysis by Bacterium CP-I. New Phytologist 72: 799.

48. Jurkevitch E (2006) The Genus Bdellovibrio. In: Dworkin M, Falkow S, Rosenberg E, Schleifer K-H, Stackebrandt E, editors. The Prokaryotes. New York: Springer New York. pp. 12-30.

49. Reichenbach H (2006) The Genus Lysobacter. In: Dworkin M, Falkow S, Rosenberg E, Schleifer K-H, Stackebrandt E, editors. The Prokaryotes. New York: Springer New York. pp. 939-957.

50. Dworkin M (1973) Cell-cell interactions in the myxobacteria. Symp Gen Microbiol 23: $125-142$.

51. Burnham JC, Collart SA, Daft MJ (1984) Myxococcal predation of the cyanobacterium Phormidium luridum in aqueous environments. Arch Microbiol 137: 220-225.

52. Kadouri D, O'Toole GA (2005) Susceptibility of Biofilms to Bdellovibrio bacteriovorus Attack. Appl Environ Microbiol 71: 4044-4051. 
53. Kadouri D, Venzon NC, O'Toole GA (2007) Vulnerability of Pathogenic Biofilms to Micavibrio aeruginosavorus. Appl Environ Microbiol 73: 605-614.

54. Shemesh Y, Jurkevitch E (2004) Plastic phenotypic resistance to predation by Bdellovibrio and like organisms in bacterial prey. Environ Microbiol 6: 12-18.

55. Pineiro S, Sahaniuk G, Romberg E, Williams H (2004) Predation pattern and phylogenetic analysis of Bdellovibrionaceae from the Great Salt Lake, Utah. Curr Microbiol 48: 113-117.

56. Enzinger RM, Cooper RC (1976) Role of bacteria and protozoa in the removal of Escherichia coli from estuarine waters. Appl Environ Microbiol 31: 758-763.

57. Manage PM, Kawabata Z, Nakano S (2000) Algicidal effect of the bacterium Alcaligenes denitrificans on Microcystis spp. Aquat Microb Ecol 22: 111-117.

58. Nogales B, Guerrero R, Esteve I (1997) A heterotrophic bacterium inhibits growth of several species of the genus Chlorobium. Arch Microbiol 167: 396-399.

59. Lueders T, Kindler R, Miltner A, Friedrich MW, Kaestner M (2006) Identification of Bacterial Micropredators Distinctively Active in a Soil Microbial Food Web. Appl Environ Microbiol 72: 5342-5348.

60. Barbeau K, Kujawinski E, Moffett J (2001) Remineralization and recycling of iron, thorium and organic carbon by heterotrophic marine protists in culture. Aquat Microb Ecol 24: 69-81.

61. Posch T, Simek K, Vrba J, Pernthaler S, Nedoma J, et al. (1999) Predator-induced changes of bacterial size-structure and productivity studied on an experimental microbial community. Aquat Microb Ecol 18: 235-246.

62. Šimek K, Vrba J, Pernthaler J, Posch T, Hartman P, et al. (1997) Morphological and compositional shifts in an experimental bacterial community influenced by protists with contrasting feeding modes. Appl Environ Microbiol 63: 587-595.

63. Afinogenova A, Konovalova S, Lambina V (1986) Loss of Trait of Species Monospecificity by Exoparasitic Bacteria of the Genus Micavibrio. Microbiology 55: 377-389.

64. Davidov Y, Friedjung A, Jurkevitch E (2006) Structure analysis of a soil community of predatory bacteria using culture-dependent and culture-independent methods reveals a hitherto undetected diversity of Bdellovibrio-and-like organisms. Environ Microbiol 8: 1667-1673.

65. Davidov Y, Huchon D, Koval SF, Jurkevitch E (2006) A new alpha-proteobacterial clade of Bdellovibrio-like predators: implications for the mitochondrial endosymbiotic theory. Environ Microbiol 8: 2179-2188.

66. Sacchi L, Bigliardi E, Corona S, Beninati T, Lo N, et al. (2004) A symbiont of the tick Ixodes ricinus invades and consumes mitochondria in a mode similar to that of the parasitic bacterium Bdellovibrio bacteriovorus. Tissue Cell 36: 43-53.

67. Beninati T, Lo N, Sacchi L, Genchi C, Noda H, et al. (2004) A Novel AlphaProteobacterium Resides in the Mitochondria of Ovarian Cells of the Tick Ixodes ricinus. Appl Environ Microbiol 70: 2596-2602.

68. Makkar NS, Casida LE (1987) Cupriavidus necator gen. nov., sp. nov.: a Nonobligate Bacterial Predator of Bacteria in Soil. Int J Syst Bacteriol 37: 323-326. 
69. Cain CC, Lee DH, Waldo RH, Henry AT, Casida EJ, et al. (2003) Synergistic antimicrobial activity of metabolites produced by a nonobligate bacterial predator. Antimicrob Agents Ch 47: 2113-2117.

70. Ensign J, Wolfe R (1965) Lysis of Bacterial Cell Walls by an Enzyme Isolated from a Myxobacter. J Bacteriol 90: 395-402.

71. Ensign J, Wolfe R (1966) Characterization of a Small Proteolytic Enzyme Which Lyses Bacterial Cell Walls. J Bacteriol 91: 524-534.

72. Daft M, McCord SB, Stewart W (1975) Ecological studies of algal-lysing bacteria in fresh waters. Freshwater Biol 5: 577-596.

73. Beebe J (1941) Studies on the Myxobacteria. Iowa State J Sci 15: 319-337.

74. Trick I, Lingens F (1984) Characterization Of Herpetosiphon spec. - A Gliding Filamentous Bacterium From Bulking-Sludge. Appl Microbiol Biotech 19: 191198.

75. Shi M, Zou L, Liu XY, Gao Y, Zhang ZK, et al. (2006) A novel bacterium Saprospira sp strain PdY3 forms bundles and lyses cyanobacteria. Frontiers in Bioscience 11: 1916-1923.

76. Chernyakovskaya TF, Dobrovol'skaya TG, Bab'eva IP (2004) The ability of saprotrophic bacteria isolated from natural habitats to lyse yeasts. Microbiology 73: 482-484.

77. Casida L (1980) Bacterial Predators of Micrococcus luteus in Soil. Appl Environ Microbiol 39: 1035-1041.

78. Griffiths B (1989) Enhanced nitrification in the presence of bacteriophagous protozoa. Soil Biol Biochem 21: 1045-1051.

79. Tso SF, Taghon GL (2006) Protozoan grazing increases mineralization of naphthalene in marine sediment. Microb Ecol 51: 460-469.

80. Shimkets L, Woese CR (1992) A Phylogenetic Analysis of the Myxobacteria: Basis for Their Classification. P Natl Acad Sci USA 89: 9459-9463.

81. Guerrero R, Pedros-Alio C, Esteve I, Mas J, Chase D, et al. (1986) Predatory Prokaryotes: Predation and Primary Consumption Evolved in Bacteria. P Natl Acad Sci USA 83: 2138-2142.

82. Amaro AM, Fuentes MS, Ogalde SR, Venegas JA, Suarez-Isla BA (2005) Identification and characterization of potentially algal-lytic marine bacteria strongly associated with the toxic dinoflagellate Alexandrium catenella. J Eukaryot Microbiol 52: 191-200.

83. Mitsutani A, Takesue K, Kirita M, Ishida Y (1992) Lysis of Skeletonema costatum by Cytophaga sp Isolated from the Coastal Water of the Ariake Sea. Nippon Suisan Gakk 58: 2159-2167.

84. Hart BA, Zahler SA (1966) Lytic Enzyme Produced by Myxococcus xanthus. J Bacteriol 92: 1632-1637.

85. Harcke E, Hutterma.A, Kuhlwein H (1972) Studies on Lytic Activities of Chondrococcus coralloides (Myxobacterales) II. Identification of the Bacteriolytic Enzyme as a Muramidase. Arch Mikrobiol 85: 6-12.

86. Willems A, Fernandez-Lopez M, Munoz-Adelantado E, Goris J, De Vos P, et al. (2003) Description of new Ensifer strains from nodules and proposal to transfer 
Ensifer adhaerens Casida 1982 to Sinorhizobium as Sinorhizobium adhaerens comb. nov. Request for an opinion. Int J Syst Evol Micr 53: 1207-1217.

87. Talbot JM, Kroeger KD, Rago A, Allen MC, Charette MA (2003) Nitrogen Flux and Speciation Through the Subterranean Estuary of Waquoit Bay, Massachusetts. Biol Bull 205: 244-245.

88. Charette M, Sholkovitz E, Hansel C (2005) Trace element cycling in a subterranean estuary: Part 1. Geochemistry of the permeable sediments. Geochim Cosmochim Ac 69: 2095-2109.

89. Testa JM, Charette MA, Sholkovitz ER, Allen MC, Rago A, et al. (2002) Dissolved Iron Cycling in the Subterranean Estuary of a Coastal Bay: Waquoit Bay, Massachusetts. Biol Bull 203: 255-256.

90. Novarino G, Warren A, Butler H, Lambourne G, Boxshall A, et al. (1997) Protistan communities in aquifers: a review. FEMS Microbiol Rev 20: 261-275.

91. Hutchens E, Radajewski S, Dumont MG, McDonald IR, Murrell JC (2004) Analysis of methanotrophic bacteria in Movile Cave by stable isotope probing. Environ Microbiol 6: 111-120.

92. Cambareri TC, Eichner EM (1998) Watershed delineation and ground water discharge to a coastal embayment. Ground Water 36: 626-634.

93. Charette M, Sholkovitz E (2006) Trace element cycling in a subterranean estuary: Part 2. Geochemistry of the pore water. Geochim Cosmochim Ac 70: 811-826.

94. Suzuki M, Nakagawa Y, Harayama S, Yamamoto S (2001) Phylogenetic analysis and taxonomic study of marine Cytophaga-like bacteria: proposal for Tenacibaculum gen. nov. with Tenacibaculum maritimum comb. nov. and Tenacibaculum ovolyticum comb. nov., and description of Tenacibaculum mesophilum sp. nov. and Tenacibaculum amylolyticum sp. nov. Int J Syst Evol Micr 51: 1639-1652.

95. Piñeiro-Vidal M, Riaza A, Santos Y (2008) Tenacibaculum discolor sp. nov. and Tenacibaculum gallaicum sp. nov., isolated from sole (Solea senegalensis) and turbot (Psetta maxima) culture systems. Int J Syst Evol Micr 58: 21-25.

96. Cole J, Chai B, Farris R, Wang Q, Kulam-Syed-Mohideen A, et al. (2007) The ribosomal database project (RDP-II): introducing myRDP space and quality controlled public data. Nucleic Acids Res 35: D169-D172.

97. Cole J, Wang Q, Cardenas E, Fish J, Chai B, et al. (2009) The Ribosomal Database Project: improved alignments and new tools for rRNA analysis. Nucleic Acids Res 37: D141-D145.

98. Ludwig W, Strunk O, Westram R, Richter L, Meier H, et al. (2004) ARB: a software environment for sequence data. Nucleic Acids Res 32: 1363-1371.

99. DeSantis TZ, Hugenholtz P, Larsen N, Rojas M, Brodie EL, et al. (2006) Greengenes, a Chimera-Checked 16S rRNA Gene Database and Workbench Compatible with ARB. Appl Environ Microbiol 72: 5069-5072.

100. Pruesse E, Quast C, Knittel K, Fuchs BM, Ludwig W, et al. (2007) SILVA: a comprehensive online resource for quality checked and aligned ribosomal RNA sequence data compatible with ARB. Nucleic Acids Res doi: 10.1093/nar/gkm864: 1-9. 
101. Zhang Z, Schwartz S, Wagner L, Miller W (2000) A greedy algorithm for aligning DNA sequences. J Comput Biol 7: 203-214.

102. Yarza P, Richter M, Peplies J, Euzeby J, Amann R, et al. (2008) The All-Species Living Tree project: A 16S rRNA-based phylogenetic tree of all sequenced type strains. Syst Appl Microbiol 31: 241-250.

103. Stamatakis A (2006) RAxML-VI-HPC: maximum likelihood-based phylogenetic analyses with thousands of taxa and mixed models. Bioinformatics 22: 26882690.

104. Felsenstein J (2005) PHYLIP (Phylogeny Inference Package) version 3.67. Seattle: Distributed by the author, Department of Genome Sciences, University of Washington.

105. Manz W, Amann R, Ludwig W, Wagner M, Schleifer K-H (1992) Phylogenetic oligodeoxynucleotide probes for the major subclasses of Proteobacteria: problems and solutions. Syst Appl Microbiol 15: 593-600.

106. Pernthaler J, Glockner F-O, Schonhuber W, Amann R (2001) Fluorescence in situ Hybridization (FISH) with rRNA-targeted Oligonucleotide Probes. In: Paul JH, editor. Methods in Microbiology. San Diego: Academic Press. pp. 208-226.

107. Pernthaler A, Pernthaler J, Amann R (2002) Fluorescence in situ hybridization and catalyzed reporter deposition for the identification of marine bacteria. Appl Environ Microbiol 68: 3094-3101.

108. Daims H, Lucker S, Wagner M (2006) daime, a novel image analysis program for microbial ecology and biofilm research. Environ Microbiol 8: 200-213.

109. Wakabayashi H, Hikida M, Masumura K (1986) Flexibacter maritimus sp. nov., a Pathogen of Marine Fishes. Int J Syst Evol Micr 36: 396-398.

110. Hansen GH, Bergh O, Michaelsen J, Knappskog D (1992) Flexibacter ovolyticus sp. nov., a Pathogen of Eggs and Larvae of Atlantic Halibut, Hippoglossus hippoglossus L. Int J Syst Evol Micr 42: 451-458.

111. Frette L, Jorgensen NOG, Irming H, Kroer N (2004) Tenacibaculum skagerrakense sp. nov., a marine bacterium isolated from the pelagic zone in Skagerrak, Denmark. Int J Syst Evol Micr 54: 519-524.

112. Mancuso Nichols C, Bowman JP, Guezennec J (2005) Olleya marilimosa gen. nov., sp. nov., an exopolysaccharide-producing marine bacterium from the family Flavobacteriaceae, isolated from the Southern Ocean. Int J Syst Evol Micr 55: 1557-1561.

113. Choi DH, Kim Y-G, Hwang CY, Yi H, Chun J, et al. (2006) Tenacibaculum litoreum sp. nov., isolated from tidal flat sediment. Int J Syst Evol Micr 56: 635640.

114. Nedashkovskaya OI, Kwon KK, Yang S-H, Lee H-S, Chung KH, et al. (2008) Lacinutrix algicola sp. nov. and Lacinutrix mariniflava sp. nov., two novel marine alga-associated bacteria and emended description of the genus Lacinutrix. Int J Syst Evol Micr 58: 2694-2698.

115. DeLong EF, Preston CM, Mincer T, Rich V, Hallam SJ, et al. (2006) Community Genomics Among Stratified Microbial Assemblages in the Ocean's Interior. Science 311: 496-503. 
116. Michael Z, Simone P, Tatiana S, Jakob P (2009) A small population of planktonic Flavobacteria with disproportionally high growth during the spring phytoplankton bloom in a prealpine lake. Environ Microbiol 11: 2676-2686.

117. Eiler A, Bertilsson S (2007) Flavobacteria Blooms in Four Eutrophic Lakes: Linking Population Dynamics of Freshwater Bacterioplankton to Resource Availability. Appl Environ Microbiol 73: 3511-3518.

118. Llobet-Brossa E, Rossello-Mora R, Amann R (1998) Microbial Community Composition of Wadden Sea Sediments as Revealed by Fluorescence In Situ Hybridization. Appl Environ Microbiol 64: 2691-2696.

119. Musat N, Werner U, Knittel K, Kolb S, Dodenhof T, et al. (2006) Microbial community structure of sandy intertidal sediments in the North Sea, Sylt-Rømø Basin, Wadden Sea. Syst Appl Microbiol 29: 333-348.

120. Brinkmeyer R, Knittel K, Jurgens J, Weyland H, Amann R, et al. (2003) Diversity and Structure of Bacterial Communities in Arctic versus Antarctic Pack Ice. Appl Environ Microbiol 69: 6610-6619.

121. Kormas KA, Tivey MK, Von Damm K, Teske A (2006) Bacterial and archaeal phylotypes associated with distinct mineralogical layers of a white smoker spire from a deep-sea hydrothermal vent site $\left(9^{\circ} \mathrm{N}\right.$, East Pacific Rise). Environ Microbiol 8: 909-920.

122. Cottrell MT, Kirchman DL (2000) Community Composition of Marine Bacterioplankton Determined by 16S rRNA Gene Clone Libraries and Fluorescence In Situ Hybridization. Appl Environ Microbiol 66: 5116-5122.

123. Janse I, Zwart G, van der Maarel MJ, Gottschal JC (2000) Composition of the bacterial community degrading Phaeocystis mucopolysaccharides in enrichment cultures. Aquat Microb Ecol 22: 119-133.

124. Covert JS, Moran MA (2001) Molecular characterization of estuarine bacterial communities that use high- and low-molecular weight fractions of dissolved organic carbon. Aquat Microb Ecol 25: 127-139.

125. Pinhassi J, Azam F, Hemphälä J, Long RA, Martinez J, et al. (1999) Coupling between bacterioplankton species composition, population dynamics, and organic matter degradation. Aquat Microb Ecol 17: 13-26.

126. DeLong EF, Franks DG, Alldredge AL (1993) Phylogenetic diversity of aggregateattached vs. free-living marine bacterial assemblages. Limnol Oceanogr 38: 924934.

127. Rath J, Wu KY, Herndl GJ, DeLong EF (1998) High phylogenetic diversity in a marine-snow-associated bacterial assemblage. Aquat Microb Ecol 14: 261-269.

128. Abell GCJ, Bowman JP (2005) Colonization and community dynamics of class Flavobacteria on diatom detritus in experimental mesocosms based on Southern Ocean seawater. FEMS Microbiol Ecol 53: 379-391.

129. Kobayashi DY, Reedy RM, Palumbo JD, Zhou J-M, Yuen GY (2005) A clp Gene Homologue Belonging to the Crp Gene Family Globally Regulates Lytic Enzyme Production, Antimicrobial Activity, and Biological Control Activity Expressed by Lysobacter enzymogenes Strain C3. Appl Environ Microbiol 71: 261-269. 
130. Bauer M, Kube M, Teeling H, Richter M, Lombardot T, et al. (2006) Whole genome analysis of the marine Bacteroidetes 'Gramella forsetii' reveals adaptations to degradation of polymeric organic matter. Environ Microbiol 8: 2201-2213.

131. González JM, Fernández-Gómez B, Fernàndez-Guerra A, Gómez-Consarnau L, Sánchez O, et al. (2008) Genome analysis of the proteorhodopsin-containing marine bacterium Polaribacter sp. MED152 (Flavobacteria). P Natl Acad Sci USA 105: 8724-8729.

132. Tsugawa W, Horiuchi S, Tanaka M, Wake H, Sode K (1996) Purification of a Marine Bacterial Glucose Dehydrogenase from Cytophaga marinoflava and its Application for Measurement of 1,5-Anhydro-D-Glucitol. Appl Biochem Biotech 56: 301-310.

133. Nedashkovskaya OI, Vancanneyt M, Dawyndt P, Engelbeen K, Vandemeulebroecke K, et al. (2005) Reclassification of [Cytophaga] marinoflava Reichenbach 1989 as Leeuwenhoekiella marinoflava gen. nov., comb. nov. and description of Leeuwenhoekiella aequorea sp. nov. Int J Syst Evol Micr 55: 1033-1038.

134. Bull CT, Shetty KG, Subbarao KV (2002) Interactions between myxobacteria, plant pathogenic fungi, and biocontrol agents. Plant Disease 86: 889-896.

135. Mathew S, Dudani A (1955) Lysis of Human Pathogenic Bacteria by Myxobacteria. Nature 175: 125.

136. Jurkevitch E, Minz D, Ramati B, Barel G (2000) Prey Range Characterization, Ribotyping, and Diversity of Soil and Rhizosphere Bdellovibrio spp. Isolated on Phytopathogenic Bacteria. Appl Environ Microbiol 66: 2365-2371.

137. Keya SO, Alexander M (1975) Regulation of parasitism by host density: The Bdellovibrio-Rhizobium interrelationship. Soil Biol Biochem 7: 231-237.

138. Hillesland KL, Lenski RE, Velicer GJ (2007) Ecological Variables Affecting Predatory Success in Myxococcus xanthus. Microb Ecol 53: 571-578.

139. Yoon J-H, Kang S-J, Oh T-K (2005) Tenacibaculum lutimaris sp. nov., isolated from a tidal flat in the Yellow Sea, Korea. Int J Syst Evol Microbiol 55: 793-798.

140. Neidhardt FC, Ingraham JL, Schaechter M (1990) Physiology of the bacterial cell: a molecular approach. Sunderland, Mass.: Sinauer Associates, Inc. 506 p.

141. Sohn JH, Lee J-H, Yi H, Chun J, Bae KS, et al. (2004) Kordia algicida gen. nov., sp. nov., an algicidal bacterium isolated from red tide. Int J Syst Evol Micr 54: 675-680.

142. Maeda T, Murakami M, Ohsugi S, Furushita M, Mitsutani A, et al. (1998) Perspectives of the development of 16S rDNA probe specific for algicidal and/or algal-lytic gliding bacteria. Fisheries Sci 64: 861-865.

143. Chrzanowski T, Šimek K (1990) Prey-size selection by freshwater flagellated protozoa. Limnol Oceanogr 35: 1429-1436.

144. González J, Sherr E, Sherr B (1990) Size-selective grazing on bacteria by natural assemblages of estuarine flagellates and ciliates. Appl Environ Microbiol 56: 583589.

145. Šimek K, Chrzanowski T (1992) Direct and indirect evidence of size-selective grazing on pelagic bacteria by freshwater nanoflagellates. Appl Environ Microbiol 58: 3715-3720. 
146. Wildschutte H (2004) Protozoan predation, diversifying selection, and the evolution of antigenic diversity in Salmonella. Proc Nat Acad Sci USA 101: 10644-10649.

147. Brown R (1975) Carbohydrate binding proteins involved in phagocytosis by Acanthamoeba. Nature 254: 434-435.

148. Wootton EC, Zubkov MV, Jones DH, Jones RH, Martel CM, et al. (2007) Biochemical prey recognition by planktonic protozoa. Environ Microbiol 9: 216222.

149. Weitere M, Bergfeld T, Rice SA, Matz C, Kjelleberg S (2005) Grazing resistance of Pseudomonas aeruginosa biofilms depends on type of protective mechanism, developmental stage and protozoan feeding mode. Environ Microbiol 7: 15931601.

150. Corno G, Jurgens K (2006) Direct and Indirect Effects of Protist Predation on Population Size Structure of a Bacterial Strain with High Phenotypic Plasticity. Appl Environ Microbiol 72: 78-86.

151. Jezbera J, Hornak K, Simek K (2006) Prey selectivity of bacterivorous protists in different size fractions of reservoir water amended with nutrients. Environ Microbiol 8: 1330-1339.

152. Kinner NE, Harvey RW, Blakeslee K, Novarino G, Meeker LD (1998) Sizeselective predation on groundwater bacteria by nanoflagellates in an organiccontaminated aquifer. Appl Environ Microbiol 64: 618-625.

153. Huws SA, McBain AJ, Gilbert P (2005) Protozoan grazing and its impact upon population dynamics in biofilm communities. J Appl Microbiol 98: 238-244.

154. Pickup ZL, Pickup R, Parry JD (2007) Effects of Bacterial Prey Species and Their Concentration on Growth of the Amoebae Acanthamoeba castellanii and Hartmannella vermiformis. Appl Environ Microbiol 73: 2631-2634.

155. Daft M, Burnham J, Yamamoto Y (1985) Lysis of Phormidium luridum by Myхососcus fulvus in continuous flow cultures. J Appl Bacteriol 59: 73-80.

156. Fraleigh PC, Burnham JC (1988) Myxococcal Predation on Cyanobacterial Populations: Nutrient Effects. Limnol Oceanogr 33: 476.

157. Fandino LB, Riemann L, Steward GF, Azam F (2005) Population dynamics of Cytophaga-Flavobacteria during marine phytoplankton blooms analyzed by realtime quantitative PCR. Aquat Microb Ecol 40: 251-257.

158. Pedrotti ML, Beauvais S, Kerros ME, Iversen K, Peters F (2009) Bacterial colonization of transparent exopolymeric particles in mesocosms under different turbulence intensities and nutrient conditions. Aquat Microb Ecol 55: 301-312.

159. Jung S-Y, Oh T-K, Yoon J-H (2006) Tenacibaculum aestuarii sp. nov., isolated from a tidal flat sediment in Korea. Int J Syst Evol Microbiol 56: 1577-1581.

160. Amann R, Fuchs BM (2008) Single-cell identification in microbial communities by improved fluorescence in situ hybridization techniques. Nat Rev Microbiol 6: 339-348.

161. Kalmbach S, Manz W, Szewzyk U (1997) Dynamics of biofilm formation in drinking water: Phylogenetic affiliation and metabolic potential of single cells assessed by formazan reduction and in situ hybridization. FEMS Microbiol Ecol 22: 265-279. 
162. Teal TK, Lies DP, Wold BJ, Newman DK (2006) Spatiometabolic Stratification of Shewanella oneidensis Biofilms. Appl Environ Microbiol 72: 7324-7330.

163. Matz C, Bergfeld T, Rice S, Kjelleberg S (2004) Microcolonies, quorum sensing and cytotoxicity determine the survival of Pseudomonas aeruginosa biofilms exposed to protozoan grazing. Environ Microbiol 6: 218-226.

164. Boenigk J, Matz C, Jurgens K, Arndt H (2001) The Influence of Preculture Conditions and Food Quality on the Ingestion and Digestion Process of Three Species of Heterotrophic Nanoflagellates. Microb Ecol 42: 168-176.

165. Fuhrman JA, Noble RT (1995) Viruses and protists cause similar bacterial mortality in coastal seawater. Limnol Oceanogr 40: 1236-1242.

166. Weinbauer MG, Hornak K, Jezbera J, Nedoma J, Dolan JR, et al. (2007) Synergistic and antagonistic effects of viral lysis and protistan grazing on bacterial biomass, production and diversity. Environ Microbiol 9: 777-788.

167. Eilers H, Pernthaler J, Glockner FO, Amann R (2000) Culturability and In Situ Abundance of Pelagic Bacteria from the North Sea. Appl Environ Microbiol 66: 3044-3051.

168. Celussi M, Paoli A, Crevatin E, Bergamasco A, Margiotta F, et al. (2009) Shortterm under-ice variability of prokaryotic plankton communities in coastal Antarctic waters (Cape Hallett, Ross Sea). Estuar Coast Shelf S 81: 491-500.

169. Hempel M, Blume M, Blindow I, Gross EM (2008) Epiphytic bacterial community composition on two common submerged macrophytes in brackish water and freshwater. BMC Microbiology 8.

170. Kennedy J, Codling CE, Jones BV, Dobson ADW, Marchesi JR (2008) Diversity of microbes associated with the marine sponge, Haliclona simulans, isolated from Irish waters and identification of polyketide synthase genes from the sponge metagenome. Environ Microbiol 10: 1888-1902.

171. Nedashkovskaya OI, Kim SB, Vancanneyt M, Shin DS, Lysenko AM, et al. (2006) Salegentibacter agarivorans sp. nov., a novel marine bacterium of the family Flavobacteriaceae isolated from the sponge Artemisina sp. Int J Syst Evol Microbiol 56: 883-887.

172. Webster NS, Wilson KJ, Blackall LL, Hill RT (2001) Phylogenetic Diversity of Bacteria Associated with the Marine Sponge Rhopaloeides odorabile. Appl Environ Microbiol 67: 434-444.

173. Azam F (1998) Microbial Control of Oceanic Carbon Flux: The Plot Thickens. Science 280: 694-696.

174. Gillespie D, Cook F (1965) Extracellular Enzymes from Strains of Sorangium. Can J Microbiol 11: 109-118.

175. Rosenberg E, Keller KH, Dworkin M (1977) Cell density-dependent growth of Myxococcus xanthus on casein. J Bacteriol 129: 770-777.

176. Hillesland KL, Velicer GJ, Lenski RE (2009) Experimental evolution of a microbial predator's ability to find prey. P Roy Soc B-Biol Sci 276: 459-467.

177. Berleman JE, Scott J, Chumley T, Kirby JR (2008) Predataxis behavior in Myxococcus xanthus. P Natl Acad Sci USA 105: 17127-17132. 
178. Wu YL, Jiang Y, Kaiser D, Alber M (2007) Social interactions in myxobacterial swarming. PLoS Comput Biol 3: 2546-2558.

179. Wu YL, Kaiser AD, Jiang Y, Alber MS (2009) Periodic reversal of direction allows Myxobacteria to swarm. Proc Nat Acad Sci USA 106: 1222-1227.

180. Howarth RW (1988) Nutrient limitation of net primary production in marine ecosystems. Ann Rev Ecol System 19: 89-110.

181. Karl D, Letelier R, Tupas L, Dore J, Christian J, et al. (1997) The role of nitrogen fixation in biogeochemical cycling in the subtropical North Pacific Ocean. Nature 388: $533-538$.

182. Solorzano L (1969) Determination of Ammonia in Natural Waters by the Phenolhypochlorite Method. Limnol Oceanogr 14: 799-801.

183. Riemann L, Steward GF, Azam F (2000) Dynamics of Bacterial Community Composition and Activity during a Mesocosm Diatom Bloom. Appl Environ Microbiol 66: 578-587.

184. Shilo M (1970) Lysis of Blue-Green Algae by Myxobacter. J Bacteriol 104: 453461.

185. Abell GC, Bowman JP (2005) Ecological and biogeographic relationships of class Flavobacteria in the Southern Ocean. FEMS Microbiol Ecol 51: 265-277.

186. Glockner FO, Fuchs BM, Amann R (1999) Bacterioplankton Compositions of Lakes and Oceans: a First Comparison Based on Fluorescence In Situ Hybridization. Appl Environ Microbiol 65: 3721-3726.

187. Zubkov MV, Fuchs BM, Tarran GA, Burkill PH, Amann R (2002) Mesoscale distribution of dominant bacterioplankton groups in the northern North Sea in early summer. Aquat Microb Ecol 29: 135-144.

188. Bowman JP (2006) The Marine Clade of the Family Flavobacteriaceae: The Genera Aequorivita, Arenibacter, Cellulophaga, Croceibacter, Formosa, Gelidibacter, Gillisia, Maribacter, Mesonia, Muricauda, Polaribacter, Psychroflexus, Psychroserpens, Robiginitalea, Salegentibacter, Tenacibaculum, Ulvibacter, Vitellibacter and Zobellia. In: Dworkin M, Falkow S, Rosenberg E, Schleifer KH, Stackebrandt E, editors. The Prokaryotes. New York: Springer New York. pp. 677-694.

189. Bowman JP, Nichols DS (2002) Aequorivita gen. nov., a member of the family Flavobacteriaceae isolated from terrestrial and marine Antarctic habitats. Int $\mathrm{J}$ Syst Evol Microbiol 52: 1533-1541.

190. Bowman JP, McCammon SA, Brown JL, McMeekin TA (1998) Glaciecola punicea gen. nov., sp. nov. and Glaciecola pallidula gen. nov., sp. nov.: psychrophilic bacteria from Antarctic sea-ice habitats. Int J Syst Bacteriol 48: 1213-1222.

191. Bowman JP, McCammon SA, Brown MV, Nichols DS, McMeekin TA (1997) Diversity and Association of Psychrophilic Bacteria in Antarctic Sea Ice. Appl Environ Microbiol 63: 3068-3078.

192. Gosink JJ, Woese CR, Staley JT (1998) Polaribacter gen. nov., with three new species, $P$. irgensii sp. nov., $P$. franzmannii sp. nov. and $P$. filamentus sp. nov., gas vacuolate polar marine bacteria of the Cytophaga-Flavobacterium-Bacteroides 
group and reclassification of 'Flectobacillus glomeratus' as Polaribacter glomeratus comb. nov. Int J Syst Bacteriol 48: 223-235.

193. Pineiro-Vidal M, Carballas CG, Gomez-Barreiro O, Riaza A, Santos Y (2008) Tenacibaculum soleae sp nov., isolated from diseased sole (Solea senegalensis Kaup). Int J Syst Evol Microbiol 58: 881-885.

194. Lee YS, Baik KS, Park SY, Kim EM, Lee DH, et al. (2009) Tenacibaculum crassostreae sp nov., isolated from the Pacific oyster, Crassostrea gigas. Int J Syst Evol Microbiol 59: 1609-1614.

195. Ivanova EP, Alexeeva YV, Flavier S, Wright JP, Zhukova NV, et al. (2004) Formosa algae gen. nov., sp. nov., a novel member of the family Flavobacteriaceae. Int J Syst Evol Microbiol 54: 705-711.

196. Nedashkovskaya OI, Kim SB, Han SK, Lysenko AM, Rohde M, et al. (2003) Mesonia algae gen. nov., sp nov., a novel marine bacterium of the family Flavobacteriaceae isolated from the green alga Acrosiphonia sonderi (Kutz) Kornm. Int J Syst Evol Microbiol 53: 1967-1971.

197. Alonso C, Warnecke F, Amann R, Pernthaler J (2007) High local and global diversity of Flavobacteria in marine plankton. Environ Microbiol 9: 1253-1266.

198. Celussi M, Cataletto B (2007) Annual dynamics of bacterioplankton assemblages in the Gulf of Trieste (Northern Adriatic Sea). Gene 406: 113-123.

199. Gomez-Pereira PR, Fuchs BM, Alonso C, Oliver MJ, van Beusekom JEE, et al. (2010) Distinct flavobacterial communities in contrasting water masses of the North Atlantic Ocean. ISME Journal 4: 472-487.

200. Kirchman DL, Yu L, Cottrell MT (2003) Diversity and Abundance of Uncultured Cytophaga-Like Bacteria in the Delaware Estuary. Appl Environ Microbiol 69: 6587-6596.

201. Manz W, Amann R, Ludwig W, Vancanneyt M, Schleifer KH (1996) Application of a suite of $16 \mathrm{~S}$ rRNA-specific oligonucleotide probes designed to investigate bacteria of the phylum cytophaga-flavobacter-bacteroides in the natural environment. Microbiology-UK 142: 1097-1106.

202. Weller R, Glockner F, Amann R (2000) 16S rRNA-targeted oligonucleotide probes for the in situ detection of members of the phylum Cytophaga-FlavobacteriumBacteroides. Sys Appl Microbiol 23: 107-114.

203. Giovannoni S, Rappe M (2000) Evolution, diversity and molecular ecology of marine prokaryotes. In: Kirchman D, editor. Microbial Ecology of the Ocean. New York: Wiley Interscience. pp. 47-84.

204. Lee N, Nielsen PH, Andreasen KH, Juretschko S, Nielsen JL, et al. (1999) Combination of Fluorescent In Situ Hybridization and Microautoradiography---a New Tool for Structure-Function Analyses in Microbial Ecology. Appl Environ Microbiol 65: 1289-1297.

205. Cottrell MT, Kirchman DL (2000) Natural assemblages of marine proteobacteria and members of the Cytophaga-Flavobacter cluster consuming low- and highmolecular-weight dissolved organic matter. Appl Environ Microbiol 66: 16921697. 
206. Alonso C, Pernthaler J (2006) Roseobacter and SAR11 dominate microbial glucose uptake in coastal North Sea waters. Environ Microbiol 8: 2022-2030.

207. Crump BC, Armbrust EV, Baross JA (1999) Phylogenetic Analysis of ParticleAttached and Free-Living Bacterial Communities in the Columbia River, Its Estuary, and the Adjacent Coastal Ocean. Appl Environ Microbiol 65: 3192-3204.

208. Fandino LB, Riemann L, Steward GF, Long RA, Azam F (2001) Variations in bacterial community structure during a dinoflagellate bloom analyzed by DGGE and 16S rDNA sequencing. Aquat Microb Ecol 23: 119-130.

209. Choi DH, Cho BC (2006) Lutibacter litoralis gen. nov., sp. nov., a marine bacterium of the family Flavobacteriaceae isolated from tidal flat sediment. Int J Syst Evol Microbiol 56: 771-776.

210. Jung S-Y, Kang S-J, Lee M-H, Lee S-Y, Oh T-K, et al. (2005) Gaetbulibacter saemankumensis gen. nov., sp. nov., a novel member of the family Flavobacteriaceae isolated from a tidal flat sediment in Korea. Int J Syst Evol Microbiol 55: 1845-1849.

211. Woyke T, Xie G, Copeland A, Gonzalez JM, Han C, et al. (2009) Assembling the Marine Metagenome, One Cell at a Time. PLoS One 4.

212. Zhao MR, Chen F, Jiao NZ (2009) Genetic Diversity and Abundance of Flavobacterial Proteorhodopsin in China Seas. Appl Environ Microbiol 75: 529533.

213. Beja O, Spudich EN, Spudich JL, Leclerc M, DeLong EF (2001) Proteorhodopsin phototrophy in the ocean. Nature 411: 786-789.

214. Gomez-Consarnau L, Gonzalez JM, Coll-Llado M, Gourdon P, Pascher T, et al. (2007) Light stimulates growth of proteorhodopsin-containing marine Flavobacteria. Nature 445: 210-213.

215. Lami R, Cottrell MT, Campbell BJ, Kirchman DL (2009) Light-dependent growth and proteorhodopsin expression by Flavobacteria and SAR11 in experiments with Delaware coastal waters. Environ Microbiol 11: 3201-3209.

216. Avendano-Herrera R, Toranzo AE, Magarinos B (2006) Tenacibaculosis infection in marine fish caused by Tenacibaculum maritimum: a review. Dis Aquat Organ 71: 255-266.

217. Wang JT, Ou YJC, Chou JH, Chen CA, Chen WM (2008) Tenacibaculum aiptasiae sp nov., isolated from a sea anemone Aiptasia pulchella. Int J Syst Evol Microbiol 58: 761-766.

218. Lee S-Y, Park S, Oh T-K, Yoon J-H (2010) Description of Olleya aquimaris sp. nov., isolated from seawater, and emended description of the genus Olleya Mancuso Nichols et al. 2005. Int J Syst Evol Microbiol 60: 887-891.

219. Yoon J-H, Kang S-J, Oh T-K (2006) Polaribacter dokdonensis sp. nov., isolated from seawater. Int J Syst Evol Microbiol 56: 1251-1255.

220. Biebl H, Pfennig N (1978) Growth Yields Of Green Sulfur Bacteria In Mixed Cultures With Sulfur And Sulfate Reducing Bacteria. Arch Microbiol 117: 9-16.

221. Bauld J, Staley JT (1976) Planctomyces maris sp. nov.: a marine isolate of the Planctomyces-Blastocaulis group of budding bacteria. J Gen Microbiol 97: 45-55. 
